\title{
HORIZONTAL MERGERS UNDER LOCALIZED COMPETITION
}

by

\author{
A. ANGELA ZEILER \\ Department of Economics
}
A thesis submitted to the Faculty of Graduate Studies and Research in partial fulfilment of the requirements for the degree of
Doctor of Philosophy in Economics
Department of Economics
Carleton University Ottawa, Ontario, Canada K1S 5B6
June 2003
Copyright (C) 2003, A. Angela Zeiler

All rights reserved. This work may not be reproduced in whole or in part, by photocopying or other means without permission of the author. 


\author{
National Library \\ of Canada \\ Acquisitions and \\ Bibliographic Services \\ 395 Wellington Street \\ Ottawa ON K1A ON4 \\ Canada
}

Bibliothèque nationale

du Canada

Acquisisitons et services bibliographiques

395 , rue Wellington Ottawa ON K1A ON4 Canada
Your file Votre référence ISBN: 0-612-88729-4 Ourfile Notre référence ISBN: 0-612-88729-4
The author has granted a nonexclusive licence allowing the National Library of Canada to reproduce, loan, distribute or sell copies of this thesis in microform, paper or electronic formats.

The author retains ownership of the copyright in this thesis. Neither the thesis nor substantial extracts from it may be printed or otherwise reproduced without the author's permission.
L'auteur a accordé une licence non exclusive permettant à la Bibliothèque nationale du Canada de reproduire, prêter, distribuer ou vendre des copies de cette thèse sous la forme de microfiche/film, de reproduction sur papier ou sur format électronique.

L'auteur conserve la propriété du droit d'auteur qui protège cette thèse. $\mathrm{Ni}$ la thèse ni des extraits substantiels de celle-ci ne doivent être imprimés ou aturement reproduits sans son autorisation.
In compliance with the Canadian Privacy Act some supporting forms may have been removed from this dissertation.

While these forms may be included in the document page count, their removal does not represent any loss of content from the dissertation.
Conformément à la loi canadienne sur la protection de la vie privée, quelques formulaires secondaires ont été enlevés de ce manuscrit.

Bien que ces formulaires aient inclus dans la pagination, il n'y aura aucun contenu manquant. 


\begin{abstract}
The purpose of this thesis is to analyse the anti-competitive effects of horizontal mergers for sellers of differentiated products under localized competition. The results of the symmetric, simultaneous price-quality Nash equilibrium are first established for the $n$ neighbour firm oligopoly game based on the spatial (circular) framework with quadratic transport costs $t$. Each firm incurs a constant marginal cost, and a fixed (quadratic) cost of quality level to produce its own single-product variant.
\end{abstract}

The generalized spatial merger model consists of an asymmetric price-quality Nash equilibrium profit-maximizing strategy for a subset of $n$-neighbour firms. The corporate authority of the multi-product firm $M$ faces a set of $q$, single-product competitors while it maximizes the joint profit of its n-neighbour firms with respect to price only, and decentralizes the choice of quality levels to its member firms for their product variants. The set of $q$, rival firms, each acting under Nash price-quality behaviour, simultaneously set a price and a quality level for its own single-product variant. In equilibrium, a large $(n \geq 7)$ multi-product firm $M$ exploits its physicallyconnected market area by setting an asymmetric price-quality strategy that creates an isolated hinterland for an "inner core" set of its firms. One result of such strategic behaviour is the merged firm $M$ effectively wards-off the price-quality competition from its peripheral rivals, and it shields the inner core firms from the spread of the price-quality war contagion. It is able to reap the maximum amount of surplus to attain the highest post-merger profit of all firms within an industry, for $n+q \geq 5$ firms. The pattern associated with the price-quality policy chosen by the multi-product firm $M$ for its equi- 
distantly located pair-wise member firms is called the symmetric cascading effect.

The second merger model examined is a two-neighbour firm Nash price-quality game in which the bi-variant merged firm $M$ controls both the price and quality of its two product variants to maximize joint profits. One result of the asymmetric Nash pricequality equilibrium outcome is a higher post-merger profit for a merged firm $M^{\prime}$ 's centralized price-quality strategy, relative to a merged firm that chooses a decentralized strategy. Numerical simulation results of the total welfare equilibrium outcome for both types of Nash merger models (decentralized and centralized) compare the levels of social inefficiency that may arise in an economy.

The third model introduces a merger between two, non-neighbour firms under price-quality Stackelberg behaviour. The asymmetric Stackelberg price-quality strategy proves to be profit-maximizing for a set of two, non-neighbouring firms whereas the same set of firms under Nash behaviour would never merge. The Stackelberg bi-product firm $M$, as leader, controls both the prices and the quality levels to maximize its joint profit, given the $q$ followers ' independent choices of prices and qualities of their singleproduct variants. The final model presented is a generalized price-quality Stackelberg merger among n-neighbour firms. The multi-product Stackelberg leader chooses prices of its $n$ product variants to maximize joint profits and delegates the quality choice to its $n$ member firms, subject to the independent price and quality choices made by the $q$ singleproduct follower firms. Each of the Stackelberg merger models is provided with comparative numerical simulations for the total welfare equilibrium outcome of an economy. 


\section{DEDICATION}

This thesis is dedicated entirely to my beloved parents, Professor Frederick Zeiler and Mrs. Alice Zeiler, R. N., for their unconditional support and encouragement. They both freely gave to me the true compass and map necessary to navigate along the equilibrium path of life. Their only directive taught me to strive for excellence through honour and personal integrity. With these words, I offer my unwavering gratitude and love, always and forever. Although you are in absentia, mother dear, your presence remains with me in all thought and action, and on every single page of this thesis. 


\section{ACKNOWLEDGEMENTS}

I would like to express my deep appreciation to my thesis supervisor, Professor Zhiqi Chen, for providing the necessary opportunity and guidance within the Department of Economics throughout the doctoral programme. To my thesis committee member Professor Donald McFetridge, I offer many thanks for his valuable comments and suggestions that led to the successful completion of my research. My thesis has also benefited greatly from the insights and kind support of Professor Keith Acheson. I also thank Professor Rose-Ann Devlin for her participation as the committee member from the University of Ottawa. 


\section{QUOTATION}

The chicken and the pig met for negotiations on a joint merger and out of talks was born the idea of ham and eggs. Initially the two were very pleased with the idea, but suddenly the pig became uneasy. "This is all very well," he said, "but while you keep on producing eggs, I end up dead." The chicken smiled knowingly, "That's all right," she said, "that's the way it is with joint ventures."

Eberhard von Kuenheim 
TABLE OF CONTENTS

\author{
Page \\ CHAPTER 1: INTRODUCTION 1 \\ 1.1 HORIZONTAL MERGERS AND CANADIAN COMPETITION POLICY 2 \\ 1.2 A REVIEW OF THE HORIZONTAL MERGER LITERATURE 6 \\ 1.3 SPATIAL MODELS AND THE INCENTIVE TO DIFFERENTIATE 10 \\ 1.4 PRODUCT DIFFERENTIATION AND SOCIAL WELFARE 15 \\ 1.5 SPATIAL HORIZONTAL MERGERS: \\ $\begin{array}{ll}\text { MAJOR RESULTS AND CONTRIBUTIONS } & 17\end{array}$ \\ 1.6 AN OVERVIEW OF THE THESIS $\quad 24$
}

CHAPTER 2: A PRICE-QUALITY OLIGOPOLY MODEL OF LOCALIZED COMPETITION

2.1 A GAME-THEORETIC MODEL OF LOCALIZED COMPETITION 33

2.2 COMPARATIVE STATICS AND WELFARE IMPLICATIONS 44

2.3 MARKET EQUILIBRIUM AND OPTIMUM PRODUCT DIVERSITY AND QUALITY

CHAPTER 3: A GENERALIZED PRICE-QUALITY MERGER MODEL

3.1 INTRODUCTION 65

3.2 A DESCRIPTION OF THE GAME-THEORETIC STRUCTURE 71

3.3 THE NASH PRICE-QUALITY GAME AND MERGER

EQUILIBRIUM OUTCOME

3.4 AN ANALYSIS OF THE NASH PRICE-QUALITY EQUILIBRIUM OUTCOME

AND THE POTENTIAL FOR ANTI-COMPETITIVE EFFECTS 82

3.5 WELFARE EFFECTS OF A PRICE-QUALITY N-NEIGHBOUR 
FIRM MERGER

3.6 THE NASH PRICE-QUALITY MERGER MODEL: CENTRALIZED

QUALITY LEVELS

3.7 THE CASE FOR A MONOPOLIST - AN INCENTIVE TO ACQUIRE ALL PRODUCT VARIETIES IN AN INDUSTRY?

CHAPTER 4: STACKELBERG PRICE-QUALITY SPATIAL MERGER MODELS

4.1 AN INTRODUCTION TO STACKELBERG PRICE-QUALITY

LEADERSHIP

4.2 A DESCRIPTION OF THE GAME-THEORETIC STRUCTURE: A

STACKELBERG PRICE-QUALITY NON-NEIGHBOUR MERGER 140

4.3 THE STACKELBERG PRICE-QUALITY GAME AND MERGER

EQUILIBRIUM OUTCOME: TWO NON-NEIGHBOURS

4.4 AN ANALYSIS OF THE STACKELBERG PRICE-QUALITY (NON-

NEIGHBOUR) MERGER EQUILIBRIUM OUTCOME AND THE

POTENTIAL FOR ANTI-COMPETITIVE EFFECTS

4.5 CONCLUDING REMARKS

4.6 THE GENERALIZED STACKELBERG PRICE-QUALITY

(NEIGHBOUR) MERGER MODEL

4.7 AN ANALYSIS OF THE STACKELBERG PRICE-QUALITY

(NEIGHBOUR) TWO-FIRM MERGER MODEL AND THE

POTENTIAL FOR ANTI-COMPETITIVE EFFECTS 


\section{LIST OF FIGURES}

2.1: The circle model of product differentiation 39

2.2: The free-entry equilibrium and social welfare optimum concepts 63

3.1: The circular industrial and market structure $\quad 73$

3.2 (A): The general shape of the asymmetric equilibrium price function 85

3.2 (B): The general shape of the asymmetric equilibrium quality level function 85

3.3: The general shape of the market share structure $\quad 89$

3.4: The general shape of the asymmetric equilibrium profit level function $\quad 92$

4.1: The circular industrial structure of a Stackelberg (non-neighbour) merger 142

4.2 (A): The general shape of the symmetric Stackelberg (non-neighbour) $\begin{array}{ll}\text { equilibrium price function } & 155\end{array}$

4.2 (B): The general shape of the symmetric Stackelberg equilibrium (non-neighbour) quality level function 


\section{LIST OF TABLES}

Page

3.1 The total welfare numerical results for a two-neighbour firm merger

$$
(q=2) \text { decentralized quality levels }
$$

3.2 The total welfare numerical results for a two-neighbour firm merger

$$
(q=4) \text { decentralized quality levels }
$$

3.3 The total welfare numerical results for a two-neighbour firm merger

$$
(q=2) \text { centralized quality levels }
$$

3.4 The total welfare numerical results for a two-neighbour firm merger

$$
(q=4) \text { centralized quality levels }
$$

3.5 The inçremental values for $\mathrm{p}_{\mathrm{i}}^{\mathrm{M}}(\mathrm{i}=1,2,3,4)$

3.6 The total welfare numerical results of a four-firm monopolist

3.7 The total welfare numerical results of a six-firm monopolist

4.1 Total welfare simulation results - Stackelberg (non-neighbour)

$$
\text { merger }(q=2)
$$

4.2 Total welfare simulation results - Stackelberg (non-neighbour)

$$
\text { merger }(q=3)
$$

4.3 Total welfare simulation results - Stackelberg (non-neighbour)

$$
\text { merger }(q=4)
$$

4.4 Total welfare simulation results - Stackelberg two-firm (non-neighbour)

$$
\operatorname{merger}(q=4)
$$




\section{LIST OF APPENDICES}

Page

APPENDIX: CHAPTER THREE

(i) A TWO-FIRM MERGER OF NON-NEIGHBOURING FIRMS 188

A. THE GENERALIZED PRICE-QUALITY MERGER MODEL 190

B. THE "SYMMETRIC CASCADING EFFECT" FOR EQUILIBRIUM PRICES AND QUALITIES 201

C. THE COMPARATIVE STATIC RESULT 205

D. THE NASH PRICE-QUALITY MERGER EQUILIBRIUM RESULTS:

A TWO-NEIGHBOUR FIRM MERGER (DECENTRALIZED QUALITY LEVELS)

E. THE NASH PRICE-QUALITY MERGER EQUILIBRIUM MODEL:

A TWO-NEIGHBOUR FIRM MERGER (CENTRALIZED QUALITY LEVELS)

APPENDIX: CHAPTER FOUR

A. THE STACKELBERG LEADER-FOLLOWER (NON-NEIGHBOUR)

TWO-FIRM MERGER MODEL

B. THE GENERALIZED STACKELBERG PRICE-QUALITY

(NEIGHBOUR) MERGER MODEL 229

REFERENCES 


\section{CHAPTER 1: INTRODUCTION}

To motivate the need to analyse the anti-competitive effects of a price-quality horizontal merger for sellers of differentiated products under localized competition, it is essential to first describe, as an example, the anecdotal evidence of recent initiatives from the financial and the banking services sectors within Canada and abroad. The application of an analysis of multidimensional differentiated product horizontal mergers under localized competition to Canadian competition policy may be further enunciated with an examination of legislative criteria that evaluate the potential post-merger anti-competitive behaviour of product-differentiated horizontal mergers. Secondly, a critical assessment of current literature with respect to both standard, and spatial horizontal mergers indicates that a wide gap exists within the current theory of game-theoretic industrial organization with respect to spatial horizontal mergers offering products possessing both horizontal and vertical characteristics.

Thirdly, to establish the results of a simultaneous price-quality oligopoly Nash equilibrium of a (circular) spatial game, it is necessary to briefly outline the salient aspects of the economic theory of product differentiation with respect to the multidimensional characteristics of a product. In order to be able to describe the Nash equilibrium market structure, including the multidimensional characteristics of products, the approach involves defining costs of "disutility" or "mismatch" for consumers having to choose from a finite set of product varieties with associated quality levels. To compare and contrast the price-quality Nash equilibrium game outcome, a description of the freeentry or long-run equilibrium and the social welfare optimum concepts of differentiated 
products is also briefly reviewed. A significant aspect of such an oligopoly result is the demonstration that there is a way to distinguish between those cases where product differentiation has an influence on industrial structure (the degree of industrial concentration) from those where it does not. The welfare analysis therefore supports the view that product differentiation is relevant to industrial structure.

\subsection{HORIZONTAL MERGERS AND CANADIAN COMPETITION POLICY}

This section starts with a brief outline of recent Canadian merger activity within the financial services sector and gives a sketch of current informational requirements needed by competition policy makers to analyse the anti-competitive impacts of horizontal mergers. The section continues with a discussion of current industrial organization literature that examines the pre- and post-merger impacts of horizontal mergers analysed within both standard and spatial game-theoretic oligopoly models. The intent of this section is to draw attention not only for the need to advance game-theoretic results and analyses of horizontal mergers for sellers of differentiated products under localized competition but to add knowledge to, or to possibly enhance the policy implications of product differentiated horizontal mergers for Canadian competition policy.

The announcement of Canada's largest proposed merger on January 23rd, 1998 in a press release by the Competition Bureau of The Royal Bank of Canada and The Bank of Montreal, against which a 35 percent or more market power threshold triggered a review of the potential anti-competitive effects, would have created the world's 22 nd-largest bank in combined assets of $\mathrm{C} \$ 453$ billion ( $\mathrm{C} \$ 39$ billion in profits). The proposed merger 
of the two banks' operations required Federal Government approval from three levels: the Competition Bureau, the Office of the Superintendent of Financial Institutions, and The Minister of Finance, who held the final determination and disallowed the proposal.

The banks' main argument for merger rested on its position that foreign (i.e., American) banks are making Canadian finance more competitive rather than less. The announcement of April 7th, 1998 at that time, of the largest proposed U.S. bank merger (U.S.\$ 70 billion in profits) of Citicorp and Travellers Group, a leading financial services provider of stocks and insurance, had lent support to the banks' position and added pressure for Canadian approval. The Royal-Montreal merger had in turn initiated speculation that other Canadian banks were expected to follow their lead and create a merger wave. Soon after, the Toronto-Dominion and the CIBC banks announced their intent to merge leaving only one "schedule 1" bank (Bank of Nova Scotia) to stand alone in the Canadian banking and financial sector.

In Canada, the Merger Enforcement Guidelines (1991) put forth by the Competition Bureau provide an interpretation of the statutory efficiencies defence for mergers under the Competition Act (1986) that may prevent or lessen competition substantially. The Guidelines' main function is to provide a framework for the economic analysis needed to evaluate an efficiency defence. The Guidelines first define both the product markets and geographic markets along with evaluative criteria to assess the type and extent to which anti-competitive effects may occur.

The Guidelines, however, do not provide any economic or statistical methodologies nor assign any weight to the evaluative criteria. The evaluative criteria 
used to assess anti-competitive effects include factors such as market shares and concentration, foreign competition, potential for business failure and exit, the availability of substitutes, and barriers to entry. These factors determine the potential for anticompetitive effects within the relevant market areas of any given industry.

The Guidelines' define both geographic and product markets without explicit reference to differentiated products but include some evaluative criteria to aid in delineating some product characteristics. The product markets' "physical and technical characteristics" criterion includes the following:

"Although two products with unique physical or technical characteristics may be found to be in the same relevant market on the basis of functional interchangeability, such products are often found to be in separate relevant markets. In general, the greater is the value that buyers place on the actual or perceived unique physical or technical characteristics of a product, the more likely it is that the product will be found to be in a distinct relevant market. Product warranties, post-sales service, order turn-around time, etc., are all included in the characteristics that make up a product" [Guidelines, 1991, p. 12]. This criterion may be interpreted to allow for a partial but not complete set of characteristics needed to define differentiated products. The distinction between products appears to be a matter of degree. The geographic market's definition evaluates sunk costs as a potential barrier to entry and realizes "potential entrants may face significant sunk costs as a result of a need to:....(ii) overcome product-differentiation-related advantages enjoyed by incumbent firms; ... [Guidelines, (1991), p. 36]. This criterion treats what is 
possibly significant impacts of product differentiation only indirectly as a barrier to entry.

The Canadian Competition Bureau released the Bank Merger Enforcement Guidelines (MEGs) on July $14^{\text {th }}, 1998$ to address specific issues pertaining to the financial services industry due to the importance of this sector within the Canadian economy. This document sets a precedent in that while the Guidelines (1991) are applied across all business sectors, the new bank merger guidelines will provide a clearer view of how the Federal Government intends to apply the Guidelines (1991) to the proposed mergers between The Royal Bank of Canada and The Bank of Montreal, and between The Canadian Imperial Bank of Commerce and The Toronto Dominion - Canada Trust.

A Senate of Canada Sixth Report, issued in December of 2002, entitled:

Competition in the Public Interest: Large Bank Mergers in Canada, suggests the Federal Government might loosen certain restrictions for approval by Parliament. In particular, the report suggests Canada's economy would benefit from one or two bank mergers as they would make banks stronger in the face of foreign competition as long as they were kept under Canadian control and foreign-ownership limitations were lifted. The Senate Report recommends that the Minister of Finance determine the final outcome of any proposals, but must justify any decision before Parliament.

The Report of the Standing Committee on Finance (March, 2003) entitled, Large Bank Mergers in Canada: Safeguarding the Public Interest for Canadians and Canadian Businesses, has issued eleven recommendations to consider the public interests of large bank mergers in four key areas. These four areas include the access of Canadians in all regions to convenient and quality financial services, the choice of financial service 
providers and the availability of financing for small businesses and Canadians, the effects on long-term growth for Canada through expansion of internationally competitive institutions, and the treatment of bank employees through a merger adjustment. The Federal Government must table a response to these recommendations within 90 days of the presentation of the report to the House of Commons.

Given the unprecedented wave of merger activity in recent years within Canada and abroad, a thorough knowledge and understanding of the market impacts of horizontal mergers have become a central issue in competition policy and enforcement.

Policymaker interest has been focussed on the unilateral competitive effects of horizontal mergers, or on those mergers that make it more profitable for merging firms to reduce output and cause market price to increase unilaterally, that is, in the absence of collusion. Hence, it is hard to find an area of public policy where advances in the theory of industrial organization are more needed. Unfortunately, current theory of horizontal mergers does not always meet up with some of the informational requirements needed for issues discussed both in the Merger Enforcement Guidelines (1991), and the specific industry guidelines for the financial and banking services sector, the recently introduced MEGs.

\subsection{A REVIEW OF THE HORIZONTAL MERGER LITERATURE}

There exists a collection of research articles which analyze the private incentives for homogeneous product oligopolistic horizontal mergers using a standard gametheoretic framework, assuming the firms compete strategically in quantities. The postmerger equilibrium effects of a single, two-firm merger includes output reduction, and the 
non-participating firms react by expanding output. Most of the literature concludes that if scale economies are absent, mergers are often unprofitable under Cournot competition. The results of the Cournot model of Salant, Switzer and Reynolds (1983) indicate that a merger would never occur since the joint post-merger profits of the member firms facing constant marginal costs would be lower than the pre-merger state. Perry and Porter (1985) show that a merger may be profitable, but other firms in the industry would benefit more from the merger.

Deneckere and Davidson (1985) assume a linear demand function with differentiated products and firms follow symmetric Bertrand (price) behaviour. Since prices are strategic complements, the post-merger effect induces a price increase by all firms. Thus, mergers are always profitable and the monopolization motive for merger is restored. Symmetric Bertrand competition increases post-merger prices and also triggers some price increases from rivals, which is beneficial to the original firm. A post-merger situation known as the "free-rider problem" for non-participants results as some outsiders will benefit more from mergers than do the parties to a merger. Mergers are jointly beneficial to the members but may be disadvantageous to an individual participant, despite the fact that merger profit is super-additive. However, the free-rider problem may deter some merger proposals which may suggest limited incentives under symmetric price competition. Deneckere and Davidson's model neglects to examine the anti-competitive effects from a merger of more than two firms. The standard oligopoly literature models' imply that in the absence of efficiency gains, either a merger is unprofitable, or a "freerider" problem exists in the post-merger industry. 
There are a couple of articles that consider mergers within a spatial framework consisting of, for example, a closed interval or an infinite line. Braid (1986) analyses Stackelberg price leadership in a spatially competitive model with infinitely many firms on an infinite line. The results show that a Stackelberg price leader charges a greater price than the Nash equilibrium price, and leads to its nearest neighbours charging a higher price than the Nash equilibrium price. A two-neighbour firm merger under Nash behaviour increases prices (and profits) of all firms and with Stackelberg price behaviour, a merger increases all prices even if the firms are not nearest neighbours. Reitzes and Levy (1995) employ a closed interval model with linear transport costs to demonstrate that in a Bertrand-Nash equilibrium with pure price discrimination, a two-firm merger increases profits as long as the merging firms are neighbours, and prices increase only to insulated consumers. Further, mergers produce larger gains for merging firms than for non-merging firms and such mergers neutralize any incentives to relocate or enter. Their results eliminate the free-rider problem of horizontal mergers as firms are able to price discriminate under asymmetric conditions.

The literature on mergers within a circular spatial game setting is sparse. Levy and Reitzes (1992) consider a localized competition model with asymmetric product differentiation and assume a unitized size of circle, and a normalized population model with quadratic transport costs. A single strategic variable (price) is used to analyse the anti-competitive effects of a two-neighbour firm merger. Their results show that mergers benefit all firms, and that all firms except the neighbours of the merger, reap fewer profits than each of the merged entities. Thus, the existence of the free-rider problem is confined 
to only one set of firms. The only other two-neighbour firm strategy considered in their paper is that of two non-neighbour mergers. They show that such a merger behaviour is not profit-maximizing but such mergers may occur in a dynamic framework where firms face possible punishment for deviating from a cooperative solution. Their model does not include other strategic variables such as quality, nor a welfare analysis of product variety. The Nash equilibrium analysis of a general strategic framework for a subset of n-firms under varying merger configurations (i.e., neighbours or non-neighbour firms) is absent. The literature on Hotelling's model has developed a number of variations using the traditional strategic variables of location and price with changes to the transport cost function, the space of characteristics, or the specification of the utility function. Economides [1989 (A)] first studied the equilibrium effects of quality variations in a duopoly of spatially differentiated products using the Hotelling model. The model assumes that the level of quality is independent of variable production costs and that quality costs are independent of the level of output. The results of the first type of game chosen indicate that within a two-stage game of variety (location) choice, and the subsequent simultaneous choice of quality and price, there exist only maximal variety differential equilibria in pure strategies and minimal quality differentiation at equilibrium. The three-stage game results in a sub-game perfect equilibrium of maximal variety differentiation followed by quality choice, and then by price choice with minimal quality differentiation at equilibrium. The oligopoly results of these two types of sequential games were not established, nor was the simultaneous Nash price-quality equilibrium for a set of n-firms. By contrast, this thesis establishes the simultaneous Nash price-quality 
equilibrium for an oligopoly based on the spatial (circular) game-theory model.

\subsection{SPATIAL MODELS AND THE INCENTIVE TO DIFFERENTIATE}

A differentiated product is defined by the number and type of characteristics that each good possesses. A single characteristic may be represented by a dimension in a suitably chosen dimensional space where the given product is defined by a point or vector in the space spanned by the axes. A group or set of products may be thought of as a number of vectors or points in the given space. Suppose that for a set of products offered in the marketplace, if all the points in characteristics space associated with the set lie on the same ray vector through the origin, then a product that is located the furthest away from the origin is deemed to be better, or, it may be said to be of higher quality. If there exists a subset of such goods which could be ranked relative to a quality index, these products are then said to be vertically differentiated. If this subset of products were to be on sale in the market at identical prices, then every consumer would rank the goods in the same order. In the absence of such a quality index, or a ranking order by consumers, these same goods would then be said to be horizontally differentiated.

Since products are said to be horizontally differentiated if demand for each is positive, given that all variants are priced equally and these same variants are said to be vertically differentiated if some particular variant gains the entire market, independent of the subset of variants offered. "The crucial distinction, in terms of equilibrium market structure, requires a modification of these definitions: the comparisons should be made when all variants are priced at their marginal production costs. The essence of horizontal differentiation is that each variant can always guarantee itself a positive demand, so the 
market space is covered by an arbitrarily large number of firms (which are all arbitrarily small) when fixed costs are negligible. By contrast, the essence of vertical differentiation is that the market can only support a finite number of firms, which all get positive demand, even when fixed costs are arbitrarily small" [Anderson, Simon P., Andre de Pailma, and Jacques-Francois Thisse (1996), p. 274].

The first spatial or location model that attempted to formalize horizontal products is assigned to Hotelling (1929). This model is generally referred to as the "address approach" as the closed interval $[a, b]$ where $b>a$ and $a \neq b$, may represent a geographic distance such as a "street". Single-product firms enter the market or street and locate themselves in such a manner in order to capture the largest number of consumers. The tastes of consumer are said to be asymmetric or heterogeneous if varied and distributed within a characteristic's space such that each consumer has a most preferred location or address. When products are offered at the same price in the market then each consumer has a distinct ranking order over all such products. A consumer is then said to possess an "ideal" or most preferred brand where variants close to the "ideal" brand in the characteristics space are considered better substitutes rather than variants that are more distantly located.

As consumers have heterogeneous tastes, each individual's preferences differ according to what is the ideal brand chosen from among the set of available products. Since variants are represented by points in multidimensional characteristic space then a consumer with asymmetric preferences is identified and located by a specific point in this space. A consumer considers neighbouring variants "close" to his/her "location" to be 
appropriate substitutes. The consumer may then find that in the marketplace that the "closest" preferred variant is offered at a much higher price but a more distant brand sells at a more acceptable price. Thus, the consumer is faced with purchasing a less-then-ideal product. The asymmetry of this situation reflects a cost component on the part of the consumer and is not usually part of a Nash equilibrium analysis of a n-firm oligopoly model. As a result, most non-spatial models assume that a consumer's cost function for every product variant is identical.

A spatial model assumes that every consumer chooses one product variant that is best suited to his or her own preferences after the costs of purchasing are taken into account, so that these horizontally differentiated (by firm location or product brand) goods are not combined in consumption. Consumers are distributed closely among themselves within the characteristics space if their tastes are similar or homogeneous while if their tastes are diversified, then they are distributed widely across the same space. Thus, a variant's demand within a group of products depends on its own price and quality, the prices, quality and locations of competing variants, and the distribution of consumers located around the circle.

Competition between fewer, nearby single-product firms' variants will give the product a greater degree of "local monopoly". If firms within a particular industry produce differentiated goods, these products of the different firms are imperfect substitutes for each other and give rise to the incentive for an individual firm to act as a monopolist with respect to its own product. The potential for such monopoly profit provides a firm with the basic incentive to differentiate its product and to effectively 
isolate its market share from rivals' actions. However, this behaviour is symmetric and may also provide an adverse effect for the firm to efficiently compete in their rivals' own markets. Thus, there is a need for an individual firm to sufficiently differentiate its own product but not to deter or lessen its own potential for rivals' markets. This implies that increasing the degree of product differentiation gives a firm a greater degree of market concentration or monopoly power but over a narrower portion of the market relative to the total market. The incentive for a single-product firm to differentiate is stronger if consumers' tastes are more varied, and if the distribution of consumers is uniform over the characteristics' space.

The products and services offered by the Canadian banking industry may best be illustrated, for example, by the characteristics product space approach, or "non-address" model. While household mortgages and guaranteed investment certificates (GICs) are different products, open and closed mortgages, or redeemable and non-redeemable GICs are differentiated ones. Each of these products is a certain type of variant, horizontally differentiated, for example, by whether a mortgage is open or closed, and by the kind of redeemable feature of an investment certificate. They are vertically differentiated, for example, by the number of years held, or by the type of interest rates (daily, monthly, or annually) that is charged or offered. The assumption of inelastic demand for product varieties within a spatial model reflects the demand for banking industry commercial and consumer products as clients generally purchase "one unit" of their preferred variant at a "fixed" price, and at a given time. The "fixed" price at which these products are sold is generally set according to the prime interest rate determined by the Bank of Canada, plus 
a certain "mark-up". Here, the decision-making authorities often delegate the responsibility of quality choice of products and services to its member branches. Such a decision may arise when monitoring and enforcement activities are costly.

For other industries, in general, a "large"or multi-product firm that is a consequence of a merger may want to differentiate its own set of joint products. The corporate entity now consists of a set of jointly produced multi-products that were previously and individually produced as single-products. The incentive to produce the same number of products but now in multiple varieties arises because consumers appear to possess heterogeneous tastes, and a single brand will be preferred only by a small segment of the joint market unless its price is reduced sufficiently to cover the market. Such a price reduction leaves the firm with smaller profits. The advantage of producing the same number of products with differing characteristics comes from the increase in total revenue that can be obtained from a given quantity since, on average, consumers' preferences will be better matched and they are willing to pay more.

However, the adverse effect is that the quantity produced of any given variety will decrease, and the multi-product firm may face a reduction in any benefits available from the economies of scale inherent in joint ownership. Thus, the optimal product differentiation strategy for the multi-product firm will necessarily require the weighing of revenue it gains from increased product differentiation against the average cost increase which results from the lower quantity of any product variety produced. Economic knowledge of multi-product firms is a scarce element in the current literature. This thesis further intends to advance the research needed to gain an understanding of product 
differentiation derived from corporate merger actions.

\subsection{PRODUCT DIFFERENTIATION AND SOCIAL WELFARE}

Product differentiation leads to a variety of goods being produced in most markets and has distributional impacts for both firms and consumers. Comparative statics of a nfirm quality-price Nash equilibrium and the free-entry market equilibrium provide a relative measure of determining whether or not the number of variants is at the optimum; that is, there may be too few or too many produced at the market equilibrium. The comparative statics analysis also indicates if consumer demand for each product variety and quality is met, that is, a variant may be over produced with an insufficient quality level.

With a small number of single-product firms in the market, each firm behaves as a local monopolist within the market for its own product by equating marginal revenue to marginal cost. Prices are above marginal cost and so each firm earns positive profits. The positive profits of incumbent firms attract new entrants which sufficiently differentiate their new products from existing products in the marketplace. Each new firm will locate far enough from the others so as to attain some monopoly power and each new firm will set its price above marginal cost. The behaviour of these new entrants causes the share of each incumbent firm's market to decline as well as their profits. Additional firms enter the market until an equilibrium is reached where all firms attain zero profits. The free-entry equilibrium number of firms equals the equilibrium number of products - product locations along with the degree of differentiation and the extent of variety are determined. 
Price above marginal costs at zero profit per firm in equilibrium means the marginal cost of a variant is less than its average cost. Since the average costs per firm are declining the symmetric localized competitive or free-entry equilibrium must be a function of scale economies or fixed costs. The equilibrium exists at a point somewhere on the downward-sloping portion of the average cost curve. At this point, scale economies are not necessarily exhausted. The equilibrium determination results in a higher degree of product variety if the impacts of scale economies are smaller or if substitution between nearby variants lessens.

As price is set at average cost, output per firm is lower than if costs had been minimized at marginal cost. The free-entry equilibrium gives rise to a less efficient allocation of resources and thus, the inherent welfare problem of product differentiation the effect of economies of scale that are not fully exhausted must be weighed against the potential greater benefits of product variety and improved quality. If more varieties exist then some.consumers gain as preferences and tastes for variety and quality are more closely met while others may lose as prices have increased and some products may no longer exist.

The market generated solution may then be compared against the social planner's solution to maximizing total welfare (the sum of consumers' surplus plus total firms' profits). The social (unconstrained or first-best) optimum outcome sets variant price at marginal cost but results in firms incurring losses equivalent to sunk costs and fixed costs of production. This is in contrast to the social optimum of a homogeneous good where price equals the marginal cost of production. The socially determined equilibrium 
number of variants, product variety and quality levels depend on the spatial parameters of the model and may be either above or below those determined by the "free-entry" market equilibrium.

\subsection{SPATIAL HORIZONTAL MERGERS: MAJOR RESULTS AND CONTRIBUTIONS}

One goal of this paper is to investigate the post-merger effects of a merger in a quality-price model in which firms compete across a set of spatially differentiated markets. The second chapter establishes the simultaneous quality-price Nash equilibrium results for $n$ product variants (or firms) under localized competition with quadratic transport costs using a circular (spatial), game-theoretic framework. The result introduces the possibility that firms can vary the vertically differentiated quality level associated with a horizontally differentiated product given a fixed location on a circle $C$ with a circumference of length $L$. One way to consider this, is that there are fixed costs, $a$, of marketing a brand or varying its quality level. This result is based on the assumptions that there are $n$ firms in the market, and each offering one differentiated product or variant, and that new entry is prohibitively costly. Thus there is a fixed, sunk cost $f$ behind the formation of a firm and such costs have increased since the establishment of the original firms.

A n-neighbour firm merger, by combining the assets of the two-or-more firms, leads to a larger firm (by a physically-connected set of neighbouring markets) than any of the n-firms were pre-merger. Suppose those $n$ firms with equidistant (fixed) locations compete across a set of spatially separated markets. These firms not only choose the 
price of output to supply the spatially differentiated markets, but they must also choose the level of quality to serve these markets. The "address model" views the merged entity as a "multi-plant", or a "multi-firm" single entity who vertically differentiates each of its firms by offering a distinct level of quality (perceived as real or imagined). For example, in the retail goods or services sector, each retail outlet differentiates itself by a distinct level of service to its customers (e.g., up-scale interior decor, an on-site after-sale product repair and service area, professional and knowledgeable staff, "in-home" sales and services, gift wrapping and same-day home delivery, special or personal client-service rooms, and a refreshment area).

Alternatively, in a "product" space, these firms must choose their basic product design (horizontal characteristic) within this space. Location provides a way for a merger of two or more neighbouring firms to commit to being a single entity "multi-product" firm. Firms that have different, but fixed, locations will have different "locational" advantages through the pricing and quality level decisions of their product brands, in serving their set of spatially-connected markets. More importantly, a merger between two-or-more neighbouring firms also allows the product variant and quality decisions of the two-or-more product variants to be more efficiently coordinated through joint internal managerial control. When a subset of two-or-more, neighbour-firms merge, these merged firms agglomerate their production activities of their variants within the confines of a much larger, joint market segment on $C$, while the outside, non-merged firms remain at their fixed locations, each having identical market segment sizes, but at equally separated distances. 
In a characteristic (product) space, the model initially begins with all $n$ industry firms, in a (pre-merger) symmetric equilibrium, producing the same horizontally differentiated product design and each single-product firm refines their own variant by choosing the same, or identical, quality levels to meet consumer demand for product variety. By contrast, for a given set of n-neighbour firms, a Nash price-quality multiproduct merger, facing a set of $q$ single-product competitors, induces the merging partners to jointly choose the same basic product design for all $n$ variants, and a set of $n$ lower, but different post-merger quality levels which efficiently meet the demands of its consumers for product variety. The Nash price-quality model allows for the corporate authority governing the merged entity, or multi-product firm $M$ to delegate the choice of quality level to its $n$-member firms while maximizing the joint $n$-firm profits with respect to price only. The merged firm's corporate authority chooses to decentralize the strategic choice of its product variants' quality levels while maintaining control over the set of product prices.

Within a circular spatial setting, a multi-product merger of $n$ variants, where the corporate authority of the multi-product firm decides on one strategic variable (price), results in an asymmetric price-quality equilibrium under Nash behaviour. In equilibrium, the multi-product firm $M$ exploits its power over its physically-connected market shares and set an asymmetric price-quality strategy that not only effectively wards-off the pricequality competition from its single-product rivals, but isolates a portion of their consumers by creating a "hinterland" for its inner-most core set of firms' products. This price-quality war is active only within the market periphery of the multi-product firm $M$. 
If there are $n \geq 7$ member-firms, the symmetrically-located outer most set of (four) firms' act as a "shield" against any further price-quality competition, and they, in turn, prevent the spread of this price-quality contagion to the inner core set of member firms. One effect of such anti-competitive behaviour is the merged firm $M$ reaps the maximum amount of post-merger profit, if there are $n+q \geq 5$ firms within the industry. The "freerider" problem exists if and only if there are $n+q=4$ industry firms.

The asymmetric post-merger prices of the multi-product firm $M$, and those of the $q$ single-product, non-merged rival firms, are all higher than they were pre-merger, but the merged firm's prices are significantly higher than those of its competitors. The asymmetric quality levels chosen, in equilibrium, by the $q$ single-product firms are higher than their (identical) pre-merger quality levels, and they are also significantly greater than those of the multi-product firm $M$ 's variants. The multi-product firm $M$ exerts its joint control over its market areas by reducing the post-merger output levels of all $n$-variants. Each of the $q$ single-product competitors supply more total output post-merger than they each produced prior to the merger.

There are a number of possible theoretic extensions related to the Nash pricequality merger model. Another variation of the Nash price-quality equilibrium merger model allows for the corporate authority of a two-neighbour firm merger to choose both the prices, and the quality levels of its two variants when it maximizes the joint profits of its two member firms. This particular choice of strategy may arise when costs of monitoring and enforcing quality levels are negligible. In equilibrium, it chooses a symmetric price-quality strategy such that the identical prices $p^{M}$, and the identical quality 
levels $a^{M}$, of its two brands are both relatively lower than if it had controlled price only. The corporate authority of the bi-variant firm $M$, takes advantage of its control over both strategic variables by setting a lower quality level $a^{M}$, for its two brands over its singleproduct competitors' choice of quality levels to gain a relatively larger joint market share, and thus, joint post-merger profit. The "free-rider" problem is absent for all $n+q \geq 4$ firms.

The Nash price-quality merger model introduces the possibility for a multiproduct firm $M$ to determine whether or not it should acquire all $n+q=n^{M}$ firms within an industry. The corporate authority of the merged firm $M$ would operate under a monopoly market structure if and only if the profit it gains in that position exceeds that which it obtains as a merged entity under an oligopoly structure, given a fixed number $n$ $+q \geq 4$ of firms. The corporate authority of the multi-product firm $M$, acting as a monopolist, maximizes the joint profit $I I^{M}$ of its $n^{M}$ member-firms by choosing a set of prices, and a set of quality levels for its $n^{M}$ product variants, subject to a consumer attaining a utility level of $V_{i} \geq 0$, for $i=1, \ldots, n$. The Kuhn-Tucker optimization problem admits an optimal symmetric price-quality solution for the monopoly model as a function of $y$, the reservation price or a consumer's maximum willingness-to-pay, and the model's parameters $n, N, L$, and $t$. The reservation price $y$ acts as a "lower bound" on the monopolist's symmetric price of its product variants to ensure consumer purchasing activity and thus, positive profits.

The numerical simulation results of the monopoly model have some interesting features. For example, a bi-variant firm $M$ has an incentive to function as a monopolist if 
it acquires two or more firms. This type of market structure may or may not be socially efficient for an economy, as the numerical value of a change in total welfare depends on an estimate of the consumer's reservation price, $y$. Higher numerical values of consumers' income $y$ translate into larger total monopoly profit. For example, if the monopolist owns six firms and a high value of a consumer's willingness-to-pay is chosen, then the monopoly profit earned exceeds that of a low value chosen for $y$. Such a market structure is not welfare enhancing but the total loss in welfare to the economy is significantly less than that of a two-firm merger with four single-product competitors, under the same model parameter conditions and a low value of consumers' income. If a monopolist operates in an economy where consumers' reservation price is high, then such a market structure is welfare enhancing.

Under simultaneous Nash price-quality behaviour, an incentive exists for a merger of two-or-more firms if and only if they are neighbouring firms since the joint postmerger profit is greater than the sum of individual pre-merger firm profits. The Stackelberg price-quality merger model demonstrates that there exists an incentive to merge if two non-neighbouring firms jointly act as a Stackelberg price-quality leader. The corporate authority of the Stackelberg firm $M$ simultaneously chooses the prices, and the quality levels of its two variants to maximize joint profit subject to the independent, but simultaneous choice of the price, and the quality level, of the $(n-2)$ single-product competitors (followers). The Stackelberg leader chooses, in equilibrium, a symmetric price-quality strategy for its bi-variants, even if the firms are physically separated by at least one rival competitor, because it takes into account the fact that by increasing both 
prices and qualities, it benefits itself and its partner by inducing the competitor-follower between them to increase the price and the quality level of its single-product. The Stackelberg leader gains a significantly larger joint market share by moving first. The Stackelberg merged firm $M$ knows that the physically-isolated follower firm, as well as the remaining competitor-followers, will respond to any price-quality strategy with an immediate switch to an optimal response. Under Nash price-quality behaviour, nonneighbouring merging firms do not take this type of response by competitors into account. The Stackelberg firm $M$, at equilibrium, sets a symmetric price-quality policy for its two brands which are both higher than the post-merger prices and qualities chosen by the single-product follower firms, given $n+q \geq 5$ firms.

The final model presented is the generalized price-quality Stackelberg multiproduct, or n-neighbour firm merger. The corporate authority of the Stackelberg firm $M$ delegates the choice of quality level to its n-member firms while it maximizes the joint $n$ firm profits with respect to prices only, subject to the prices, and the quality levels independently, but simultaneously chosen by the $q$ single-product competitor-follower firms. The Stackelberg leader, firm $M$, chooses to decentralize the strategic choice of its product variants' quality levels while it maintains control over the set of product prices. The Stackelberg multi-product leader, firm $M$, in equilibrium, chooses an asymmetric price-quality policy for its $n$ product variants. The post-merger prices, and the quality levels, are both higher than the post-merger prices and quality levels chosen in equilibrium by the same multi-product firm $M$ under Nash behaviour.

The highest post-merger price and quality level of the follower-competitor is set 
by those symmetrically-located firms nearest to the Stackelberg leaders' market periphery. An n-neighbour firm Stackelberg merger increases the post-merger profits of all firms, where the leader gains the highest joint share, while the symmetrically-located, single-product competitor-followers situated the furthest in distance from the multiproduct Stackelberg firm $M$, realize the least. A comparison of the joint post-merger profit of a multi-product firm under price-quality Stackelberg behaviour with that of an identical firm under price-quality Nash behaviour, shows that the leader accrues a significantly higher share by simply moving first!

\subsection{AN OVERVIEW OF THE THESIS}

Chapter 2.0 establishes the results of the n-neighbour firm simultaneous pricequality Nash equilibrium model under localized competition with quadratic transport costs, $t$, borne by consumers in the purchase of preferred product variant. The consumers possess an inelastic demand for goods offered by the $n$-firms, and either buy a single product variant, or none. The spatial game model is based on a circular structure having a length, or size $L$, and a uniformly distributed population of size $N$. The chapter continues by providing an analysis of the comparative static results, and a comparison of the social welfare (optimum, first-best and second-best) equilibrium models.

Chapter 3.0 presents the generalized spatial game-theoretic model consisting of a price-quality Nash profit-maximizing merger strategy for a subset (i.e., two-or-more) nneighbour firms located within a circular space. The corporate entity, or multi-product firm $M$, acts as a "single-decision maker" whereby it maximizes joint profit of its $n$ member firms with respect to price, while allowing its n-member firms to each act 
independently in their choice of quality levels for their product variants. In effect, the merged firm, in its authority, decentralizes the decision regarding the quality levels of its $n$ product variants. The mathematical optimization problem to determine the generalized asymmetric price-quality Nash equilibrium outcome involves the solution set of (2n) second-order, recursive, non-homogeneous difference equations for both prices, and qualities. The set of $q$ outside competitor firms, or single-product firms, each acting under independent simultaneous Nash price-quality behaviour, set a price and a quality level for its single-product variant. The spatial game between $q+l$ firms results in an asymmetric price-quality policy set by the multi-product firm $M$ for its physicallyconnected product markets.

The second spatial model examined is that of a simultaneous Nash price-quality game for a merger consisting of two-neighbour firms. Here, the bi-variant merged firm $M$ controls both the prices, and the quality levels of the jointly produced variants so as to maximize joint profits. The simultaneous asymmetric Nash price-quality equilibrium outcome for a two-neighbour firm merger is established for the cases of $q=2,3$, and 4 outside competitors, or non-merged firms, respectively, within an industry. The bivariant firm $M$, controls both the strategic price and quality variables in its profit maximization, and sets identical prices, and identical quality levels for both variants in equilibrium, while the $q$ rival firms set an asymmetric price-quality for their singleproduct variants. The "free-rider" problem is absent for the bi-variant firm $M$ 's postmerger profits.

These Nash spatial game models naturally lead to the question of whether or not 
incentives exist for an oligopoly multi-product firm $M$ to acquire all firms within an industry and to assume the role of a monopolist. The generalized monopoly model for $n$ firms is described and analysed with respect to determining the post-merger effect on prices, quality levels, and total joint profit of its $n$ product variants. The chapter concludes with an examination of the numerical simulation results for the social welfare equilibrium outcome of both types of two-firm merger Nash models (decentralized or centralized decision-making), and the monopoly model.

Chapter 4.0 introduces the two-firm, non-neighbour merger under simultaneous price-quality Stackelberg behaviour and establishes the Stackelberg price-quality equilibrium outcome for the cases of $q=2,3$, and 4 single-product firms (rivals) within an industry. The Stackelberg price-quality strategy proves to be profit-maximizing for a set of two, non-neighbouring firms whereas the same set of firms under Nash pricequality behaviour would never merge, given the profit motive. The bi-variant firm $M$ not only acts as a Stackelberg leader, but controls both the prices and the quality levels of the two firms' product variants. The final model of the chapter examines the generalized spatial game-theoretic model composed of a price-quality Stackelberg profit-maximizing merger strategy for a subset of $n$-firms (neighbours) located within a circular structure. The Stackelberg leader controls only the prices of its $n$-firm members while it maximizes joint profits and allows for independent Nash behaviour among its $n$-firm members in their quality level choices. Each of the respective models is provided with comparative numerical simulation results for the total welfare equilibrium values of a two-firm merger with four competitor-follower firms. The "free-rider" problem is absent for the post- 
merger profits of both types of Stackelberg models.

An Application of the Nash Price-Quality Merger Model to the Banking Industry

An application of the Nash price-quality merger model may be drawn from the banking and financial services sector. The following description is a brief outline of a possible address model and its potential for anti-competitive post-merger impacts. Although the major banks offer many of the same, but different products and services, assume for simplicity, that the focus is on a single product, a risk-free asset, such as an investment vehicle (e.g., a term deposit or a guaranteed investment certificate). Suppose that each of the $i=1, \ldots, n^{*}$ banks are in a pre-merger symmetric price-quality equilibrium, horizontally differentiated, for example, by their branch location. The $n^{*}$ banks sell the risk-free assets to consumers at a "price", or an annual rate of return, $\left\{r_{l}, \ldots, r_{n}\right\}$, and they each set a level of quality for professional services rendered, determined by $\left\{a_{1}, \ldots, a_{n}\right\}$. The fixed cost of quality increases, for example, with the number of professional employees available and the hours of service. The pre-merger symmetric Nash pricequality equilibrium is denoted by $\left\{r^{*}, a^{*}\right\}$. Each bank $i=1, \ldots, n^{*}$ supplies an amount of $X_{i}$ $=N / n^{*}$, of the risk-free asset and in equilibrium, the total output of the asset is $X^{*}=$ $N / n^{*}$. Each of the banks earns a pre-merger profit of $\pi^{*}$.

Suppose that there is a merger of a subset of $n$ banks whose locations of operation are the branches of the new multi-product corporate entity. The merged bank $B$ now faces a set of $k=1, \ldots, q$ single-product rival banks selling the same risk-free asset. Here, the banking authority of the merged bank $B$, has a choice whether to delegate the responsibility of quality choice of the risk-free asset to its member branches or not. If it 
decentralizes the choice of quality level to its member branches, it will choose a rate of return to maximize joint profits, $\Pi B$. Such a decision may arise when monitoring and enforcement activities are too costly. Each member bank independently chooses its own level of quality, $a_{i}^{B}$, for the risk-free asset, $i=1, \ldots, n$. Alternatively, the banking authority may choose both the rate of return, and the quality level of services provided at its $n$ branches to maximize the joint profits, $\Pi P$.

The asymmetric equilibrium outcome of the Nash price-quality merger model shows that the effect on the rate of return $r$ will be higher, or $r_{i}^{B}>r^{*}$, for each $i=1, \ldots, n$, than the pre-merger rate of return, $r^{*}$. The post-merger rates of interest chosen by the corporate banking authority for its n-member banks' products are lower than those chosen by the same corporate authority who chooses to delegate the levels of quality of services to its $n$-member branches. The post-merger equilibrium levels of quality, $a_{i}^{B}>a^{*}$, for the product variants $(i=1, \ldots, n)$ are higher than the symmetric levels independently chosen by the $n$ firms in the pre-merger state. However, if the corporate banking authority does not delegate the responsibility of quality choice to its bank branches, it will choose, in equilibrium, a set of lower quality levels for its $n$-member branches' professional services. The merged bank $B$ chooses a price-quality strategy for its $n$ risk-free assets to earn a joint post-merger profit, $\pi^{B}>n \pi^{*}$, if there are $n+q \geq 4$ firms. The corporate authority of the merged bank $B$ who chooses to decentralize quality choice enjoys a lower joint post-merger profit than the merged bank who chooses both the prices and the quality levels of the $n$ risk-free assets.

The process for merger approval in Canada is determined by three Federal 
Government departments, the Competition Bureau, the Office of the Superintendent of Financial Institutions (OSFI), and Finance Canada. There is scope for intervention by the authorities at the Competition Bureau whose mandate is to examine such proposals for potential anti-competitive effects. They may set certain conditions for the conditional approval of a bank merger as defined by the Bank Merger Enforcement Guidelines (1998). For example, it may impose a restriction on the quality level, i.e., by increasing the number of professional staff, or hours of service. Such a condition may result in higher fixed costs for the merged bank $B$ who may pass on these costs indirectly to consumers by decreasing the rates of return $r_{i}^{B},(i=1, \ldots, n)$ of the risk-free assets. This is equivalent to increasing the prices to consumers for its $n$ products. A general condition of any business merger approval requires that prices not to exceed a five per cent increase within two years after a newly merged corporation commences business activity. These types of policy measures, such as a restriction on branch quality level or prices, may or may not be welfare enhancing. Further analysis to determine the impact on social welfare would depend on the merger model's asymmetric equilibrium outcome, $\left\{r_{i}^{B}, a_{i}^{B}\right\}$ for $i=$ $1, \ldots, n$, as a function of the parameters, $t, N$, and $L$.

The OSFI is responsible for the prudential aspects of a merger. Their concerns regard such issues as, for example, the financial viability and the risk profile of the proposed bank merger. The final approval of a proposed merger rests with the Minister of Finance. 


\section{An Application of the Nash Price-Quality Merger Model to Cartel Formation}

An application of the Nash price-quality model may be illustrated by those industries that exhibit cartel formation of firms which consist of binding contracts with side payments (e.g., exhaustible resources such as diamonds, or renewable resources such as tobacco). Diamonds may be horizontally differentiated, for example by the cut or style (e.g., round, square, or pear-shaped) for a given carat weight, and vertically differentiated by a number of characteristics (e.g., colour, purity, or clarity). Cartels are distinguished from pure tacit agreements by the fact that firms meet to communicate and concur on selected price-quality strategies. It is assumed here that all cartel non-members act as independent Nash single-product competitors who benefit from such cartel behaviour as they each gain a post-cartel profit greater than what they independently achieved prior to the formation of a cartel.

The results of both the Nash and Stackelberg merger analysis may also be interpreted in the context of cartel theory. For example, the $n$-firm merger may be viewed as a cartel with side payments. A cartel usually negotiates a set of prices, but may not necessarily set qualities. The cartel may position itself as a single firm under Nash pricequality behaviour, or act as a leader with respect to Stackelberg price-quality behaviour.

In the case where the cartel consists of two members, negotiating an agreement is relatively easy as equilibrium profits earned by each of the two firms are identical. Without a set of side payments, a multi-product cartel $C(n \geq 3)$ with an asymmetric price-quality strategy would have more difficulties in reaching a final agreement due to quality cost differences of the variants. With a set of $n$ product variants, each member- 
firm of the cartel charges a different price-quality combination, and a sells varying amounts. To reach an agreement in this case, for example, may be simplified by tying all product price-quality ranges to the price of a certain product such as either the lowest price-quality, or the highest price-quality.

A multi-product cartel $C$ has significant difficulties when the division of profits arise as each member contributes a different amount due to cost heterogeneity. Side payments, where legal, can be the most effective way of cartel members to reach an agreement. The asymmetric Nash price-quality equilibrium identifies cartel members ( $n$ 27) whose specific locations generate either the relatively lowest, or highest individual profits. Cartel members offering product variants that are located nearest to outside competitors obtain the highest (global) profits, $\pi_{l}^{C}=\pi_{n}^{C}$, while those centrally-located cartel firm(s) farthest from any single-product rivals contribute the second-highest (local) level of cartel-member profit, $\pi_{i(\max )}$ for $i=3, \ldots, n-2$. In either case, these firms must agree to pay a significant portion of their profits to a side-payment scheme.

One such side-payment scheme, denoted by $S$, whose level may be constructed by considering the average of the total joint cartel profit $\pi_{\text {ave }}=(1 / n) \sum_{i l}{ }^{n} \pi_{i}^{(}$, and the individual firm-member profit of the multi-product cartel $C$, denoted by $\pi^{c}$, such that $\pi_{i}^{C}$ $<S<\pi_{\text {ave }}^{r}$. The amount $S$ would consist of the weighted amount per member-firm $\pi_{i}^{(\cdot-}$ (1/n) $\sum_{i=1}^{n} \pi_{i}^{(}$, transferred to those member firms whose profit is less than the average total cartel profit. The amount of transfer is aimed at recovering the profit differences among all cartel members. These transfers, or side-payments benefit those cartel members who not only ward-off the outside competition as a result of the multi-product 
cartel's price-quality policy, but also must agree to such a cartel arrangement that supports their role as producing the lowest market shares, and thus, cartel-member profits. From this example of a cartel arrangement, a binding contract must be agreed to which reinforces collusion and avoids defection among cartel members by use of a noncooperative asymmetric price-quality strategy with side payments 


\section{CHAPTER 2: A PRICE-QUALITY OLIGOPOLY MODEL OF}

\section{LOCALIZED COMPETITION}

\subsection{A GAME-THEORETIC MODEL OF LOCALIZED COMPETITION}

The spatial model chosen here is the opposite approach to Chamberlinian nonlocalized competition - the Kaldorian case of localized competition - and is analysed by means of an address model similar to Salop (1979). The $n$ variants of the vertically differentiated product by quality are spaced equally around a circle $C$ of circumference $L$ such that the arc length or distance between two successive variants is $L / n^{1}$. The variants may be indexed by $x_{i}=(i-1) L / n$ for $i=1, \ldots, n$ on $L$ in a clockwise manner beginning with variant 1 at 12 o'clock.

All consumers have an inelastic demand and purchase one unit of the variant $x_{i}$ that gives him/her the maximum indirect utility with a given level of a quality $a_{i}$. Each consumer possesses the same marginal valuation $\theta \geq 1$ of the quality for a given quality level $a_{i}$ of variant $x_{i}$. A given consumer located at $x \in C$ that buys from the firm offering the lowest "delivered price" has the conditional indirect utility function for variant $x_{i}$ given by

$$
V_{i}(\theta, x)=y+\theta a_{i}-p_{i}-t\left|x-x_{i}\right|^{2}, \quad \text { for } i=1, \ldots, n
$$

where $\mid x-x_{i} /$ denotes the shortest length between $x$ and $x_{i}$ on $C, t / x-\left.x_{i}\right|^{2}$ is the quadratic

Economides [1989, B] showed that for $n \geq 3$ the equi-spaced placement of $n$ variants is the Nash equilibrium of a two-stage (location-price) game. 
(convex) transportation cost with unit cost $t$; and, $p_{i}$ is the base price ${ }^{2}$. The population $N$ of consumers having income $y$ is uniformly distributed on $C$ with density $N / L$ and the distance $t / x-\left.x_{i}\right|^{2}$ may either represent geographical distance or measure the implicit cost to the consumer of purchasing a good deviating from the consumer's "ideal" variant. It is assumed throughout this chapter that consumer income $y$ is sufficiently high enough and plays no explicit role in determining the price-quality Nash equilibrium.

Most products embody both a horizontal and vertical characteristic. The combination of the two types of characteristics is expressed in the indirect utility function where a consumer type is described by his/her marginal willingness to pay $\theta$ for the vertical characteristic and by his/her "ideal" point with respect to the horizontal characteristic $x$. The specification of a product variant is a pair denoted by $\left(a_{i} x_{i}\right)$. The assumption of additive utility in the two characteristics implies that the two dimensions of the characteristic's space are explicitly identified. This means that the two characteristics are independent and may be examined in isolation. Both elements or components of variants are simultaneously chosen by firms to reflect the situation that product design often requires the specification of all characteristics. For example, within the class of small or compact cars, horizontally differentiated by their exterior colours, each type of small car is produced with a given engine size. The available engine sizes, or the different levels of fuel consumption associated with size of an engine, may be thought to define a vertical characteristic.

Firms that operate in markets for differentiated goods (variants) employ a

${ }^{2}$ Salop (1979) assumes linear, rather than quadratic (convex) transportation costs. 
technology that distinguishes between levels of quality variations, denoted by $a_{i}$, for a given variant $x_{i}$. Consumers demand more of a level of a quality $a_{i}$ for a given variant $x_{i}$ at given (fixed) prices, rather than less. Since all consumers prefer high quality for a given price, consumers who possess a high $\theta$ however, are more willing to pay to obtain higher level of quality. Thus, $\theta$ maybe viewed as a taste parameter that vertically differentiates a given horizontally differentiated variant $x_{i}$ with a quality level $a_{i}$. The indirect utility function may also be expressed as

$$
V_{i}=a_{i}-(1 / \theta) \bar{p}, \text { where } \bar{p}=p_{i}+t\left|x-x_{i}\right|^{2}
$$

Preferences may now be interpreted in an alternative manner where $\theta$ is the inverse of the marginal rate of substitution between income and quality. All consumers derive the same surplus from the variant $x_{i}$ but different income levels imply different marginal rates of substitution between income and quality $(1 / \theta)$.

The associated fixed costs of a quality feature $c\left(a_{i}\right)=1 / 2 a_{i}^{2}$ for $i=1, \ldots, n$ variants are assumed to be independent of the level of output so that variable and marginal costs remain unaffected. Higher quality levels inherent in product variants however, require a higher level of fixed costs. This is applicable when quality improvement involves mainly research and development expenditures. Another example of such a quality feature is that of advertising expenditures used to market a brand, which can be added to any variant to increase the perceived attractiveness of the product. Advertising here may be thought of as conventional advertising (like television commercials or newspaper advertisements) to inform consumers by positioning a product or service by location. Certain lines of 
women's clothing for example, have a perceived higher quality if sold at exclusive retailers (e.g., Holt Renfrew or Talbot's) rather than chain stores. Exclusive retailers are usually located in central or "upper-scale" shopping areas or malls while chain stores (e.g., Wal-Mart, Zellers, and The Bay) are located in rural (non-central) areas or strip malls. This kind of advertising gives rise to what has been called "image" differentiation, as opposed to "real" or "quality" differentiation [see Scherer (1980), pp. 376-386]. These examples of "image" differentiation may be described by the "address" approach where each of the $n$-firms are associated with a certain level of quality of services.

A more specific example is the type and variety of investment vehicles offered by major banks and credit unions. Such products include guaranteed investment certificates, mutual funds, treasury-bills, and bonds. Each of these products is a certain type of variant, horizontally differentiated, for example, by the number of years held and vertically differentiated, for example, by features such as the availability of deposit insurance and the ability to redeem. The price at which these product variants are offered are equivalent to the various interest rates. The fixed costs of quality associated with these variants are determined, for example, by the level of risk, the availability of depositinsurance, and whether or not they serve as appropriate instruments under registered retirement savings plans.

The first step in determining the Nash equilibrium of the simultaneous qualityprice game for $n$ differentiated goods is the construction of each firm's variant demands. It is assumed that each variant has a positive demand and that price differences for pairs of successive variants are not too large. Thus, variant $x_{i}$ is in direct competition only with 
variants $x_{i-1}$ and $x_{i+1}$. Suppose that prices $\left(p_{i-1}, p_{i} p_{i+1}\right)$ are fixed so that if a consumer located at $x \in C$ buys variant $x_{i}$ then so does a consumer between $x$ and $x_{i}$. The market size of variant $x_{i}$ is described by the length of an $\operatorname{arc}$ of $C$ whose end points are given by the positions of consumers indifferent between $x_{i-1}$ and $x_{i}$, and $x_{i}$ and $x_{i+1}$, respectively. The location $x^{\prime}\left(p_{i-1}, p_{i}, a_{i-1}, a_{i}\right)$ of a consumer indifferent between buying variants $i-1$ and $i$ with qualities $a_{i-1}$ and $a_{i}$ are the solution to the finite difference equation,

$$
\begin{array}{r}
p_{i-1}-\theta a_{i-1}+t\left|x^{\prime}-x_{i-1}\right|^{2}=p_{i}-\theta a_{i}+t\left|x^{\prime}-x_{i}\right|^{2}, \text { where, } \\
x^{\prime}\left(p_{i-1}, p_{i}, a_{i-1}, a_{i}\right)=\frac{\left[\left(p_{i}-\theta a_{i}\right)-\left(p_{i-1}-\theta a_{i-1}\right)\right]}{(2 t L / n)}+(2 i-1) \frac{L}{2 n}
\end{array}
$$

Similarly, for consumers indifferent between variants $x_{i}$ and $x_{i, 1}$,

$$
x^{\prime}\left(p_{i}, p_{i+1}, a_{i}, a_{i+1}\right)=\frac{\left[\left(p_{i+1}-\theta a_{i+1}\right)-\left(p_{i}-\theta a_{i}\right)\right]}{(2 t L / n)}+(2 i+1) \frac{L}{2 n}
$$

The length of the market segment, found by subtracting (2.0) from (2.1) which, after multiplication by consumer density $N / L$, yields the demand for variant $x_{i}$ given by

$$
\begin{gathered}
X_{i}\left(p_{i-1}, p_{i}, p_{i+1}, a_{i}, a_{i-1}, a_{i+1}\right)= \\
\frac{N}{L}\left[\frac{\left[\left(p_{i+1}-\theta a_{i+1}\right)-2\left(p_{i}-\theta a_{i}\right)+\left(p_{i-1}-\theta a_{i-1}\right]\right.}{2 t L / n}+\frac{L}{n}\right], \text { for } i=1, \ldots, n
\end{gathered}
$$

As seen from equation (2.2) a variant's demand depends only on its own price and the prices of its two nearest neighbours. This property of the demand functions is a general 
characteristic of the spatial circle model: a differentiated product having a positive demand competes with at most with two other variants for any given set of prices and quality levels. Thus, in the two-dimensional localized competition model, a product variant is a strong gross substitute for at most two others and it is this localized nature of competition that allows for anti-competitive incentives and ensuing behaviour amongst horizontal mergers ${ }^{3}$. The Figure 2.1 illustrates the respective market segmentation for product variants along a circle $C$.

Each firm (variant) $x_{i} \in C$ has identical (constant) marginal cost's $c$ and common sunk cost's $f$ which include location-specific costs that are sufficient in magnitude to prevent new firms from entering or existing firms from moving. It is assumed that each firm owns the exclusive technology (patent) for the production of their particular variant and, operates at constant and identical average cost. A firm's profit function is given by

$$
\begin{gathered}
\pi_{i}\left(p_{i-1}, p_{i}, p_{i+1}, a_{i-1}, a_{i}, a_{i+1}\right)= \\
\left(p_{i}-c\right) X_{i}\left(p_{i-1}, p_{i}, p_{i+1}, a_{i-1}, a_{i}, a_{i+1}\right)-\frac{1}{2} a_{i}^{2}-f, \text { for } i=1, \ldots, n
\end{gathered}
$$

The necessary conditions $\partial \pi / \partial \mathrm{p}_{\mathrm{i}}=0$ for prices $i=1, \ldots, n$ are given by the following

This property of the demand functions holds for strictly convex transportation cost functions. When transportation costs are linear [Salop (1979)], demand functions are discontinuous at prices for which one variant attracts all consumers of a neighbouring variant. When transport cost functions are strictly concave, market segments may not be connected. Then the competition is not localized to the same extent, as one variant may be in direct competition with more than two others. 


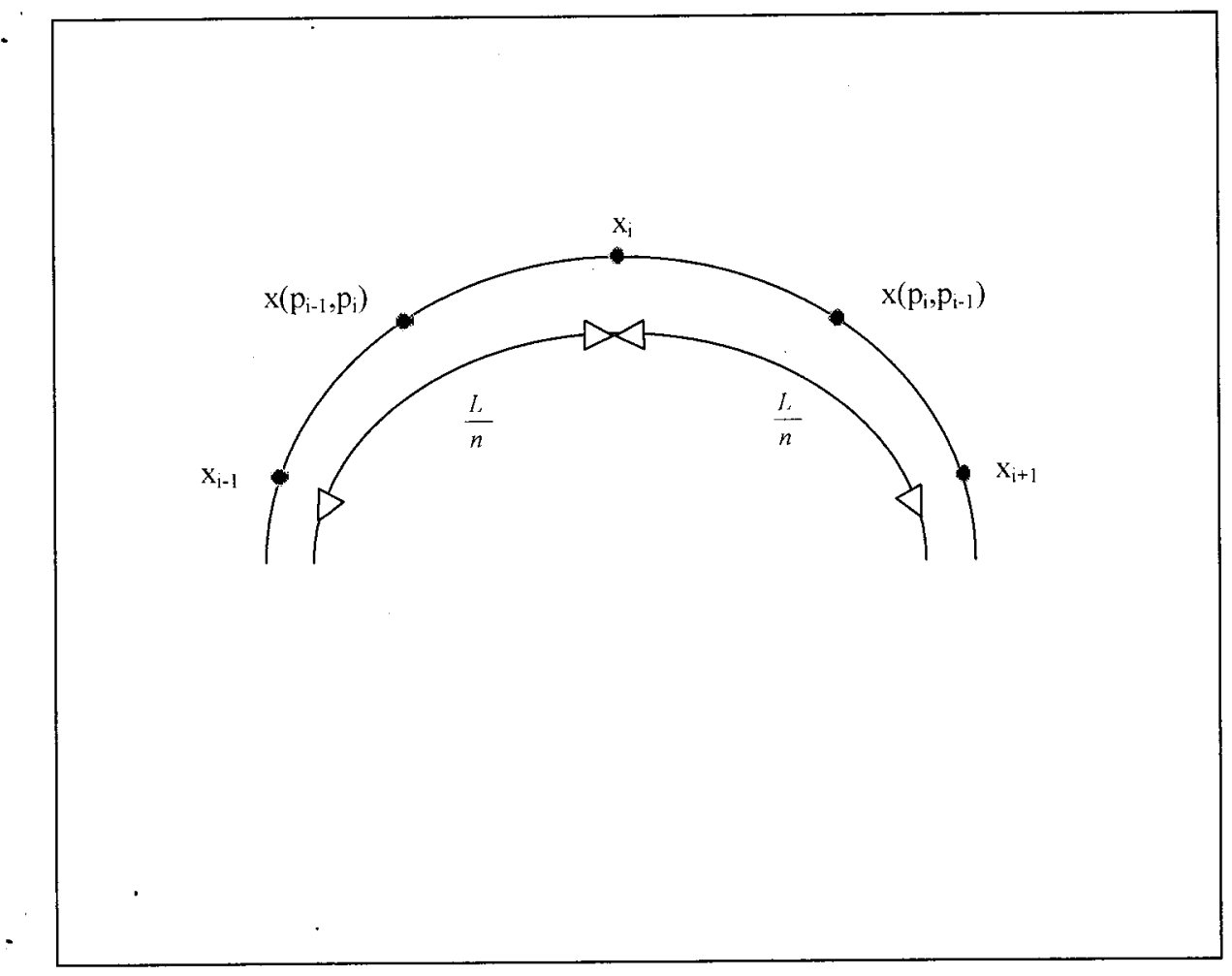

Figure 2.1: The circle model of product differentiation 
expressions:

$$
\begin{gathered}
p_{i}\left(p_{i-1}, p_{i+1}, a_{i-1}, a_{i}, a_{i+1}\right)= \\
\frac{1}{4}\left[\left(p_{i+1}-\theta a_{i+1}\right)+\left(p_{i-1}-\theta a_{i-1}\right)\right]+\frac{1}{2} t\left(\frac{L}{n}\right)^{2}+\frac{1}{2}\left(\theta a_{i}+c\right)
\end{gathered}
$$

which is firm $i$ 's reaction function.

The necessary conditions $\partial \pi / \partial a_{i}=0$ for qualities $i=1, \ldots, n$ are given by the following expressions:

$$
a_{i}=\left(\frac{\theta n N}{t L^{2}}\right)\left(p_{i}-c\right)
$$

Under Nash behaviour, each firm $i$ knows it cannot influence its rivals' behaviour with respect to prices and qualities. Since each firm $i$ face the same costs, the necessary conditions are symmetric with equi-distant firms and all firms set identical prices $p_{i-1}=p_{i}$ $=p_{i+I} \equiv p_{i}^{*} ;$ and, identical quality levels $a_{i-1}=a_{i}=a_{i+I} \equiv a_{i}^{*}$.

The symmetric Nash equilibrium outcome is defined $a^{4}$

$$
p_{i}^{*} \equiv p^{*}=t\left(\frac{L}{n}\right)^{2}+c ; a_{i}^{*} \equiv a^{*}=\frac{\theta N}{n} ; X_{i}^{*} \equiv X^{*}=\frac{N}{n} \text {. }
$$

The Nash equilibrium profit of a given firm of the simultaneous quality-price game is given by

Sufficient conditions for maximization are $\partial^{2} \pi_{\mathrm{i}} / \partial \mathrm{p}_{\mathrm{i}}^{2}=-2 \mathrm{nN} / \mathrm{tL}^{2}\left\langle 0 ; \partial^{2} \pi_{\mathrm{i}} / \partial \mathrm{a}_{\mathrm{i}}{ }^{2}=-1\langle 0\right.$; and, $\left.\left(\partial^{2} \pi_{\mathrm{i}} / \partial \mathrm{p}_{\mathrm{i}}^{2}\right)\left(\partial^{2} \pi_{\mathrm{i}} / \partial \mathrm{a}_{\mathrm{i}}^{2}\right)-\left(\partial^{2} \pi_{\mathrm{i}} / \partial \mathrm{a}_{\mathrm{i}} \partial \mathrm{p}_{\mathrm{i}}\right)^{2}>0 \Leftrightarrow\left(2 \mathrm{nN} / \mathrm{LL}^{2}\right)-\left(\theta^{2} \mathrm{nN} / \mathrm{tL}^{2}\right)^{2}>0 \Leftrightarrow \mathrm{t}\right\rangle \theta^{2} \mathrm{nN} / 2 \mathrm{~L}^{2}$. 


$$
\begin{aligned}
& \pi_{i}^{*}(n)=\pi^{*}(n)=\left(p^{*}-c\right) X^{*}-\frac{1}{2}\left(a^{*}\right)^{2}-f \\
& =\left(\frac{N}{2 n^{3}}\right)\left(2 t L^{2}-\theta^{2} n N\right)-f
\end{aligned}
$$

Theorem 1: The symmetric n-firm (variant) Nash equilibrium outcomes of the simultaneous quality-price game for price, quality, output per firm, and, profit per firm, are given by equations (2.6) and (2.7).ई

In order to compare and contrast this new, horizontal-vertical result with other established models of product differentiation, the following review first examines models with pure horizontal attributes only, and then models of pure vertical differentiation. The above $n$-firm simultaneous quality-price Nash equilibrium may be compared with that of the circular n-firm Bertrand-Nash equilibrium result of Levy and Reitzes (1992). By setting $L=1, \theta=0$, and $N=1$ in their horizontal differentiated Bertrand-Nash equilibrium price then the equilibrium price's, $p^{*}=c+t / n^{2}$ are identical. Profit per firm, independent of the vertical differentiation parameter $\theta$, is greater as fixed quality costs are absent.

A simultaneous price-quality equilibrium may be established for a $n$-firm oligopoly pure vertical differentiation model. Let the conditional indirect utility of a consumer of type $\theta$ buying variant $i$ be given by $V_{i}(\theta)=y-p_{i}+\theta q_{i}$ for $i=1,2, \ldots, n$ where $q_{i} \in\left[q_{-}, q^{-}\right]$, with $q_{-}>0$, is the quality of variant $i$ and $\theta>0$, is consumer $\theta^{\prime}$ s marginal willingness-to-pay for quality. Consumers are identical in their intensity of preference for quality. Suppose there are $n$ firms each selling a distinct vertically 
differentiated variant. The demand for variant $i$ is given by the mass of consumers in its market segment and is continuous in all prices if the consumer density is atom-less. Each firm produces its variant at zero marginal cost and there is no fixed cost associated with quality so that profit per variant is the price times quantity demanded. From the indirect utility function, the marginal consumer type is $\theta^{\prime}=\left(p_{i+1}-p_{i}\right) /\left(q_{i+1}-q_{i}\right)$ provided that $\theta^{\prime}>0$.

The simultaneous price-quality equilibrium of an oligopoly model under pure vertical differentiation can be shown as given by $p_{I}^{*}=\ldots=p_{n}{ }^{*}=0$ and $q_{1}{ }^{*}=\ldots=q_{n}{ }^{*}$ $=q^{-}$. Given the indirect utility function, then a firm producing a lower quality than $q^{-}$ may only attract consumers by charging a negative price. This equilibrium result may be compared with Bertrand's result for homogeneous products in that firms choose the socially optimal outcome (prices equal marginal cost and qualities are the highest allowed). The difference between this result and that for horizontal differentiation is because here all consumers agree on the ranking of the variants. Similarly, given the multi-dimensional indirect utility function of the Nash price-quality equilibrium result established for the spatial (circular) model, since all consumers have an identical $\theta$, then a firm producing a lower quality than $a^{*}$, may only capture consumers by charging a price less than the Nash equilibrium price, $p^{*}$, but where $p^{*}>c$.

For another illustration of a pure vertical differentiated product model, consider the indirect utility function of vertical preferences first proposed by Mussa and Rosen (1978). Their paper considers the monopoly and the perfectly competitive models only, and a brief comparison between these solutions (variables denoted by $\mathrm{m}$, and $\mathrm{c}$, respectively) may be outlined. Assume that consumers purchase one unit of a good and 
that there are constant costs of producing a given variety, and increasing marginal costs of higher quality varieties. Let $\theta \in\left[\theta_{-}, \theta^{-}\right]$and $\theta_{-}>0$.

(1) The highest level of consumer type $\theta$ purchases the same quality under both market structures, $q^{m}(\theta)=q^{c}(\theta)$, and for every other type of consumer, the monopolist sells a lower quality product than that sold under competition, or $q^{m}(\theta)<q^{c}(\theta)$ for all $\theta<\theta^{-}$. That is, some consumers with a low type of $\theta$ that buy under competition are not served in a monopolist's market.

(2) For consumers of type $\left[\theta^{*}, \theta^{-}\right]$who purchase a variety from a monopolist, the range of quality is greater than the range of quality sold to these same consumers under competition. The monopolist broadens the quality range at the low quality end as it able to exploit its monopoly power using both price and quality to discriminate more, relative to those consumers with greater demands.

(3) For any quality level $q^{h}>0$ sold under both market structures, the monopoly price is greater than the competitive price, $p^{m}>p^{c}$, and the price differential increases with $q^{h}$. Since $p^{c}$ equals the unit cost of producing quality $q^{c}$, or $C\left(q^{h}\right)$, then $p^{m}>C\left(q^{h}\right)$.

(4) The loss in consumers' surplus under a monopoly market increases with $\theta$, and the largest loss occurs for consumers with type $\theta^{-}$. This total loss follows from the general loss in consumers' surplus due to monopoly pricing, and from the fact that the reduction in surplus increases with $\theta$.

(5) With a standard monopolist, reduction in quantity is relative to marginal cost pricing. In this model, the monopolist may not necessarily reduce the quantity of any given quality. The monopolist sells some qualities which are not produced under competition. 
However, for the quality level $q^{h}$ sold under both market structures, the monopolist does reduce quantity.

\subsection{COMPARATIVE STATICS AND WELFARE IMPLICATIONS}

A few, simple comparative statics are in order before an examination of total welfare and its implications is discussed. For example, the symmetric equilibrium also involves higher qualities, for a given $n$ and $N$, being associated with higher $\theta$. Since $\theta$ is the (marginal) evaluation of quality by consumers then higher valuations elicit higher quality in the marketplace. The symmetric quality strictly increases, i.e., $\partial a^{*} / \partial \theta=N / n>$ 0 , with respect to a unit increase in the marginal valuation of quality while a firm's profit strictly declines with a unit increase in $\theta$ since $\partial \pi^{*}\left(\mathrm{a}^{*}\right) / \partial \theta=\partial \pi^{*} /\left.\partial \theta\right|_{\mathrm{a}^{*} \text { fixed }}+\left(\partial \pi / \partial \mathrm{a}^{*}\right)$ $\left(\partial \mathrm{a}^{*} / \partial \theta\right)=-2 \mathrm{NtL}^{2} / \mathrm{n}^{3} \theta+\mathrm{N}\left(2 \mathrm{tL}^{2}-\mathrm{nN} \theta^{2}\right) / \mathrm{n}^{3} \theta=-\theta \mathrm{N}^{2} / \mathrm{n}^{2}<0$. Higher levels of quality of a given product variant require higher fixed costs that translate into an overall percentage decline in profit for each unit increase in consumers' marginal valuation of quality. For a unit increase in $\theta$, and the quality level fixed, then the profits decline that result outweighs the small positive increase in profit from a variation in quality. The symmetric equilibrium profit of each firm in the multi-dimensional model, for a given $t, L, n$, and $N$, declines by a certain percentage amount, given a unit increase in the square of the vertical quality parameter $\theta$. The pure horizontal product variant model is devoid of such an added cost to profit.

For a given $\theta$ and $N$, the equilibrium quality is inversely proportional to the number of product variants' $n$ in the marketplace. Since a unit increase in $n$, the number of product variants, implies $\partial a^{*} / \partial n=\partial a^{*} / \partial n p_{p^{*} \text { fixed }}+\left(\partial a^{*} / \partial p^{*}\right)\left(\partial p^{*} / \partial n\right)=\theta N / n^{2}-2 \theta N / n^{2}$ 
$=-\theta N / n^{2}<0$, i.e., the level of quality strictly declines as each additional firm locates around $C$ or, as additional variants are added to the marketplace. The effect on equilibrium quality is the sum of two components where the positive effect of an increase in variants (prices fixed) is outweighed by the absolute decline in prices by increasing the number of variants. As the symmetric output level, $X^{*}$, for a given $N$, is inversely proportional to the number of variants, then output per firm strictly decreases for a unit increase in the number of variants within the market, i.e., $\partial X^{*} / \partial n=-N / n^{2}<0$. Equilibrium profit is inversely proportional to the cube of $n$, the number of horizontally differentiated variants, minus a term that allows for the added cost of the vertically differentiated component of the variant (i.e., the inverse of the square of $n$ ). Thus, for a unit increase in $n$, or as a product variant is added to the market, individual firm profit strictly decreases by a percentage amount given as $\partial \pi^{*}\left(\mathrm{a}^{*}\right) / \partial \mathrm{n}=\partial \pi^{*} / \partial \mathrm{n}_{\mathrm{a}^{*} \text { fixed }}+\left(\partial \pi^{*} / \partial \mathbf{a}^{*}\right)$ $\left(\partial \mathrm{a}^{*} / \partial \mathrm{n}\right)=-\mathrm{tL}^{2} / \mathrm{n}^{4}-\mathrm{N}\left(2 \mathrm{tL}^{2}-\theta^{2} \mathrm{nN}\right) / \mathrm{n}^{4}<0 \Leftrightarrow \mathrm{n}>3 \mathrm{tL}^{2} / \theta^{2} \mathrm{~N}$, i.e., as long as the lower bound on $n$ holds. The profit of a firm that sells a purely horizontal differentiated product does not enjoy the additional percentage decline in its profit due to the vertically differentiated element of a variant.

Note that, for a given $n$ and $\theta$, quality $a^{*}(n)$ at the symmetric equilibrium is increasing with $N$, the number of consumers. This implies that the equilibrium quality level will be high if the market is large, for a given $n$. As the quality level is determined by the equilibrium point at which marginal revenue equals marginal cost, then the marginal revenue with respect to quality increases with an increase in $N$, or the marginal investment in quality becomes more profitable the more consumers there are in the 
market. Similarly, since $\partial \pi^{*}\left(a^{*}\right) / \partial N=\partial \pi^{*} /\left.\partial N\right|_{a^{*} \text { fixed }}+\left(\partial \pi^{*} / \partial a^{*}\right)\left(\partial a^{*} / \partial N\right)=-$ $\left(a^{*}\right)^{2} t L^{2} / n N^{2} \theta^{2}+a^{*} \theta / n^{2} N \theta^{2}\left(2 t L^{2}-n N \theta^{2}\right)=t L^{2} / n^{3}-\theta^{2} N / n^{2}>0 \Leftrightarrow N<t L^{2} / n \theta^{2}$, a firm's profit is strictly increasing with respect to a unit increase in the number of consumers $N$, as long as the upper bound on $N$ holds. This effect is the sum of two terms. While $a^{*}$ is fixed, a unit increase in $N$ implies a reduction in profit and when $a^{*}$ varies, a unit increase in $N$ has a positive impact on profit. It is in a firm's best interest to maintain a high enough quality to satisfy an expanding consumer population. The symmetric Nash equilibrium outcome reflects such "scale" effects. As $\partial a * / \partial N=\theta / n>0$, the symmetric equilibrium quality is strictly increasing for a unit increase in the number of consumers $N$, and each firm's output is strictly increasing for a unit increase in $N$ since $\partial X^{*} / \partial N=1 / n>$ 0 . A unit increase in $N$ about the symmetric equilibrium price is determined by the expression, $\partial p^{*} / \partial N=\partial p^{*} / \partial N_{a^{*} f i x e d}+\left(\partial p^{*} / \partial a^{*}\right)\left(\partial a^{*} / \partial N\right)=-t L^{2} a * / \theta n N^{2}+t L^{2} / n^{2} N=0$ and shows that such an effect is in its sum, zero.

The effect of a unit increase in $L$ on the symmetric equilibrium price is strictly positive as $\partial p^{*} / \partial L=2 t L / n^{2}>0$. For a given $t$ and $n$, the symmetric price $p^{*}$ is directly proportional to the square of $L$, so that each unit increase in L effectively enlarges each firm's market share with a corresponding percentage increase in price. Each firm's profit strictly increases, i.e., $\partial \pi^{*} / \partial L=2 t L N / n^{3}>0$, for a unit increase in $L$. Since $\partial a^{*} / \partial L=$ $\left.\left(\partial a^{*} / \partial L\right)\right|_{p^{*} \text { fixed }}+\left(\partial a^{*} / \partial p^{*}\right)\left(\partial p^{*} / \partial L\right)=-2 \theta N / L n+2 \theta N / L n=0$, a unit increase in $L$ has no effect on equilibrium quality $a^{*}$. The positive effect of a unit increase in $L$ on a firm's profit is given by $\partial \pi^{*}(n) / \partial L=2 t L N / n^{3}>0$ and indicates that a larger spatial area has a direct influence on profit through an expansion of a firm's market size, given a fixed $n$. 
It is clear from the equilibrium outcome that price is independent of $\theta$ and is linearly increasing in the disutility parameter $t$, and increasing in the square of the circumference $L$. The equilibrium price is not a function of the vertical differentiation parameter $\theta$ as each firm's output of a product variant contains a fixed level of quality independent of production costs and consumers' valuations of quality. Furthermore, $\partial p^{*} / \partial \theta=\partial p^{*} /\left.\partial \theta\right|_{a^{*} \text { fixed }}+\left(\partial p^{*} / \partial a^{*}\right)(\partial a * / \partial \theta)=-t L^{2} / \theta n^{2}+t L^{2} / \theta n^{2}=0$ indicates an absence of an effect of a unit increase in $\theta$ on equilibrium price. This result is not present in the pure horizontally differentiated variant model. Hence, equilibrium price is independent of the consumers' valuation of quality when unit production cost is independent of quality.

For a given $n$, a larger $t$ and/or $L$ of $p^{*}$ mean consumers are more "loyal" since the effective distance between firms is greater. Similarly, if $t \rightarrow 0$ or $L \rightarrow 0$, then we arrive at the Bertrand result that firms price at marginal cost, $c$. For these two limiting cases, the perceived spatial differentiation among all $n$ firms vanishes. Thus, the second order condition, $t>\theta^{2} n N / 2 L^{2}$, which ensures a global maximum for the profit function in both prices and qualities, may be viewed as the support sufficient for both a positive price-cost margin and the physical, spatial separation of $n$ firms. Furthermore, the effect of a unit increase in the transport parameter $t$ on the equilibrium price $p^{*}$ implies $\partial p^{*} / \partial t=L^{2} / n^{2}>$ 0 , a positive percentage increase for an equilibrium price. This result is identical to that of the pure horizontal differentiation product model. The greater the increase in the disutility or mismatch between a product and a consumer, the greater the effect on the percentage increase in a firm's profit since $\partial \pi^{*}(n) / \partial t=L^{2} N / n^{3}>0$. A unit increase in $t$ 
on equilibrium quality $a^{*}$ has no effect as $\partial a^{*} / \partial t=\partial a^{*} / \partial t_{p^{*} f i x e d}+\left(\partial a * / \partial p^{*}\right)\left(\partial p^{*} / \partial t\right)=-$ $\theta N / L n+\theta N / L n=0$.

The short-run equilibrium price, $p^{*}$ is inversely proportional to the square of $n$, the number of product variants. Since the short-run equilibrium price is strictly decreasing in $n$ for a given positive $t$ and $L$, then in the limit, as $n \rightarrow \infty$, the equilibrium price tends to the perfectly competitive result of marginal cost. As $n$ rises, the circle model becomes more crowded or dense with variants and each consumer will find a preferred variant arbitrarily near to his own location. Also, $\partial p^{*} / \partial n=\partial p^{*} / \partial n_{a^{*} \text { fixed }}+$ $\left(\partial p^{*} / \partial a^{*}\right)\left(\partial a^{*} / \partial n\right)=-t L^{2} / n^{3}-t L^{2} / n^{3}=-2 t L^{2} / n^{3}<0$ implies an identical negative effect of a unit increase in the number of variants on equilibrium price. The first term shows for a given (fixed) level in quality, then a unit increase in $n$ has an impact of a certain percentage decline in price. This same impact is present in the purely horizontal variant model while the second effect of $n$ on $p^{*}$ due to varying quality is absent. Note that knowledge of a given consumer's valuations for two variants allows one to determine that consumer's valuations for all other variants. The difference between valuations of the most preferred, and the second most preferred variants, tends to zero for all consumers as $n$ gets sufficiently large enough.

Output per firm $X^{*}=N / n$ (the $N$ consumers are shared equally among the firms), so profits in the short-run are given by $\pi^{*}(n)=N /\left(2 t L^{2}-\theta^{2} n N\right) / 2 n^{3}-f$. To determine the welfare effects of the short-run equilibrium, let total social surplus $W$ be measured by the sum of total profits and consumers' surplus CS. Let $n$ be the (fixed) number of firms, and suppose that there is a symmetric situation in which each firm's profit equals $\pi$. The 
short-run measure of total welfare is determined as $W^{*}=n \pi^{*}+C S^{*}$. Consumers' surplus, $C S^{*}$, is calculated as the product of the number of consumers $N$, times the area under the (inelastic) demand curve and minus the area due to transport costs, which is given by

$$
\begin{aligned}
& C S^{*}(n)=N \int_{p^{*}}^{\theta a^{*}} d p-\frac{2 n N}{L} \int_{0}^{L / 2 n} t x^{2} d x=N\left(\theta a^{*}-p^{*}\right)-\frac{N t L^{2}}{12 n^{2}} \\
& =\frac{\theta^{2} N^{2}}{n}-N c-\frac{N t L^{2}}{n^{2}}-\frac{N t L^{2}}{12 n^{2}}
\end{aligned}
$$

where the Nash equilibrium values have been substituted in for $a^{*}$ and $p^{*}$. Hence, total short-run welfare $W^{*}(n)$ is calculated as

$$
\begin{gathered}
W^{*}(n)=n \pi^{*}(n)+C S^{*}(n)=n\left[\frac{N}{2 n^{3}}\left(2 t L^{2}-\theta^{2} n N\right)-f\right]+\frac{\theta^{2} N^{2}}{n}-N c-\frac{N t L^{2}}{n^{2}}-\frac{N t L^{2}}{12 n^{2}} \\
=\frac{\theta^{2} N^{2}}{2 n}-\frac{N t L^{2}}{12 n^{2}}-N c-n f .
\end{gathered}
$$

It is evident that consumers' surplus increases with respect to $n$, the number of firms or product variants as $\partial C S^{*}(n) / \partial n=-\theta^{2} N^{2} / n^{2}+2 N t L^{2} / n^{3}>0 \Leftrightarrow t>\theta^{2} N n / 2 L^{2}$, which is the second order condition. Now, since $C S^{*}\left(a^{*}\right)=N \theta a^{*}-N c-t L^{2} a^{*} / \theta n-t L^{2} a^{*} / 12 \theta n$, another interpretation may be provided for $\partial C S^{*}\left(a^{*}\right) / \partial n=\partial C S^{*}\left(a^{*}\right) / \partial n_{a^{*} \text { fixed }}+$ $\left(\partial C S^{*} / \partial a^{*}\right)\left(\partial a^{*} / \partial n\right)=t L^{2} a^{*} / \theta n^{2}+t L^{2} a^{*} / 12 \theta n^{2}-N / n^{3}\left(\theta n N-t L^{2}\right)>0 \Leftrightarrow t>6 \theta N n / 13 L^{2}$ $\Leftrightarrow n<13 t L^{2} / 6 \theta^{*} N$. With equilibrium quality fixed, there is a positive effect on $C S^{*}$ with respect to a unit increase in $n$, and a negative effect on $C S^{*}$ by varying quality with a unit increase in the number of variants. Since $\partial \mathrm{CS}^{*}\left(\mathrm{a}^{*}\right) / \partial \theta=\partial \mathrm{CS}^{*} /\left.\partial \theta\right|_{\mathrm{a}^{*} \mathrm{fixed}}+\left(\partial \mathrm{CS} * / \partial \mathrm{a}^{*}\right)$ 
$\left(\partial a^{*} / \partial \theta\right)=\theta \mathrm{N}^{2} / \mathrm{n}+\theta \mathrm{N}^{2} / \mathrm{n}=2 \theta \mathrm{N}^{2} / \mathrm{n}>0$, this implies a positive effect on $C S^{*}$ from a unit increase in $\theta$ with equilibrium quality fixed, and a positive effect on $C S^{*}$ from a unit increase in $\theta$ with a variation in quality. Note that $\partial C S^{*}(n) / \partial t=-N L^{2} / 13 n^{2}<0$ means that for a unit increase in the disutility parameter $t$ then consumers' surplus decreases by a given certain percentage amount.

It is evident that consumers' surplus increases by a certain percentage amount for a unit increase in $N$ since $\partial \mathrm{CS}^{*}(\mathrm{n}) / \partial \mathrm{N}>0 \Leftrightarrow \mathrm{N}>13 \mathrm{tL}^{2} / 24 \theta^{2} \mathrm{n}+\mathrm{cn}^{2} / 2 \theta^{2}$, i.e., there exists a lower bound on $N$ for which $C S^{*}$ increases by a certain percentage amount for a unit increase in the number of consumers. Consumers' surplus decreases by a certain percentage amount for a given unit increase in $L$, i.e., the size of the spatial model, since $\partial C S^{*}(n) / \partial L=-2 t N L / n^{2}-N t L^{2} / 6 n^{2}<0$. The effect of a unit increase in $N$ on $C S^{*}$ is given by $\partial C S^{*}\left(a^{*}\right) / \partial N=\partial C S^{*}\left(a^{*}\right) / \partial N_{a^{*} \text { ixed }}+\left(\partial C S^{*} / \partial a^{*}\right)\left(\partial a^{*} / \partial N\right)=\left(\theta^{2} N / n-c\right)-13 t L^{2} / n^{2}<0$ $\Leftrightarrow N>13 t L^{2} / 24 n \theta^{2}+c n^{2} / 2 n \theta^{2}$, i.e., as long as the lower bound on $N$ holds. The first term indicates (with $\mathrm{a}^{*}$ fixed) a positive effect, while the second term has a negative effect as equilibrium quality varies. The effect of a unit increase in the disutility parameter $t$ on $C S^{*}$ is given by the following equation; i.e., $\partial \mathrm{CS}\left(\mathrm{a}^{*}\right) / \partial \mathrm{t}=-13 \mathrm{NL}^{2} / 12 \mathrm{n}^{2}<$ 0 . A unit increase in the mismatch parameter $t$ implies a percentage decline in consumers' surplus.

Note that total welfare declines as the (fixed) $n$ increases since $\partial W^{*}(n) / \partial n=$ $n \partial \pi^{*}(n) / \partial n+\pi^{*}(n)+\partial C S^{*}(n) / \partial n=-\theta^{2} N^{2} / 2 n^{2}-f+N t L^{2} / 6 n^{3}<0$. As $\partial C S^{*}(n) / \partial n>0$, then the effect of $n\left[\partial \pi^{*}(n) / \partial n\right]<0$, i.e., profit per firm declines as $n$ increases, is dominant, at least in the short-run. Since $W^{*}\left(a^{*}\right)=\left(a^{*}\right)^{2}\left(2 t L^{2}-n N \theta^{*}\right) / 2 N \theta^{2}-n f-N c-a^{*}\left(t L^{2}-\right.$ 
$\left.\theta^{\prime} n N\right) / 12 \theta n$, then an alternative interpretation for such an effect of a unit increase of $n$ on $\mathrm{W}^{*}$ is given by the following equation:

$$
\begin{aligned}
& \partial W *(a *) / \partial n=\partial W * /\left.\partial n\right|_{a * f i x e d}+(\partial W * / \partial a *)(\partial a * / \partial n)= \\
& {\left[-1 / 2\left(a^{*}\right)^{2}+a^{*} t L^{2} / \theta n^{2}-f\right]-\left(\theta N / n^{2}\right)\left[2 a^{*} t L^{2} / N \theta^{2}-a^{*} n / 2-t L^{2} / 12 \theta n+\theta N / 12\right]} \\
& \quad=-\theta^{2} N^{2} / 2 n^{2}-f+N t L^{2} / 6 n^{3}<0 .
\end{aligned}
$$

With both terms, $a^{*}$ fixed and as $a^{*}$ varies, respectively, then as the number of variants offered in the marketplace increases then total welfare declines by a given percentage amount. The effect of an increase in the number of consumers $N$ on total welfare is ambiguous. Since $\partial \mathrm{W}^{*}\left(\mathrm{a}^{*}\right) / \partial \mathrm{N}=\partial \mathrm{W}^{*} /\left.\partial \mathrm{N}\right|_{\mathrm{a}^{*} \text { fixed }}+\left(\partial \mathrm{W}^{*} / \partial \mathrm{a}^{*}\right)\left(\partial \mathrm{a}^{*} / \partial \mathrm{N}\right)=\left[-\left(\mathrm{a}^{*}\right)^{2} \mathrm{tL}^{2} / \mathrm{N}^{2} \theta^{2}\right.$ $\left.+a^{*} \theta / 12-c\right]+\theta / n\left[2 a^{*} t L^{2} / N \theta^{2}-a^{*} n / 2-\mathrm{tL}^{2} / 12 \theta n+N \theta / 12\right]$, then $\partial W^{*}\left(a^{*}\right) / \partial N>0 \Leftrightarrow N>$ $\mathrm{nc} / \theta^{2}+\mathrm{tL}^{2} / 12 \mathrm{n} \theta^{2}$ and $\partial \mathrm{W}^{*}\left(\mathrm{a}^{*}\right) / \partial \mathrm{N}<0 \Leftrightarrow \mathrm{N}<\mathrm{nc} / \theta^{2}+\mathrm{tL}^{2} / 12 \mathrm{n} \theta^{2}$. It is interesting to note that for a pure, horizontally differentiated model, the effect of $\partial \mathrm{W}^{*}(\mathrm{n}) / \partial \mathrm{N}=-\mathrm{c}<0$, i.e., an increase in the number of consumers on total welfare is strictly decreasing since the term for $\theta$ is absent. Thus, with a fixed quality level added to a horizontally differentiated variant, the total welfare level may increase depending on the above inequality for $N$.

Now, for an increase in consumers' valuation of quality, $\theta$, the effect on $W^{*}$ is given by the following equation; $\partial \mathrm{W}^{*}\left(\mathrm{a}^{*}\right) / \partial \theta=\partial \mathrm{W}^{*} /\left.\partial \theta\right|_{\mathrm{a}^{*} \text { fixed }}+\left(\partial \mathrm{W}^{*} / \partial \mathrm{a}^{*}\right)\left(\partial \mathrm{a}^{*} / \partial \theta\right)=[-$ $\left.2\left(a^{*}\right)^{2} \mathrm{tL}^{2} / \mathrm{N} \theta^{3}+\mathrm{a}^{*} \mathrm{tL}^{2} / 12 \theta^{2}+\mathrm{a}^{*} \mathrm{~N} / 12\right]+\mathrm{N} / \mathrm{n}\left[2 \mathrm{a}^{*} \mathrm{tL}^{2} / \mathrm{N} \theta^{2}-\mathrm{a}^{*} \mathrm{n} / 2-\mathrm{tL}^{2} / 12 \mathrm{n} \theta+\theta \mathrm{N} / 12\right]=$ $\theta \mathrm{N}^{2} / \mathrm{n}>0$. The second term is positive for a unit increase in $\theta$ while $\mathrm{a}^{*}$ varies and strictly dominates the first term, for a fixed $\mathrm{a}^{*}$ level. 


\subsection{MARKET EQUILIBRIUM AND OPTIMUM PRODUCT DIVERSITY AND}

\section{QUALITY}

This section examines both the long-run, or free-entry equilibrium for a circle model with product and quality differentiation and the social optimum necessary to achieve the maximization of total welfare. The equilibrium output per firm in the circle model is $X^{*}=N / n$ (the $N$ consumers are shared equally among the $n$ firms), so that profit per firm in the short-run is given by $\pi^{*}(n)=N\left(2 t L^{2}-\theta^{2} n N\right) / 2 n^{3}-f$. Solving for the zeroprofit long-run, or free-entry equilibrium number of firms, $n^{e}$, by setting $\pi^{*}(n)=0$ produces a cubic equation in $n$ for which the (real root) solution is given by

$$
n^{e}=\frac{N^{1 / 3}}{6^{2 / 3} f^{1 / 2}} \frac{\left[\left(s_{e}\right)^{2 / 3}-6^{1 / 3} \theta^{2} N^{4 / 3}\right]}{\left(s_{e}\right)^{1 / 3}}
$$

where $s_{e}=18 t L^{2} f^{2}+6^{t}\left(54 f t^{2} L^{4}+N^{4} \theta^{6}\right)^{1 / 2}$.

The other two roots of the cubic equation are complex conjugates and the real root $n^{e}$ may not necessarily be an integer solution. The ratio indicates the importance of both the sunk cost $f$ and the number of consumers $N$. The equation also shows that doubling the number of consumers $N$ has the effect of raising the number of firms by a multiplicative factor of $2^{l / 3}<2$. Also, halving the sunk cost $f$ has an effect of increasing the number of firms by a multiplicative factor of $2^{l: 2}<2$. This implies that the number of firms less than doubles as price competition becomes more intense since more firms are located in the product space, and they become closer substitutes for neighbouring products. Similarly, if the circumference $L$ doubles (the product space doubles) and the 
number of consumers $N$ doubles, then the equilibrium number of firms approximately doubles. In this latter effect only the "scale" of the model is changed by leaving the number of consumers per unit distance $(N / L)$ constant.

The free entry equilibrium price $p^{e}\left(n^{e}\right)$ is given by

$$
\begin{gathered}
p^{e}\left(n^{e}\right)=c+\left[\frac{2 f\left(t L^{2}\right)^{2}}{n^{e} N\left(2 t L^{2}-\theta^{2} n^{e} N\right)}\right]^{1 / 2} \\
=c+\frac{2^{1 / 2} 6^{2 / 3} f t L^{2} s_{e}^{1 / 3}}{N^{2 / 3}\left(s_{e}^{2 / 3}-6^{1 / 3} \theta^{2} N^{4 / 3}\right)^{1 / 2}\left[(2) 6^{2 / 3} t L^{2} f^{1 / 2} s_{e}^{1 / 3}-\theta^{2} N^{4 / 3}\left(s_{e}^{2 / 3}-6^{1 / 3} \theta^{2} N^{4 / 3}\right)\right]^{1 / 2}}
\end{gathered}
$$

while the quality level $a^{e}\left(n^{e}\right)$ is calculated as the following

$$
\begin{aligned}
& =a^{e}\left(n^{e}\right)=\theta X^{e}=\left[\frac{2 n^{e} N f \theta^{2}}{\left(2 t L^{2}-\theta^{2} n^{e} N\right)}\right]^{1 / 2} \\
& =\frac{\theta(2 f)^{1 / 2} N^{2 / 3}\left(s_{e}^{2 / 3}-6^{1 / 3} \theta^{2} N^{4 / 3}\right)^{1 / 2}}{\left[(2) 6^{2 / 3} t L^{2} f^{1 / 2} s_{e}^{1 / 3}-\theta^{2} N^{4 / 3}\left(s_{e}^{2 / 3}-6^{1 / 3} \theta^{2} N^{4 / 3}\right)\right]^{1 / 2}} .
\end{aligned}
$$

Free entry output per firm $X^{e}\left(n^{e}\right)$ is determined by the expression

$$
\begin{gathered}
X^{e}\left(n^{e}\right)=\left[\frac{2 n^{e} N f}{\left(2 t L^{2}-\theta^{2} n^{e} N\right)}\right]^{1 / 2} \\
=\frac{(2 f)^{1 / 2} N^{2 / 3}\left(s_{e}^{2 / 3}-6^{1 / 3} \theta^{2} N^{4 / 3}\right)^{1 / 2}}{\left[(2) 6^{2 / 3} t L^{2} f^{1 / 2} s_{e}^{1 / 3}-\theta^{2} N^{4 / 3}\left(s_{e}^{2 / 3}-6^{1 / 3} \theta^{2} N^{4 / 3}\right)\right]^{1 / 2}}
\end{gathered}
$$

and long-run profit per firm $\pi^{e}\left(n^{e}\right)=0$. Thus, total welfare $W^{e}\left(n^{e}\right)=C S^{e}\left(n^{e}\right)$ as long-run 
profit per firm, $\pi^{e}\left(n^{e}\right)=0$.

The two fundamental theorems of welfare economics give the comparisons between the Pareto optimal allocations to those found in a perfectly competitive economy. Firms are price-takers in a perfectly competitive economy in all sectors and efficiently produce their output at a price equal to marginal cost. Perfect competition does not appear to be an exact prescriptive in markets with differentiated products associated with some degree of market power. The link between market equilibrium and social optimality will be severed as marginal cost pricing is unlikely to exist when consumers have idiosyncratic tastes and preferences for variants of a differentiated product.

Firms that exist and sell to many consumers generally possess increasing returns to scale, or some indivisibility (e.g., a fixed cost) in production, at least over some range of output. These economies of scale arising in production or marketing, retailing, and distribution for some output range are consistent with perfect competition - at least with the well-known U-shaped average cost function. However, with certain types of economies of scale and diversity of consumer tastes, the number of product variants available in the market will be under-provided in comparison with the number of consumer types. Thus, price-taking behaviour is an inadequate description since firms have a degree of market power. In product differentiation models, the minimum efficient scale is not the appropriate measure for evaluating a market outcome: a trade-off exists between production efficiency and the benefits of product diversity. The problem now is to analyse the relationship between market equilibrium and social optimum in the 
presence of economies of scale and product variants.

The problem is usually posed as a question between the number of firms in equilibrium and the social optimum - does the "right" number of firms or product variants exist, or does the market indicate insufficient/excess product diversity? However, with the circular model of product differentiation there is an added dimension, that of optimum quality. Even if equilibrium and product diversity were numerically identical, the price, quality level and output per firm would not necessarily coincide.

Part of the above problem has been addressed in the literature by Spence [Spence (1976), p. 220]. This paper examines the nature of a particular trade-off, "because revenues do not capture the consumers' surplus, revenues may not cover costs even when the social value of the product is positive. This is a force tending to eliminate products that should be produced. Second, when a product is introduced, it affects other profits adversely. Since the entering firm does not take these effects into account, it may enter when it is not generating a social benefit. This a force tending to generate too many products in the case of substitutes." As noted in the introduction to the model, localized competition is between products that are substitutes and reinforces the concept of opposing "externalities" alluded to by Spence.

The nature of such opposite "externalities" may be described in a more formal manner where total social surplus $W$ is measured by the sum of total profits and consumer surplus $C S$. The number of firms, $n$, each has symmetric profits denoted by $\pi$. Total welfare $W=n \pi+C S$ differentiated with respect to $n$ is given by the expression $n d \pi / d n+$ $\pi+d C S / d n$. Firms will enter in a free entry equilibrium until $\pi^{e}=0$, and the "externality" 
that dominate depends on the derivative of the welfare function evaluated at the optimum. This implies that the "marginal" entrant ignores both the positive effect it has on consumers $(n C S / d n)$, and the negative effect $(n d \pi / d n)$ it incurs on existing firms' profits.

Free-entry equilibrium is one method of determining (locally) whether or not product diversity is under- or over-provided. Another method is to directly calculate the equilibrium and optimum firm values. The criterion for defining the social optimum is that of the first-best optimum defined as the outcome that would be chosen by a social planner whose objective is to maximize $W$ by choice of prices, quality and the number of firms. The first-best optimal price is equivalent to marginal cost under competitive conditions. However, with the presence of indivisibilities or increasing returns, all firms incur losses. This criterion is reasonable if a social planner can make a non-distortionary lump-sum transfer to cover losses incurred due to sunk costs $f$ and fixed quality costs $a$.

If the social planner is unable to make such a transfer, then suppose that the planner faces a break-even constraint. This is a second-best problem, whereby $W$ is maximized by choice of $n$ subject to a zero-profit constraint so that prices are determined from the break-even constraint (e.g., free-entry $p^{e}$ ). Another type of second-best problem arises when the planner may only determine the number of firms (e.g., by subsidizing or taxing entry) but not their pricing. In this case, $W$ is maximized subject to an oligopolistic pricing constraint (say, $p^{*}>p^{e}$, the exogenous Nash equilibrium price) and determines the efficiency of the entry decision per se, separated by any distortions inherent in the pricing equilibrium.

The first-best welfare maximization problem considered here is the maximization 
of total net social surplus with respect to the number of variants $n$. The term $t x^{2}$ is the transport cost paid by a consumer a distance $x$ from the nearest firm where $n$ firms operate in the circular market at a distance $L / n$ apart, and the marginal consumer travels a distance $L / 2 n$ to the nearest firm. Thus, a consumer located at distance $x \leq L / 2 n$ obtains a surplus in excess of marginal cost $c$ of $\left(\theta a^{*}-c-t x^{2}\right)$ where $t$ is the unit transport cost and $\theta a^{*}$ may be treated as the consumers' (net) reservation price. Hence, with density $L / N$ consumers per market, the total net surplus when product variants are offered at marginal cost is given by the following expression;

$$
W^{f}=n\left[\frac{2 N}{L} \int_{0}^{L / 2 n}\left(\theta a-t x^{2}-c\right) d x\right]-n f-n\left(\frac{1}{2} a^{2}\right)
$$

which on integration yields,

$$
W^{f}(a)=N \theta a-N c-\frac{N t L^{2}}{12 n^{2}}-n f-\frac{n}{2} a^{2} .
$$

The first-best optimum quality level $a^{f}\left(n^{f}\right)$ are obtained as the solution to the equation $\partial W^{f}(a) / \partial a=0$, where,

$$
a^{f}\left(n^{f}\right)=\frac{N \theta}{n^{f}}
$$

After substitution of $\alpha^{f}(n)$ into $W^{f}(a)$ we obtain the expression;

$$
W^{f}(n)=-\frac{N t L^{2}}{12 n^{2}}+\frac{N^{2} \theta^{2}}{2 n}-N c-n f
$$

The first-best optimum $n^{f}$ is obtained by the real root solution of the cubic equation that results from $\partial W^{f}(n) / \partial n=0$ (which may not necessarily be an integer solution); 


$$
\begin{gathered}
n^{f}=\frac{N^{1 / 3}\left[\left(s_{f}\right)^{2 / 3}-6^{1 / 3} \theta^{2} N^{4 / 3}\right]}{6^{2 / 3} f^{1 / 2} s_{f}^{1 / 3}} ; \text { where, } \\
s_{f}=3 t L^{2} f^{1 / 2}+3^{1 / 2}\left(3 f t^{2} L^{4}+2 N^{4} \theta^{6}\right)^{1 / 2} .
\end{gathered}
$$

The other two roots of the cubic equation are the complex conjugates. If we compare this result with the free-entry market equilibria, then we have that $n^{f}<n^{e}$; or, Proposition 1: The free-entry equilibrium product diversity level $n^{e}$ is greater than that of the first-best optimum product diversity level $n$.

Proof: To show that $\mathrm{n}^{\mathrm{e}}>\mathrm{n}^{\mathrm{f}}$, it is sufficient to prove the following inequality;

$$
\begin{aligned}
& \left.\partial W^{f / \partial n}\right|_{n=n^{e}}>0 . \text { Thus, } \partial W^{f}(n) /\left.\partial n\right|_{n=n^{e}}=N t L^{2} / 6\left(n^{e}\right)^{3}-\theta^{2} N^{2} / 2\left(n^{e}\right)^{2}-f>0 \\
& \Leftrightarrow \quad N t L^{2}-3 \theta^{2} N^{2} n^{e}>6 f\left(n^{e}\right)^{3} \Leftrightarrow N t L^{2}>3 n^{e}\left[2 f\left(n^{e}\right)^{2}+\theta^{2} N^{2}\right] \\
& \Leftrightarrow \quad 12 t L^{2} f^{1 / 2} s_{e}>\left(s_{e}^{2 / 3}-6^{1 / 3} \theta^{2} N^{4 / 3}\right)\left[2\left(s_{e}^{2 / 3}-6^{1 / 3} \theta^{2} N^{4 / 3}\right)^{2}+\theta^{2} N^{4 / 3} 6^{4 / 3} s_{e}^{2 / 3}\right] \\
& \Leftrightarrow \quad 12 t L^{2} f^{1 / 2} s_{e}>2\left(s_{e}^{2}-6 N^{4} \theta^{6}\right) \Leftrightarrow s_{e}\left(6 t L^{2} f^{1 / 2}-s_{e}\right)+6 N^{4} \theta^{6}>0 \Leftrightarrow \\
& {\left[18 t L^{2} f^{1 / 2}+6^{1 / 2}\left(54 f t^{2} L^{4}+N^{4} \theta^{6}\right)^{1 / 2}\right]\left[-12 t L^{2} f^{1 / 2}-6^{1 / 2}\left(54 f t^{2} L^{4}+N^{4} \theta^{6}\right)^{1 / 2}\right]>-6 N^{4} \theta^{6}} \\
& \Leftrightarrow \quad 30 f^{1 / 2} t L^{2}\left[18 t L^{2} f^{1 / 2}+6^{1 / 2}\left(54 f t^{2} L^{4}+N^{4} \theta^{6}\right)^{1 / 2}\right]<0 \Leftrightarrow s_{e}<0 .
\end{aligned}
$$

Thus, $\partial W^{f}(n) /\left.\partial n\right|_{n-n} ^{e}>0 \Leftrightarrow s_{e}<0$. This implies the following inequality,

$18 t L^{2} f^{1 / 2}+6^{1 / 2}\left(54 f t^{2} L^{4}+N^{4} \theta^{6}\right)^{1 / 2}<0 \Leftrightarrow 324\left(t L^{2}\right)^{2} f<6\left(54 f t^{2} L^{4}+N^{4} \theta^{6}\right) \Leftrightarrow 0<N^{4} \theta^{6}$.

Hence, $n^{e}>n^{f}$. Q.E.D. 
For the free-entry market criterion, the market always over-provides product variety. This result indicates that those firms under conditions of localized competition are more competitive, and suggests that if the price competition were less intensive, then the number of firms in equilibrium would be smaller and closer to the optimum.

The first-best optimum quality level $\alpha^{f}\left(n^{f}\right)$ is given by

$$
\left.a^{f_{(n}}\right)=\frac{N \theta}{n^{f}}=\frac{N^{2 / 3} 6^{2 / 3} f^{1 / 2} \theta s_{f}^{1 / 3}}{\left(s_{f}^{2 / 3}-6^{1 / 3} \theta^{2} N^{4 / 3}\right)}
$$

and, the first-best optimum output per firm $X^{f}\left(n^{f}\right)$ is given by

$$
X^{f}\left(n^{\mathcal{f}}\right)=\frac{N^{2 / 3} 6^{2 / 3} f^{1 / 2} s_{f}^{1 / 3}}{\left(s_{f}^{2 / 3}-6^{1 / 3} \theta^{2} N^{4 / 3}\right)}
$$

Finally, the first-best profits per firm losses are given by the following function,

$$
\pi^{f}\left(n^{f}\right)=\frac{1}{2}\left(a^{f}\right)^{2}-f=\frac{N^{2} \theta^{2}}{2\left(n^{f}\right)^{2}}-f .
$$

Proposition 2: The first-best optimum quality level $\alpha^{f}$ exceeds that of the free-entry equilibrium quality level $a^{e}$, or $a^{e}<\alpha^{f}$.

Proof: To show that $\mathrm{a}^{\mathrm{e}}<\mathrm{a}^{\mathrm{f}}$ it is sufficient to prove the following inequality,

$$
\begin{gathered}
\partial W^{f}(a) /\left.\partial a\right|_{a=a^{e}}<0 \leftrightarrow N \theta-n^{e} a^{e}<0 \Leftrightarrow N \theta<n^{e}\left(2 n^{e} N f \theta^{2}\right)^{1 / 2} /\left(2 t L^{2}-\theta^{2} n^{e} N\right)^{1 / 2} \\
\Leftrightarrow N\left(2 t L^{2}-\theta^{2} n^{e} N\right)<2 f\left(n^{e}\right)^{3} \Leftrightarrow 2 t L^{2} N<n^{e}\left[2 f\left(n^{e}\right)^{2}+\theta^{2} N^{2}\right] \Leftrightarrow \\
72 t L^{2} f^{1 / 2} s_{e}<\left(s_{e}^{2 / 3}-6^{1 / 3} \theta^{2} N^{4 / 3}\right)\left[\theta^{2} N^{4 / 3} 6^{4 / 3} s_{e}^{2 / 3}+2\left(s_{e}^{2 / 3}-6^{1 / 3} \theta^{2} N^{4 / 3}\right)^{2}\right] \Leftrightarrow
\end{gathered}
$$


$72 t L^{2} f^{1 / 2} s_{e}<2\left(s_{e}^{2}-6 N^{4} \theta^{6}\right) \Leftrightarrow s_{e}\left(36 t L^{2} f^{1 / 2}-s_{e}\right)<-6 N^{4} \theta^{6} \Leftrightarrow$

$\left.18 t L^{2} f^{1 / 2}+6^{1 / 2}\left(54 f t^{2} L^{4}+N^{4} \theta^{6}\right)^{1 / 2}\right]\left[18 t L^{2} f^{1 / 2}-6^{1 / 2}\left(54 f t^{2} L^{4}+N^{4} \theta^{6}\right)^{1 / 2}\right]<-6 N^{4} \theta$

$\Leftrightarrow-6 N^{4} \theta^{6}<-6 N^{4} \theta^{6}$. Hence $\partial W^{f}(a) /\left.\partial a\right|_{a=a^{e}}<0 \Leftrightarrow-6 N^{4} \theta^{6}<-6 N^{4} \theta^{6}$. Q.E.D.

An equivalent comparison of free-entry equilibrium quality $a^{e}$ to first-best optimum quality $a^{f}$ shows that the market under-provides the necessary level of quality as long as $\left(2 t L^{2}-\theta^{f} n^{f} N\right)>0$ holds for the inequality between product varieties.

Thus, for the circular model, the market may fail to provide the optimal degree of product diversity and quality level. The social welfare criterion indicates that a variety is produced if the change in gross surplus (the sum of revenues and consumer surplus) minus the total cost of production is positive. However, the market criterion used for production is profitability and there is no analytical reason why the maximization of net social surplus will occur at the same point (i.e., at the same number of varieties introduced) at which the expected profit from the introduction of an additional variant becomes zero.

Finally, the second-best welfare maximization problem considered here is the maximization of total net social surplus, equation (2.15), subject to the break-even constraint of zero profit per firm (i.e., the oligopolistic pricing constraint equivalent to the free-entry equilibrium price $p^{e}=c+\left[2\left(t L^{2}\right)^{2} f / n N\left(2 t L^{2}-\theta^{2} n N\right)\right]^{1 / 2}$ where $n=n^{s}$. The second-best optimum $n^{s}$ is identical to the solution for the first-best optimum $n^{f}$. Thus, $n^{s}$ $=n^{f}, a^{s}=a^{f}$, and the second-best price $p^{s}\left(n^{s}\right)>p^{f}\left(n^{f}\right)$, where $p^{s}\left(n^{s}\right)$ is given by the 
following equation,

$$
p^{s}\left(n^{s}\right)=c+\frac{t L^{2}(2 f)^{1 / 2}}{\left[n^{s} N\left(2 t L^{2}-\theta^{2} n^{s} N\right)\right]^{1 / 2}}
$$

The second-best optimum quality level $a^{s}\left(n^{s}\right)$ is given by,

$$
a^{s}\left(n^{s}\right)=\frac{\theta N}{n^{s}}=\frac{\theta N^{2 / 3} 6^{2 / 3} f^{1 / 2} s_{s}^{1 / 3}}{\left(s_{s}^{2 / 3}-6^{1 / 3} \theta^{2} N^{4 / 3}\right)}
$$

while the second-best output per firm $X^{s}\left(n^{s}\right)$ is given by

$$
X^{s}\left(n^{s}\right)=\frac{N}{n^{s}}=\frac{N^{2 / 3} 6^{2 / 3} f^{1 / 2} s_{s}^{1 / 3}}{\left(s_{s}^{2 / 3}-6^{1 / 3} \theta^{2} N^{4 / 3}\right)} .
$$

The second-best optimum profit per firm $\pi^{s}\left(n^{s}\right)=0$ so that the second-best welfare function $W^{s}\left(n^{s}\right)=C S^{s}\left(n^{s}\right)$ is given by the following equation,

$$
\begin{array}{r}
C S^{s}\left(n^{s}\right)=N\left[\theta a^{s}-p^{s}-\frac{2 n}{L} \int_{0}^{L / 2 n} t x^{2} d x\right] \\
=N\left[\frac{\theta^{2} N}{n^{s}}-c-\frac{t L^{2}(2 f)^{1 / 2}}{\left[n^{s} N\left(2 t L^{2}-\theta^{2} n^{s} N\right)\right]^{1 / 2}}-\frac{t L^{2}}{12\left(n^{s}\right)^{2}}\right]
\end{array}
$$

For all of the above equations $s_{s}=s_{f}$ is equivalent to,

$$
s_{s}=3 t L^{2} f^{1 / 2}+3^{1 / 2}\left(3 f t^{2} L^{4}+2 N^{4} \theta^{6}\right)^{1 / 2}
$$

Throughout the analysis it is assumed that each consumer buys one unit of the variant 
yielding the greatest utility, that this variant is affordable, and the non-purchase alternative is never preferred. These assumptions allow for a somewhat simple analysis. Since a rise in price (with all prices' equal) is simply a transfer from consumers to firms without deadweight loss (because individual demand is inelastic), the three different optimum concepts so far discussed are amenable to a graphic interpretation. While the free-entry market number of firms differs, the first-best and the second-best number of firms are identical $\left(n^{f}=n^{s}\right)$. Thus, the iso-welfare functions or contours are vertical in $p$ - $n$ space. These contours are illustrated in Figure 2.2, along with the Nash equilibrium price locus $p^{*}(n)$, which together determine the various levels of equilibrium product diversity. If the welfare function is strictly quasi-concave in $n$ then the iso-welfare functions (vertical lines) correspond to successively lower values of welfare moving away from (in either direction) the first-best (equivalent to second-best) optimum number of firms $n^{f}=$ $n^{s}$. Also, since $n^{f}=n^{s}$ then $a^{f}=a^{s}$, i.e., first-best and second-best optimum quality levels are identical, but $p^{s}\left(n^{s}\right)>p^{e}\left(n^{e}\right)>p^{f}\left(n^{f}\right)$.

Although the optimal free-entry equilibrium results are obtained by constraining firm profit levels to zero and the second-best optimum maximizes total welfare subject to the constraint of zero firm profit, the results show that there exists a second-best welfare "trade-off" between product diversity and quality level. The social planner knows that $n^{e}$ $>n^{s}$, i.e., product diversity is greater under a free-market solution, but $a^{e}<a^{s}$, i.e., second-best quality is greater than what is optimum under a long-run equilibrium. However, since $p^{e}\left(n^{e}\right)>p^{s}\left(n^{s}\right)>p^{f}\left(n^{f}\right)$ the corresponding welfare levels are such that $W^{f}\left(n^{f}\right)=W^{s}\left(n^{s}\right)>W^{e}\left(n^{e}\right)$ and $W^{s}\left(n^{s}\right)=C S^{s}\left(n^{s}\right)>{ }^{c s e}\left(n^{e}\right)$. 


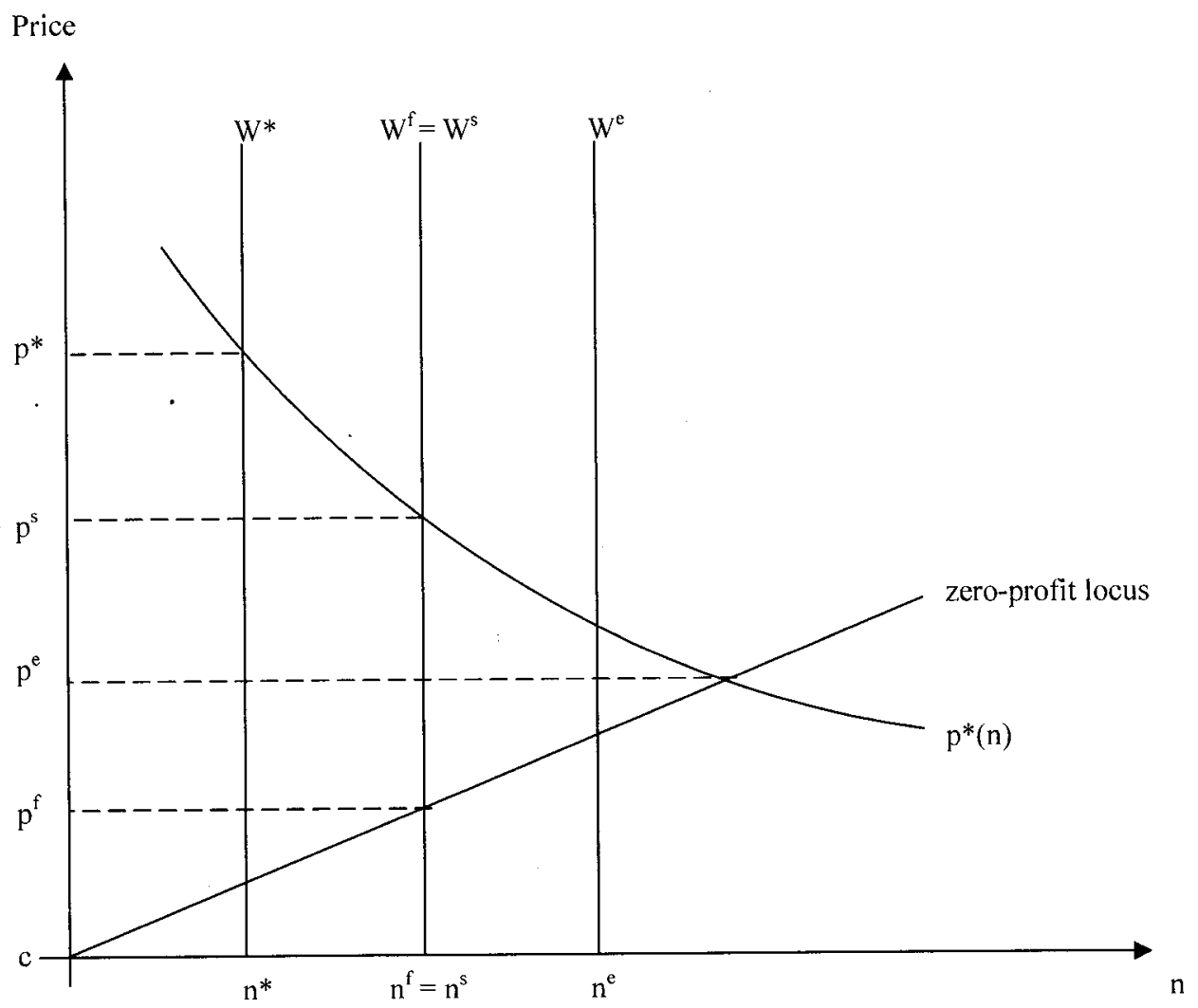

Figure 2.2: The free-entry equilibrium and social welfare optimum concepts 
Although the above result for the second-best maximization problem subject to a break-even constraint of zero profit per firm adds no new information, the next step is to consider maximizing $W^{s}$ subject to the Nash equilibrium price and quality to determine the level of product diversity, $n^{s}$ and the quality level $a^{s}$. The result of maximizing $W^{s}$ subject to the oligopolistic Nash equilibrium price $p *$ is given by the following equation:

$$
\begin{gathered}
W^{s}=2 n N / L \int_{0}^{L / 2 n}\left[\theta^{2} n N / t L^{2}\left(p^{*}-c\right)-t x^{2}-c\right] d x-n f \\
-n / 2\left(\theta n N / t L^{2}\right)^{2}\left(p^{*}-c\right)^{2} \\
=2 n N / L \int_{0}^{L / 2 n}\left[\theta^{2} N / n-t x^{2}-c\right] d x-n f-\theta^{2} N^{2} / 2 n .
\end{gathered}
$$

The integration of the above function $W^{s}$ gives the following result, where $n=n^{s}$;

$$
W^{s}\left(n^{s}\right)=N^{2} \theta^{2} / 2 n^{s}-N t L^{2} / 12\left(n^{s}\right)^{2}-N c-n^{s} f
$$

Thus, $W^{s}\left(n^{s}\right)=W^{f}\left(n^{f}\right)$ and $\partial W^{s}\left(n^{s}\right) / \partial n^{s}=0 \leftrightarrow n^{s}=n^{f}$. Hence, $a^{s}=a^{f}$. Both the product diversity levels and quality levels are numerically identical for both the first-best, and all second-best social welfare criteria. 


\section{CHAPTER 3: A GENERALIZED PRICE-QUALITY MERGER MODEL}

\subsection{INTRODUCTION}

This chapter provides a generalized structure of Salop's (1979) seminal article on a circular model of horizontal product differentiation by introducing a multi-product firm $M$, offering a set of $n$ product variants that face a set of $q$ competitors, or rival firms, each selling a unique, single-product variant. The model is extended to include a unique quality level, or a vertically differentiated characteristic, associated with the set of $(n+q)$ horizontally differentiated product variants within a circular market structure. For this type of locally competitive market arrangement of a fixed finite number of symmetricallylocated firms, a group of $n$ firms under a joint merger, acts as a single competitor in prices and quality levels of its product variants against a set of $q$, single-product firms.

What is a merger in this context? A "merger" is a combination of business firms into one, or the absorption of two-or-more entities into something greater. A circular (spatial) model is used to determine the anti-competitive effects of joint production of a single firm under localized competition having a set of $n$, physically-connected markets. Since consumers differ, firms belonging to the $q+1$ players (the set of $q$, single-product firms and the multi-product firm $M$ ), respectively, are challenged by serving particular sets of clients in each of their respective markets. The multi-product firm $M$, as a single entity, confronts its objective to jointly maximize the profits of all $n$ product-variants as a function of the price, and the quality reactions of its nearest competitors. The degree of product diversity for mergers under localized competition is important to anti-trust authorities as the use of "market-segmenting strategies" is a type of corporate strategy. 
The fundamental role and use of market-segmenting strategies in the competitive strategy process of major corporations is now well-developed and analyzed [Porter (1990)].

These profitable "product differentiation strategies" are built on the differences between consumers and on the understanding that different groups, or segments of consumers all have different valuations of the horizontal and vertical characteristics embedded in multi-product variants. It is assumed that consumers either purchase a single unit or none of their preferred product that is available in a number $n+q$, of different varieties. Such a merger under localized competition and its ensuing profitmaximizing behaviour then is in direct contrast, for example, with those of the nonspatial, single-product oligopoly models, or that of the Chamberlinian localized competition model consisting of heterogeneous-products and identical consumers who purchase multiple product varieties.

The existence of a price-quality Nash equilibrium is proved specifically for the case of quadratic transportation costs. The Nash price-quality equilibrium outcome of the non-cooperative game between the multi-product merged firm $M$, and the set of $q$ outside competitors, is shown to have unique properties with respect to the merged entity's pricequality policy, market shares, and joint profits. Through joint coordination and control of its set of $n$ physically-connected market areas, at equilibrium, the multi-product firm $M$ chooses an asymmetric price-quality policy for its firms' set of $n$ product variants even though the pre-merger market positions of the variants are symmetrically located.

The main objective of the multi-product firm $M$ is to maximize the joint profits of its $n$-firm members. As it has complete authority over the direction of strategic decision- 
making with respect to the prices and qualities of its product brands, it may choose to delegate certain strategic responsibilities. For example, it may only be concerned with control over the pricing of its product brands to maximize profits and may allow its $n$ firm members to individually choose their preferred level of brand quality. The corporate authority may find that a decision on a set of specific types of qualities too costly to monitor and enforce among its member firms especially if the merged firm owns a significant number of product variants, or if the physical distance of firm sites (or joint market size) from the central authority imposes higher human resource and administrative costs. The multi-product firm $M$ may also implicitly signal trust in member cooperation by delegating the level of quality choice and thereby avoid potential internal conflict.

With either a relatively large number of product variants, or if the physical size of the $n$-firms ' product markets is relatively large $(L / n)$, then certain costs maybe significant and the corporate firm maximizes joint profits by choosing only a set of prices, and allows the member firms to independently set the quality levels of its multi-products. The central authority of the merged firm may find certain costs prohibitive (e.g., human resource and administration), for either the need to set-up independent units of managers to maintain quality standards at all firm sites, or a centralized monitoring and enforcement board to review quality levels and dispense appropriate action. The corporate authority may also realize that there are certain implicit benefits from decentralized decision-making in the implied trust awarded to its member firms by maintaining firm loyalty and cooperation.

One result of a n-neighbour firm merger, is the high degree of market power and 
control that the multi-firm $M$ is able to exert over both of its peripheral market segments open to direct outside competition by setting the lowest price, and the lowest quality level for those two variants. For its isolated inner set of "core" member firms that are excluded from any outside competition, they are assigned progressively higher prices, and higher quality levels for its product variants.

Another result of the asymmetric price-quality policy equilibrium is that the profits of the inner core members are penultimately the highest (local maximum), while the highest profit levels are achieved by those firms located at the periphery of firm $M$ 's jointly-connected market area. Since each of the product variants generates a particular profit level depending on the intensity of local competition, it is strategically advantageous for the firm $M$ to set a price-quality policy that necessarily adjusts to the physical proximity of outside competition to gain the largest market shares possible.

The dual result of the multi-product firm M's asymmetric price-quality strategy is summarized as the following: (i) the peripheral member firms act as a "shield", and are effectively exploited by the central authority of the multi-product firm $M$ to prevent the intense price-quality warfare, or contagion from spreading to the set of inner core member firms; and (ii) it successfully creates an isolated "hinterland" area of inner core member firms which build up a secondary or local profit center that deters consumers from traveling near the periphery market area to purchase their preferred product variants. In this context, the generalization and extension of Salop's original circle model of product differentiation is useful to analyze any merger activity situations in which the strategic coordination of prices and quality levels is present in both horizontally and vertically 
differentiated product markets. The multi-product firm $M$ is able to exploit the locations or characteristics of its set of $n$ product variants to extract the maximum amount of surplus available.

The second section of the chapter sets up the description of the game-theoretic structure of the generalized model while the more formal definition of the Nash pricequality game $\Gamma$ between the $q+1$ players is completed in section three. The third section develops the formal mathematical optimization models consisting of a system of $(2 n+$ 2q) linear second-order recursive non-homogeneous price-quality difference equations for the multi-product merged firm, and the set of $q$ competitor firms, respectively. This leads to the solution, and the characterization of the existence and uniqueness of the simultaneous price-quality Nash equilibrium (decentralized quality levels) with fixed, symmetric firm site locations. The fourth section of the chapter presents an analysis of the generalized Nash price-quality equilibrium outcome and the potential for anticompetitive effects within an industry.

An analysis of the numerical simulation results and social welfare implications for a two-neighbour firm merger with two outside competitors, and four outside competitors, respectively, is presented in the fifth section for the decentralized quality decision-making merger made by the corporate authority of a bi-variant firm $M$. The simulation results illustrate that a major anti-competitive effect of the symmetric price-quality policy of the two-product firm $M$, in which the quality level choice is delegated to its member firms, is deemed to be a socially inefficient merger, as measured by the negative effect of a change in total welfare. The merged firm $M$ is able to extract the maximum surplus available due 
to the price-quality characteristics, and the positioning, of its variants in its jointlyconnected market area.

The sixth section of the chapter presents the results of the Nash price-quality equilibrium outcome of a two-neighbour firm merger where the bi-variant firm $M$ maximizes joint profit with respect to both the price, and the quality level of its two variants. The formal Nash equilibrium solution of this game is determined for a twoneighbour firm merger with $q=2,3$, and 4 outside single-product firms, respectively, and is used to highlight and compare the equilibrium results of the Nash game with decentralized (quality level) decision-making [see Appendix 3(E)].

The seventh section examines a comparative static result which determines the incremental effect on both the prices, and the qualities of existing products if a multiproduct firm $M$ acquires one, or more additional product variants. These Nash spatial game merger models naturally lead to the question of whether or not a profit incentive exists for an (oligopoly) multi-product firm $M$ to acquire all firms within an industry and assume the role of a monopolist. The generalized monopoly model which consists of $n$ neighbour firms is analyzed with respect to the effects of its optimal (symmetric) solution on the prices, qualities, and joint profits of its $n$ variants. The section concludes with the numerical simulation results on the social welfare of an economy where the monopolist owns four, and six product brands, respectively, in an industry.

The final section of the chapter presents some remarks aimed at integrating the findings of the model with a summary and a brief outline of anti-competitive policy implications. 


\subsection{A DESCRIPTION OF THE GAME-THEORETIC STRUCTURE}

The industrial market structure consists of a total number of $n+q$ firms symmetrically placed around a circle $C$ of length, or circumference, $L$. The set of consumers $N$, is uniformly distributed along the circle's perimeter with a density of $N / L$. There are $n$ firms who are members of a merged entity $M$, or multi-product firm which jointly produces a set of $M=\{1,2, \ldots, n\}$ product variants. The $q$ firms belonging to the set $F=\{n+1, n+2, \ldots, n+k, \ldots, n+q\}$ remain outside to such merger activity. The $n+q$ horizontally differentiated variants that are also vertically differentiated (by quality), are equally spaced about the circle $C$ where the distance, or arc length between two successive variants is $L /(n+q)$. The product variants are indexed and located on $C$ by $x_{i}$, where $x_{i}=(i-1) L /(n+q)$ for the $i=1,2, \ldots, n, n+1, \ldots, n+k, \ldots, n+q$ firms. By convention, the index starts with variant 1 , situated at the 12 o'clock position on $C$, and where the variant labeling proceeds in a (positive) clockwise-manner.

The inelastic demand of each consumer from the population set $N$ implies that one unit of the variant $x_{i}$ is bought so as to achieve the highest indirect utility for a given level of quality, $a_{i}$. A consumer located at $x \in C$ who purchases a product variant from a firm offering the lowest "delivered price" has a conditional indirect utility function given by, $V_{i}\left(x, p_{i}, a_{i}\right)=y+\theta a_{i}-p_{i}-t b-x_{i}^{2} ; \quad$ for $i=1,2, \ldots, n+q$

Since the term $\left|\mathrm{x}-\mathrm{x}_{\mathrm{i}}\right|$ denotes the shortest arc length between $x$ and $x_{i}$ on $C$, then the term $\mathrm{t}\left|\mathrm{x}-\mathrm{x}_{\mathrm{i}}\right|^{2}=\mathrm{t}\left(\mathrm{x}-\mathrm{x}_{\mathrm{i}}\right)^{2}$ is the convex (quadratic) transportation cost with unit cost $t$, and $p_{i}$ is the base price of the product variant. It is assumed that, without loss of generality, that the marginal valuation of quality is $\theta=1$, for a given level of quality $a_{i}$ inherent in each 
variant $x_{i}{ }^{1}$ The demand for variant $X_{i}$ is calculated from the equations expressing indifferent consumers located on either side of variant $x_{i}$ 's location, which, after multiplication by the consumer density $N / L$, is given as the following expression;

$$
X_{i}=X_{i}\left(p_{i-1}, p_{i}, p_{i+1} ; a_{i-1}, a_{i}, a_{i+1}\right)=\frac{N}{L}\left[\frac{\left[\left(p_{i+1}-a_{i+1}\right)-2\left(p_{i}-a_{i}\right)+\left(p_{i-1}-a_{i-1}\right)\right]}{2 t L /(n+q)}+\frac{L}{(n+q)}\right]
$$

for $i=1,2, \ldots, n, n+1, n+2, \ldots, n+q$. The demand for each variant $x_{i}$ is a function not only of its own price $p_{i}$ and quality level $a_{i}$, but also those prices and quality levels of its immediate, next-door neighbours. This property of a consumer's demand function is restricted to game-theoretic spatial models based on a circular structure. A horizontal, and vertical differentiated product is in direct competition with at most two other neighbours' variants, for a given set of prices and quality levels. Thus, in this twodimensional localized model, a product variant is a strong gross substitute for at most two others and it is this localized nature of competition that allows for anti-competitive incentives and ensuing behaviour amongst horizontal mergers.

The Figure 3.1 illustrates the industrial and firm market structure of a single, multi-variant product firm $M=\{1,2, \ldots, n\}$ for $n \geq 2$, and the associated set $F=$ $\{n+1, n+2, \ldots, n+q\}$ for $q \geq 2$, of single-product variant firms consisting of the outside competition. Both $n \geq 2$ and $q \geq 2$ imply $n+q \geq 4$ for the existence of a (post-merger)

1

The fact that consumers have the same (constant) valuation of quality $\theta=1$ does not imply that they all choose the same variant. Consumers have idiosyncratic preferences about variant locations expressed by their demand functions $\mathrm{X}_{\mathrm{i}}$. 


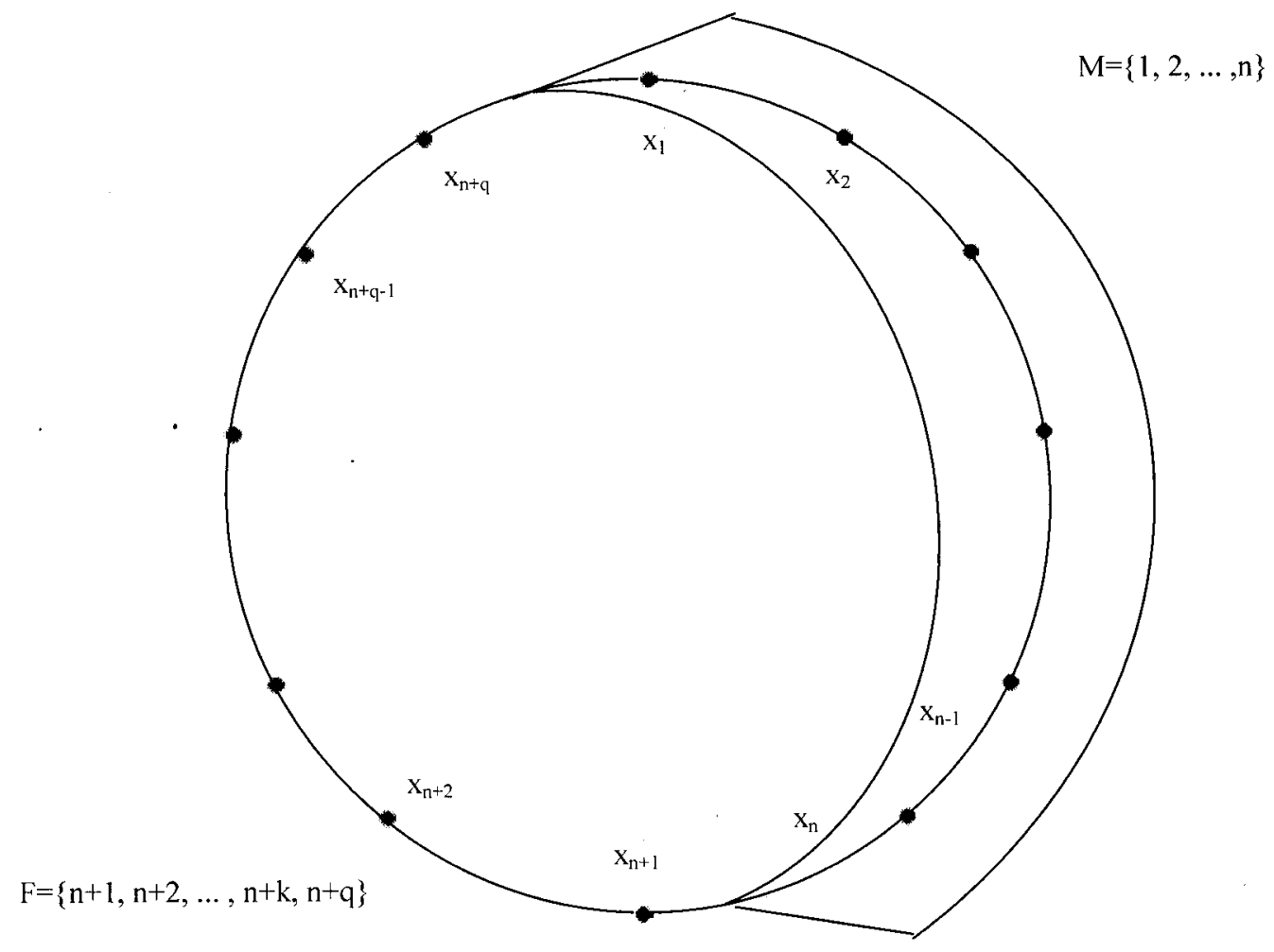

Figure 3.1: The circular market and industrial structure 
pure strategy Nash equilibrium in prices and qualities. ${ }^{2}$ The merged firm $M$ controls a substantial market size, or a portion of a circular arc of length $n L /(n+q)$ over its set of $n$ multi-variant products having as its boundaries the midway points of its nearest two outside competitors. Each of the outside competitive firms has an identical market size of length $L /(n+q)$ over its single product-variant. The Nash price-quality game is one between $q+1$ players: a (joint) multi-product firm $M$, and the $q$ single-product firms compete against each other in the prices and the qualitites of their product variants.

\subsection{THE NASH QUALITY-PRICE GAME AND MERGER EQUILIBRIUM}

\section{OUTCOME}

To determine the post-merger anti-competitive effects of a single, n-neighbour firm merger, i.e., when a merger consists of two-or-more neighbouring firms, it is assumed that the newly merged entity continues to operate from all locations and decentralizes the decision regarding choice of quality levels to its $n$ member firms. The merged entity, firm $M$ chooses the prices, $p_{i}^{M}$ for all $n$ product variants under its control. Also, there are no shut-downs of plants or firms, or the deletion from production of one or more of the product variants.

The description of the simultaneous price-quality game $\Gamma$ :

The merged firm $M$ : Let $p^{M}=\left\{p_{I}^{M}, \ldots, p_{n}^{M}\right\}$ denote the price vector of the multivariant product firm $M$ and let $a^{M}=\left\{a_{l}{ }^{M}, \ldots, a_{n}^{M}\right\}$ denote the associated vector of quality

2

In the original Salop (1979) circular model, there must be at least $n \geq 3$ firms, or players to ensure the existence of a pure strategy price Nash equilibrium under localized competition. By contrast, with a compact interval $[a, b]$, or a linear segment spatial model, the condition for existence is $n \geq 2$ firms. 
levels. Also, let $X^{M}=\left\{X_{I}^{M}, \ldots, X_{n}^{M}\right\}$ denote the vector of consumers' demands that firm multi-product firm $M=\{1,2, \ldots, n\}$ faces. Suppose that there is a merger between two-ormore adjacent, next-door or neighbouring firms ${ }^{3}$. The marginal production costs are a (constant) $c$ per unit of product variant and fixed quality costs per firm are set at $1 / 2\left(a_{i}{ }^{M}\right)^{2}$ for $i \in M$. Each member firm of $M$ earns a profit of $\pi_{i}^{M}=\left(p_{i}^{M}-c\right) X_{i}^{M}-1 / 2\left(a_{i}^{M}\right)^{2}-f$, where $i$ $\epsilon M$, and $f$ denotes the (identical) fixed sunk costs associated with the firm location site. The corporate authority of the merged entity $M$ chooses prices $p^{M}$, and decentralizes the choice of quality levels $a^{M}$ to its $n$-firm members so as to maximize their joint profits $\Pi_{M}$ $=\sum_{i \in M} \pi_{i}^{M}($.$) , and takes the strategic behaviour of its q$ outside competitors as given. A single member firm's choice of a quality level for its product variant is independent of its fellow members' choices. All strategic moves within the multi-product firm $M$ are simultaneous. The strategy spaces of the strategic variables, $p_{i}{ }^{M}$ and $a_{i}{ }^{M}$, are given by the sets, $P_{i}{ }^{M}=[0, y)^{n}$ and $A_{i}^{M}=[0, \infty)^{n}$, for $i=\{1,2, \ldots, n\}$, respectively. Thus, a joint pure strategy for firm $M$ is a price-quality pair $\left\{p^{M}, a^{M}\right\} \in\left\{[0, y)^{n} \times[0, \infty)^{n}\right\}$.

The outside competition $F$ : Let $p^{F}=\left\{p_{n+1}{ }^{F}, \ldots, p_{n+q}{ }^{F}\right\}$ denote the price vector of the single- product variants supplied by the remaining $q$ single-product firms while $a^{l}=$ $\left\{a_{n+1}{ }^{F}, \ldots, a_{n+q}{ }^{F}\right\}$ is the associated quality level vector of a single product variant for each firm $k \in F, k=\{n+1, \ldots, n+q\}$. Each of the $q$ outside firms face individual consumer demands denoted by the vector $X^{H}=\left\{X_{n-1}^{F}, \ldots, X_{n+q}^{F}\right\}$. The marginal production costs are a

3

For any two-or-more, non-neighbours firm merger configuration on $C$, with at least one or more of the non-merged firms between them, the post-merger profit of the merged entity equals its pre-merger profit. Hence, this particular firm site configuration is feasible, but is not a profit-maximizing strategy [see Appendix (I): Chapter 3 for proof]. 
(constant) $c$ per unit of single-product variant, and each firm $k \epsilon F$ has a fixed quality cost of $1 / 2\left(a_{k}^{F}\right)^{2}$. Each outside single-product firm $k \epsilon F$ possesses a profit level of $\pi_{k}^{F}=\left(p_{k}{ }^{F}-\right.$ c) $X_{k}^{F}-1 / 2\left(a_{k}^{F}\right)^{2}-f$, and each of the single-product firms $k \epsilon F$ individually chooses a pricequality pair $\left(p_{k}^{F}, a_{k}^{F}\right)$ so as to maximize their individual profits $\pi_{k}^{F^{\prime}}($.$) . Each single-product$ firm $k \epsilon F$ takes the strategic behaviour of its competitors as given. The strategy spaces of the strategic variables, $p_{k}^{F}$ and $a_{k}^{F}$, for $k=\{1,2, \ldots, q\}$ are given by the sets, $P_{k}^{F^{*}}=[0, y)$ and $A_{k}^{F}=[0, \infty)$, respectively. Thus, a pure strategy for each of the outside competitors $k$ $\epsilon F$ is a price-quality pair $\left\{p_{k}{ }^{H}, a_{k}{ }^{F}\right\} \in\{[0, y) \times[0, \infty)\}$. To complete the formal structure and solution of the price-quality game $\Gamma$, the objective functions of the players are analytically described to form the price-quality best-response functions of the multiproduct firm $M$, and for the set of $q$ members of outside rival firms, or competitors.

The strategic form of the Nash price-quality game $\Gamma$ is a list of sets consisting of the players, strategies and payoffs, respectively. It may be formally stated as in the following definition:

Definition 1: The strategic form of the game $\Gamma$ may be defined as the list $\Gamma=<(M, F)$, $\left(p^{M}, p^{F} ; a^{M}, a^{H}\right),\left(\pi_{n+1}^{F}, \ldots, \pi_{n+q}^{F} ; \Sigma_{i \in M} \pi_{i}^{M}().\right)>$.

\section{Best-Response Price and Quality Functions of the Multi-Product Firm M:}

The price and quality best-reply functions of the merged firm $M$ are determined by simultaneously solving the respective $(2 n)$ first-order or necessary conditions for the set of $n$ prices $\left(p_{l}^{M}, \ldots, p_{n}{ }^{M}\right)$ chosen by the merged entity, and for the set of $n$ qualities $\left(a_{l}^{M}, \ldots, a_{n}^{M}\right)$ independently chosen by the $n$-firms. The corporate firm $M$ maximizes joint profit with respect to the set of prices $\left(p_{l}{ }^{M}, \ldots, p_{n}{ }^{M}\right)$ using the following joint profit 
function;

$$
\begin{aligned}
& \max \Pi_{M}=\max \sum_{i=1}^{n} \pi_{i}\left(p_{1}{ }^{M}, \ldots, p_{n}{ }^{M}, a_{1}{ }^{M}, \ldots, a_{n}^{M} ; p_{n+1}^{F}, \ldots, p_{n+q}^{F}, a_{n+1}^{F}, \ldots, a_{n+q}^{F}\right)= \\
& \left(p_{1}^{M}-c\right) \frac{N}{L}\left[\frac{\left(p_{2}{ }^{M}-a_{2}{ }^{M}\right)-2\left(p_{1}{ }^{M}-a_{1}{ }^{M}\right)+\left(p_{n+q}^{F}-a_{n+q}^{F}\right)}{2 t L /(n+q)}+\frac{L}{n+q}\right]-\frac{1}{2}\left(a_{1}^{M}\right)^{2}-f+ \\
& \sum_{i=2}^{n-1}\left(p_{i}^{M}-c\right) \frac{N}{L}\left[\frac{\left(p_{i+1}^{M}-a_{i+1}^{M}\right)-2\left(p_{i}{ }^{M}-a_{i}{ }^{M}\right)+\left(p_{i-1}{ }^{M}-a_{i-1}{ }^{M}\right)}{2 t L /(n+q)}+\frac{L}{n+q}\right]-\frac{1}{2} \sum_{i=2}^{n-1}\left(a_{i}^{M}\right)^{2}-(n+q-2) f \\
& +\left(p_{n}^{M}-c\right) \frac{N}{L}\left[\frac{\left(p_{n+1}^{F}-a_{n+1}^{F}\right)-2\left(p_{n}{ }^{M}-a_{n}{ }^{M}\right)+\left(p_{n-1}{ }^{M}-a_{n-1}{ }^{M}\right)}{2 t L /(n+q)}+\frac{L}{n+q}\right]-\frac{1}{2}\left(a_{n}{ }^{M}\right)^{2}-f
\end{aligned}
$$

The joint profit function of the multi-product firm $M$ is written above as the sum of three algebraic terms to reflect the nature of the functional dependence of its own two peripheral members' profit on the two, immediate outside competitors' prices and qualities of their single-product variants. The unconstrained mathematical optimization problem of the merged firm $M$ involves the simultaneous choice of the set of $n$ prices $\left(p_{l}{ }^{M}, \ldots, p_{n}{ }^{M}\right)$ by the corporate authority, and of the set of $n$ quality levels $\left(a_{l}{ }^{M}, \ldots, a_{n}{ }^{M}\right)$ by member firms, to maximize its joint profit independently of the strategic price and quality decisions made by their $q$ competitors.

The $n$ first-order conditions for quality levels $\left(a_{l}^{M}, \ldots, a_{n}{ }^{M}\right)$ are characterized by the following set of three equations:

$$
a_{1}^{M}=\frac{N(n+q)}{t L^{2}}\left(p_{1}^{M}-c\right)
$$


$a_{i}^{M}=\frac{N(n+q)}{t L^{2}}\left(p_{i}^{M}-c\right)$ for $i=2, \ldots, n-1$

$a_{n}^{M}=\frac{N(n+q)}{t L^{2}}\left(p_{n}^{M}-c\right)$

The $n$ first-order conditions for prices $\left(p_{l}{ }^{M}, \ldots, p_{n}{ }^{M}\right)$ may be written as the following set of three equations:

$p_{1}^{M}=\frac{t L^{2}\left(p_{n+q}^{F}-a_{n+q}^{F}\right)}{\left[2 t L^{2}-N(n+q)\right]}+\frac{n\left(t L^{2}\right)^{2}}{(n+q)^{2}\left[2 t L^{2}-N(n+q)\right]}+\frac{\left[t L^{2}-N(n+q)\right] c}{\left[2 t L^{2}-N(n+q)\right]}$

$p_{i}^{M}=\frac{1}{2}\left(p_{i-1}^{M}+p_{i+1}^{M}\right)+\frac{\left(t L^{2}\right)^{2}}{(n+q)^{2}\left[2 t L^{2}-N(n+q)\right]}$ for $i=2, \ldots, n-1$

$p_{n}^{M}=\frac{t L^{2}\left(p_{n+1}^{F}-a_{n+1}^{F}\right)}{\left[2 t L^{2}-N(n+q)\right]}+\frac{n\left(t L^{2}\right)^{2}}{(n+q)^{2}\left[2 t L^{2}-N(n+q)\right]}+\frac{\left[t L^{2}-N(n+q)\right] c}{\left[2 t L^{2}-N(n+q)\right]}$

The set of equations, (3.7) to (3.9), represent a system of $n$ linear, recursive, nonhomogeneous second-order difference equations with constant coefficients. The two equations (3.7) and (3.9) determine the boundary, or initial conditions of the remaining $(n-2)$ difference equations. Each of the initial conditions are a function of the price of their own nearest member firm, and a function of both the price and quality of their nearest, or peripheral competitor firm neighbour. The $(n-2)$ price difference equations (3.8) of the system, are each solely a function of their two respective neighbour member 
firms' prices.

Best-Response Price and Quality Functions of the q Outside Competitors:

The price and quality best-reply functions of each of the $k=1, \ldots, q$ outside competitor firms are simultaneously determined by independently solving the (2q) firstorder conditions for the set of $q$ prices $\left(p_{n+l}{ }^{F}, \ldots, p_{n+q}{ }^{F}\right)$, and for the set of $q$ quality levels $\left(a_{n+1} \stackrel{F}{k}, \ldots, a_{n+q} l i\right)$. Each outside rival firm $k=1, \ldots, q$ independently chooses a price $p_{n+k} l i$, and quality $a_{n+k}{ }^{F}$ by maximizing its own $(n+k)$-th profit function. The unconstrained mathematical optimization problem of the $(n+k)$-th competitive firm is given by the following equation (3.10);

$\operatorname{Max} \pi_{n+k}\left(p_{n+k-1}^{F}, p_{n+k}^{F}, p_{n+k+1}^{F} ; a_{n+k-1}^{F}, a_{n+k}^{F}, a_{n+k+1}^{F}\right)=$ $\left(p_{n+k}^{F}-c\right) \frac{N}{L}\left[\frac{\left(p_{n+k+1}^{F}-a_{n+k+1}^{F}\right)-2\left(p_{n+k}^{F}-a_{n+k}^{F}-a_{n+k}^{F}\right)+\left(p_{n+k-1}^{F}-a_{n+k-1}^{F}\right)}{2 t L /(n+q)}+\frac{L}{(n+q)}\right]-1 / 2\left(a_{n+k}^{F}\right)^{2}-f$

The $q$ first-order conditions for the quality levels are characterized by the following equation:

$a_{n+k}^{F}=\frac{N(n+q)}{t L^{2}}\left(p_{n+k}^{F}-c\right)$ for $k=1, \ldots, q$

The $q$ first-order conditions for the prices may be written by the following set of three equations:

$$
p_{n+1}^{F}=\frac{\left[t L^{2}-N(n+q)\right] p_{n+2}^{F}}{2\left[2 t L^{2}-N(n+q)\right]}+\frac{t L^{2}\left(p_{n}^{M}-a_{n}^{M}\right)}{2\left[2 t L^{2}-N(n+q)\right]}+\frac{\left(t L^{2}\right)^{2}}{(n+q)^{2}\left[2 t L^{2}-N(n+q)\right]}+\frac{1}{2} c
$$


$p_{n+k}^{F}=\frac{\left[t L^{2}-N(n+q)\right] p_{n+k-1}^{F}}{2\left[2 t L^{2}-N(n+q)\right]}+\frac{\left[t L^{2}-N(n+q)\right] p_{n+k+1}^{F}}{2\left[2 t L^{2}-N(n+q)\right]}+\frac{t L^{2}\left[c(n+q)^{2}+t L^{2}\right]}{(n+q)^{2}\left[2 t L^{2}-N(n+q)\right]}$ for $k=1, \ldots, q$

$p_{n+q}^{F}=\frac{\left[t L^{2}-N(n+q)\right] p_{n+q-1}^{F}}{2\left[2 t L^{2}-N(n+q)\right]}+\frac{t L^{2}\left(p_{1}^{M}-a_{1}^{M}\right)}{2\left[2 t L^{2}-N(n+q)\right]}+\frac{\left(t L^{2}\right)^{2}}{(n+q)^{2}\left[2 t L^{2}-N(n+q)\right]}+\frac{1}{2} c$

The set of $q$ equations, (3.12) to (3.14), represent a system of $q$ linear, recursive, nonhomogeneous second-order difference equations with constant coefficients. The two equations, (3.12) and (3.14) determine the initial, or boundary conditions of the $(q-2)$ price difference equations. Each of the boundary conditions are a function of a neighbour member firm's price and a function of both the price and quality of the peripheral competitor firm. The (q-2) price difference equations of (3.13) are each solely a function of their nearest two neighbours', or member firms' prices. The following proposition characterizes the price-quality Nash equilibrium.

\section{The Nash Equilibrium of the Price-Quality Game $\Gamma$ :}

Proposition 3.1(A): The price-quality Nash equilibrium pairs of the game $\Gamma$ for the multiproduct merged firm $M$, with decentralized quality levels, are given by the respective strategic variable solutions of the system of non-homogeneous, linear and recursive, second-order difference equations as the following expressions:

$$
p_{i}^{M}=r^{*}+i s^{*}-\frac{i^{2}\left(t L^{2}\right)^{2}}{(n+q)^{2}\left[2 t L^{2}-N(n+q)\right]} ; \text { for } i=1,2, \ldots, n
$$

The coefficients, $r^{*}$ and $s^{*}$, respectively, are given by the following expressions: 


$$
\begin{aligned}
& r^{*}=c+\frac{\left[t L^{2}-N(n+q)\right]}{\left[2 t L^{2}-N(n+q)\right]}\left(c_{1}^{*} \alpha+c_{2}^{*} \beta\right)+\frac{t L^{2}\left[t L^{2}-N(n+q)\right]}{(n+q)^{2}\left[2 t L^{2}-N(n+q)\right]} \\
& s^{*}=\frac{(n+1)\left(t L^{2}\right)^{2}}{(n+q)^{2}\left[2 t L^{2}-N(n+q)\right]} \\
& a_{i}^{M}=\frac{N(n+q)}{t L^{2}}\left(p_{i}{ }^{M}-c\right)=\frac{N(n+q)}{t L^{2}}\left[r^{*}+i s^{*}-\frac{i^{2}\left(t L^{2}\right)^{2}}{(n+q)^{2}\left[2 t L^{2}-N(n+q)\right]}-c\right]
\end{aligned}
$$

Proof: see Appendix 3.A for the solutions of the strategic game variables.

Proposition 3.1(B): The price-quality Nash equilibrium pairs of the game $\Gamma$ for the single-product, outside competitors $k \epsilon F$ are the strategic variable solutions of the system of non-homogeneous, linear and recursive second-order difference equations as the following expressions:

$p_{n+k}^{F}=c+\frac{t L^{2}}{(n+q)^{2}}+c_{1}^{*}(\alpha)^{k}+c_{2}^{*}(\beta)^{k}$ for $k=1,2, \ldots, q$

The coefficients, $c_{1}{ }^{*}$ and $c_{2}{ }^{*}$, respectively, are given by the following expressions:

$$
\begin{aligned}
& c_{1}^{*}=\frac{t L^{2}\left(\alpha^{q} l-\alpha^{2} r\right)\left[t L^{2}-N(n+q)\right]\left[2 t L^{2}-N(n+q)\right]}{\alpha^{4}(n+q)^{2}[d]}\left[\frac{n\left(t L^{2}\right)^{2}}{\left[2 t L^{2}-N(n+q)\right]}\right. \\
& \left.-\left[t L^{2}-N(n+q)\right]-1\right] \\
& c_{2}^{*}=\left(\alpha^{2}\right) c_{1}^{*}
\end{aligned}
$$


$a_{n+k}^{F}=\frac{N(n+q)}{t L^{2}}\left(p_{n+k}^{F}-c\right)=\frac{N(n+q)}{t L^{2}}\left[c_{1}^{*}(\alpha)^{k}+c_{2}^{*}(\beta)^{k}+\frac{t L^{2}}{(n+q)^{2}}\right]$ for $k=1,2, \ldots, q$

The above equations contain the terms $l=2\left[2 t L^{2}-N(n+q)\right]-\alpha\left[t L^{2}-N(n+q)\right]$ and $r=$ $\left[(4-\alpha) t L^{2}-(2-\alpha) N(n+q)\right]$. The term $[\mathrm{d}]=\left(\mathrm{b}_{1}\right)\left(\mathrm{b}_{2}\right)-\left(\alpha^{\mathrm{q}} 1-\alpha^{2} \mathrm{r}\right)^{2}\left[\mathrm{tL}^{2}-\mathrm{N}(\mathrm{n}+\mathrm{q})\right]^{2}=\alpha^{3}\left(\alpha^{t} l-\right.$ $\left.\alpha^{2} r\right)\left[2 t L^{2}-N(n+q)\right]\left[2 t L^{2}\left\{\alpha^{q} l(l-1)-\alpha^{2} r(r-1)\right\}-N(n+q)\left\{\alpha^{q} l(l-2)-\alpha^{2} r(r-2)\right\}\right]$ contains the expressions, $b_{l}=\left(\alpha^{4} l^{2}-\alpha^{2} r^{2}\right)\left[2 t L^{2}-N(n+q)\right]-\left(\alpha^{q} l-\alpha^{2} r\right)\left[t L^{2}-N(n+q)\right]$ and $b_{2}=\alpha^{3}\left(\alpha^{A} l^{2}-\right.$ $\left.\alpha^{2} r^{2}\right)\left[2 t L^{2}-N(n+q)\right]-\left(\alpha^{q} l-\alpha^{2} r\right)\left[t L^{2}-N(n+q)\right]$.

Proof: see Appendix 3.A for the solutions of the strategic game variables.

\subsection{AN ANALYSIS OF THE NASH PRICE-QUALITY EQUILIBRIUM OUTCOME AND THE POTENTIAL FOR ANTI-COMPETITIVE EFFECTS}

This section contains the main existence and uniqueness results of the Nash pricequality game $\Gamma$. The characteristics and properties of the equilibrium outcome for the post-merger prices, quality levels, market shares, and the profit levels of all firms within the structure of the post-merger industry are described and analyzed with respect to the number of member firms to the merger. The merged firm $M$ that delegates quality choices to its member firms sets a symmetric price-quality policy if the firm produces two variants, [see Appendix 3(D) for solution], while an asymmetric price-quality strategy results for a multi-product firm producing three-or-more variants.

A: The case for $(n=2)$ member firms and $(q=2)$ outside competitors:

If the merged entity $M$ consists of two neighbour firms then the symmetric Nash equilibrium price-quality outcome is such that both variants have identical prices and 
qualities, where $p_{1}^{M}=p_{2}{ }^{M}=p^{M}$ and $a_{1}{ }^{M}=a_{2}{ }^{M}=a^{M}$. For the $q=2$ outside competitor firms, the symmetric Nash equilibrium price-quality outcome is such that the two singleproduct firms set identical prices and identical quality levels, where $p_{1}^{F}=p_{2}^{F}=p^{F}$ and $a_{1}^{F^{F}}$ $=a_{2}^{F}=a^{F}$. The firm $M^{\prime} s$ post-merger equilibrium price is higher than the price set by its rivals, $p^{M}>p^{F}$, while the post-merger quality level is higher than that set by its competitors', $a^{M}>a^{F}$. Since $X^{M}<X^{H}$, then $\pi^{M}<\pi^{F} \Leftrightarrow t>2 N / L^{2}$. Therefore, a "freerider" problem exists in this case, $(n+q=4)$ firms.

The corporate authority of the bi-variant firm $M$ anticipates a high decentralized equilibrium quality level chosen by its two member firms and sets, in equilibrium, an identical high price for the two product variants. Also, the intense competition arising from the two single-product firms located directly next-door to its joint market periphery, induces the member firms to set a higher quality level than what is chosen by their two symmetrically-located neighbours. Thus, this price-quality strategy results in a higher joint post-merger profit than if either of the member firms acted independently, but not relative to its single-product competitors.

\section{$B$ : The case for $(n \geq 3)$ member firms and $(q \geq 2)$ outside competitor firms:}

If the corporate entity $M$ consists of $n \geq 3$ member firms then the Nash equilibrium price-quality outcome results in an asymmetric price-quality policy. The firm $M$ 's prices are lowest (and identical) for those firms situated at $x_{l}$ and $x_{n}$ on $C$ and steadily increase to a maximum price for the firm(s) located centrally within firm $M$ 's total jointly-connected market. For example, if $n=3$ then $p_{l}{ }^{M}=p_{3}{ }^{M}<p_{2}{ }^{M}$, and if $n=4$ then $p_{I}{ }^{M}$ $=p_{+}{ }^{M}<p_{2}{ }^{M}=p_{3}{ }^{M}$. In general, the asymmetric post-merger equilibrium price pattern may 
be stated as $p_{1}^{M}=p_{n}{ }^{M}<p_{2}{ }^{M}=p_{n-1}{ }^{M}<p_{3}{ }^{M}=p_{n-2}{ }^{M}<\ldots<p_{i(\max )}{ }^{M}$ for $i=1, \ldots, n$ and terminates with one highest product variant price for at least one centrally-located firm on $C$ (if $n$ is odd), and for at most two centrally-located firms (if $n$ is even). Formally, by differentiating the expression for $p_{i}^{M}$ in Proposition 3.1(A) with respect to the variable $i$, then $\partial p_{i}^{M} / \partial i=0 \Leftrightarrow i_{\max }=1 / 2(n+1) \Rightarrow \partial p_{i}^{M} / \partial i>0 \Leftrightarrow i_{\max }<1 / 2(n+1)$ and $\partial p_{i}^{M} / \partial i<0 \Leftrightarrow i_{\max }>$ $1 / 2(n+1)$ which gives the above price pattern depending on whether or not $n$ is even or odd for the indexation parameter, $i=1, \ldots, n$ [see Appendix 3(B) for proof]. Figure 3.2(A) depicts the general shape of the asymmetric equilibrium price function for the merged entity $M$ as a function of the number of its member firms, $n$.

Similarly, firm $M$ 's quality levels are lowest for the two member firms located on the periphery and increase to a maximum quality level for the firm(s) located centrally within firm $M$ 's total jointly-connected market. For example, if $n=3$ then $a_{I}{ }^{M}=a_{3}{ }^{M}<$ $a_{2}{ }^{M}$, and if $n=4$ then $a_{1}{ }^{M}=a_{4}{ }^{M}<a_{2}{ }^{M}=a_{3}{ }^{M}$. In general, the asymmetric post-merger equilibrium quality level pattern may be described as $a_{i}{ }^{M}=a_{n}{ }^{M}<a_{2}{ }^{M}=a_{n-l}{ }^{M}<a_{3}{ }^{M}=a_{n-}$ ${ }_{2}^{M}<\ldots<a_{i(\max )}{ }^{M}$ for $i=1, \ldots, n$ and terminates with one highest product variant quality level for at least one centrally-located firm on $C$ (if $n$ is odd), and for at most two centrally-located firms (if $n$ is even). Formally, by differentiating the expression for $a_{i}^{M}$ with respect to the indexation parameter $i$ in Proposition 3.1(A), then $\partial a_{i}^{M} / \partial i=i_{\max }=$ $N(n+q) / t L^{2}\left(\partial p_{i}^{M} / \partial i\right)=0 \leftrightarrow i_{\max }=1 / 2(n+1)$ for $i=1, \ldots, n$ [see Appendix 3(B) for proof].

The firm $M$ 's asymmetric price-quality policy produces an effect on both prices and quality levels that can be called the "symmetric cascading effect" central to the merger's "well-protected", and physically-isolated "interior" firms. The firm M's 


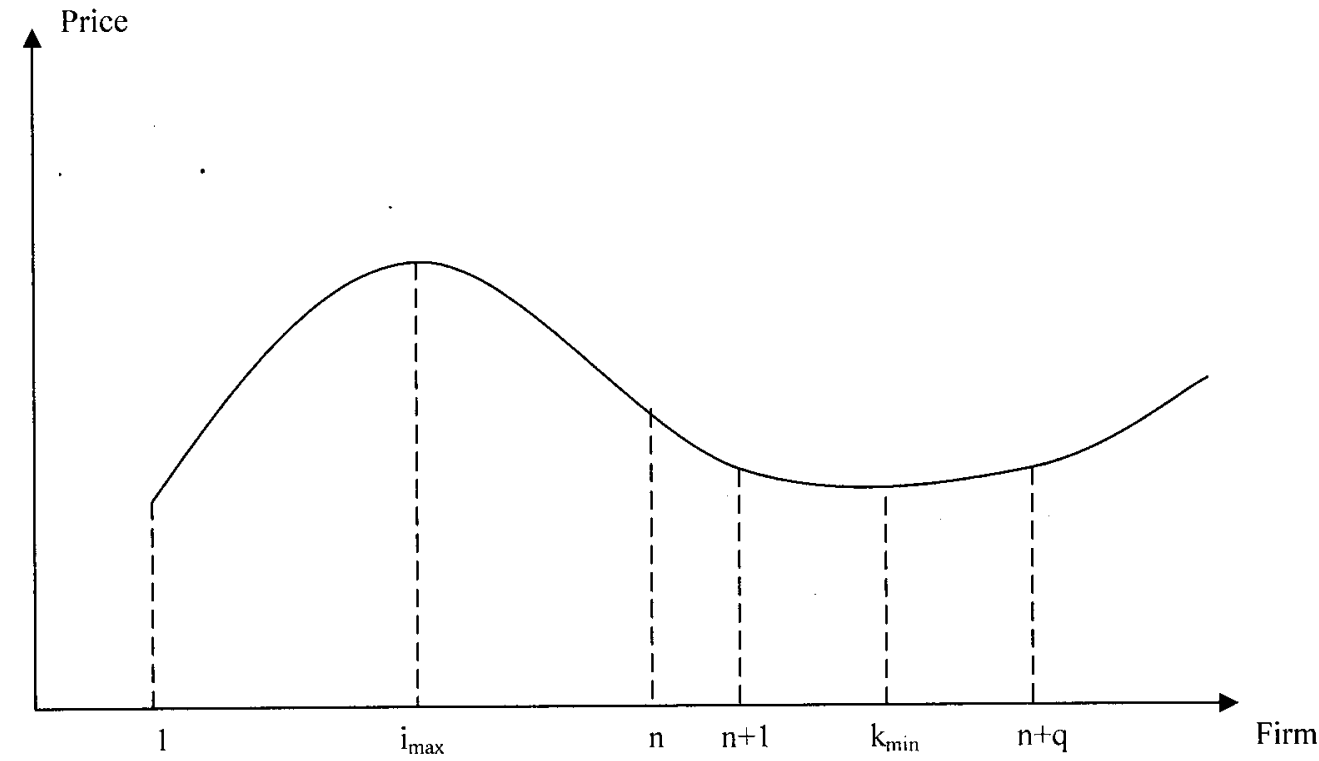

Figure 3.2(A): The general shape of the asymmetric equilibrium price function

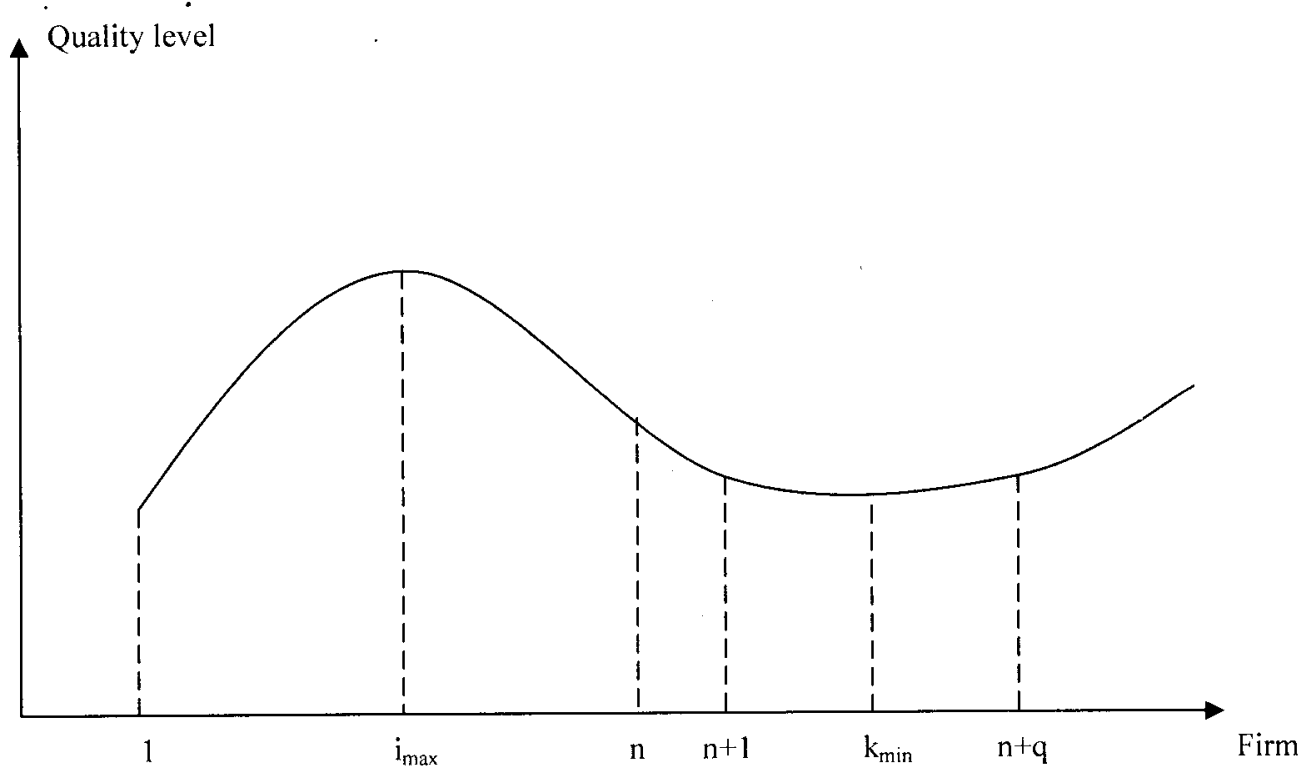

Figure 3.2(B): The general shape of the asymmetric equilibrium quality level function 
peripheral product variants $l$ and $n$ are solely affected by the outside competitors located at $x_{n+1}$ and $x_{n+q}$, respectively. The lowest prices and qualities of firm $M$ offered in the market are in direct response to such outside competition and effectively capture a large market share. Thus, the multi-product firm $M$ confronts intense competition only at its end markets thereby effectively lowering both the price and quality of its two variants located at the joint market extremes. The firm $M$ 's prices and qualities are highest for those centrally-located firms are due not only to the absence of outside competition, but are largely as a consequence of an isolated set of consumers. The corporate entity $M$ realizes it must balance its high variant prices along with a high level of product quality to attract and maintain consumers' interests, otherwise they would attain a higher utility by purchasing their preferred variants from distant member firms if such high prices for variants offered lower quality levels.

The asymmetric equilibrium price-quality policy confers a similar effect on the outside competitive firms' post-merger prices and qualities that can be called the "reverse symmetric cascading effect". For example, if $n \geq 2$, and for $q=3$, then prices are such that $p_{1}^{F}=p_{3}^{{ }^{F}}>p_{2}{ }^{F}$, and for quality levels, then $a_{1}^{F}=a_{3}^{F}>a_{2}{ }^{F}$. If there are $q=4$ competitors, or rival firms, then prices are such that $p_{1}^{F}=p_{4}^{F^{F}}>p_{2}^{F^{F}}=p_{3}^{F^{F}}$, and quality levels follow $a_{1}^{F}=a_{+}^{F}>a_{2}^{F}=a_{3}^{F}$. In general, then post-merger prices are such that $p_{n+1}{ }^{F}$ $=p_{n+q}{ }^{r}>p_{n-2}{ }^{F}=p_{n+q-l^{\prime}}{ }^{l}>p_{n+3}{ }^{F}=p_{n+q-2^{*}}>\ldots>p_{n+k(m n)^{F}}>\ldots$ and the post-merger quality levels are such that $a_{n+1}{ }^{F}=a_{n-q}{ }^{F}>a_{n+2}{ }^{F}=a_{n+q-1}{ }^{F}>a_{n^{+1}}{ }^{F}=a_{n+q-2^{F}}>\ldots>a_{n^{+} k(m i n)}{ }^{F}$. .. where both processes terminate with one lowest price and one lowest quality level, for at least one central firm ( $q$ odd), or at most two central firms ( $q$ even). Formally, the 
derivative of the expression for ${p^{++k}}^{F}$ from Corollary 3.1(B), with respect to the variable $k$, gives the condition, denoted by $k_{\min }$, and is derived from $\partial p_{n: k}{ }^{F} / \partial k<0 \Leftrightarrow-2<q$ for $q \geq 3$ and $0<|\alpha| \leq 1$ and $\partial p_{n+k} F / \partial k>0 \Leftrightarrow q>-2$ [see Appendix 3(B) for proof].

A similar condition, denoted by $k_{\text {min }}$, for the asymmetric equilibrium qualities is derived from $\partial a_{n+k}{ }^{F} / \partial k=N(n+q) / t L^{2}\left[\partial p_{n+k}{ }^{F} / \partial k\right]<0 \Leftrightarrow-2<q$ and $\partial a_{n \div k}{ }^{F} / \partial k>0 \Leftrightarrow q>-2$ [see Appendix 3(B) for proof]. Figure 3.2(B) shows the general shape of the asymmetric equilibrium quality levels as a function of $n$ and $q$ for both the merged firm $M$, and the outside competitors $k \epsilon F$.

The following corollary characterizes the outcome of the Nash price-quality equilibrium market shares for the multi-product firm $M$, and the set of $q$ outside competitor firms.

\section{Pattern of the Nash Equilibrium Market Shares:}

Corollary 3.1(A): The price-quality Nash equilibrium outcome for the market shares, or the quantity sold by the multi-product merged entity $M$ with decentralized quality levels is given by the following expressions:

$$
\begin{aligned}
& X_{1}^{M}=X_{n}^{M}=\frac{N}{(n+q)}-\frac{N\left[t L^{2}-N(n+q)\right]}{2(n+q)\left[2 t L^{2}-N(n+q)\right]}+\frac{N(n+q)\left[t L^{2}-N(n+q)\right]\left(c_{1}^{*} \alpha\right)}{t L^{2}\left[2 t L^{2}-N(n+q)\right]} \\
& X_{2}^{M}=X_{n-1}^{M}=\frac{N}{(n+q)}-\frac{N\left[t L^{2}-N(n+q)\right]}{(n+q)\left[2 t L^{2}-N(n+q)\right]}=\frac{N t L^{2}}{(n+q)\left[2 t L^{2}-N(n+q)\right]} \\
& X_{i}^{M}=\frac{N}{(n+q)} \quad \text { for } i=3,4, \ldots, n-2 .
\end{aligned}
$$


Corollary 3.1(B): The price-quality Nash equilibrium outcome for the market shares, or the quantity sold by the set of $q$ outside competitors is given by the following expressions (3.18):

$$
\begin{aligned}
& X_{n+1}^{F}=X_{n+q}^{F}=\frac{N}{(n+q)}+\frac{(n-1) N\left[t L^{2}-N(n+q)\right]}{2 t L^{2}(n+q)\left[2 t L^{2}-N(n+q)\right]} \\
& +\frac{N(n+q)\left[t L^{2}-N(n+q)\right]}{2\left(t L^{2}\right)^{2}}\left[c_{1}^{*}\left(\alpha^{2}+1\right)-\frac{2 t L^{2}\left(c_{1}^{*} \alpha\right)}{\left[2 t L^{2}-N(n+q)\right]}\right] \\
& X_{n+k}^{F}=\frac{N}{(n+q)}+\frac{N(n+q)\left[t L^{2}-N(n+q)\right]}{2\left(t L^{2}\right)^{2}}\left[c_{1} \alpha^{k-1}\left(\alpha^{2}+\alpha-1\right)-c_{1} \alpha^{-k+1}\left(\alpha^{2}-\alpha-1\right)\right] \text { for } k=2, \ldots q-1
\end{aligned}
$$

The merged firm $M$ 's market shares decline successively from those member firms situated at the periphery to those centrally-located firms within $M$ 's total market. In general, then $X_{1}^{M}=X_{n}^{M}>X_{2}^{M}=X_{n-1}{ }^{M}>X_{3}^{M}=X_{+}^{M}=X_{5}^{M}=\ldots=X_{n-2}{ }^{M}$. The market shares of all outside competitors are proportionately larger than any single firm's market share of a member belonging to $M$. The market shares of the competitor, or rival firms are such that $X_{n+l}{ }^{F}=X_{n+4}{ }^{F}>\ldots>X_{n, k(m i n)}{ }^{F}$ for $k=2, \ldots, q-1$. Figure 3.3 shows the general shape of the structure of market shares for all firms in the post-merger industry.

The next corollary describes the Nash price-quality equilibrium outcome of the profit levels of all firms in the post-merger industry. The analytical expressions for the equilibrium profits are derived by using the equilibrium outcomes of Proposition (3.1), and Corollary (3.1). 


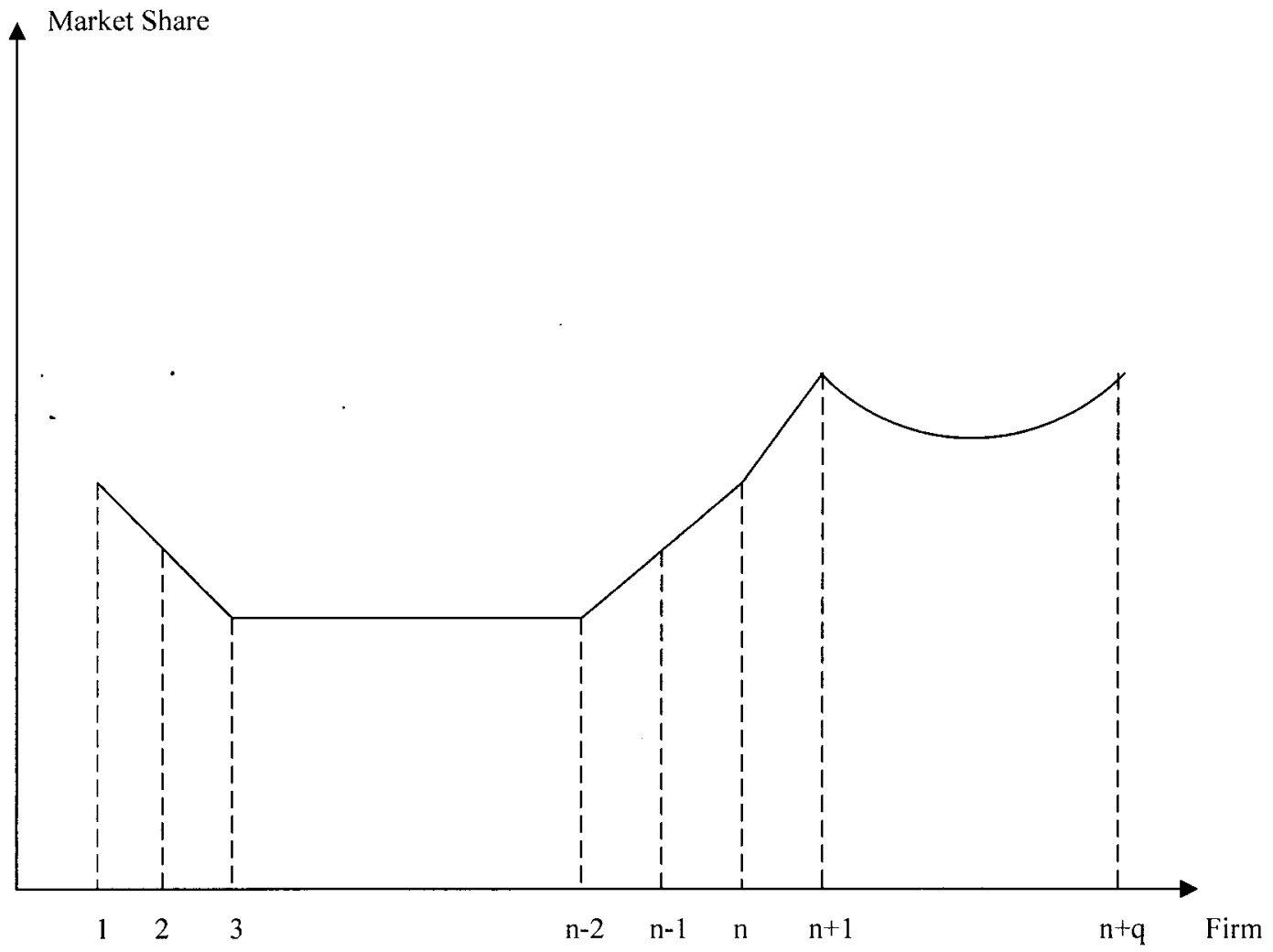

Figure 3.3: The general shape of the market share structure 


\section{Pattern of the Nash Equilibrium Profit Levels:}

Corollary 3.2(A): The price-quality Nash equilibrium outcomes for the profit levels of the multi-product firm $M$, where quality levels are decentralized, are given by the following expressions (3.19):

$$
\begin{aligned}
& \pi_{1}^{M}=\pi_{n}^{M}=\left(p_{1}^{M}-c\right) X_{1}^{M}-\frac{1}{2}\left(a_{1}^{M}\right)^{2}-f=\left(p_{1}^{M}-c\right) X_{1}^{M}-\frac{N^{2}(n+q)^{2}}{2\left(t L^{2}\right)^{2}}\left(p_{1}{ }^{M}-c\right)^{2}-f \\
& \pi_{2}^{M}=\pi_{n-1}^{M}=\left(p_{2}^{M}-c\right) X_{2}^{M}-\frac{1}{2}\left(a_{2}^{M}\right)^{2}-f=\left(p_{2}{ }^{M}-c\right) X_{2}^{M}-\frac{N^{2}(n+q)^{2}}{2\left(t L^{2}\right)^{2}}\left(p_{2}{ }^{M}-c\right)^{2}-f \\
& \pi_{i}^{M}=\left(p_{i}^{M}-c\right) X_{i}^{M}-\frac{1}{2}\left(a_{i}{ }^{M}\right)^{2}-f=\left(p_{i}^{M}-c\right) X_{i}^{M}-\frac{N^{2}(n+q)^{2}}{2\left(t L^{2}\right)^{2}}\left(p_{i}{ }^{M}-c\right)^{2}-f \\
& \text { for } i=3,4, \ldots, n-2 .
\end{aligned}
$$

Proof: see Appendix 3(A) for the equilibrium profit expressions. 
Corollary 3.2(B): The price-quality Nash equilibrium outcome of the profit levels for the outside competitors $k \in F$ is given by the following expression (3.20):

$$
\begin{aligned}
& \pi_{n+k}^{F}=\left(p_{n+k}^{F}-c\right) X_{n+k}^{F}-\frac{1}{2}\left(a_{n+k}^{F}\right)^{2}-f=\left(p_{n+k}^{F}-c\right) X_{n+k}^{F}-\frac{N^{2}(n+q)^{2}}{2\left(t L^{2}\right)^{2}}\left(p_{n+k}^{F}-c\right)^{2}-f= \\
& {\left[c_{1}^{*}\left(\alpha^{k}+\alpha^{-k+2}\right)+\frac{t L^{2}}{(n+q)^{2}}\right]\left[\frac{N\left[2 t L^{2}-N(n+q)\right]}{2 t L^{2}(n+q)}-\frac{N^{2}(n+q)^{2}}{2\left(t L^{2}\right)^{2}}\left[c_{1}^{*}\left(\alpha^{k}+\alpha^{-k+2}\right)\right]+\right.} \\
& \frac{N(n+q)\left[t L^{2}-N(n+q)\right]}{2\left(t L^{2}\right)^{2}}\left[c_{1}^{*}\left(\alpha^{k-1}+\alpha^{-k+1}\right)\left(\alpha^{2}+\alpha+1\right)\right]-f \quad \text { for } k=1, \ldots, q
\end{aligned}
$$

The highest level of profit of a member firm belonging to $M$ accrues to either the "interior" central firms, or the firms situated on the periphery of the entity's total market. These particular profit levels depend on the number of firms, $n$, belonging to $M$, while all other member firms each receive a lower profit level. For example, if the joint merger consists of two-neighbour firms, each firm receives an identical profit level. If joint membership consists of $3 \leq n \leq 6$ firms, then the highest level of profit accrues to either one central firm ( $n$ odd), or at most two central firms ( $n$ even). Thus, the asymmetric equilibrium price-quality policy "supports" the "symmetric cascading effect" of equilibrium profits if $M$ produces a small number of variants. Figure 3.4 shows the pattern and general shape of the asymmetric equilibrium profit levels as a function of a firm's site. For the particular cases of $n=2, \ldots, 6$ number of firms belonging to a multiproduct firm $M$, it is understood that for the general shapes of these respective 


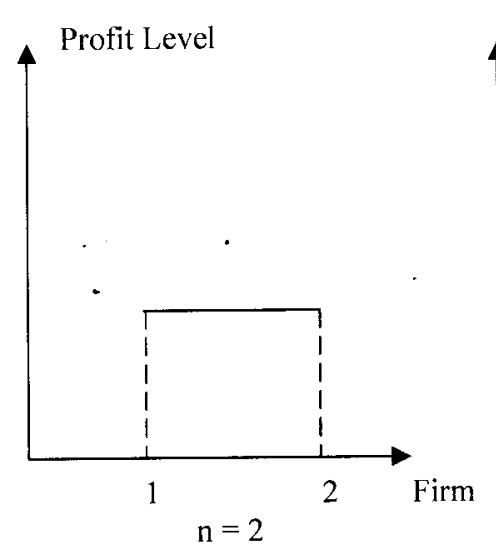

(even and identical)

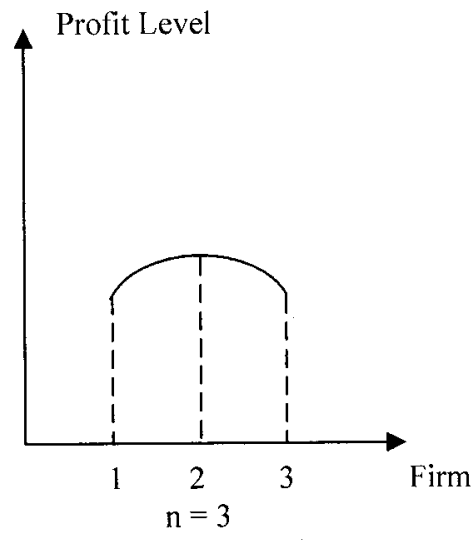

(odd)

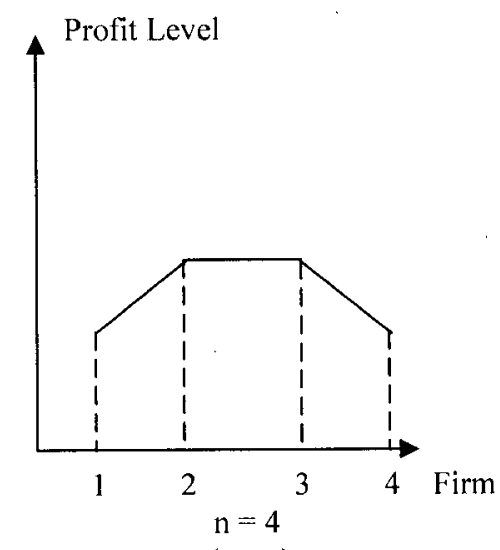

(even)

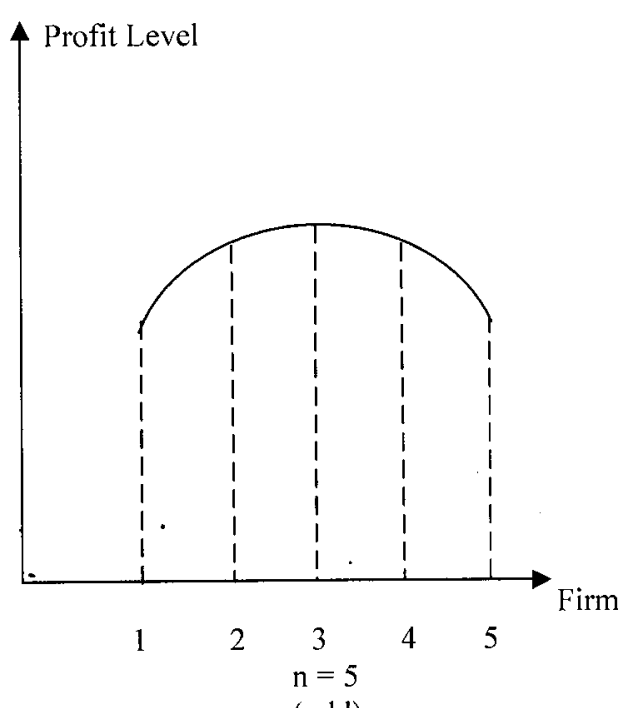

(odd)
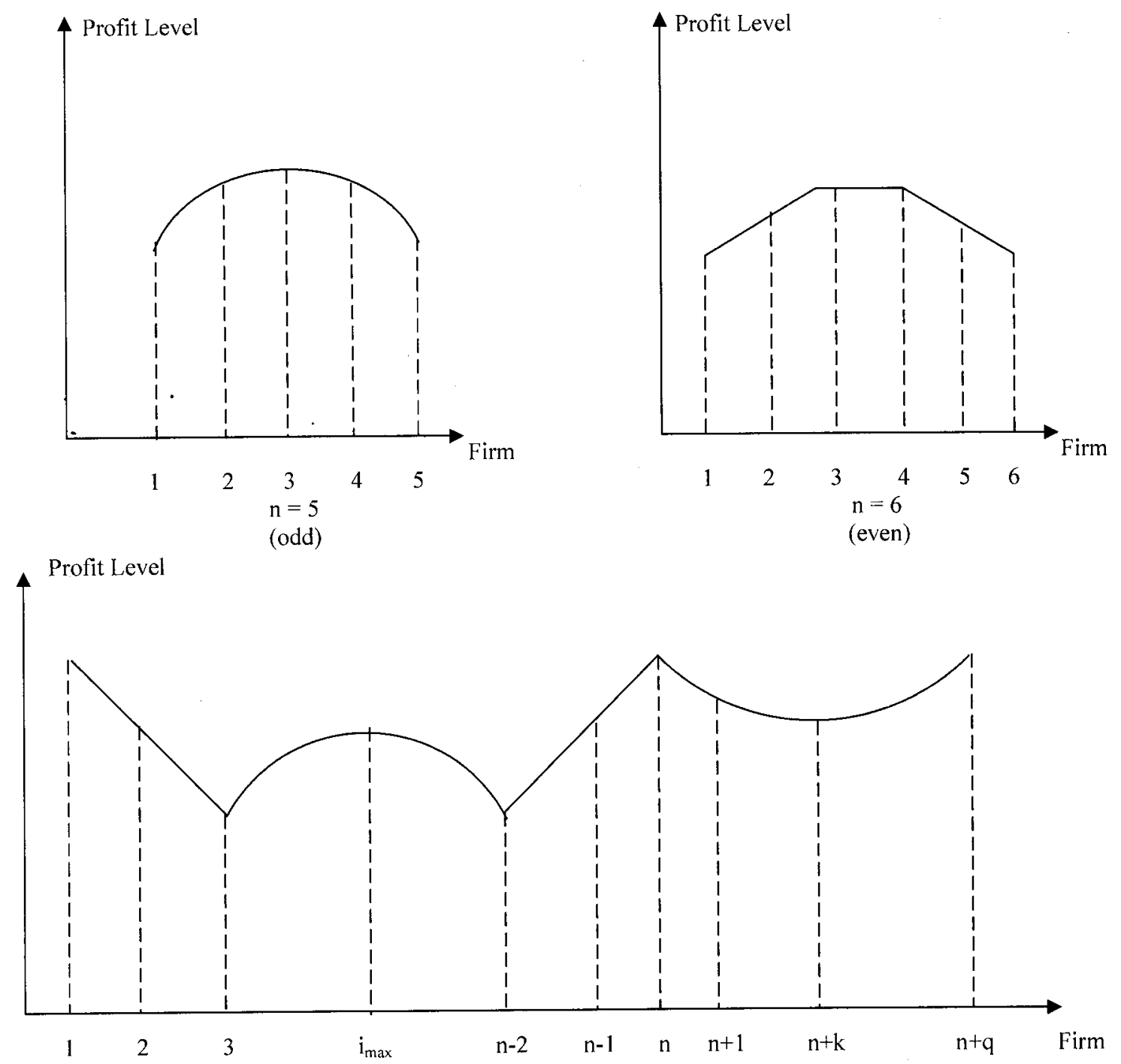

Figure 3.4: The general shape of the asymmetric equilibrium profit level function 
equilibrium profit shares that the corresponding general shapes of the equilibrium profit shares for $q \geq 3$ competitor firms are identical to that drawn for the graph which depicts a merger of $n \geq 7$ firms.

However, when firm $M$ 's membership is large, $(n \geq 7)$, the "weight" of the asymmetric equilibrium price-quality policy collapses and produces a different pattern of member equilibrium profit levels. The peripheral member firms, offering the lowest price and the lowest quality level, obtain the highest profits due to their relatively largest market shares as a result of the direct, next-door price-quality competition of outside firms. These member firms, located at $x_{I}$ and $x_{n}$, respectively, offer the same lowest price and the same lowest quality level for their variants as a result of the immediate competition from their respective next-door single-product competitors. The next set of firms, located at $x_{2}$ and $x_{n-1}$, respectively, obtain the second highest profit shares and second highest market shares. This strategy prevents those consumers, subject to the increasingly higher prices and the increasingly higher qualities of the interior firms, from traveling away from such firms and attempting to purchase their preferred product variant from the outside competition. Thus, the multi-product firm $M$ is able to strategically control, and contain the price-quality "warfare" to a small set of its product variants.

For the isolated set of inner or core firms, $c_{m}$, located at $x_{3}, x_{4}, \ldots, x_{i(\max )}, \ldots, x_{n-3}, x_{n-}$ ${ }_{2}$ on $C$, each firm receives an increasingly larger share of member profits as a result of the corporate entity's equilibrium price-quality policy. For these firms, the successively higher prices and higher qualities conferred on variants with the relatively smallest, but equivalent set of market shares $X_{i}=N /(n+q)$, for $i=3, \ldots, n-2$, not only effectively capture 
their isolated consumers, but they also balance and maintain member loyalty by maximizing joint firm profits. For $n \geq 7$, the "highest" profit share of the core set of inner firms is attained by those firm(s) located at $x_{i(\max )}$, and this is a local maximum. The price-quality strategy determined by the firm $M$ prevents the spread of the price-quality competition to its set of core member firms' product variants, and maintains an acceptable (minimum) level of market shares. The multi-product firm $M$ "weights" or "balances" the internal concentration of its core members with that of its peripheral firms to the outside competition at the expense of those member firms whose market shares are the proportionately smallest. This pair of member firms are equi-distantly located at $x_{3}$, and $x_{n-2}$, respectively, on $C$, and contribute the lowest profit levels to $M$. These member firms act as an effective shield to control the spread of the price-quality warfare to the inner set of core firms, $c_{m}$. Thus, the multi-product firm $M$ strategically exploits the characteristics of its product brands in order to extract the maximum amount of surplus.

The price-quality equilibrium strategy confers a higher set of prices and qualities to its inner core member firms to sustain an acceptable level of market shares for these jointly-connected markets. This strategy effectively isolates the core members from outside rivals. Those consumers attempting to purchase their preferred variants from $M$ 's rival competitors are essentially "blocked" by the lowest prices, and qualities of the peripheral member firms. As a result, these peripheral firms act a "dual role" by extracting the highest levels of market shares and member profits from the jointlyconnected markets, and they also effectively "block" consumers traveling further to the competing rival firms. Hence, the asymmetric price-quality equilibrium strategy supports 
the dual objective of the multi-product firm $M$, i.e., to protect it from outside competition, and to prevent a spread of the price-quality war at the periphery to its inner core set of member firms.

In general, for $n \geq 7$, the asymmetric price-quality policy produces member profit levels such that $\pi_{1}{ }^{M}=\pi_{n}{ }^{M}>\pi_{2}{ }^{M}=\pi_{n-1}{ }^{M}>\pi_{3}{ }^{M}=\pi_{n-2}{ }^{M}<\pi_{+}{ }^{M}=\pi_{n-3}{ }^{M}<\pi_{5}{ }^{M}=\pi_{n-4}{ }^{M}<\ldots$ $<. \pi_{i(\max )}{ }^{M}$ and, terminates with at least one firm of the core member set having the relatively highest profit ( $\mathrm{n}$ odd), or at most, two firms of the core set having the relatively highest profit ( $n$ even). The core member set, $c_{m}$, may be characterized as the set of firms who must satisfy both the inequality, $c_{m}=n-6 \geq 1$ and contribute a set of penultimately highest profit(s) to $M$. The "symmetric cascading effect" on equilibrium profit levels is now confined to the successively smaller core member set, $c_{m}$.

A single, two-neighbour firm merger increases the post-merger equilibrium profits of all $n+q$ firms in the industry. If there are only $q=2$ outside competitors then each firm receives an identical, symmetric equilibrium profit level of $\pi_{1}^{F}=\pi_{2}^{F}=\pi^{i}$. When there are $n=2$ member firms belonging to $M$, a "free-rider" problem exists since joint profits $\pi_{1}^{M}+\pi_{2}^{M}=\pi^{M}<\pi^{F} \Leftrightarrow 2 N / L^{2}<t<4 N / L^{2}$, but each single-product firm earns more profit than each party, $\pi_{i}^{M}(i=1,2)$ of the merged entity, $M$. Since there are two member firms of $M$, then $\pi_{\text {ave }}{ }^{M}=\pi_{i}^{M}(i=1,2)$. If $M$ consists of only two member firms and if there are $q \geq 3$ outside competitors, then $\pi^{M}>\pi_{n+1}^{F}=\pi_{n+q}{ }^{F}>\pi_{n+2}{ }^{F}=\pi_{n+q-1}{ }^{F}>\ldots$ $>\pi_{n+k(\min )}{ }^{F}$, for $k=1, \ldots, q$. This result is contrary to that of Levy and Reitzes (1992) who find that the "free-rider problem", or $\pi^{M}<\pi_{n+1}{ }^{F}=\pi_{n+q}{ }^{F}$, for $q \geq 3$, is confined to only one set of outside firms, i.e., those nearest outside competitors equi-distant from $M$ 's 
peripheral firms. If $M$ consists of three or more member firms and if there are $q \geq 3$ outside rival firms, there is an absence of the "free-rider problem" amongst the set of post-merger equilibrium profit levels. Thus, $\pi^{M}>\pi_{n+l}^{F}=\pi_{n+q}^{F}>\ldots>\pi_{n+k(\min )}{ }^{F}$, for $k=$ $1, \ldots, q$ and the average profit of a multi-product firm $M$ is greater than the profit level of a single-product firm, or $\pi_{a v e}{ }^{M}>\pi_{n+k}{ }^{F}$, for $k=1, \ldots, q$.

If there are $q \geq 3$ outside competitors, then the asymmetric price-quality equilibrium produces a "reverse cascading effect" on the outside competitor firms' equilibrium profit levels such that $\pi_{n+1}^{F}=\pi_{n+q}^{F}>\pi_{n+2}^{F}=\pi_{n+q-1}^{F}>\pi_{n+3}{ }^{F}=\pi_{n+q-2}{ }^{F}>\ldots$ $>\pi_{n+k(m i n)}{ }^{F}$ and terminates with at least one outside competitor firm having the lowest equilibrium profit ( $q$ odd), or with at most two outside competitors having the lowest equilibrium profits ( $n$ even) [for proof, see Appendix 3.B]. For $n \geq 7$, it can be shown that the firm $M$ 's members' equilibrium profit level $\pi_{l}^{M}=\pi_{n}^{M}>\pi_{n+k}{ }^{F}$ for $k=1,2, \ldots, q$. The peripheral member firms, $x_{I}$ and $x_{n}$, located nearest to $M$ 's competing rivals obtain the highest level of post-merger industry profit, and is greater than the highest equilibrium level achieved by any of the outside competitor firms.

The lowest-price, and the lowest-quality product variant contributes the greatest share of profits to the multi-product firm $M$ 's joint post-merger profit as this combination generates the largest market shares, $X_{l}^{M}=X_{n}^{M}$ [see Figure 3.3]. The variants' offering the next lowest price and quality level generates the second largest market shares, $X_{2}^{M}=X_{n}$ ${ }_{l}^{M}$, and second largest post-merger profit levels. These two (symmetric) member firms essentially continue in the act of the price-quality warfare against any further outside competition for the successively higher prices, and quality levels of the inner set of core 
member firms' product variants. The equal market shares of the shielded core firms, $X_{3}^{M}$ $=X_{n-2}{ }^{M}=\ldots=X_{i(\max )}{ }^{M}$ yield successively higher profit shares, culminating with the most isolated central firm(s) generating the relatively highest (a local maximum for $n \geq 7$ ) profit level for the set of core firms. The asymmetric price-quality policy of the merged firm M's physically-connected market area successfully exploits its set of multi-variants to gain the maximum amount of producers' surplus at the expense of consumers' surplus.

Note that, for $q \geq 3$, the following may be verified: (i) for $n$ sufficiently large enough, or $n \geq 7$ (sufficiently low enough, or $3 \leq n \leq 6$ ), the firm $M$ 's central (peripheral) firm(s) receives a higher profit level than the central single-product competitor firm(s); and, (ii) if $n \geq 3$, the multi-product firm $M$ 's average profit level, denoted by $\pi_{\text {ave }}{ }^{M}$, where $\pi_{a v e}^{M}=\sum_{i=1}^{n} \pi_{i}^{M} / n$, is higher than the highest profit share of the outside competitor firms, $\pi_{n+1}^{F}=\pi_{n+q}^{F}$, or $\pi_{a v e}{ }^{M}>\pi_{n+1}^{F}=\pi_{n+q}^{F}$ [see Figure 3.4].

The next section describes and measures the potential for socially inefficient mergers resulting from the asymmetric price-quality strategy of the multi-product firm $M$ with a simple numerical welfare comparison of two-neighbour firm mergers.

\subsection{WELFARE EFFECTS OF A PRICE-QUALITY n-NEIGHBOUR FIRM}

\section{MERGER}

\section{Prices and Quality Levels}

In the standard Cournot model an $n$-firm merger results in increased consumer prices in the absence of what Farrell and Shapiro (1990) refer to as "cost synergies". For that model, "in the absence of fixed costs, all mergers in quantity competition are socially 
undesirable" [Gaudet and Salant (1992)]. In the case of the standard Bertrand gametheoretic merger model, for example, Deneckere and Davidson (1986) prove that all symmetric product differentiated mergers under price competition are socially desirable. This section first describes the pre- and post-merger effects of an n-neighbour firm merger on prices, quality levels, and the quantity sold of post-merger industry firms. The section concludes with a numerical simulation of total welfare results of a two-neighbour firm merger for both types of a Nash merged firm $M$ (i.e., decentralized quality levels, and non-decentralized quality levels), where there are $(q=2)$ and $(q=4)$ outside competitor firms, respectively. These simulations of total welfare show that for certain numerical values of a model's parameters, a two-neighbour firm merger under price-quality competition, is socially inefficient.

The asymmetric price-quality equilibrium policy of the multi-product firm $M$ (decentralized quality) may also be compared with the symmetric pre-merger price $p^{*}=c$ $+t L^{2} /\left(n^{*}\right)^{2}$, pre-merger quality level $a^{*}=N / n^{*}$, and the pre-merger market share $X^{*}=$ $N / n^{*}$, where $n^{*}$ denotes the total number of (pre-merger) industry firms. Suppose that $n^{*}$ $=4$, so that $p^{*}=c+t L^{2} / 16$, and the number of firms are such that $n=2$ and $q=2$ in the post-merger case. Then $p_{1}^{M}=p_{2}^{M}>p^{*}$ and $a_{1}^{M}=a_{2}^{M}=a^{M}>a^{*}=N / 4$. For the case of $n$ $=2$ and $q=4$ post-merger firms, then $p^{M}>p^{*}=c+t L^{2} / 36$ and $a^{M}>a^{*}=N / 6$. The post-merger price of the merged firm $M$ is greater than the pre-merger price and the postmerger quality level of the bi-variant firm $M$ is greater than that of the pre-merger quality level. For the outside competitors, the post-merger price $p^{F}>p^{*}$ and the post-merger quality $a^{F}>a^{*}$, in the case of $q=2$ competitors, while $p_{k(l)}^{F}>p^{*}, p_{k(2)}^{F}>p^{*} \Leftrightarrow t>$ 


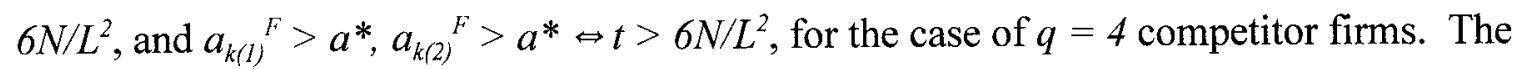
post-merger quality levels of the four competitor firms are greater than the pre-merger quality level, and the post-merger prices of the same competitors are greater than their pre-merger prices.

The comparison of the post-merger price $p_{i}^{M}(i=1, \ldots, n)$ with the pre-merger price $p_{i}^{*}=c+t L^{2} /\left(n^{*}\right)^{2}, i=1,2, \ldots, n^{*}$, where $n^{*}=n+q$, indicates that the impact of an $n$ neighbour firm merger on consumer prices, is measured by the (positive) increasing difference between the post-merger and the pre-merger price, as $n *$ increases from $i=1$ to $i_{\text {max }}$, for a given set of parameter values $t, L$ and $N$. The inequality expression is given by;

$$
\begin{aligned}
& \Delta(p)^{1}=p_{1}^{M}-p_{1}^{*}=p_{1}^{M}-\left[c+\frac{t L^{2}}{\left(n^{*}\right)^{2}}\right]<\Delta(p)^{2}=p_{2}^{M}-p_{2}^{*}=p_{2}^{M}-\left[c+\frac{t L^{2}}{\left(n^{*}\right)^{2}}\right] \\
& <\ldots<\Delta(p)^{i(\max )}=p_{i(\max )}^{M}-\left[c+\frac{t L^{2}}{\left(n^{*}\right)^{2}}\right] ; \text { where } \Delta(p)^{1}>0 \ldots \Delta(p)^{i(\max )}>0,
\end{aligned}
$$

since $p_{1}{ }^{*}=p_{2}{ }^{*}=\ldots=p^{*}$ for $i=1, \ldots, n^{*}$. However, as the number of firms $n$ to the merger increases, then both $\Delta(p)^{I}$ and $\Delta(p)^{2}$ declines, or where there is a relatively high concentration of core members. Also, an n-neighbour firm merger always, and not surprisingly, increases prices for consumers located within the core market area of the merged firm, or where firms are members of the set $c_{m}$ having identical output levels $X_{i}^{M}$ $=N /(n+q)$, for $i=3, \ldots, n-2$.

The post-merger effect of the multi-product firm $M$ is the increase in quality levels 
of the product variants, especially in its (symmetric) peripheral market areas [see Appendix (B) for proof]. A major question is whether or not the quality level reductions offset the increasing levels of quality associated with the product variants of the core member firms, $c_{m}$, as well as the reduction in the degree in competition that results from the merger. By the symmetry of the model, the lowest levels of quality occur for those product variants sold on the firm $M^{\prime}$ 's peripheral markets, $a_{i}{ }^{M}=a_{n}{ }^{M}$. The comparison of the post-merger quality levels $a_{i}^{M}=N(n+q) / t L^{2}\left(p_{i}^{M}-c\right)$ with the pre-merger quality level $a_{i}^{*}=N / n^{*}$, for $i=1,2, \ldots, n^{*}$ is measured by the (positive) difference between post-merger and pre-merger quality levels, as $n^{*}$ increases from $i=I$ to $i_{\text {max }}$, for a given set of parameter values $t, L$ and $N$, and $n^{*}=n+q \geq 4$. The inequality expression is given by, $\Delta(a)^{1}=a_{1}^{M}-a_{1}^{*}=\left[a_{1}^{M}-\frac{N}{n^{*}}\right]<\Delta(a)^{2}=a_{2}^{M}-a_{2}^{*}=\left[a_{2}^{M}-\frac{N}{n^{*}}\right]<\ldots$
$<\Delta(a)^{i(\max )}=a_{i(\max )}^{M}-a_{i(\max )}^{*}=\left[a_{i(\max )}^{M}-\frac{N}{n^{*}}\right] ;$ where $\Delta\left(a^{1}\right)>0 \ldots \Delta(a)^{i(\max )}>0$, since $a_{l}^{*}=\ldots=a_{i(\max )}{ }^{*}=a^{*}=N / n^{*}$ for $i=1, \ldots, n^{*}$. Since the merged firm $M$ follows an asymmetric quality policy where $a_{1}^{M}<a_{2}{ }^{M}<\ldots<a_{i(\max )}{ }^{M}$, then the consumer markets most likely to benefit from increasing levels of product variant quality are those located furthest from firm $M$ 's market periphery, or those located at the core of the joint market. However, as the number of firms $n$ to the merger increases, then the $\Delta(a)^{i(\max )}$ increases, or, the difference between the pre-merger and the highest post-merger quality level of the central product variant becomes increasingly larger where there is a high degree of core 
members, $c_{m}$, so that consumers are relatively better off. Consumers must also bear the increasing costs of the prices that are associated with the increasing quality levels of their preferred product variants.

\section{Output and Total Surplus}

The aggregation of the output supplied in each local market over the relevant market areas (mathematical summation) indicates the impact of an n-neighbour firm merger on the total output supplied by the merged firm $M(i=1, \ldots, n)$, and the outside competitors $(k=1, \ldots, q)$. Let $X_{i}^{*}=N / n^{*}$, where $n^{*}=n+q$, denotes the aggregate output supplied by each firm $(i=1, \ldots, n)$ in the pre-merger game. For the post-merger equilibrium output levels, $X_{i}^{M}$ denotes the aggregate output of each member firm $(i=$ $1, \ldots, n)$ of $M$, and $X_{n+k}^{F}$ denotes the aggregate output of each non-merged firm $(k=1, \ldots, q)$. The differences in output supplied in the post-merger to the pre-merger game are as follows:

(1) for $2 \leq n \leq 4$ and $i=1,2,3$ and 4 then the following inequalities both hold:

$$
X_{i}^{M}<X_{i}^{*}=\frac{N}{n^{*}} ; \quad \sum_{i=1}^{n} X_{i}^{M}<\sum_{i=1}^{n} X_{i}^{*}=\frac{n N}{n^{*}}
$$

(2) for $n \geq 5$ and $i=3, \ldots, n-2$ then the following inequalities both hold:

$$
\begin{aligned}
& X_{1}^{M}=X_{n}^{M}>X_{2}^{M}=X_{n-1}^{M}>X_{i}^{M}=\frac{N}{(n+q)}=\frac{N}{n^{*}}=X_{i}^{*} \\
& \sum_{i=1}^{n} X_{i}^{M}=2 X_{1}^{M}+2 X_{2}^{M}+\frac{(n-4) N}{(n+q)}<\sum_{i=1}^{n} X_{i}^{*}=\frac{n N}{n^{*}} \Leftrightarrow X_{1}^{M}+X_{2}^{M}<\frac{2 N}{n^{*}}
\end{aligned}
$$


(3) for the post-merger market shares of the $q$ single-product competitors, the following inequalities hold for either cases (1) and (2) noted above for the market shares of the multi-product firm $M$ :

for $q=2$ then $\sum_{k=1}^{2} X_{n+k}^{F}=2 X_{n+1}^{F}$

for $q \geq 3$ then $\sum_{k=1}^{q} X_{n+k}^{F}=2 X_{n+1}^{F}+\sum_{k=2}^{q-2} X_{n+k}^{F}>\sum_{i=1}^{q} X_{i}^{*}=\frac{q N}{n^{*}}$

The merged firm $M$, through its asymmetric quality-price policy, is able to exploit its potentially greater control over its joint-market size by reducing levels of its variants' output relative to the pre-merger symmetric market shares $X_{i}^{*}=N / n^{*}$ for $i=1, \ldots, n^{*}$. For example, if $n=2$ and $q=2$, then each of the post-merger market shares of the bi-variant firm $M, X_{1}^{M}=X_{2}^{M}=X^{M}$ are less than their pre-merger output level of $X_{i}^{*}=N / n^{*}=N / 4$; and the sum of the joint market shares of firm $M$ is less than the sum of $X_{1}{ }^{*}+X_{2}^{*}=$ $2 N / n^{*}=N / 2$ [refer to (1)]. Similarly, for $n \geq 5$, then the market shares of the peripheral member firms belonging to the multi-product firm $M$ are the largest, and the joint aggregate, or sum of all member firms post-merger market shares are less than the sum of the pre-merger market shares [refer to (2)]. These peripheral member firms are actively engaged in the price-quality warfare with their nearest outside single-product competitors, and compete by selling the greatest quantity of all variants produced by the multi-product firm $M$.

Moreover, each non-merged competitor $q$ produces more total output post-merger than it produced prior to the merger [refer to (3)]. As the aggregate output supplied post- 
merger, by the $q$ competitors is larger than the aggregate pre-merger level, an $n$-neighbour firm merger may not necessarily be beneficial to those consumers located within the rivals' market areas even though $a^{F}>a^{*}$ since $p^{F}>p^{*}$.

\section{A Welfare Analysis of the Nash Price-Quality Merger Model}

The complex nature of the equations (3.19) and (3.20), the price-quality equilibrium outcome for the profit levels of the multi-product firm $M$, and the $q$ outside competitors, respectively, makes analytical investigation of merger profitability intractable. Table 3.1 illustrates the numerical simulation of the effects of a profitable two-firm merger (corporate authority chooses price only), with $(q=2)$ outside competitors, on consumers' surplus (CS), on the aggregate profit of the merged and nonmerged firms, or producers' surplus (PS), and on total welfare (TW). Similarly, Table 3.2 gives the numerical simulation of the post-merger effects of a two-neighbour firm merger (decentralized quality levels), with $(q=4)$ outside rivals, on the CS, the PS, and the TW [see Appendix D: Chapter 3].

The numerical results in the case of $(q=2)$ competitor firms are calculated for the parameter values of $N=L=2$, for each set of transport costs $t=5$ and 6 , respectively. For the case of $(q=4)$ competitor firms, the numerical results are calculated for the parameter values of $N=L=2$, respectively, for each set of transport costs $t=6,7$ and 8 . The calculation of consumers' surplus must be done separately for symmetric prices and asymmetric prices, respectively, with respect to transport costs incurred. For example, with symmetric pricing of the pre-merger n-firm oligopoly model, the aggregate consumers' surplus $C S$ is calculated as total income $N y$, plus the area under the inelastic 
demand curve, or $C S^{*}=N\left(a^{*}-p^{*}\right)$, minus the area with respect to transport costs incurred, $-t N L^{2} / 12 n^{2}$, where $n$ is the number of pre-merger firms. Formally, the aggregate $C S^{*}$ equation is given by the following expression;

$$
C S^{*}=N y+N \int_{p^{*}}^{a^{*}} d p-\frac{2 n N}{L} \int_{0}^{L / 2 n} t x^{2} d x=N y+N\left(a^{*}-p^{*}\right)-\frac{t N L^{2}}{12 n^{2}} .
$$

Thus, in the case of $n=4$ pre-merger firms and $N=L=2$, then $C S^{*}=2 y+2\left(a^{*}-p^{*}\right)$ $t / 24$. With symmetric pricing the point at which the consumer is indifferent between two firms is exactly at the midpoint of the distance between the two firms.

Under asymmetric pricing, the point at which the consumer is indifferent between two firms charging different prices must be first calculated separately for each such pair by equating the respective utility functions. Once the indifferent point is found, then the total area with respect to transport costs is calculated. For example, in the case of $(q=2)$ competitor firms and $N=L=2$ and $t=6$, then the aggregate consumers' surplus $C S=2 y$ $+2\left(a^{M}-p^{M}\right)+2\left(a_{k(l)}^{F}-p_{k(l)}{ }^{F}\right)-0.435$. The total transport costs incurred under asymmetric pricing are greater than the total transport costs incurred with symmetric pricing, or $-t / 24=-0.25$. The producers' surplus is given by $P S=\pi^{M}+2\left[\pi_{k(l)}^{l i}\right]$.

Note that since consumers either purchase one or none of a product variant, then aggregate $C S>0$. By the indirect utility function of equation (3.1), a positive amount of consumer income $y$, must be added to ensure a sufficient monetary amount to cover the expenditure on a single unit of a product-variant; that is, the cost of the base price $p_{i}$, the cost of the quality level $a_{i}$, and the transport cost $t$ that is incurred. The changes in 
consumers' surplus are denoted by $\Delta(C S)$, the change in producers' surplus is $\Delta(P S)$, and the change in total welfare, is given as $\Delta(T W)$. These changes are examined in Tables 3.1 and 3.2, respectively, and they are the numerical differences between the values of the post-mergèr variables to that of the values of the pre-merger variables.

Given the impact of the merger on post-merger prices and quality levels (analyzed in section 3.3), it is simple to see that an n-neighbour firm merger reduces consumers' surplus as shown by the numerical simulations of the two-firm merger case with a corporate authority that decentralizes the quality levels of its bi-variants. The loss in consumers' surplus increases as the unit transport cost $t$ rises, given that the total number of firms $(n=2)$ to the merger is constant, with a small number of ( $q=2$ or 4 ) outside competitors, for a given value of $N$, the population size and $L$, the circular size of the industry. With a fixed $N$ and $L$, and for a fixed number of member firms $n$ and unit transport cost $t$, the gain in producers' surplus increases significantly as the number of outside competitors $(q)$ grows. The gains to producers' profit levels are even more significant, for a given value of $N$ and $L$, if the value of the unit transport cost $t$, increases for a given industry size. The change in the total welfare of the economy, $\Delta(T W)<0$, is proportionately smaller if the size of $N$ and $L$ are small relative to the total industry size and if consumers of the bi-variants incur low transport costs. The merger is socially inefficient if the loss in consumers' surplus is relatively larger than the gains in profits to producers. However, for $n=2$, and if the number of rivals increases, the change in total welfare loss is less for the parameter values of $N=L=2$, for the same set of unit transport costs, $t=6$. 
Table 3.1: The Total Welfare Numerical Results for a Two-Neighbour Firm Merger $(q=2)$ decentralized quality levels

( $\mathrm{n}=2$ and $\mathrm{q}=2)$ and $\mathrm{N}=\mathrm{L}=2(\mathrm{t}=5$ and 6$)$

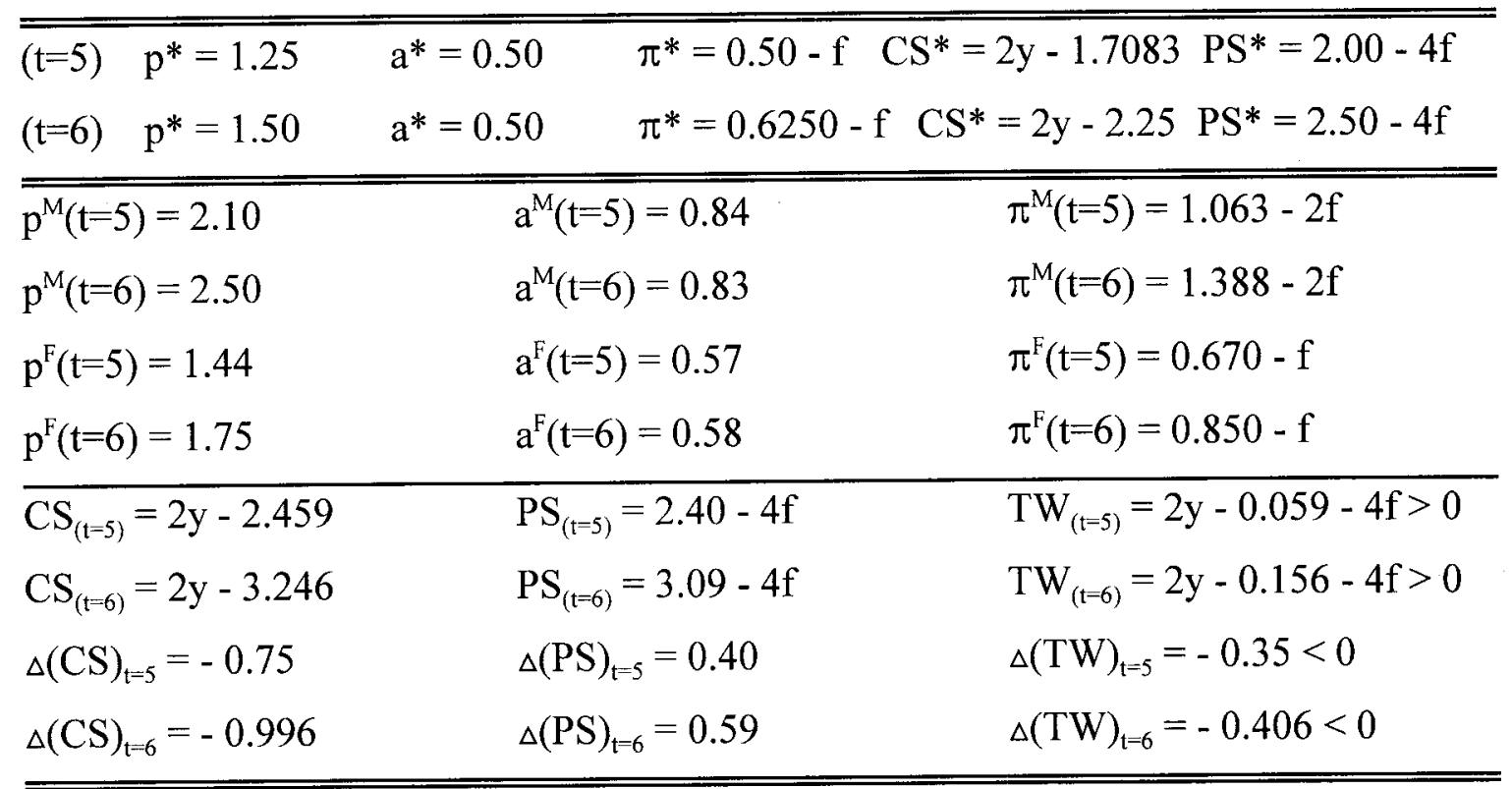

In the case of a two-neighbour firm merger with decentralized quality levels, for $q$ $=2$ and 4 , the post-merger profit increases significantly, as the unit transport cost $t$, increases. If there are two outside competitors, there is a lack of a "free-rider" problem (since $t>4 N / L^{2}$ ) as these single-product firms each gain a lesser amount of post-merger profit than does their neighbouring merged firm, $M$. However, for a given $t$, each member firm earns less profit than one of its single-product competitors. There is an absence of this problem if the number of rivals increases to $q=4$ and $t>6 N / L^{2}$. For these same unit transport costs $t$, the economy experiences a loss in total welfare as $\Delta(T W)$ $<0$, if the size of the parameters, $N$ and $L$, increase. Thus, this type of merger is deemed to be socially inefficient.

When the number of outside competitors increases to $q=4$, the economy 
experiences a decline in the change of total welfare as the unit transport cost, $t$, increases. However, the loss in the change of total welfare to the economy is proportionately less if the transport cost $t=6$, for the same set of parameters $N=L=2$, since the $\Delta(P S)$ is significantly less when there are more $(q=4)$ single-product varieties in the industry. The bi-variant firm $M$ 's profits decline as the number of outside competitors increases. Thus, the loss in the change in consumers' surplus is significantly less with more product varieties, given the same set of parameters and $t=6$. For this same value of $t=6$, the pre-merger transport costs of (-0.11) are more than those incurred by consumers in a post-merger economy $(-0.085)$. For $t=7$, and $N=L=2$, however, the post-merger transport costs of $(-0.346)$ are greater than the pre-merger transport costs of $(-0.1296)$.

Table 3.2: The Total Welfare Numerical Results for a Two-Neighbour Firm Merger $(q=4)$ decentralized quality levels

$(\mathrm{n}=2$ and $\mathrm{q}=4)$ and $\mathrm{N}=\mathrm{L}=2(\mathrm{t}=6,7$ and 8$)$

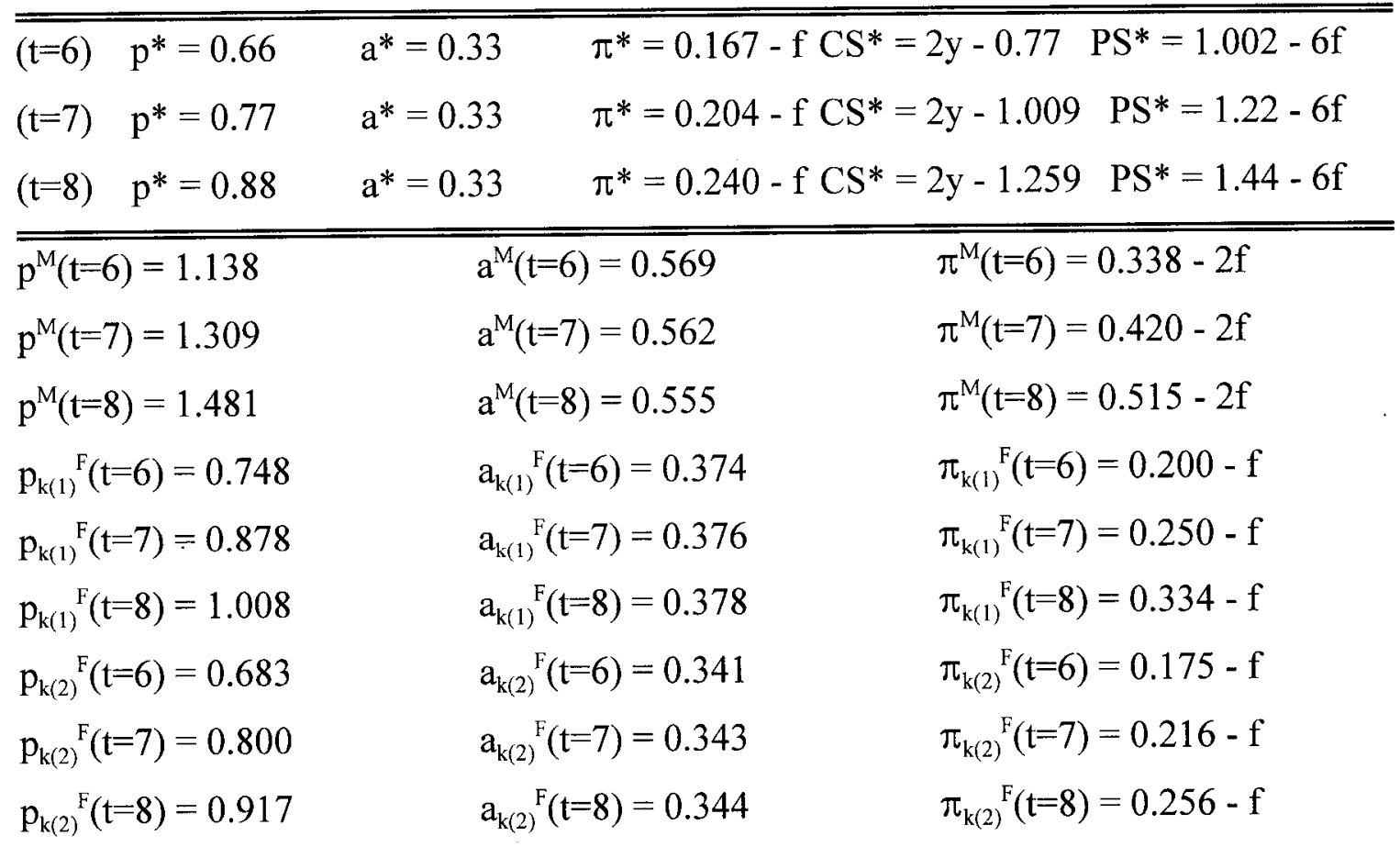




\begin{tabular}{|c|c|c|}
\hline $\mathrm{CS}_{(\mathrm{t}-6)}=2 \mathrm{y}-2.689$ & $\mathrm{PS}_{(\mathrm{t}=6)}=1.055-6 \mathrm{f}$ & $\mathrm{TW}_{(\mathrm{t}=6)}=2 \mathrm{y}-1.634-6 \mathrm{f}>0$ \\
\hline $\mathrm{CS}_{(\mathrm{t}-7)}=2 \mathrm{y}-3.631$ & $\mathrm{PS}_{(t-7)}=1.352-6 \mathrm{f}$ & $\mathrm{TW}_{(\mathrm{t}-7)}=2 \mathrm{y}-2.266-6 \mathrm{f}>0$ \\
\hline $\mathrm{CS}_{(1-8)}=2 \mathrm{y}-5.259$ & $\mathrm{PS}_{(t-8)}=1.694-6 \mathrm{f}$ & $\mathrm{TW}_{(\mathrm{t}-8)}=2 \mathrm{y}-3.600-6 \mathrm{f}>0$ \\
\hline$\Delta(\mathrm{CS})_{\mathrm{t}=6}=-1.919$ & $\Delta(\mathrm{PS})_{\mathrm{t}-6}=0.073$ & $\Delta(\mathrm{TW})_{t=6}=-1.846<0$ \\
\hline$\Delta(\mathrm{CS})_{\mathrm{t}=7}=-2.609$ & $\Delta(\mathrm{PS})_{\mathrm{i}-7}=0.132$ & $\Delta(\mathrm{TW})_{\mathrm{t}=7}=-2.477<0$ \\
\hline$\Delta(\mathrm{CS})_{\mathrm{t}=8}=-4.035$ & $\Delta(\mathrm{PS})_{\mathrm{t}=8}=0.203$ & $\Delta(\mathrm{TW})_{\mathrm{t}-8}=-3.382<0$ \\
\hline
\end{tabular}

\subsection{THE NASH PRICE-QUALITY MERGER MODEL: CENTRALIZED}

\section{QUALITY LEVELS}

This section examines the Nash price-quality merger model where the corporate authority of the bi-variant firm $M$ controls both the price, and the quality levels of its two variants when maximizing the joint profits of its two member firms. This model serves to compare and contrast the Nash price-quality equilibrium results of the two-neighbour firm merger whose corporate management delegates the choice of the quality level to its member firms.

Suppose there is a merger between two-neighbour firms located at $x_{i}$ and $x_{i+1}$ on $C$, respectively. The corporate authority of the bi-variant firm $M$ simultaneously chooses prices $\left\{p_{i}^{M}, p_{i+1}{ }^{M}\right\}$, and quality levels $\left\{a_{i}^{M}, a_{i+1}{ }^{M}\right\}$, so as to maximize the joint profit $\pi^{M}=$ $\pi_{i}^{M}+\pi_{i+1}{ }^{M}$ of its two firms. The corporate authority of the merged firm $M$ assumes that its price-quality choice is not reflected in the simultaneous choice of price and quality independently set by each of the remaining $(n-2)$ single-product competitors in the industry.

The joint profit function of the two-neighbour firm merger is given by the following equation: 
$\pi^{M}=\pi_{i}^{M}+\pi_{i+1}^{M}=\left(p_{i}{ }^{M}-c\right) X_{i}^{M}-\frac{1}{2}\left(a_{i}^{M}\right)^{2}+\left(p_{i+1}^{M}-c\right) X_{i+1}^{M}-\frac{1}{2}\left(a_{i+1}^{M}\right)^{2}-2 f$

From the necessary conditions with respect to prices for $i=1, \ldots, n, \partial \pi^{M} / \partial p_{i}^{M}=0$ and $\partial \pi^{M} / \partial p_{i+1}{ }^{M}=0$, respectively, the best-response price functions are derived as the following equations:

$p_{i}^{M}=\frac{1}{2}\left(p_{i+1}^{M}+p_{i-1}^{F}\right)+\frac{1}{2} a_{i}^{M}-\frac{1}{4} a_{i+1}^{M}-\frac{1}{4} a_{i-1}^{F}+\frac{t L^{2}}{2 n^{2}}$

$p_{i+1}^{M}=\frac{1}{2}\left(p_{i}^{M}+p_{i+2}^{F}\right)+\frac{1}{2} a_{i+1}^{M}-\frac{1}{4} a_{i}^{M}-\frac{1}{4} a_{i+2}^{F}+\frac{t L^{2}}{2 n^{2}}$

From the necessary conditions with respect to quality levels for $i=1, \ldots, n, \partial \pi^{M} / \partial a_{i}^{M}=0$ and $\partial \pi^{M} / \partial a_{i+1}{ }^{M}=0$, respectively, the best-response quality functions are derived as the following equations:

$$
\begin{aligned}
& a_{i}^{M}=\frac{n N}{2 t L^{2}}\left(2 p_{i}{ }^{M}-p_{i+1}^{M}-c\right) \\
& a_{i+1}^{M}=\frac{n N}{2 t L^{2}}\left(2 p_{i+1}^{M}-p_{i}^{M}-c\right)
\end{aligned}
$$

The market shares $X_{i}^{M}$ and $X_{i+l}{ }^{M}$, respectively, are each functions of the nearest outside competitors' price and quality level. Since $p_{i-1}{ }^{F}=p_{i+2}{ }^{F} \equiv p_{k(l)}{ }^{F}$ and $a_{i-1}{ }^{l}=a_{i+2}{ }^{l i} \equiv a_{k(l)}{ }^{l i}$ are fixed for the nearest equi-distant single-product rival firms, and if $a_{i}^{M}=a_{i+1}{ }^{M} \equiv a^{M}$, then equations (3.22) and (3.23) are symmetric, and the merged firm $M$ sets, in equilibrium, 
identical prices $p_{i}^{M}=p_{i+1}{ }^{M} \equiv p^{M}$ and quality levels $a_{i}^{M}=a_{i+1}{ }^{M} \equiv a^{M}$, for its two brands.

The best-response price and quality functions for each of the $(n-2)$ single-product competitors are derived from the profit-maximizing first-order conditions, and they are determined separately and recursively, for those firms located at $x_{i}, x_{2}, \ldots, x_{i-1}, x_{i \downarrow 2}, x_{i \nmid 3}, \ldots$, $x_{n}$ on $C$, for $j=1, \ldots, n(n \geq 4)$. For example, the best-response function $p_{i+2}{ }^{F}$, and the bestresponse quality function $a_{i+2}{ }^{F}$, of the firm $x_{i+2}$, are derived from the following profitmaximizing problem:

$$
\begin{aligned}
& \pi_{i+2}^{F}=\left(p_{i+2}^{F}-c\right) \frac{N}{L}\left[\frac{\left(p_{i+3}^{F}-a_{i+3}^{F}\right)-2\left(p_{i+2}^{F}-a_{i+2}^{F}\right)+\left(p_{i+1}^{M}-a_{i+1}^{M}\right)}{2 t L / n}+\frac{L}{n}\right]-\frac{1}{2}\left(a_{i+3}^{F}\right)^{2}-f \\
& p_{i+2}^{F}=\frac{1}{4}\left(p_{i+1}^{M}-a_{i+1}^{M}\right)+\frac{1}{4}\left(p_{i+3}^{F}-a_{i+3}^{F}\right)+\frac{1}{2} a_{i+2}^{F}+\frac{t L^{2}}{2 n^{2}}
\end{aligned}
$$

$a_{i+2}^{F}=\frac{n N}{t L^{2}}\left(p_{i+2}^{F}-c\right)$

Substituting equations (3.24), (3.25), (3.27), and (3.28) into equation (3.22) gives the post-merger equilibrium price function $p^{M}$ as the following expression:

$$
p^{M}=\frac{\left(2 t L^{2}-n N\right) p_{k(1)}^{F}}{\left(4 t L^{2}-n N\right)}+\frac{4\left(t L^{2}\right)^{2}}{n^{2}\left(4 t L^{2}-n N\right)}+\frac{\left(2 t L^{2}+n N\right) c}{\left(4 t L^{2}-n N\right)}
$$

Note that $p^{M}$ is a function not only of the parameters $t, N, L$, and $n$, but is also a function of $p_{k(l)}{ }^{F}$, the price of the two nearest equi-distant single-product firms' variants. The equilibrium solution of $p_{k(j)}{ }^{F}$, and $a_{k(j)}{ }^{k}$, for $j=1,2, \ldots, n-2$, is determined recursively, 
for a given $n \geq 4$, by each independent Nash profit-maximization problem, and it is symmetric with respect to the prices (and quality levels) of the neighbouring firms. For example, if there are $n=4$ pre-merger firms, suppose that firms 1 and 2 merge. Then firms 3 and 4 are the nearest equi-distant single-product rivals located on either side of the merged firm $M$. These two outside competitors set in equilibrium, identical prices $p_{k(l)}{ }^{F}$, and quality levels, $a_{k(l)}{ }^{F}$, for their product variants. The price $p_{k(l)}{ }^{F}$ is a function of the price $p^{M}$ of the bi-variant firm $M$.

If there are $n=5$ pre-merger firms, then the next nearest neighbours' prices to the merged firm $M$ are given by $p_{3}^{F}=p_{5}^{F} \equiv p_{k(l)}^{F}$, and $p_{k(2)}^{F} \equiv p_{4}^{F}$. The price $p_{k(2)}{ }^{F}$ is a function of the price $p_{k(l)}^{F}$ only. As an example, the profit function (3.26) is a function of the variables, $p_{i+3}{ }^{F}$ and $a_{i+3}{ }^{F}$, respectively. If there are $n=5$ pre-merger firms, then the outermost single-product firm is $x_{i+3}$, located on $C$. Then the profit-maximization problem for this firm must be solved for the Nash equilibrium values of $p_{k(2)}{ }^{k}$ and $a_{k(2)}{ }^{F}$. These equilibrium values are substituted into (3.26) to solve for the equilibrium variables, $p_{k(l)}^{F}$ and $a_{k(l)}{ }^{F}$.

Therefore, by the recursive solution of the single-product firms Nash equilibrium prices and quality levels, then all pair-wise non-merged firms equi-distant from the merged firm $M$ set, in equilibrium, identical prices such that, in general, $p^{M}>p_{k(1)}^{F}>p_{k(2)}{ }^{I}$ $>\ldots$ if and only if $t>n N / 2 L^{2}$. The Nash equilibrium outcome for the quality levels is such that, in general, the bi-variant firm $M$ chooses, in equilibrium a lower level of quality $a^{M}\left\langle a_{k(1)}{ }^{F}>a_{k(2)}{ }^{F}>\ldots\right.$ that its $(n-2)$ single-product competitors. For $n \geq 4$, it can be shown that a two-neighbour firm merger increases the post-merger profits in the 
industry, such that $\pi^{M}>\pi_{k(l)}^{F}>\pi_{k(2)}{ }^{F}>\ldots$, and all single-product firms earn less profits than each party to the merged firm $M$. The Nash equilibrium outcome solutions of a twoneighbour firm merger whose corporate authority chooses both prices and qualities, with $q=2,3$, and 4 single-product competitors, are given in Appendix (3.E).

If the merged firm $M$ consists of only two firms, with a small number of outside competitors, $2 \leq q \leq 4$, the corporate authority may choose to maximize joint profits by setting both the price, and the quality level of its two variants. In equilibrium, it chooses a price-quality policy such that the identical prices, and the identical quality level of its two brands, are both relatively lower than if it had chosen prices only. The corporate authority of firm $M$, takes advantage of its control over both strategic variables by setting a lower quality level $a^{M}$, for its two brands over its competitors' choice of quality levels to gain a relatively larger joint market share, and thus, joint post-merger profit.

By contrast, for a bi-variant firm $M$, with a small number of outside competitors, 2 $\leq q \leq 4$, the equilibrium outcome result of the decentralization of the quality levels to member firms, shows that the corporate authority anticipates a set of higher quality levels and compensates by setting a relatively higher price, in equilibrium, than it would have chosen, if it had initially controlled both the price, and the quality level of its two products. With a small number of member firms $(n=2)$, the corporate authority realizes these two firms expend a greater effort in choosing their variants' qualities, and in equilibrium, they independently set relatively higher quality levels than if the corporate authority alone would have chosen. Thus, the merged firm $M$ accrues a relatively smaller post-merger profit than it would have under centralized decision-making, and is a result 
of the proportionately smaller joint market share, or quantity sold, of its higher quality, and higher priced, two product brands.

\section{A. The case of $(n=2)$ member firms and $(q=2)$ outside competitors:}

For the bi-variant firm $M$ which controls both strategic variables in its joint profitmaximization, the post-merger equilibrium price is higher than that set by the two singleproduct competitors, $p^{M}>p^{F} \Leftrightarrow t>4 N / L^{2}$, while the post-merger equilibrium quality level is smaller relative to its rivals, $a^{M}<a^{F}$. The second-order condition for $n+q=4$ is given by $t>2 N / L^{2}$. However, if $2 N / L^{2}<t \leq 4 N / L^{2}$, then $p^{M}<p^{H}$ and $\pi^{M}>\pi^{r}$ since $X^{M}>X^{r}$. If $t>4 N / L^{2}$, then $X^{M}<X^{t i}$ and $\pi^{M}>\pi^{*}$. The "free-rider" problem is absent for this case. In the case of the $n=2$ and $q=2$ industry structure, the Nash price-quality equilibrium, for both the decentralized, and centralized decision-making models, the outcome is a symmetric price-quality policy. However, the equilibrium price chosen by the corporate authority of the merged firm $M$ (centralized quality), say $p_{(s)}^{M}<p_{(d)}^{M}$, where the price $p^{M}(d)$ is chosen by the corporate authority of the merged firm $M$ (decentralized quality), but the equilibrium quality independently set by the member firms of the merged firm $M$ (decentralized quality), $a_{(d)}^{M}>a_{(s)}^{M}$. The single-product competitors of the bi-variant firm $M$ (decentralized quality) each set a post-merger price such that ${p^{F_{(d)}}}^{{ }^{\prime}}>p_{(s)}^{F^{\prime}}$, and a quality level such that $a_{(s)}^{H_{(s)}}<a_{(d)}^{F}$, for each of their single-product variants.

\section{B. The case of $(n=2)$ member firms and $(q=4)$ outside competitors:}

For the bi-variant firm $M$ which controls both strategic variables in its joint profitmaximization, the post-merger equilibrium price is higher than that set by the four singleproduct competitors, $p^{M}>p_{k(l)} F \Leftrightarrow t \geq 6 N / L^{2}$, while the post-merger equilibrium quality 
level is smaller relative to its rivals, $a^{M}<a_{k(l)} F$. The second-order condition for $n+q=6$ is given by $t>3 N / L^{2}$. However, if $3 N / L^{2}<t<6 N / L^{2}$, then $p^{M}<p_{k(l)}{ }^{F}$ and $\pi^{M}>\pi^{t}$ since $X^{M}>X^{F}$. If $t \geq 6 N / L^{2}$, then $X^{M}<X^{F}$ and $\pi^{M}>\pi^{F}$. The "free-rider" problem is therefore, absent. In the case of the $n=2$ and $q=4$ industry structure, the Nash price-quality equilibrium, for both the decentralized, and centralized decision-making models, the outcome is a symmetric price-quality policy. However, the equilibrium price chosen by the corporate authority of the merged firm $M$ (centralized quality), say $p_{(s)}^{M}<p_{(d)}^{M}$, where the price $p^{M}{ }_{(d)}$ is chosen by the corporate authority of the merged firm $M$ (decentralized quality), but the equilibrium quality independently set by the member firms of the merged firm $M$ (decentralized quality), $a_{(s)}^{M}<a_{(d)}^{M}$. The single-product competitors of the bivariant firm $M$ (decentralized quality) each set a post-merger price such that $p_{(d)}^{I^{*}}<p_{(s)}^{I^{*}}$, and a quality level such that $a_{(s)}^{F} \geq a_{(d)}^{H}$, for each of their single-product variants.

\section{A Welfare Analysis of the Centralized Nash Price-Quality Merger Model}

This section provides a simple numerical simulation of the total welfare analysis of a two-neighbour firm merger whose corporate authority controls both the price, and the quality level of its two product variants when it maximizes the joint profit of its two member firms. The solutions of the price-quality Nash equilibrium outcome for prices, qualities, and profits of a two-neighbour firm merger with $q=2,3$, and 4 outside rivals, respectively, are provided in Appendix (E) of Chapter 3. Wherever possible, these numerical results are contrasted with the Nash price-quality equilibrium outcome of a two-firm merger where the corporate authority of the bi-variant firm $M$ decentralizes the quality choice [see section 3.5]. 
The numerical results in the case of $(q=2)$ outside competitor firms are calculated for the parameter values of $N=L=1$, and $N=L=2$, respectively, for each set of transport costs $t=5$ and $t=6$. For the case of $(q=4)$ competitor firms, the numerical results are calculated for the parameter values of $N=L=2$ and $N=L=3$, respectively, for each set of transport costs of $t=6$ and $t=7$.

For a two-firm merger with two competitors, the post-merger profit decreases, as the unit transport cost increases for a given set of $N$ and $L$ values. There is a lack of the "free-rider" problem but each (identical) member firms' profit is far less than that of a single-product rival, except for $t=6$, and $N=L=1$. For any set of parameter $N$ and $L$ values, the change in total welfare of the economy, $\Delta(T W)<0$, decreases as $t$ increases. Thus, this type of merger is deemed to be socially inefficient.

The loss in total welfare to the economy is proportionately greater if the bi-variant firm $M$ controls both strategic variables, for the same set of parameters $N=2$ and $L=2$ [see section 3.5]. Although the post-merger prices are greater under decentralized decision-making, the level of post-merger quality is significantly greater than the quality level chosen, in equilibrium, by the merged firm $M$ that controls both prices and qualities of its bi-variants. Thus, the loss in consumers' surplus is significantly greater, as well as the gain to producers' surplus in a concentrated industry.

Table 3.3: The Total Welfare Numerical Results for a Two-Neighbour Firm Merger $(q=2)$ centralized quality levels $(\mathrm{n}=2$ and $\mathrm{q}=2)$ and $\mathrm{N}=\mathrm{L}=1(\mathrm{t}=5$ and 6$)$

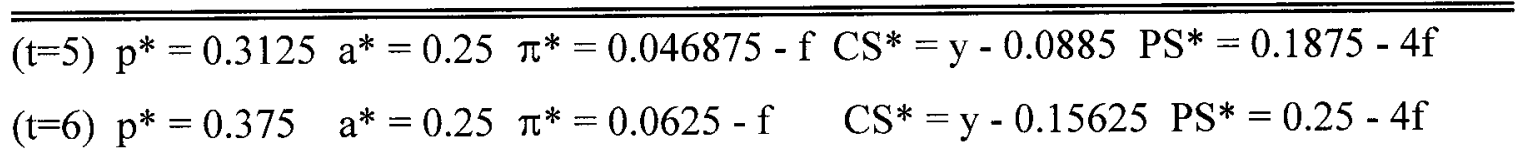




\begin{tabular}{|c|c|c|}
\hline $\mathrm{p}^{\mathrm{M}}(\mathrm{t}=5)=0.44$ & $\mathrm{a}^{\mathrm{M}}(\mathrm{t}=5)=0.17$ & $\pi^{\mathrm{M}}(\mathrm{t}=5)=0.125-2 \mathrm{f}$ \\
\hline $\mathrm{p}^{\mathrm{M}}(\mathrm{t}=6)=0.54$ & $\mathrm{a}^{\mathrm{M}}(\mathrm{t}=6)=0.18$ & $\pi^{\mathrm{M}}(\mathrm{t}=6)=0.62-2 \mathrm{f}$ \\
\hline $\mathrm{p}^{\mathrm{F}}(\mathrm{t}=5)=0.40$ & $\mathrm{a}^{\mathrm{F}}(\mathrm{t}=5)=0.31$ & $\pi^{\mathrm{F}}(\mathrm{t}=5)=0.078-\mathrm{f}$ \\
\hline $\mathrm{p}^{\mathrm{F}}(\mathrm{t}=6)=0.47$ & $\mathrm{a}^{\mathrm{F}}(\mathrm{t}=6)=0.32$ & $\pi^{\mathrm{F}}(\mathrm{t}=6)=0.101-\mathrm{f}$ \\
\hline $\mathrm{CS}_{(t-5)}=\mathrm{y}-0.4275$ & $\mathrm{PS}_{(t-5)}=0.28-4 \mathrm{f}$ & $\mathrm{TW}_{(t-5)}=\mathrm{y}-0.1475-4 \mathrm{f}>0$ \\
\hline $\mathrm{CS}_{(1-6)}=\mathrm{y}-0.6125$ & $\mathrm{PS}_{(\mathrm{t}=6)}=0.82-4 \mathrm{f}$ & $\mathrm{TW}_{(\mathrm{t}=6)}=\mathrm{y}+0.2074-4 \mathrm{f}>0$ \\
\hline$\Delta(\mathrm{CS})_{t-5}=-0.339$ & $\Delta(\mathrm{PS})_{t=5}=0.0935$ & $\Delta(\mathrm{TW})_{t=5}=-0.2245<0$ \\
\hline$\Delta(\mathrm{CS})_{t-6}=-0.456$ & $\Delta(\mathrm{PS})_{\mathrm{t}=6}=0.057$ & $\Delta(\mathrm{TW})_{\mathrm{t}=6}=-0.3393<0$ \\
\hline \multicolumn{3}{|c|}{$(\mathrm{n}=2$ and $\mathrm{q}=2)$ and $\mathrm{N}=\mathrm{L}=2(\mathrm{t}=5$ and 6$)$} \\
\hline \multicolumn{3}{|c|}{$(\mathrm{t}=5) \mathrm{p}^{*}=1.25 \mathrm{a}^{*}=0.50 \pi^{*}=0.50-\mathrm{f} \mathrm{CS}^{*}=2 \mathrm{y}-1.7083 \mathrm{PS}^{*}=2.00-4 \mathrm{f}$} \\
\hline \multicolumn{3}{|c|}{$(\mathrm{t}=6) \mathrm{p}^{*}=1.50 \mathrm{a}^{*}=0.50 \pi^{*}=0.6250-\mathrm{f} \mathrm{CS}^{*}=2 \mathrm{y}-2.25 \mathrm{PS}^{*}=2.50-4 \mathrm{f}$} \\
\hline $\mathrm{p}^{\mathrm{M}}(\mathrm{t}=5)=1.90$ & $\mathrm{a}^{\mathrm{M}}(\mathrm{t}=5)=0.31$ & $\pi^{\mathrm{M}}(\mathrm{t}=5)=1.306-2 \mathrm{f}$ \\
\hline $\mathrm{p}^{\mathrm{M}}(\mathrm{t}=6)=2.30$ & $\mathrm{a}^{\mathrm{M}}(\mathrm{t}=6)=0.38$ & $\pi^{\mathrm{M}}(\mathrm{t}=6)=1.627-2 \mathrm{f}$ \\
\hline $\mathrm{p}^{\mathrm{F}}(\mathrm{t}=5)=1.54$ & $\mathrm{a}^{\mathrm{F}}(\mathrm{t}=5)=0.57$ & $\pi^{\mathrm{F}}(\mathrm{t}=5)=0.766-\mathrm{f}$ \\
\hline $\mathrm{p}^{\mathrm{F}}(\mathrm{t}=6)=1.84$ & $\mathrm{a}^{\mathrm{F}}(\mathrm{t}=6)=0.62$ & $\pi^{\mathrm{F}}(\mathrm{t}=6)=0.947-\mathrm{f}$ \\
\hline $\mathrm{CS}_{(t=5)}=2 \mathrm{y}-5.647$ & $\mathrm{PS}_{(\mathrm{t}-5)}=2.84-4 \mathrm{f}$ & $\mathrm{TW}_{(1-5)}=2 \mathrm{y}-2.807-4 \mathrm{f}>0$ \\
\hline $\mathrm{CS}_{(\mathrm{t}=6)}=2 \mathrm{y}-6.876$ & $\mathrm{PS}_{(\mathrm{t}=6)}=3.52-4 \mathrm{f}$ & $\mathrm{TW}_{(\mathrm{t}-6)}=2 \mathrm{y}-3.356-4 \mathrm{f}>0$ \\
\hline$\Delta(\mathrm{CS})_{\mathrm{t}=5}=-3.93$ & $\Delta(\mathrm{PS})_{\mathrm{t}=5}=0.84$ & $\Delta(\mathrm{TW})_{\mathrm{t}=5}=-3.099<0$ \\
\hline$\Delta(\mathrm{CS})_{t-6}=-4.65$ & $\Delta(\mathrm{PS})_{t=6}=1.02$ & $\Delta(\mathrm{TW})_{\mathrm{t}=6}=-3.630<0$ \\
\hline
\end{tabular}

For a bi-variant firm $M$ with $q=4$ single-product competitors, the economy experiences a decline in the change of total welfare if the unit transport cost, $t=6$.

However, the loss in total welfare to the economy is proportionately greater if the merged firm $M$ does not delegate the choice of quality levels to its member firms, for the same set of parameters, $t, N$ and $L$. Although the post-merger prices of the bi-variant firm $M$ are greater under decentralized decision-making, the level of post-merger quality is 
significantly greater than the quality level chosen, in equilibrium, by the bi-variant firm $M$ that controls both strategic variables in its joint profit maximization. Thus, the loss in consumers' surplus is significantly less, given the same set of parameters $t=6, N=2$, and $L=2$. Part of the calculated consumers' surplus is the amount due to transport costs $(-0.1985)$ if $t=6$, and these are significantly greater than the amount which consumers experience under the same type of merger with decentralized quality levels $(-0.085)$.

If the unit transport cost increases to $t=7$, however, the merger is deemed to be socially inefficient as $\Delta(T W)<0$, under a centralized quality choice merger, as the gain to producers is significantly greater [see section 3.5]. For the same unit transport cost $t=7$, and proportionately increasing the population and the circle size to $N=3$ and $L=3$, respectively, the economy experiences a socially inefficient merger as $\Delta(T W)<0$. Since the number of consumers has increased, they also incur greater costs to acquire their preferred product variant as the distance traveled is greater. Thus, the change in loss of consumers' surplus is significantly greater than the loss incurred relative to the set of parameters, $N=L=2$. For all producers with a doubling in market area size of $L=2$, it appears that the size of the population $N$ would have to be far higher in order to gain proportionately larger post-merger market shares, and thus profits. There is an absence of the "free-rider" problem under centralized decision-making as the gain in market shares translates into higher, joint (symmetric) post-merger profits. The identical profit of each member firm $\pi_{I}^{M}=\pi_{2}^{M}$ is greater than that of any single-product competitor.

Table 3.4: The Total Welfare Numerical Results for a Two-Neighbour Firm Merger $(q=4)$ centralized quality levels 
( $\mathrm{n}=2$ and $\mathrm{q}=4)$ and $\mathrm{N}=\mathrm{L}=2(\mathrm{t}=6$ and 7$)$

\begin{tabular}{lll}
\hline \hline$(\mathrm{t}=6) \mathrm{p}^{*}=0.66 \mathrm{a}^{*}=0.33$ & $\pi^{*}=0.167-\mathrm{f} \mathrm{CS}^{*}=2 \mathrm{y}-0.77$ & $\mathrm{PS}^{*}=1.002-6 \mathrm{f}$ \\
$(\mathrm{t}=7) \mathrm{p}^{*}=0.77 \mathrm{a}^{*}=0.33$ & $\pi^{*}=0.204-\mathrm{fCS}^{*}=2 \mathrm{y}-1.009$ & $\mathrm{PS}^{*}=1.22-6 \mathrm{f}$ \\
\hline \hline $\mathrm{p}^{\mathrm{M}}(\mathrm{t}=6)=0.99$ & $\mathrm{a}^{\mathrm{M}}(\mathrm{t}=6)=0.24$ & $\pi^{\mathrm{M}}(\mathrm{t}=6)=0.431-2 \mathrm{f}$ \\
$\mathrm{p}^{\mathrm{M}}(\mathrm{t}=7)=1.17$ & $\mathrm{a}^{\mathrm{M}}(\mathrm{t}=7)=0.25$ & $\pi^{\mathrm{M}}(\mathrm{t}=7)=0.524-2 \mathrm{f}$ \\
$\mathrm{p}_{\mathrm{k}(1)}{ }^{\mathrm{F}}(\mathrm{t}=6)=0.80$ & $\mathrm{a}_{\mathrm{k}(1)}{ }^{\mathrm{F}}(\mathrm{t}=6)=0.40$ & $\pi_{\mathrm{k}(1)}{ }^{\mathrm{F}}(\mathrm{t}=6)=0.245-\mathrm{f}$ \\
$\mathrm{p}_{\mathrm{k}(1)}{ }^{\mathrm{F}}(\mathrm{t}=7)=0.94$ & $\mathrm{a}_{\mathrm{k}(1)}{ }^{\mathrm{F}}(\mathrm{t}=7)=0.40$ & $\pi_{\mathrm{k}(1)}{ }^{\mathrm{F}}(\mathrm{t}=7)=0.295-\mathrm{f}$ \\
$\mathrm{p}_{\mathrm{k}(2)}{ }^{\mathrm{F}}(\mathrm{t}=6)=0.70$ & $\mathrm{a}_{\mathrm{k}(2)}{ }^{\mathrm{F}}(\mathrm{t}=6)=0.34$ & $\pi_{\mathrm{k}(2)}{ }^{\mathrm{F}}(\mathrm{t}=6)=0.181-\mathrm{f}$ \\
$\mathrm{p}_{\mathrm{k}(2)}{ }^{\mathrm{F}}(\mathrm{t}=7)=0.81$ & $\mathrm{a}_{\mathrm{k}(2)}{ }^{\mathrm{F}}(\mathrm{t}=7)=0.34$ & $\pi_{\mathrm{k}(2)}{ }^{\mathrm{F}}(\mathrm{t}=7)=0.222-\mathrm{f}$ \\
$\mathrm{CS}_{(\mathrm{t}=6)}=2 \mathrm{y}-3.213$ & $\mathrm{PS}_{(\mathrm{t}=6)}=1.28-6 f$ & $\mathrm{TW}_{(\mathrm{t}=6)}=2 \mathrm{y}-1.933-6 \mathrm{f}>0$ \\
$\mathrm{CS}_{(\mathrm{t}=7)}=2 \mathrm{y}-4.211$ & $\mathrm{PS}_{(\mathrm{t}=7)}=1.56-6 f$ & $\mathrm{TW}_{(\mathrm{t}=7)}=2 \mathrm{y}-2.651-6 \mathrm{f}>0$ \\
$\Delta(\mathrm{CS})_{\mathrm{t}=6}=-2.443$ & $\Delta(\mathrm{PS})_{\mathrm{t}=6}=0.278$ & $\Delta(\mathrm{TW})_{\mathrm{t}=6}=-2.165<0$ \\
$\Delta(\mathrm{CS})_{\mathrm{t}=7}=-3.202$ & $\Delta(\mathrm{PS})_{\mathrm{t}=7}=0.340$ & $\Delta(\mathrm{TW})_{\mathrm{t}=7}=-2.862<0$ \\
\hline
\end{tabular}

$(\mathrm{n}=2$ and $\mathrm{q}=4)$ and $\mathrm{N}=\mathrm{L}=3(\mathrm{t}=6$ and 7$)$

$(\mathrm{t}=6) \mathrm{p}^{*}=1.50 \mathrm{a}^{*}=0.50 \pi^{*}=0.625-\mathrm{f} \mathrm{CS}^{*}=3 \mathrm{y}-3.375 \mathrm{PS}^{*}=3.75-6 \mathrm{f}$

$(\mathrm{t}=7) \mathrm{p}^{*}=1.75 \mathrm{a}^{*}=0.50 \pi^{*}=0.75-\mathrm{f} \mathrm{CS}^{*}=3 \mathrm{y}-4.1875 \mathrm{PS}^{*}=4.50-6 \mathrm{f}$

\begin{tabular}{lll}
\hline \hline $\mathrm{p}^{\mathrm{M}}(\mathrm{t}=6)=2.285$ & $\mathrm{a}^{\mathrm{M}}(\mathrm{t}=6)=0.381$ & $\pi^{\mathrm{M}}(\mathrm{t}=6)=1.596-2 \mathrm{f}$ \\
$\mathrm{p}^{\mathrm{M}}(\mathrm{t}=7)=2.682$ & $\mathrm{a}^{\mathrm{M}}(\mathrm{t}=7)=0.383$ & $\pi^{\mathrm{M}}(\mathrm{t}=7)=1.909-2 \mathrm{f}$ \\
$\mathrm{p}_{\mathrm{k}(1)}{ }^{\mathrm{F}}(\mathrm{t}=6)=1.785$ & $\mathrm{a}_{\mathrm{k}(1)}{ }^{\mathrm{F}}(\mathrm{t}=6)=0.594$ & $\pi_{\mathrm{k}(1)}{ }^{\mathrm{F}}(\mathrm{t}=6)=0.886-\mathrm{f}$ \\
$\mathrm{p}_{\mathrm{k}(1)}{ }^{\mathrm{F}}(\mathrm{t}=7)=2.074$ & $\mathrm{a}_{\mathrm{k}(1)}{ }^{\mathrm{F}}(\mathrm{t}=7)=0.595$ & $\pi_{\mathrm{k}(1)}{ }^{\mathrm{F}}(\mathrm{t}=7)=1.053-\mathrm{f}$ \\
$\mathrm{p}_{\mathrm{k}(2)}{ }^{\mathrm{F}}(\mathrm{t}=6)=1.57$ & $\mathrm{a}_{\mathrm{k}(2)}{ }^{\mathrm{F}}(\mathrm{t}=6)=0.523$ & $\pi_{\mathrm{k}(2)}{ }^{\mathrm{F}}(\mathrm{t}=6)=0.686-\mathrm{f}$ \\
$\mathrm{p}_{\mathrm{k}(2)}{ }^{\mathrm{F}}(\mathrm{t}=7)=1.84$ & $\mathrm{a}_{\mathrm{k}(2)}{ }^{\mathrm{F}}(\mathrm{t}=7)=0.524$ & $\pi_{\mathrm{k}(2)}{ }^{\mathrm{F}}(\mathrm{t}=7)=0.825-\mathrm{f}$ \\
$\mathrm{CS}_{(\mathrm{t}=6)}=3 \mathrm{y}-12.956$ & $\mathrm{PS}_{(\mathrm{t}=6)}=4.74-6 f$ & $\mathrm{TW}_{(\mathrm{t}=6)}=3 \mathrm{y}-8.216-6 \mathrm{f}>0$ \\
$\mathrm{CS}_{(\mathrm{t}=7)}=3 \mathrm{y}-15.943$ & $\mathrm{PS}_{(\mathrm{t}=7)}=5.61-6 f$ & $\mathrm{TW}$ \\
$\Delta(\mathrm{CS})_{\mathrm{t}=6}=-9.581$ & $\Delta(\mathrm{PS})_{\mathrm{t}=6}=0.99$ & $\Delta(\mathrm{TW})_{\mathrm{t}=6}=-8.591<0$ \\
$\Delta(\mathrm{CS})_{\mathrm{t}=7}=-11.755$ & $\Delta(\mathrm{PS})_{\mathrm{t}=7}=1.11$ & $\Delta(\mathrm{TW})_{\mathrm{t}=7}=-10.645<0$
\end{tabular}




\subsection{THE CASE FOR A MONOPOLIST - AN INCENTIVE TO ACQUIRE ALL PRODUCT VARIETIES IN AN INDUSTRY?}

The section starts by examining a useful comparative static that gives an analytical measure of the effect on existing equilibrium prices and qualities of adding another product variant to the firm $M$ 's set of variants. This leads to the question of determining whether or not an incentive exists for a multi-product firm to acquire the entire set of product varieties within an industry. The partial price-quality equilibrium model and its optimum solution for a monopolist who acquires all $n$ firms is analyzed in the following section as well as the ensuing numerical welfare simulations for a two-neighbour firm merger where there are $q=2$, and $q=4$, respectively, outside single-product firms within an industry.

\section{A Comparative Static Result}

An instructive way to identify and measure the anti-competitive price and quality effects from the post-merger Nash equilibrium results of a horizontal n-firm merger is to solve the "total price differential locus", $d p_{i}^{M}=\left(\partial p_{i}^{M} / \partial n\right) d n+\left(\partial p_{i}^{M} / \partial q\right) d q$, subject to the constraint, $d n+d q=0$. The effect on equilibrium prices, $p_{i}^{M}(i=1, . ., n)$, of the multiproduct firm $M$ adding one, or more additional variants to its set of products may be measured by increasing $n$, while holding $n+q=k$ (constant), where $k \geq 4$. This implies $d p_{i}^{M} / d n=\partial p_{i}^{M} / \partial n-\partial p_{i}^{M} / \partial q$, the solution of which is given by the following expression [see Appendix 3(C)]:

$$
\frac{d p_{i}^{M}}{d n}=\frac{i\left(t L^{2}\right)^{2}}{(n+q)^{2}\left[2 t L^{2}-N(n+q)\right]}+\frac{\left(t L^{2}\right)^{2}\left[t L^{2}-N(n+q)\right]^{2}}{2(n+q)^{2}\left[2 t L^{2}-N(n+q)\right]^{2}}>0
$$


Since the sign of the above expression for $d p_{i}^{M} / d n>0$ means that by adding another variant to the firm $M$ 's product line, prices of all products will rise by a given positive incremental amount. Table 3.5 illustrates these incremental values of $p_{i}^{M}(i=1,2,3,4)$ for the cases of an original $n=2$ firm merger, for example, where $n+q=k=4$ and $n+q=$ $k=5$, respectively. With the bi-variant firm $M$, the equilibrium policy was to set both identical prices, and identical quality levels. Now, if a two-firm merged entity acquires one or more firms, then it adopts the asymmetric pricing-quality policy of a merged firm producing three or more variants as long as there is at least one outside competitor remaining in the industry. The incremental values are determined for the prices $i=1,2,3$ and 4 , in the case of $n=3$ (one additional variant), if $n+q=4$, and $n=3$ and 4 (one or two additional variants), if $n+q=5$ respectively, such that the transport costs are $t=5$ and 6 and the parameters are set at $N=L=1$.

Table 3.5: The incremental values for $\underline{p}_{i}{ }^{\mathrm{M}}(i=1,2,3$ and 4)

\begin{tabular}{lllll}
\hline$(n+q=k=4)$ for $N=L=1$ and $t=5,6$ \\
\hline & $\Delta \mathrm{p}_{1}{ }^{\mathrm{M}}$ & $\Delta \mathrm{p}_{2}{ }^{\mathrm{M}}$ & $\Delta \mathrm{p}_{3}{ }^{\mathrm{M}}$ & $\Delta \mathrm{p}_{4}{ }^{\mathrm{M}}$ \\
$(\mathrm{n}=3, \mathrm{q}=1$ and $\mathrm{t}=5)$ & 0.282 & 0.542 & 0.282 & - \\
$(\mathrm{n}=3, \mathrm{q}=1$ and $\mathrm{t}=6)$ & 0.352 & 0.633 & 0.352 & - \\
\hline$(n+q=k=5)$ for $N=L=1$ and $t=5,6$ & & & \\
\hline$(\mathrm{n}=3, \mathrm{q}=2$ and $\mathrm{t}=5)$ & 0.20 & 0.40 & 0.20 & - \\
$(\mathrm{n}=3, \mathrm{q}=2$ and $\mathrm{t}=6)$ & 0.220 & 0.426 & 0.220 & - \\
$(\mathrm{n}=4, \mathrm{q}=1$ and $\mathrm{t}=5)$ & 0.20 & 0.40 & 0.40 & 0.20 \\
$(\mathrm{n}=4, \mathrm{q}=1$ and $\mathrm{t}=6)$ & 0.220 & 0.426 & 0.426 & 0.220 \\
\hline
\end{tabular}

Suppose that for an original two-neighbour firm merger situated within a 
relatively small population and market area $(N=L=1)$, with a number of $(q=2)$ outside competitors, the firm $M$ acquires an additional firm. If the merged firm $M$ adds another variant to its product line ( $n=3$ and $q=1$ ), it adheres to the asymmetric pricing policy and sets prices for the three variants such that $p_{1}{ }^{M}=p_{3}{ }^{M}<p_{2}{ }^{M}$. The effect on the current equilibrium prices is such that price $p_{l}{ }^{M}=p_{3}{ }^{M}$ will increase by an additional, incremental amount of 0.282 units if $t=5$, while the price of its "new" product variant has risen by an additional amount of $p_{2}^{M}=0.542$ units if $t=5$.

If the original two-firm merger acquires two more firms for the case of $n+q=5$, then the merged firm $M$ would have followed the "old" asymmetric oligopoly pricing policy of $p_{1}{ }^{M}=p_{4}{ }^{M}<p_{2}{ }^{M}=p_{3}{ }^{M}$ for its set of product variants if and only if there was at least one rival competitor remaining in the industry. Thus, price would have risen by additional amount of 0.220 units for variants one and four, respectively, and price would have risen by an identical additional amount of 0.426 units, respectively, for the variants two and three, if $t=6$.

Note that if these incremental values for either one, or two additional variants are valued at $t=6$, then the prices of all products rise by an even greater additional amount. This positive, incremental effect on prices implies that consumers within the market area of $M$ that previously bought from that firm will now find it increasingly costly to purchase their preferred product variant as they suffer a greater loss in utility. For example, as the "new" post-merger prices $p_{i}^{M}(i=1,2,3$ and 4) increase, for $n+q=5$, the gain to producer's surplus accrues as the number of potential product variants offered in its larger joint market area increases for the multi-product firm $M$. 
Although not examined here, the "total quality level differential locus", or $d a_{i}^{M}=$ $\left(\partial a_{i}{ }^{M} / \partial n\right) d n+\left(\partial a_{i}{ }^{M} / \partial q\right) d q$ subject to $d n+d q=0$ may also be calculated. It is simply the expression $d a_{i}{ }^{M} / d n=\left[N(n+q) / t L^{2}\right] d p_{i}{ }^{M} / d n$. Since $d p_{i}^{M} / d n>0$, by equation (3.30), and $N(n+q) / t L^{2}>0 \Rightarrow d a_{i}^{M} / d n>0$ for $n+q=k \geq 4$.

\section{The Monopoly Model}

An important business issue for the multi-product firm $M$ is whether or not it is profitable to acquire all $n$ product variants within an industry, or to maintain only a subset of such varieties thereof. The merged firm $M$ will have an incentive to "buy-out" all firms, for a given $n$, if and only if its joint post-merger profit $I^{M}$, is greater than the sum of the individual firm pre-merger profits. The monopolist firm $M$ 's objective is to maximize total joint profit, by simultaneously choosing a set of prices $\left(p_{1}^{M}, \ldots, p_{n}{ }^{M}\right)$, and a set of quality levels $\left(a_{l}{ }^{M}, \ldots, a_{n}{ }^{M}\right)$. The monopolist's equivalent optimization problem is to maximize the joint profit of its $n$ firms by setting marginal revenue equal to its marginal costs of production.

The mathematical optimization problem that the multi-product monopolist firm $M$ faces is solved by the Kuhn-Tucker method since the corporate authority of firm $M$ must satisfy the inequality constraint for the utility of a consumer, $V_{i}\left(x_{i}\right)=y+a_{i}-p_{i}-t\left(x-x_{i}\right)^{2}$ $\geq 0$, for $i=1, \ldots, n$. The monopolist firm $M$ maximizes the following objective function $I M^{M}$, subject to $V_{i}\left(x_{i}\right) \geq 0$, to solve the respective (2n) necessary conditions for the set of $n$ prices, and for the set of $n$ centralized quality levels: $\max \Pi^{M}=\max \sum_{i=1}^{n} \pi_{i}\left(p_{1}{ }^{M}, \ldots, p_{n}{ }^{M} ; a_{1}{ }^{M}, \ldots, a_{n}{ }^{M}\right)=$ 
$\sum_{i=1}^{n}\left(p_{i}{ }^{M}-c\right) \frac{N}{L}\left[\frac{\left(p_{i+1}{ }^{M}-a_{i+1}{ }^{M}\right)-2\left(p_{i}{ }^{M}-a_{i}{ }^{M}\right)+\left(p_{i-1}{ }^{M}-a_{i-1}{ }^{M}\right)}{2 t L / n}+\frac{L}{n}\right]-\frac{1}{2} \sum_{i=1}^{n}\left(a_{i}{ }^{M}\right)^{2}-n f$

It can be shown that the Kuhn-Tucker optimal (corner) solution of the monopolist's symmetric prices $p_{l}{ }^{M}=\ldots=p_{n}{ }^{M} \equiv p^{M}$, and the symmetric quality levels $a_{l}{ }^{M}=\ldots=a_{n}{ }^{M}$ $\equiv a^{M}$, may be written as the following set of equations:

$p^{M}=y+\frac{N}{n}-\frac{\left(t L^{2}\right)}{4 n^{2}} ; \quad a^{M}=\frac{N}{n}$

Since the monopolist's price-quality solution, (3.31) is a function of a consumer's income $y$, or the "reservation price" of an individual's inelastic demand curve, the following condition on $y$ must be met as consumers are assumed to possess sufficient income to purchase one unit of their preferred product variant:

$y>\frac{\left(t L^{2}-2 n N\right)}{4 n}$

The numerical solution of a price-quality, product-differentiated monopolist is determined for a particular value of $n$, the number of product brands or firms it owns, and parameter values, $t, L$, and $N$.

A couple of numerical values for consumers' income $y$ are chosen to display the potential monopoly price-quality optimum solutions to determine the total welfare effects on an economy for a multi-product firm $M$ that is a sole producer of a set of $n$-variants. The following Tables 3.6 and 3.7, indicate the numerical simulation results of a 
monopolist who owns four firms, and six firms, respectively. The parameter values of $N$ $=L=2$ and $t=6$, are used for the four-firm monopolist, while the values of $N=L=2$ and $t=7$, are used for the six-firm monopolist. For each of the monopoly examples, the numerical values are calculated for two particular values of consumers' income, denoted by $y^{l}$ and $y^{2}$, respectively, are chosen to determine the monopolist's optimal solution of prices, qualities and total profit.

Table 3.6: The Total Welfare Numerical Results of a Four-Firm Monopolist $(\mathrm{n}=4)$ and $\mathrm{N}=\mathrm{L}=2$ for $\mathrm{t}=6$

\begin{tabular}{|c|c|c|}
\hline$(\mathrm{t}=6) \quad \mathrm{p}^{*}=1.50$ & $\pi^{*}=0.625-\mathrm{f}$ & $2 y-2.25 P^{*}=2.50-4 f$ \\
\hline $\mathrm{y}^{1}=2.0$ & \multicolumn{2}{|l|}{$y^{2}=3.5$} \\
\hline \multicolumn{2}{|l|}{$\overline{p^{M}\left(y^{1}, t=6\right)=2.125}$} & $\pi^{\mathrm{M}}\left(\mathrm{y}^{1}, \mathrm{t}=6\right)=3.75-4 \mathrm{f}$ \\
\hline \multicolumn{2}{|l|}{$\mathrm{p}^{\mathrm{M}}\left(\mathrm{y}^{2}, \mathrm{t}=6\right)=3.625$} & $\pi^{\mathrm{M}}\left(\mathrm{y}^{2}, \mathrm{t}=6\right)=6.75-4 \mathrm{f}$ \\
\hline \multicolumn{2}{|c|}{$\operatorname{CS}\left(y^{1}, t=6\right)=2 y^{1}-3.5=0.5>0$} & $4.25-4 \mathrm{f}>0$ \\
\hline $\operatorname{CS}\left(y^{2}, t=6\right)=2 y^{2}-6.5=0.5>0$ & $5=0.5>0$ & $7.25-4 f>0$ \\
\hline$\Delta\left(\mathrm{CS}, \mathrm{y}^{1}, \mathrm{t}=6\right)=-1.25$ & $\Delta\left(\mathrm{PS}, \mathrm{y}^{1}, \mathrm{t}=6\right)=1.25$ & $\Delta\left(\mathrm{TW}, \mathrm{y}^{1}, \mathrm{t}=6\right)=0$ \\
\hline$\Delta\left(\mathrm{CS}, \mathrm{y}^{2}, \mathrm{t}=6\right)=-4.25$ & $\Delta\left(\mathrm{PS}, \mathrm{y}^{2}, \mathrm{t}=6\right)=4.25$ & $\Delta\left(\mathrm{TW}, \mathrm{y}^{2}, \mathrm{t}=6\right)=0$ \\
\hline
\end{tabular}

A monopolist which produces four product variants sets both higher prices, and higher quality levels than a two-neighbour merged firm $M$ with two single-product rivals, given a high level of consumers' willingness-to-pay [for comparison, see Table 3.3]. The monopoly profit under these same conditions, increases as the unit transport cost increases. Thus, an incentive exists for a monopoly market structure to develop in an industry consisting of four firms, since the monopoly profit realized is significantly greater than that of two-neighbour firm merger with two single-product competitors. For 
a given $t=6$, the total welfare effect on an economy remains unchanged since $\Delta(T W)=0$, but the monopolist gains a greater share of surplus if $y$ is higher. In either the pre-merger industry or the "post-merger" (monopoly) industry, both the symmetric quality levels, and the transport costs borne by consumers are numerically equivalent. Under a monopoly market strúcture, the transport costs incurred by consumers are equivalent to $\left(-t L^{2} N / 12 n^{2}\right.$ $=-0.25)$ are less than the transport costs borne by consumers purchasing variants from a two-firm merger, two single-product competitor market, given $t=6$.

\section{Table 3.7: The Total Welfare Numerical Results of a Six-Firm Monopolist}

$(\mathrm{n}=6)$ and $\mathrm{N}=\mathrm{L}=2$ for $\mathrm{t}=7$

\begin{tabular}{lcc}
\hline$(\mathrm{t}=7) \quad \mathrm{p}^{*}=0.77$ & $\mathrm{a}^{*}=0.33$ & $\pi^{*}=0.204-\mathrm{f} \mathrm{CS}^{*}=2 \mathrm{y}-1.009$ PS* \\
\hline \hline $\mathrm{y}^{1}=4.0$ & $\mathrm{y}^{2}=5.0$ & \\
\hline $\mathrm{p}^{\mathrm{M}}\left(\mathrm{y}^{1}, \mathrm{t}=7\right)=4.1388$ & $\mathrm{a}^{\mathrm{M}}\left(\mathrm{y}^{1}, \mathrm{t}=7\right)=0.33-6 f$ \\
$\mathrm{p}^{\mathrm{M}}\left(\mathrm{y}^{2}, \mathrm{t}=7\right)=5.1388$ & $\mathrm{a}^{\mathrm{M}}\left(\mathrm{y}^{2}, \mathrm{t}=7\right)=0.33$ & $\pi^{\mathrm{M}}\left(\mathrm{y}^{1}, \mathrm{t}=7\right)=7.944-6 \mathrm{f}$ \\
$\mathrm{CS}\left(\mathrm{y}^{1}, \mathrm{t}=7\right)=2 \mathrm{y}^{1}-3.935=4.065>0$ & $\pi^{\mathrm{M}}\left(\mathrm{y}^{2}, \mathrm{t}=7\right)=9.944-6 \mathrm{f}$ \\
$\mathrm{CS}\left(\mathrm{y}^{2}, \mathrm{t}=7\right)=2 \mathrm{y}^{2}-4.935=5.065>0$ & $\mathrm{TW}\left(\mathrm{y}^{1}, \mathrm{t}=7\right)=12.009-6 \mathrm{f}>0$ \\
$\Delta\left(\mathrm{CS}, \mathrm{y}^{1}, \mathrm{t}=7\right)=-2.9262$ & $\Delta\left(\mathrm{PS}, \mathrm{y}^{1}, \mathrm{t}=7\right)=6.722$ & $\mathrm{TW}\left(\mathrm{y}^{2}, \mathrm{t}=7\right)=15.009-6 \mathrm{f}>0$ \\
$\Delta\left(\mathrm{CS}, \mathrm{y}^{2}, \mathrm{t}=7\right)=-3.9262$ & $\Delta\left(\mathrm{PS}, \mathrm{y}^{2}, \mathrm{t}=7\right)=8.722$ & $\Delta\left(\mathrm{TW}, \mathrm{y}^{1}, \mathrm{t}=7\right)=+3.796>0$ \\
\hline
\end{tabular}

For a monopolist that owns six firms, and if consumers' income is either a low, or a high level, then the price $p^{M}$, and the quality level $a^{M}$ are both higher than that set by the bi-variant (centralized) merged firm $M$ with four single-product rivals [see Table 3.4 for comparison]. This monopolist producing six product variants has a socially efficient effect on the economy as $\Delta(T W)>0$ for any value of the estimated $y$. Although the same monopolist serving consumers with six product brands does gain a greater profit than all 
producers under a two-firm with four competitors market structure, the change in the consumers' surplus loss is significantly less [see Table 3.4]. The monopolist's consumers incur a lower aggregate traveling cost $(-t / 54)$ to purchase these significantly higher, identically priced brands with the higher quality level, but they purchase a lower aggregate quantity of all product varieties from the monopolist. Both the market, and consumers' surplus losses are proportionately less if six firms operated within a monopolistic industry. However, the monopolist gains a significant portion of $C S$ and a much higher $P S$ since the $\Delta(T W)>0$ is greater if consumers' possess a significantly higher reservation price $y$.

Since the spatial model considers only $n$-neighbour firms that are profitable, such a merger leads to an overall increase in the aggregate profit of the industry. As the $n$ neighbour firm merger is profitable in the spatial model and it improves the overall profitability of the industry, then an n-neighbour firm merger would be socially efficient as long as the gains to total welfare are positive. Although the consumer demand function is perfectly inelastic, a change in price due to a merger serves not only to redistribute the total welfare of the economy but is also a potential source of deadweight welfare loss. With an asymmetric price-quality strategy, deadweight welfare loss arises both from the distortions in the quality levels, and the higher transport costs incurred by consumers. For example, the numerical simulation model results indicate all mergers are socially inefficient, since $\Delta(T W)<0$. Thus, the negative change in total surplus is not just simply a transfer of consumers' surplus to producers' surplus since $\Delta(C S)<0$ and $\Delta(P S)$ $>0$, but also includes the effects of higher transport costs and the distortion in quality 
levels.

Thus, in the Nash price-quality merger model, the presence of a multi-product firm $M$ only serves to exert greater control, or market power over all variants. This evidence is even greater if the multi-product firm $M$ acts as a monopolist that owns all firms within an industry. Under Nash price-quality behaviour, it is the sole reason why such a merger is potentially profitable for the merged firm $M$, and therefore, it is also the reason why aggregate post-merger profits, and total producers' surplus in the industry, more than proportionately increase. Otherwise, an n-firm, non-neighbour merger is not profitable [see proof in Appendix (I): Chapter 3].

\subsection{SUMMARY AND POLICY IMPLICATIONS}

The circular (spatial) game-theoretic model in this chapter is based on a multiproduct firm, $M$, whose variants are both horizontally and vertically differentiated, and it competes simultaneously in both prices and qualities, against $q$ outside competitors, each of whom produces a horizontally, and vertically differentiated variant. The symmetric Nash equilibrium price-quality outcome is a result of a single, two-neighbour firm merger and $q \geq 2$ outside competitors. The asymmetric Nash equilibrium price-quality outcome is a consequence of a corporate merger comprised of $n \geq 3$ member firms which coordinates its post-merger activities to optimally exploit its members' market positions with $q \geq 2$ outside competitors, and to balance its "internal" competition amongst the set of core members having identical market shares.

The asymmetric nature of the post-merger equilibrium produces a simultaneous "symmetric cascading effect" on both the prices and the qualities of the multi-variants 
offered for sale in markets controlled by the corporate entity, $M$. The lowest prices and qualities are set by the pair of peripheral member firms while the highest price and quality are set by the central core member(s). A similar "reverse cascading effect" affects the post-merger equilibrium prices, and qualities set by the set of $q$ outside competitor firms. For those firms with the largest market area who benefit from being situated next-door on either side of $M$ 's joint market area, their price and quality level are the highest among all independent single-product producers, while the central outside firm(s) physically located the furthest from $M$, possessing the smallest market shares, set the smallest price, and quality level. Although initial positions of all $(n+q)$ product variants are fixed and symmetrically distributed about $C$, the asymmetric equilibrium price-quality outcome wields significant, (both positive and negative) market power on some physicallyconnected market segments. Such market power is derived from the very nature of localized competition where products differentiated by both price and quality, compete directly only with their nearest neighbours. The presence of a multi-product firm $M$ only serves to exert greater control, or market power over all variants.

An n-neighbour firm merger, by combining the assets of the n-neighbours, leads to a physically larger (connected neighbouring markets) firm than any of the $n$ firms were pre-merger. In contrast to an $n$-firm merger in the standard Bertrand oligopoly model, the n-neighbour firms are now competing across a set of spatially-connected markets, an $n$ firm merger in this context leads to a quite different outcome. The Bertrand-quality firms in a spatial model choose not only the quantity of output to supply the spatially differentiated markets, but they must also choose among their $n$-spatially connected firms 
where to produce the set of $n$-product variants.

Horizontal mergers in spatially differentiated markets necessarily bring about the redesign of the total product since the quality levels are altered, which may, or may not serve the total market in a more efficient manner. The symmetric pre-merger pricequality equilibrium implies identical horizontal and vertical characteristics for a given set of $n$ product variants. For the same, fixed number of variants, the benefits to consumers, if any, under an $n$-firm merger for the set of "new" product variants may not be sufficient to offset the price-increasing and quality-decreasing effects of the reduction in competitive pressures in the local markets to which the merger gives rise. These same post-merger $n$ product variants each acquire a "new" vertical component. As a result, the merger does reduce consumers' surplus. However, as the model is confined to profitable mergers, and both the merged and non-merged firms benefit financially from the merger, if a profitable two-or-more neighbour firm merger decreases total surplus it is said to be (socially) inefficient.

Another aspect of these types of mergers concerns strategies aimed at either eliminating one or more product variants through the divestiture, or the shut-down of member-firms. Although it is assumed within the Nash model that no plant shut-downs occur, the direct post-merger effects of such policies, and the consequences of shedding one or more product variants from an extensive product line $(n \geq 7)$ may be explained in the context of the n-neighbour firm Nash price-quality merger model. If the corporate authority of a multi-product firm $M$ decides to withdraw one or more brands from its product line, the computation of a new Nash price-quality equilibrium would be 
necessary to provide a formal analysis of the equilibrium outcome on prices, quality levels, and firm-member profits. The following discussion therefore gives an heuristic approach to such a potential strategy.

For example, each of the member-firms of the multi-product firm $M$ are subject to a constraint aimed at recovering an avoidable cost $f$. Suppose that $f$ lies between the postmerger profits of the single-product competitor firms, $\pi_{n+1}{ }^{F}=\pi_{n \div q}{ }^{F}$, and the multiproduct firm $M$ 's average profit, $\pi_{a v e}{ }^{M}$, that is, $\pi_{n+1}{ }^{F}<f<\pi_{a v e}{ }^{M}$. In this particular case, the multi-product firm $M(n \geq 7)$, as a single joint firm, is the only one able to effectively recover its total fixed costs, $n f$. However, at least two of $M$ 's member-firms are now not in a position to recover its individual fixed $\operatorname{cost} f$. The lowest profit accrues to the symmetric member firms, $\pi_{3}^{M}=\pi_{n-2}{ }^{M}$ located nearest to the pair of peripheral memberfirms (highest profit) $\pi_{l}^{M}=\pi_{n}^{M}$. These particular firms represent possible candidates for the elimination of two (symmetric) product brands from the original product line. Such a strategy requires a careful examination of the possible consequences, or "trade-offs" that face the multi-product firm $M$ in its decision.

Suppose that the corporate authority of a multi-product firm decides to sell the two member firms having the lowest post-merger profit located at $x_{3}$ and $x_{n-2}$, respectively. The "new" price-quality (and thus profit) effects of such a move depend on the number of original product variants. If the old product line consisted of seven brands then three sets of "new" prices and qualities would need to be determined for the remaining five products. With the elimination of the two symmetrically-located firms at $x_{3}$ and $x_{5}$, respectively, the corporate authority of the merged firm $M$ may need to set 
lower prices and/or higher quality levels for both these two symmetric variants in order to attract and maintain consumers. Consumers now have fewer product choices and now find it increasingly difficult to match their particular product preferences (i.e., they incur greater transport costs to purchase a product brand). The "new" lower prices and/or higher qualities, (and thus profit) would need to be weighted against the savings in fixed costs, $2 f$, that would arise as a result of the deletion of these two products. The highest profit would now accrue to the inner member firm. With an original product line of eight or more variants, it seems apparent that the multi-product firm $M$ would be able to buildup an isolated set of inner core member firms culminating with a global maximum profit for those firm(s) located at the physical center of the joint market area. It is difficult, $a$ priori, to know the exact price-quality pattern of the "new" product line without calculating a "new" Nash price-quality equilibrium, i.e., the maximization of joint profit subject to the elimination of these two member-firms.

There are other potential candidate firms for elimination if, for example, the equilibrium outcome of the strategy set by the corporate authority of the multi-product firm $M$ to maximize joint profit creates a "symmetric" set of two product lines. Suppose that the intent multi-product firm $M$ is to divest itself of those centrally-located inner firm(s) which originally contributed the locally maximal profit. There now would be at least one variant deleted from the original product line and the corporate authority of the multi-product firm $M$ again faces the same issues as described in the previous example in order to choose a set of "new" symmetric prices and qualities for their nearest two symmetrically-located interior firms. Consumers now must travel in either direction to 
purchase their preferred product variant, that is, to those firms immediately located nearest the two "symmetric" product lines. The "new" pattern of the price-quality policy set by the firm $M$ may appear to be "skewed" whereby the prices and qualities grow progressively higher as one moves from the outer-most periphery market area located near single-product rivals, to the two interior member-firms faced with an expanded market area. The "symmetric" global maximum profit of the firm(s) for the two product lines would now not necessarily arise at a centrally-located firm(s), as it would now depend on the remaining number of brands in each set of "symmetric" product variants. The "symmetric" highest profit would most likely accrue to the pair of member-firms located nearer to the two interior member-firms. Again, a new Nash price-quality equilibrium would need to be computed to determine the profit equilibrium trade-off between maintaining or eliminating the product brand(s), and the post-merger anticompetitive effects of such a merger configuration.

Canadian anti-trust policy-makers' concern over the unilateral anti-competitive effects of horizontal mergers has no doubt been motivated not only by the substantial increase in the number of pre-merger filings over the past decade, but by the type of differentiated products and concentration of product market areas. Thus, it is clearly important to the decision makers at the Canadian Competition Bureau to understand what market forces underlie this surge in merger activity, for only then can they evaluate the likely impact mergers will have in current and future markets. The spatial (circular) model has attempted to show how both a horizontally, and a vertically differentiated merger confers profitable advantages to firms who compete in both prices and qualities 
across a set of spatially-connected markets. The spatial characteristics of competition are critically important because it provides a manner in which a horizontal merger can, by combining the assets of two-or-more neighbour-firms, commit to being a "bigger" firm serving a vast, physically-connected market area. The model has shown that the merged firm $M$ is "bigger" not only in terms of total market share relative to its non-merged rivals, but also under what conditions such n-neighbour firms are profitable and therefore, can be expected to occur. They are as a result, likely to occur in industries that are relatively physically concentrated in geographical space. 


\section{CHAPTER 4: STACKELBERG PRICE-QUALITY SPATIAL MERGER}

\section{MODELS}

\subsection{AN INTRODUCTION TO STACKELBERG PRICE-QUALITY LEADERSHIP}

This chapter examines Stackelberg price-quality leadership in a spatially competitive model with a finite number $(n \geq 4)$ of firms on a circular structure, $C$. In the circular model of spatial competition under simultaneous price-quality Nash behaviour, firms had an incentive to merge if and only if they were next-door neighbours. The incentive to merge is absent if two parties to a merger are separated by at least one outside competitor firm when joint profits are maximized in a simultaneous Nash pricequality manner [see proof in Appendix(I): Chapter 3].

A natural question arises as to whether or not other types of game-theoretic behaviour might induce firms to merge when the (fixed) firm site configuration is that of either non-neighbours, or nearest neighbours. Under the Nash price-quality equilibrium, a merger of two or more firms makes a difference to post-merger prices and quality levels of the multi-product variants only if the merging firms are nearest neighbours. In this chapter we show that with Stackelberg price-quality leadership, a merger of two or more firms makes a difference to post-merger prices and quality levels of the multi-product variants even if the firms are not nearest neighbours. This chapter first analyzes the Stackelberg price-quality leadership model of two, non-neighbour merging firms, while the second part presents a merger model of n-neighbour firms with Stackelberg pricequality leadership behaviour. For the generalized model, the Stackelberg leader assigns the decision to choose the quality levels of the product variants to its member firms. The 
member firms each act independently in their choice of the quality level for its own product brand.

The Nash decentralized price-quality merger model demonstrated that two-ormore merging firms that act under Nash behaviour increase prices and decrease quality levels of their jointly produced multi-variants relative to the pure Nash oligopoly (n-firm) equilibrium if and only if the firms are nearest neighbours. Hence, the joint profits of two-or-more neighbouring firms are greater than the profits that would accrue if each of these neighbouring firms acted alone. Furthermore, if $n+q \geq 5$, then the "free-rider" problem is absent. Such an equilibrium result occurs because the firms realize that they can jointly increase prices and increase quality levels without losing any consumers between them, and this provides the incentive to merge. However, if the merging firms are physically separated by one or more firms, this incentive is absent. The incentive to merge under Nash behaviour is absent since the two non-neighbouring firms do not gain a joint higher market share for their bi-variants. Their optimal price-quality best-response leaves them with a joint post-merger profit level identical to that of what two individual firms would earn at the pre-merger profit level.

The results of this chapter demonstrate that for two, non-neighbouring merging firms $(n \geq 6)$ that jointly act as a Stackelberg price-quality leader symmetrically increase the prices, and decrease the symmetric quality levels of their bi-variants, even if they are physically separated, because they take into account the fact that each firm, by increasing the prices and decreasing the qualities, benefits itself and its partner by inducing the competitor-follower firm between them to increase the price and quality level of its 
single-product variant, relative to the pre-merger equilibrium. The Stackelberg leader gains a significantly higher (joint) market share by moving first. The Stackelberg firm $M$ believes that the physically isolated competitor, as well as the other follower firms, will respond to any initial price-quality decision with an immediate switch to an optimal response. The Nash merging firms do not take this type of response by other firms into account.

A comparison of the Stackelberg price-quality equilibrium outcome with the Nash price-quality equilibrium of a two-firm (neighbour) merger shows that the higher prices, and the higher quality levels, result in proportionately greater joint market shares and thus, significantly higher joint profits. Changes in business and market conditions within certain industries may require such an immediate type of first-mover behaviour to take advantage of current opportunities, and to reap gains to stakeholders and stockholders alike. If one is in a "parade" of some sort, it is best to lead it!

The second section gives the description of the game-theoretic structure of the two-firm, non-neighbour merger model while the following section provides a formal definition of the Stackelberg price-quality leader-follower game $\Gamma^{S}$ between $q+1$ players. The third section continues with the formal, two-stage mathematical optimization models consisting of a system of $[4+2 q]$ linear recursive nonhomogeneous price-quality difference equations for the bi-variant product merged firm $M$, the leader, and the $q$, competitor-rival firms, or followers, respectively. This leads to the two-stage solution, and the characterization of the existence, and uniqueness of the Stackelberg price-quality equilibrium, for a two-firm, non-neighbour merger for each of $q$ 
$=2,3$, and 4 , number of competitor-follower firms, and all firms have fixed, symmetric firm site locations.

The fourth section provides an analysis of the Stackelberg equilibrium outcome for prices, quality levels, and profit shares of all post-merger industry firms. The analysis is further illustrated by the numerical simulation welfare results of the Stackelberg pricequality equilibrium outcome, for each case of $q=2,3$, and 4 number of follower firms. The numerical simulation welfare results are measured relative to the symmetric premerger Nash price-quality equilibrium outcome established for an $n$-firm oligopoly. The Stackelberg firm $M$, at equilibrium, sets a symmetric price-quality policy (centralized quality levels), for its two product variants such that prices are higher while qualities are lower than the post-merger prices and qualities chosen by its outside competitors, if the total number of pre-merger industry firms is $n \geq 6$. For the case of two post-merger competitors, $n+q=4$, the Stackelberg leader chooses, in equilibrium, a symmetric price, and a decentralized quality for its two variants that is less than that chosen by the two follower firms. Furthermore, if there are $q=2$ or 3 follower firms, the highest price and quality level is set by the isolated competitor-follower located between the Stackelberg leader's two locally monopolistic market areas, and for all the other follower firms, prices and quality levels symmetrically decline for all pairwise non-merged firms located equi-distantly on either side of the Stackelberg firm $M$, with the lowest price and quality level for that follower firm's single-product variant located furthest in distance from the merged firm $M$. The numerical simulations show that a two-firm, nonneighbour Stackelberg price-quality merger increases the post-merger profits of all firms 
such that the Stackelberg leader $M$ attains the highest share while the isolated competitorfollower gains the second highest profit level. The post-merger profits for all other follower firms symmetrically decline for all pairwise non-merged firms situated at equidistant locations from the symmetric peripheral market areas of the Stackelberg firm, $M$.

The second model, presented in the fifth section, describes the game-theoretic structure of an n-neighbour firm Stackelberg merger. The Stackelberg price-quality leader-follower game $\Gamma^{s}$ is between $q+1$ players, where the n-neighbour firms merge to compete in prices and decentralized qualities, as a single leader against $q$, single-product follower firms. The section continues with the two-stage, mathematical optimization models where each stage consists of a system of $(2 n+2 q)$ linear, recursive, nonhomogeneous price-quality difference equations of the multi-product firm $M$, the leader, and the $q$, single-product competitors, or followers, respectively. The method of backward induction leads to the two-stage solution, and the characterization of the existence, and uniqueness of the Stackelberg price-quality equilibrium, of an n-neighbour firm merger with q competitor-follower firms.

The Stackelberg firm $M$, at equilibrium, chooses an asymmetric price-quality strategy for its $n$ product variants. The post-merger prices and decentralized quality levels are both higher than the post-merger prices and quality levels chosen by all the followers, and are both higher than the post-merger prices and quality levels set by the same multi-product firm under Nash behaviour. The pattern of the Stackelberg pricequality equilibrium outcome is supported by the numerical simulation results presented in the sixth section, for the case of an $(n=2)$ neighbour firm merger with $q=4$ follower 
firms. The highest post-merger price, and quality level set by the follower-competitors symmetrically located nearest to the multi-product leader, firm $M$. For all other rival nonmerged firms, prices and quality levels symmetrically decline for all the pairwise follower firms located equi-distantly on either side of the first set of competitor-followers located nearest to the Stackelberg firm $M$. The numerical simulation results show that a twoneighbour Stackelberg firm merger increases the post-merger profits of all firms such that the leader, firm $M$, captures the highest share while the (pairwise) followers situated the furthest in distance from the merger, gain the least.

Von Stackelberg (1934) analyzes both price leadership and quantity leadership in a standard duopoly model. Deneckere and Davidson (1985) examine merger activity in a symmetric product differentiated industry (standard oligopoly model) without price leadership, whereas the model in this chapter examines merger activity in a spatial product differentiated industry, with price-quality leadership.

Braid (1986) examines Stackelberg price leadership in a spatially competitive model with infinitely many firms on an infinite line. The locations of the firms are fixed, and the evenly distributed consumers with inelastic demand bear the linear transport costs of their preferred variant. Under Nash equilibrium, collusion of two firms makes a difference to prices only if the colluding firms are nearest neighbours. With Stackelberg price leadership, collusion makes a difference to prices even if the firms are separated by one follower firm. Collusion increases the profits of the colluding firms, but it increases the profits of its nearest neighbours even more. An analysis of more than two firms colluding is absent, as is the anti-competitive effects of total welfare on an economy. 


\subsection{A DESCRIPTION OF THE GAME-THEORETIC STRUCTURE:}

\section{A STACKELBERG PRICE-QUALITY NON-NEIGHBOUR MERGER}

Suppose that the industrial market structure consists of a total number of $n \geq 4$ pre-merger firms symmetrically located at $x_{i}, x_{2}, \ldots, x_{i-1}, x_{i}, x_{i-1}, \ldots, x_{n}$, around a circle $C$ of length, or circumference $L$. Each of the $j \in\{1, \ldots, n\}$ firms produces and offers in their respective markets a single product variant. The $n$ horizontally differentiated variants that are also vertically differentiated (by quality), are equally spaced about $C$, where the distance or arc length between two successive variants (or firms) is $L / n$. The firms or product variants are indexed by location on $C$ by $x_{j}$ where $x_{j}=(j-1) L / n$ for the $j=1,2, \ldots, n$ firms. By convention, the variant labeling proceeds in a (positive) clockwise-manner starting with variant $j$, situated at the 12 o'clock position on $C$.

The set of consumers $N$, is uniformly distributed along the circle's perimeter with a density of $N / L$. Suppose that there is a merger between two non-neighbouring firms situated at $x_{i}$ and $x_{i+2}$, on $C$, where there is one outside competitor-follower firm, $x_{i 1 l}$, separating the two parties to a merger. The remaining $(n-2)$, or $q$ follower firms located at $x_{1}, x_{2}, \ldots, x_{i-1}, x_{i+1}, x_{i, 3}, \ldots, x_{n}$, on $C$ remain outside to the merger

In the Stackelberg game model, the merged entity $M=\{i, i+2\}$ acts as the leader, by deciding first as to the choices of prices and the choice of qualities of its two product variants to the two member firms, after viewing the price-quality choices made by the $q$ single-product follower firms. The $q$ competitor-follower firms each observe the merged entity's price and quality decision, and then each of the follower, single-product firms individually and simultaneously decides on a price and quality for its single product 
variant. In the two-firm, non-neighbour Stackelberg price-quality game, the sequence of moves are known and assumed by both the merged firm $M$, and the remaining $(n-2)$, or $q$, non-merged firms.

The Figure 4.1 illustrates the industrial and firm market structure of a single, bivariant product firm $M=\{i, i+2\}$, and the associated set $F=\{1,2, i-1, i+1, i+3, \ldots, n\}$ of single-product variant firms consisting of the $q \geq 4$ outside followers, or non-merged firms. The existence of a pure strategy Stackelberg price-quality equilibrium depends on the assumption that at least $n \geq 4$ pre-merger firms participate in the game. The firm $M$ controls a non-connected market area, or a portion of $C$ comprised of two disjoint arcs of total length $2 L / n$ over its set of two product variants. Each of the follower firms has an identical market size of length $L / n$ over its single-product variant. The Stackelberg pricequality game is one between $1+q$ players: the merged firm $M$ and the $q$ follower firms, respectively, compete against each other in the prices and qualities of their variants.

\subsection{THE STACKELBERG PRICE-QUALITY GAME AND MERGER EQUILIBRIUM OUTCOME: TWO NON-NEIGHBOURS}

This section contains the main existence and uniqueness results of the Stackelberg price-quality game $\Gamma^{S}$. The Stackelberg equilibrium outcome for the post-merger prices, quality levels, market shares, and the profit levels of all firms within the structure of the post-merger industry are described with respect to the number of $q=2,3$, and 4 followercompetitors for a two-firm non-neighbour merger. The corporate authority of the centralized Stackelberg leader, firm $M$, takes the followers' price-quality decision into consideration when it maximizes joint profit with respect to the prices and qualities of its 


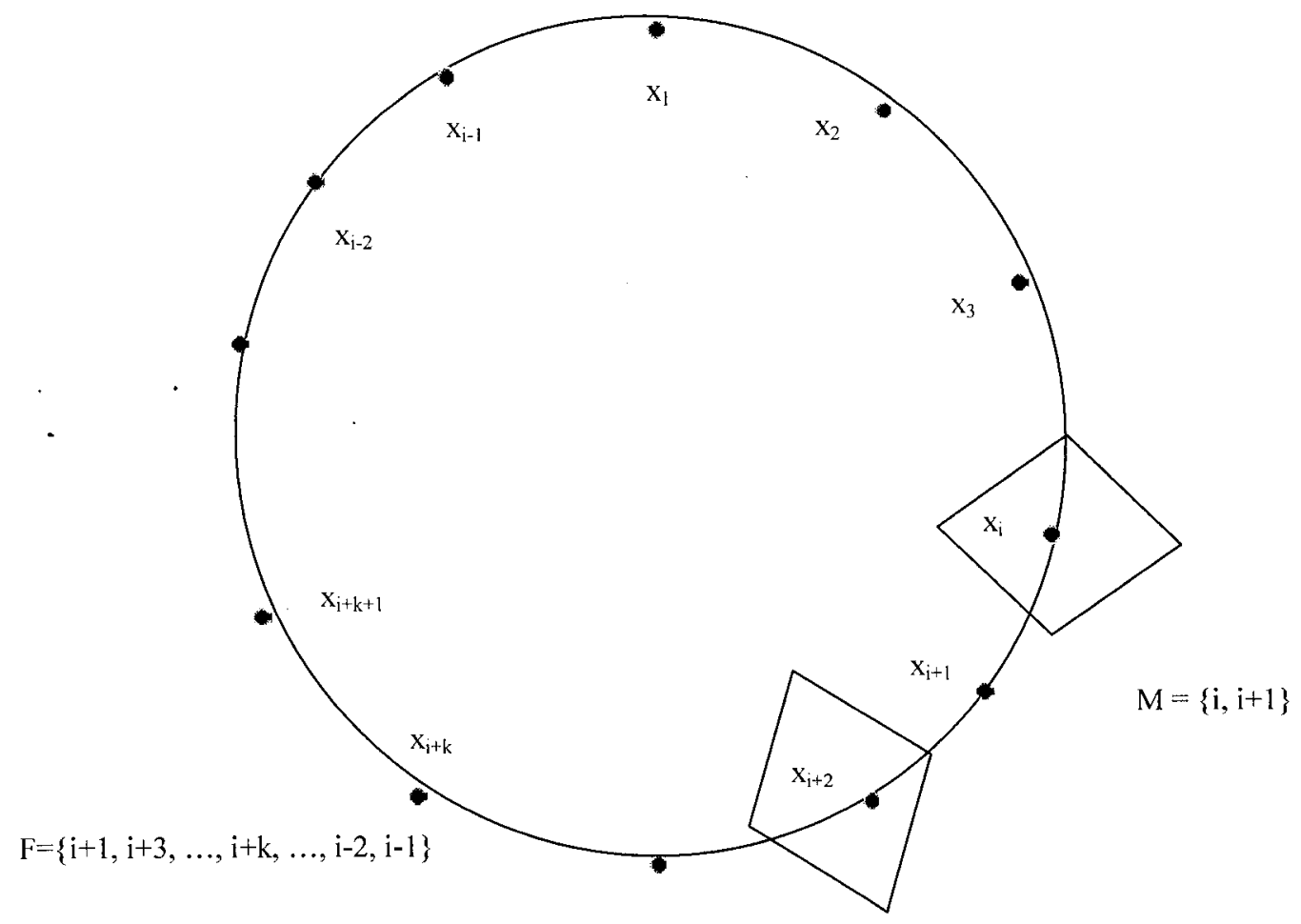

Figure 4.1: The circular industrial structure under a Stackelberg merger 
two variants. The Stackelberg leader sets, in equilibrium, a symmetric price-quality strategy for its two product variants.

To determine the potential for post-merger anti-competitive effects of a single, two non-neighbour firm merger, i.e., when the merged firm consists of two firms physically separated by at least one outside follower firm, it is assumed that the newly merged entity continues to operate from both locations and that both firms share postmerger profits equally. It is also assumed that there is no deletion from production of one of the two product variants, or a single plant shut-down.

The description of the Stackelberg price-quality game $\Gamma^{S}$ :

The Stackelberg leader, firm $M$ : Let $p^{M}=\left\{p_{i}^{M}, p_{i+2}{ }^{M}\right\}$ denote the price vector of the bi-variant product firm $M=\{i, i+2\}$, and let $a^{M}=\left\{a_{i}^{M}, a_{i+2}{ }^{M}\right\}$ denote the associated vector of quality levels. Also, let $X^{M}=\left\{X_{i}^{M}, X_{i+2}{ }^{M}\right\}$ denote the vector of consumers' demands that firm $M$ faces. The marginal production costs are a (constant) $c$ per unit of product variant and fixed quality costs per firm are set at $1 / 2\left(a_{i}^{M}\right)^{2}$ for firm $i$. Without loss of generality, let $p_{i}^{M}$ represent the price of variant $i$ net of marginal costs, $c$, so that the marginal costs are ignored for the sake of algebraic simplicity. The member firm $i$ contributes a (gross) of marginal costs, profit share of $\pi_{i}^{M}=\left(p_{i}^{M}\right) X_{i}^{M}-1 / 2\left(a_{i}^{M}\right)^{2}-f$, where $f$ denotes the (identical) fixed sunk costs associated with the firm location site. Similarly, $p_{i \cdot 2}{ }^{M}$ represents the price of variant $i+2$ net of marginal costs, $c$, and fixed quality costs are set at $1 / 2\left(a_{i}, 2^{M}\right)^{2}$ for firm $i+2$. Firm $i+2$ has a (gross) profit share of $\pi_{i, 2}{ }^{M}=\left(p_{i, 2}{ }^{M}\right) X_{i, 2}{ }^{M}-1 / 2\left(a_{i, 2}{ }^{M}\right)^{2}-f$. 
The merged entity $M$, acting in the role of a (Stackelberg) leader ${ }^{I}$, chooses prices $p^{M}$, and quality levels $a^{M}$, so as to maximize joint profits $\Pi_{M}^{S}=\Sigma_{i \in M} \pi_{i}^{M}($.$) , subject to the$ followers simultaneous choice of prices $\left\{p_{1}^{F}, p_{2}^{F}, \ldots, p_{i-1}^{l}, p_{i+1}^{F}, p_{i+3}{ }^{F}, \ldots, p_{n}^{F}\right\}$ and quality levels $\left\{a_{1}^{F}, a_{2}^{F}, \ldots, a_{i-1}^{F}, a_{i+1}^{F}, a_{i+3}^{F}, \ldots, a_{n}^{F}\right\}$ that are individually decided by each of the $q$ competitor-follower firms. The firm $M$ assumes that their strategic behaviour is reflected in the price-quality decisions made by each firm $k \in F$, where $k=\{1,2, \ldots, q\}$. The strategy spaces of the strategic variables $p^{M}$ and $a^{M}$ are given by the sets, $P^{M}=[0, y)^{2}$ and $A^{M}=[0, \infty)^{2}$, respectively. Thus, a joint pure strategy for firm $M$ is a price-quality pair $\left(p^{M}, a^{M}\right) \in\left\{[0, y)^{2} \times[0, \infty)^{2}\right\}$.

The outside competition $F$ : Let $p^{F}=\left\{p_{1}^{F}, p_{2}^{l}, \ldots, p_{i-1}^{F}, p_{i \cdot 1}^{F}, p_{i, 3}{ }^{l i}, \ldots, p_{n}^{l i}\right\}$ denote the price vector of the single product variants supplied by the $q$ follower firms while $a^{M}=$ $\left\{a_{1}^{F}, a_{2}^{F}, \ldots, a_{i-1}^{F}, a_{i \cdot 1}^{F}, a_{i, 3}^{F}, \ldots, a_{n}^{F}\right\}$ is the associated quality level vector of the single product variants for each firm $k \in F$. Each of the outside firms face individual consumer demands denoted by the vector $X^{I^{*}}=\left\{X_{1}^{F}, X_{2}^{F}, \ldots, X_{i-1}^{F}, X_{i+1}^{F}, X_{i \cdot 3}^{F}, \ldots, X_{n}^{F}\right\}$. The marginal production costs are a (constant) $c$ per unit of single product variant, and each firm $k \in F$ has a fixed quality cost of $1 / 2\left(a_{k}^{F}\right)^{2}$. Without loss of generality, let $p_{k}^{F}$ represent the price of variant $k$, net of marginal costs, $c$, for the sake of algebraic simplicity. Each follower firm $k \in F$ has a (gross) of marginal costs, profit function denoted by $\pi_{k}^{F^{*}}=\left(p_{k}^{F^{*}}\right) X_{k}^{l^{*}}-1 / 2\left(a_{k}^{I^{i}}\right)^{2}-$ $f$, where $f$ denotes the (identical) fixed sunk costs associated with the site location of each

This model's equilibrium outcome is not analogous to price leadership in a non-spatial oligopoly model. In the standard Bertrand oligopoly model, a price leader (or a group of firms acting as a leader) increases post-merger profits, but the remaining, or outside firms increase their profits even more, due to the spillover effect of the merger activity. 
firm. After each of the $q$ follower firms observes the price-quality decision made by the merged firm $M$, they each choose a pure strategy pair $\left(p_{k}{ }^{F}, a_{k}{ }^{F}\right)$ so as to maximize individual profits, $\pi_{k}^{F}($.$) . Each firm k \in F$ assumes that their strategic behaviour is not reflected in the price-quality pair decisions made by other follower member firms, but is dependent on the joint choice of $\left(p^{M}, a^{M}\right)$ made by the merged firm $M$. The strategy spaces of each follower firm $k \epsilon F$ of the strategic variables $p_{k}^{F}$ and $a_{k}^{F}$ are given by the sets, $P^{k}$ $=[0, y)$ and $A^{F}=[0, \infty)$, respectively.

A pure price strategy for each follower firm $k \in F$ is a function $f_{k}:[0, y) \rightarrow[0, y)$ and a pure quality strategy for each firm $k \in F$ is a function $g_{k}:[0, \infty) \rightarrow[0, \infty)$. When the merged entity $M$ chooses a pure strategy pair $\left(p^{M}, a^{M}\right)$, then the best replies by each follower firm $k \in F$ is $p_{k}{ }^{F}=f_{k}\left(p^{M}\right)$ and $a_{k}^{F}=g_{k}\left(a^{M}\right)$. All follower firms $k \in F$ each have unique best replies, $R_{f}^{p}\left(p^{M}\right) \forall p^{M}$ and $R_{f}^{a}\left(a^{M}\right) \forall a^{M}$. Thus, the optimal pure strategies are the functions $R_{f}:[0, y) \rightarrow[0, y)$ and $R_{f}:[0, \infty) \rightarrow[0, \infty)$. The merged firm $M$ knows that the outside competitive firms will choose $R_{f}^{p}$ and $R_{k}^{a}$, and hence anticipates a certain level of profit given by the reduced-form profit function: $\Pi_{M}^{S}\left(p^{M}, a^{M}, R_{f}^{p}\left(p^{M}\right), R_{f}^{a}\left(a^{M}\right)\right)$.

The strategic form of the game $\Gamma^{S}$ is a list of sets comprised of the players, pure strategies and payoffs, respectively. It may be formally stated as the following definition: Definition 1: The strategic form of the Stackelberg price-quality game is given as $\Gamma^{S}=<$ $(M, F),\left(p^{M}, a^{M} ; f_{k}, g_{k}\right), \pi_{k}^{F}, \Pi_{M}^{S}()>$..

The pre-merger industry consists of $n \geq 4$ firms located at $x_{1}, x_{2}, \ldots, x_{i-1}, x_{i}, x_{i-1}, \ldots$, $x_{n}$, on $C$, where $j \in\{1, \ldots, n\}$. Suppose that there is a merger between two nonneighbouring firms located at $x_{i}$ and $x_{i, 2}$, on $C$, respectively. The corporate authority of 
the merged entity $M$, acting as a leader, maximizes its joint profits $\Pi_{M}($. ) by choosing a set of prices $\left\{p_{i}^{M}, p_{i+2}{ }^{M}\right\}$, and a set of quality levels $\left\{a_{i}^{M}, a_{i+2}{ }^{M}\right\}$ for its two product variants, while it also takes into consideration the $q$ firms' (followers') independent, but simultaneous choice of prices $\left\{p_{l}^{F}, p_{2}^{F}, \ldots, p_{i-l}{ }^{F}, p_{i-1}{ }^{F}, p_{i+3}{ }^{F}, \ldots, p_{n}{ }^{F}\right\}$, and quality levels $\left\{a_{l}^{l^{F}}\right.$, $\left.a_{2}^{F}, \ldots, a_{i-1}{ }^{F}, a_{i, l}{ }^{F}, a_{i, 3}{ }^{F}, \ldots, a_{n}^{F}\right\}$, of their respective $q$ single-product variants.

The Stackelberg price-quality equilibrium of the circular game between the $q+1$ players, the leader, or the bi-variant firm $M$, and the set of $q$ competitive firms, or followers, is solved by using the backward induction method. Firstly, after viewing the simultaneous price-quality choice made by the corporate authority of firm $M$, each of the $q$ non-merged firms maximize their profits by simultaneously choosing a price and quality level for its single-product variant, taking as given the choices made by the corporate authority of the merged firm $M$, and all other competitor-follower firms. Secondly, the merged entity $M$, anticipating the price-quality decisions of the $q$ competitor firms, maximizes the joint profits of its two, non-neighbour firms by the simultaneous choice of prices and qualities of its two product variants.

\section{Best-Response Price and Quality Functions of the q Stackelberg Followers:}

The best-response price, and quality functions of the follower member firms are solved from the respective first-order conditions, and must be determined separately for those firms located at $x_{i \downarrow 1}, x_{i-3,}$, and for those firms located at $x_{i \downarrow \downarrow}, x_{i+1,}, \ldots, x_{i-2}$ on $C$, given $n \geq 4$ pre-merger firms. The mathematical optimization problem of the $(i+1)$-th firm is to choose the price $p_{i+1}{ }^{F}$, and the quality level $a_{i+l}{ }^{F}$, from the following profit function given by: 
$\max \pi_{i+1}^{F}=\left(p_{i+1}^{F}\right) \frac{N}{L}\left[\frac{\left(p_{i+2}^{M}-a_{i+2}^{M}\right)-2\left(p_{i+1}^{F}-a_{i+1}^{F}\right)+\left(p_{i}^{M}-a_{i}^{M}\right)}{2 t L / n}+\frac{L}{n}\right]-\frac{1}{2}\left(a_{i+1}^{F}\right)^{2}-f$

The first-order conditions determine the best-response functions $p_{i+1}{ }^{l}$ and $a_{i+1} l^{l}$, respectively, for the $(i+1)-t h$ firm and are given by the following expressions:

$p_{i+1}^{F}=\frac{t L^{2}\left(p_{i}^{M}-a_{i}^{M}\right)}{2\left(2 t L^{2}-n N\right)}+\frac{t L^{2}\left(p_{i+2}^{M}-a_{i+2}^{M}\right)}{2\left(2 t L^{2}-n N\right)}+\frac{\left(t L^{2}\right)^{2}}{n^{2}\left(2 t L^{2}-n N\right)} ; \quad a_{i+1}^{F}=\frac{n N}{t L^{2}}\left(p_{i+1}^{F}\right)$

The profit-maximization problem for the follower firm located at $x_{i+3}\left(\right.$ or $\left.x_{i-1}\right)$ is to simultaneously choose the price $p_{i+3}{ }^{F}$, and the quality level $a_{i+3}{ }^{F}$ that maximizes the following profit function:

$$
\max \pi_{i+3}^{F}=\left(p_{i+3}^{F}\right) \frac{N}{L}\left[\frac{\left(p_{i+4}^{F}-a_{i+4}^{F}\right)-2\left(p_{i+3}^{F}-a_{i+3}^{F}\right)+\left(p_{i+2}^{M}-a_{i+2}^{M}\right)}{2 t L / n}+\frac{L}{n}\right]-\frac{1}{2}\left(a_{i+3}^{F}\right)^{2}-f
$$

The first-order conditions of the price variable $p_{i, 3}{ }^{F}$, and the quality variable $a_{i, 3}{ }^{F}$, respectively, determine the following best-response functions given by the equations;

$$
p_{i+3}^{F}=\frac{t L^{2}\left(p_{i+2}^{M}-a_{i+2}^{M}\right)}{2\left(2 t L^{2}-n N\right)}+\frac{\left(t L^{2}-n N\right) p_{i+4}^{F}}{2\left(2 t L^{2}-n N\right)}+\frac{\left(t L^{2}\right)^{2}}{n^{2}\left(2 t L^{2}-n N\right)} ; \quad a_{i+3}^{F}=\frac{n N}{t L^{2}}\left(p_{i+3}^{F}\right)
$$

Finally, the remaining $k=4,5, \ldots, q$ or $(i-2)$ follower firms' price-quality best-response functions need to be determined. The best-response functions of the $(i+k)$-th firm are found by solving the two first-order conditions for the price variable $p_{i+k}{ }^{k}$, and the quality variable $a_{i+k}{ }^{F}$, respectively, from the following mathematical optimization problem (4.5): 
$\max \pi_{i+k}^{F}=\left(p_{i+k}^{F}\right) \frac{N}{L}\left[\frac{\left(p_{i+k+1}^{F}-a_{i+k+1}^{F}\right)-2\left(p_{i+k}^{F}-a_{i+k}^{F}\right)+\left(p_{i+k-1}^{F}-a_{i+k-1}^{F}\right)}{2 t L / n}+\frac{L}{n}\right]-\frac{1}{2}\left(a_{i+k}^{F}\right)^{2}-f$

The price-quality best-response functions for the $k=4, \ldots, q$ follower firms are given by the following expressions:

$$
p_{i+k}^{F}=\frac{\left(t L^{2}-n N\right) p_{i+k-1}^{F}}{2\left(2 t L^{2}-n N\right)}+\frac{\left(t L^{2}-n N\right) p_{i+k+1}^{F}}{2\left(2 t L^{2}-n N\right)}+\frac{\left(t L^{2}\right)^{2}}{n^{2}\left(2 t L^{2}-n N\right)} ; \quad a_{i+k}^{F}=\frac{n N}{t L^{2}}\left(p_{i+k}^{F}\right)
$$

Note that the best-response price function of the $(i+3)-t h$ firm, equation (4.4), is a function of $p_{i \perp t}{ }_{F}$. The second-stage price-quality equilibrium of the non-merged firms must be functions solely of the merged firm $M$ 's prices and qualities, in order to obtain the reduced-form profit function for firm $M$. The system of linear recursive nonhomogeneous difference equations must first be solved individually, for a given value of $n \geq 4$. Once this intermediate solution set for equations (4.2) to (4.4) is determined for a given value of $n$, the expressions for the follower firms' prices and qualities are then functions solely of the prices and qualities of the Stackelberg merged firm $M$.

\section{Best-Response Price-Quality Functions of the Stackelberg Leader:}

Suppose there is a merger between two, non-neighbouring firms located at $x_{i}$ and $x_{i, 2}$, respectively, on $C$. The merged firm $M$, acting as the Stackelberg leader, jointly maximizes its profit by choosing prices $\left\{p_{i}^{M}, p_{i+2}{ }^{M}\right\}$, and quality levels $\left\{a_{i}^{M}, a_{i+2}{ }^{M}\right\}$, subject to the price and quality choices made by the competitor firms, or the Stackelberg followers. Thus, the mathematical optimization problem for the Stackelberg firm $M$ is 
stated as the following:

$\max \Pi_{M}=\max \left(\pi_{i}^{M}+\pi_{i+2}^{M}\right)=$

$\left(p_{i}{ }^{M}\right) \frac{N}{L}\left[\frac{\left(p_{i+1}^{F}-a_{i+1}^{F}\right)-2\left(p_{i}{ }^{M}-a_{i}{ }^{M}\right)+\left(p_{i-1}^{F}-a_{i-1}^{F}\right)}{2 t L / n}+\frac{L}{n}\right]-\frac{1}{2}\left(a_{i}{ }^{M}\right)^{2}-f+$

$\left(p_{i+2}^{M}\right) \frac{N}{L}\left[\frac{\left(p_{i+3}^{F}-a_{i+3}^{F}\right)-2\left(p_{i+2}^{M}-a_{i+2}^{M}\right)+\left(p_{i-1}^{F}-a_{i-1}^{F}\right)}{2 t L / n}+\frac{L}{n}\right]-\frac{1}{2}\left(a_{i+2}^{M}\right)^{2}-f$

subject to $\left\{p_{i-1}{ }^{F}, p_{i+1}{ }^{F}, p_{i, 3}{ }^{F}\right\}$ and $\left\{a_{i-1}{ }^{F}, a_{i+1}{ }^{F}, a_{i 13}{ }^{F}\right\}$.

The firm M's reduced-form profit function is found by the substitution of the intermediate solution set for equations (4.2) to (4.4), the strategic price and quality variables of the followers, for a given value of $n \geq 4$. Once the Stackelberg leader's price-quality equilibrium is solved, for a given value of $n$, the $q$ followers' price-quality equilibrium may then be determined.

The following propositions characterize the Stackelberg price-quality equilibrium with respect to the particular cases of $n=4,5$ and 6 firms, respectively. The general solution of the Stackelberg model is difficult to solve mathematically, so the particular cases provided are for a two-firm non-neighbour merged firm with two, three, and four single-product Stackelberg followers, respectively.

\section{The Stackelberg Equilibrium of the Price-Quality Game $\Gamma^{s}$ :}

Proposition 4.1(A): The Stackelberg centralized equilibrium price-quality pairs of the game $\Gamma^{S}$ for the merged firm $M$, and for the follower-competitors, are given by the 
respective strategic variable solutions for the particular case of $n=4$.

1: The Stackelberg firm $M$

$$
p^{M}=\frac{\left(t L^{2}-2 N\right)\left(3 t L^{2}-8 N\right)}{32\left(t L^{2}-3 N\right)} ; \quad a^{M}=\frac{N\left(3 t L^{2}-8 N\right)}{16\left(t L^{2}-3 N\right)}
$$

2. The $q=2$ follower-competitor firms:

$$
p^{F}=\frac{t L^{2}\left(5 t L^{2}-8 N\right)}{64\left(t L^{2}-2 N\right)} ; \quad a^{F}=\frac{N\left(5 t L^{2}-8 N\right)}{16\left(t L^{2}-2 N\right)}
$$

Proof: see Appendix 4.A for the solutions of the individual cases for $n$.

Proposition 4.1(B): The Stackelberg centralized equilibrium price-quality pairs of the game $\Gamma^{S}$ for the merged firm $M$, and for the follower-competitors, are given by the respective strategic variable solutions for the particular case of $n=5$.

\section{The Stackelberg firm $M$ :}

$$
\begin{aligned}
& p^{M}=\frac{2\left(2 t L^{2}-5 N\right)\left(3 t L^{2}-5 N\right)\left[2\left(2 t L^{2}-N\right)\left(3 t L^{2}-5 N\right)+\left(t L^{2}-5 N\right)\left(7 t L^{2}-15 N\right)\right]}{25\left(7 t L^{2}-15 N\right)\left[4\left(2 t L^{2}-5 N\right)\left(3 t L^{2}-5 N\right)-5 N\left(7 t L^{2}-15 N\right)\right]} \\
& a^{M}=\frac{N\left[2\left(2 t L^{2}-5 N\right)\left(3 t L^{2}-5 N\right)+\left(t L^{2}-5 N\right)\left(7 t L^{2}-15 N\right)\right]}{5\left[4\left(2 t L^{2}-5 N\right)\left(3 t L^{2}-5 N\right)-5 N\left(7 t L^{2}-15 N\right)\right]}
\end{aligned}
$$

2. The $q=3$ follower-competitor firms:

$$
p_{k(1)}^{F}=\frac{\left(t L^{2}\right)^{2}}{25\left(2 t L^{2}-5 N\right)}+\frac{t L^{2}\left[2\left(2 t L^{2}-5 N\right)\left(3 t L^{2}-5 N\right)-5 N\left(7 t L^{2}-15 N\right)\right][u]}{25\left(2 t L^{2}-5 N\right)\left(7 t L^{2}-15 N\right)[l]}
$$




$$
\begin{aligned}
& a_{k(1)}^{F}=\frac{N t L^{2}}{5\left(2 t L^{2}-5 N\right)}+\frac{N\left[2\left(2 t L^{2}-5 N\right)\left(3 t L^{2}-5 N\right)-5 N\left(7 t L^{2}-15 N\right)\right][u]}{5\left(2 t L^{2}-5 N\right)\left(7 t L^{2}-15 N\right)[l]} \\
& p_{k(2)}^{F}=\frac{2\left(t L^{2}\right)^{2}}{25\left(3 t L^{2}-5 N\right)}+\frac{t L^{2}\left[2\left(2 t L^{2}-5 N\right)\left(3 t L^{2}-5 N\right)-5 N\left(7 t L^{2}-15 N\right)\right][u]}{25\left(3 t L^{2}-5 N\right)\left(7 t L^{2}-15 N\right)[l]} \\
& a_{k(2)}^{F}=\frac{2 N t L^{2}}{5\left(3 t L^{2}-5 N\right)}+\frac{N\left[2\left(2 t L^{2}-5 N\right)\left(3 t L^{2}-5 N\right)-5 N\left(7 t L^{2}-15 N\right)\right][u]}{5\left(3 t L^{2}-5 N\right)\left(7 t L^{2}-15 N\right)[l]}
\end{aligned}
$$

The above equilibrium expressions contain the term $[u]=2\left(2 t L^{2}-5 N\right)\left(3 t L^{2}-5 N\right)+\left(t L^{2}\right.$ $-5 N)\left(7 t L^{2}-15 N\right)$ and $[l]=4\left(2 t L^{2}-5 N\right)\left(3 t L^{2}-5 N\right)-5 N\left(7 t L^{2}-15 N\right)$.

Proof: see Appendix 4.A for the solutions of the individual cases for $n$.

Proposition 4.1(C): The Stackelberg centralized equilibrium price-quality pairs of the game $\Gamma^{\varsigma}$ for the merged firm $M$, and for the follower-competitors, are given by the respective strategic variable solutions for the particular case of $n=6$.

\section{1: The Stackelberg firm $M$ :}

$$
\begin{aligned}
& p^{M}=\frac{\left(t L^{2}-2 N\right)\left(t L^{2}-3 N\right)\left(t L^{2}-4 N\right)\left(5 t L^{2}-18 N\right)\left[8\left(t L^{2}-3 N\right)^{2}-\left(t L^{2}-6 N\right)^{2}\right]}{2\left[16\left(t L^{2}-3 N\right)^{2}+t L^{2}\left(t L^{2}-6 N\right)\right][l]} \\
& a^{M}=\frac{3 N\left(t L^{2}-2 N\right)\left(t L^{2}-4 N\right)\left(5 t L^{2}-18 N\right)}{4[l]}
\end{aligned}
$$

The above equilibrium expressions contain the terms $[]=.8\left(t L^{2}-3 N\right)^{2}-\left(t L^{2}-6 N\right)^{2}$, and $[l]=4\left(t L^{2}-3 N\right)[]-.3 N\left[16\left(t L^{2}-3 N\right)^{2}+t L^{2}\left(t L^{2}-6 N\right)\right]$.

\section{The $q=4$ follower-competitor firms:}




$$
\begin{aligned}
& p_{k(1)}^{F}=\frac{\left(t L^{2}\right)^{2}}{72\left(t L^{2}-3 N\right)}+\frac{t L^{2}\left(t L^{2}-2 N\right)\left(t L^{2}-4 N\right)\left(t L^{2}-6 N\right)\left(5 t L^{2}-18 N\right)[u]}{8\left(t L^{2}-3 N\right)\left[16\left(t L^{2}-3 N\right)^{2}+t L^{2}\left(t L^{2}-6 N\right)\right][l]} \\
& a_{k(1)}^{F}=\frac{N t L^{2}}{12\left(t L^{2}-3 N\right)}+\frac{3 N\left(t L^{2}-2 N\right)\left(t L^{2}-4 N\right)\left(t L^{2}-6 N\right)\left(5 t L^{2}-18 N\right)[u]}{4\left(t L^{2}-3 N\right)\left[16\left(t L^{2}-3 N\right)^{2}+t L^{2}\left(t L^{2}-6 N\right)\right][l]} \\
& p_{k(2)}^{F}=\frac{\left(t L^{2}\right)^{2}\left(5 t L^{2}-18 N\right)}{36\left[8\left(t L^{2}-3 N\right)^{2}-\left(t L^{2}-6 N\right)^{2}\right]} \\
& +\frac{t L^{2}\left(t L^{2}-2 N\right)\left(t L^{2}-3 N\right)\left(t L^{2}-4 N\right)\left(t L^{2}-6 N\right)\left(5 t L^{2}-18 N\right)[u]}{2\left[16\left(t L^{2}-3 N\right)^{2}+t L^{2}\left(t L^{2}-6 N\right)\right]\left[8\left(t L^{2}-3 N\right)^{2}-\left(t L^{2}-6 N\right)^{2}\right][l]} \\
& a_{k(2)}^{F}=\frac{N t L^{2}\left(5 t L^{2}-18 N\right)}{6\left[8\left(t L^{2}-3 N\right)^{2}-\left(t L^{2}-6 N\right)^{2}\right]} \\
& +\frac{t L^{2}\left(t L^{2}-2 N\right)\left(t L^{2}-4 N\right)\left(t L^{2}-6 N\right)^{2}\left(5 t L^{2}-18 N\right)[u]}{4\left[16\left(t L^{2}-3 N\right)^{2}+t L^{2}\left(t L^{2}-6 N\right)\right]\left[8\left(t L^{2}-3 N\right)^{2}-\left(t L^{2}-6 N\right)^{2}\right][l]} \\
& p_{k(3)}^{F}=\frac{\left(t L^{2}\right)^{2}\left(t L^{2}-4 N\right)}{6\left[8\left(t L^{2}-3 N\right)^{2}-\left(t L^{2}-6 N\right)^{2}\right]} \\
& +\frac{3 N\left(t L^{2}-2 N\right)\left(t L^{2}-3 N\right)\left(t L^{2}-4 N\right)\left(t L^{2}-6 N\right)\left(5 t L^{2}-18 N\right)[u]}{\left[16\left(t L^{2}-3 N\right)^{2}+t L^{2}\left(t L^{2}-6 N\right)\right]\left[8\left(t L^{2}-3 N\right)^{2}-\left(t L^{2}-6 N\right)^{2}\right][l]} \\
& \cdot
\end{aligned}
$$


$+\frac{3 N\left(t L^{2}-2 N\right)\left(t L^{2}-4 N\right)\left(t L^{2}-6 N\right)^{2}\left(5 t L^{2}-18 N\right)[u]}{2\left[16\left(t L^{2}-3 N\right)^{2}+t L^{2}\left(t L^{2}-6 N\right)\right]\left[8\left(t L^{2}-3 N\right)^{2}-\left(t L^{2}-6 N\right)^{2}\right][l]}$

The above' equilibrium expressions contain the term $[u]=8\left(t L^{2}-3 N\right)^{2}+3\left(t L^{2}-4 N\right)\left(2 t L^{2}\right.$ $-3 N)]$.

Proof: see Appendix 4.A for the solutions of the individual cases for $n$.

In the first stage of the game, the Stackelberg leader, firm M's symmetric pricequality equilibrium pairs $\left\{p^{M}, a^{M}\right\}$ are functions not only of the parameters $t, N$, and $L$, but are a function of their nearest equi-distant competitors' variants' prices and qualities, $\left\{p_{i-}\right.$ $\left.{ }_{l}^{F}, p_{i+1}^{F}, p_{i+3}{ }^{F}\right\}$ and $\left\{a_{i-1}{ }^{F}, a_{i+1}^{F}, a_{i+3}^{F}\right\}$, respectively. The followers, or $q$ competitors, act under Nash behaviour to each simultaneously choose a price and quality level for their product variant in the second stage of the game. By convention, the price and quality level solution of the difference equations (4.2) are denoted by $p_{i+1}^{F} \equiv p_{k(l)}{ }^{k}$, and $a_{i+1}{ }^{k} \equiv$ $a_{k(l)}{ }^{F}$, respectively. The solution of $p_{i+3}{ }^{F}=p_{i-1}{ }^{F} \equiv p_{k(2)}{ }^{F}$ and thus, $a_{i \cdot 3^{l}}{ }^{i}=a_{i-l}^{F} \equiv a_{k(2)}{ }^{F}$ is determined recursively by equation (4.4), for a given $n \geq 4$, Similarly, the solution of $p_{i, k}^{F}$, for $k=4, \ldots, q$, for a given $n \geq 4$, is solved recursively by equation (4.6).

For example, in the particular case of $n=4$ pre-merger firms in the industry, suppose that firms $i$ and $i+2$ merge. Then firms $i+1$ and $i+3$ are the nearest neighbours on either side of the two local monopoly market areas of the Stackelberg firm $M$. They set identical prices $p_{i+1}{ }^{F}=p_{i \cdots 3}{ }^{F} \equiv p_{k(l)}{ }^{F}$, and quality levels $a_{i+1}{ }^{l *}=a_{i+3}{ }^{F} \equiv a_{k(l)}{ }^{l *}$, for each of their product variants. Both the (recursive) price, and quality level difference equations of (4.2) for the two follower firms must be solved separately in the case of $n=4$ firms, as 
they are both functions only of their two respective neighbours' prices and qualities, that is, the Stackelberg leader's two joint firms. The Stackelberg equilibrium outcome, in this case, is such that $p^{M}<p_{k(l)}{ }^{F}$ and $a^{M}<a_{k(l)}^{F}$. This particular case is examined further in the discussion following the method of solving the recursive difference equations for the cases of $n \geq 5$ pre-merger firms.

For $n=5$ firms, then $p_{i+1}^{F} \equiv p_{k(l)}^{F}$, and the next nearest and equi-distant competitors to the bi-variant firm $M$ set their prices at $p_{i+3}{ }^{F}=p_{i \cdot 4}{ }^{l} \equiv p_{k(2)}{ }^{F}$ and similarly for the respective quality levels. For $n \geq 4$, the price $p_{k(l)}{ }^{F}$ is a function of the prices and qualities of the Stackelberg firm $M^{\prime} s$ bi-variants. The price $p_{k(2)}{ }^{F}$ is a function both of its nearest outside competitors' price and quality, and the price and quality of the merged firm $M$ if $n \geq 5$. In the case of $n \geq 6$ industry firms, then the price $p_{k(3)}{ }^{l i}$ is a function only of the nearest outside competitors' prices and qualities.

Thus, by recursive application of the Stackelberg price difference equations (4.4) and (4.6), then for all pairwise non-merged firms equi-distant from the Stackelberg firm $M^{\prime}$ 's two local monopoly market areas, they set identical equilibrium prices such that $p^{M}>$ $p_{k(l)}^{F}>p_{k(2)}^{F}>p_{k(3)}^{l+}>\ldots$, if $n \geq 5$. For $n$ (an odd number of firms), there are at most two outside competitors with the (identical) lowest prices for their respective single-product variants, while if $n$ (an even number of firms), then there is at most one competitor offering the lowest price for a variant in the post-merger industry. Figure $4.2(\mathrm{~A})$ describes the general shape of the Stackelberg equilibrium post-merger prices of all firms $(n \geq 5)$ in the industry.

In a similar manner, the recursive application of the Stackelberg quality difference 


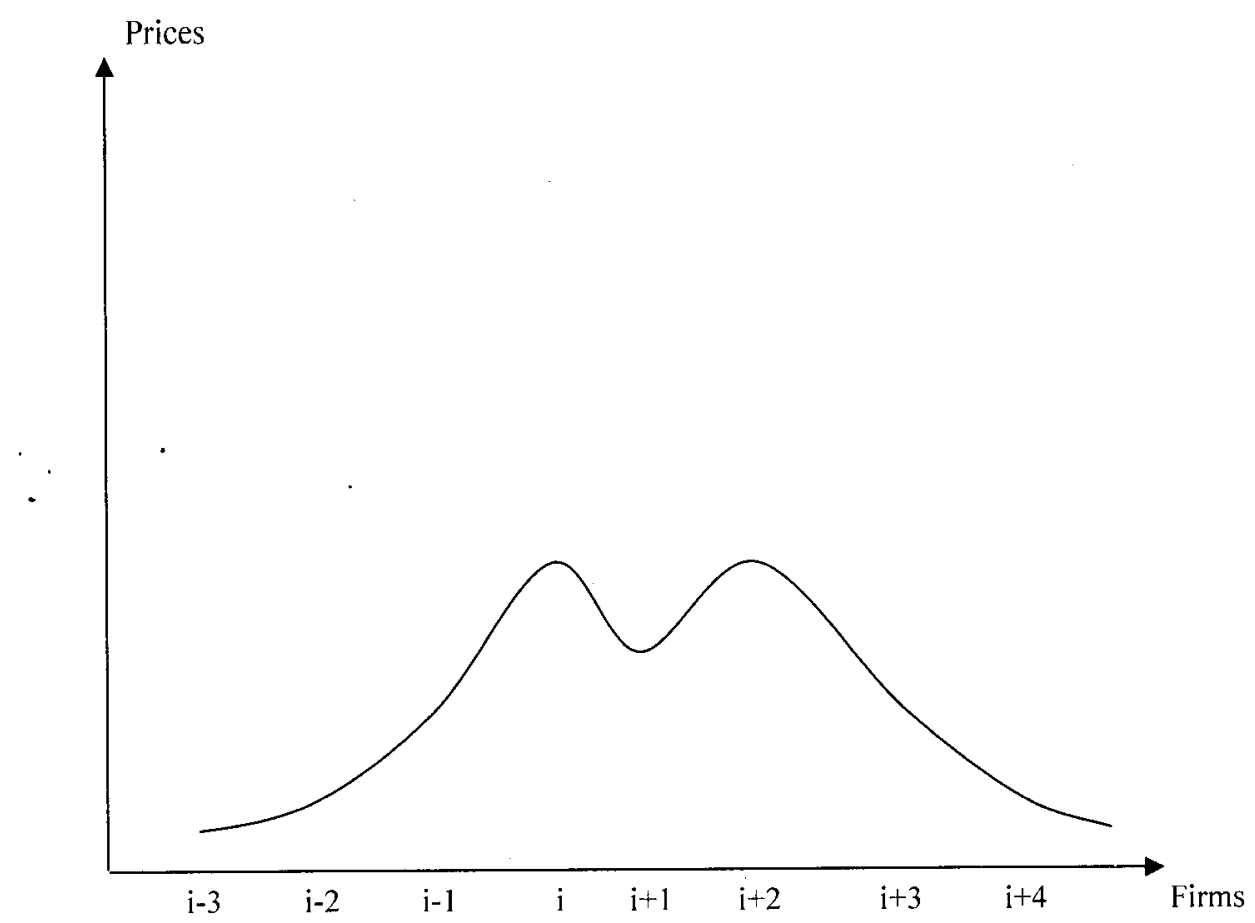

Figure 4.2(A): The general shape of the asymmetric Stackelberg equilibrium price function: non-neighbour merged firm

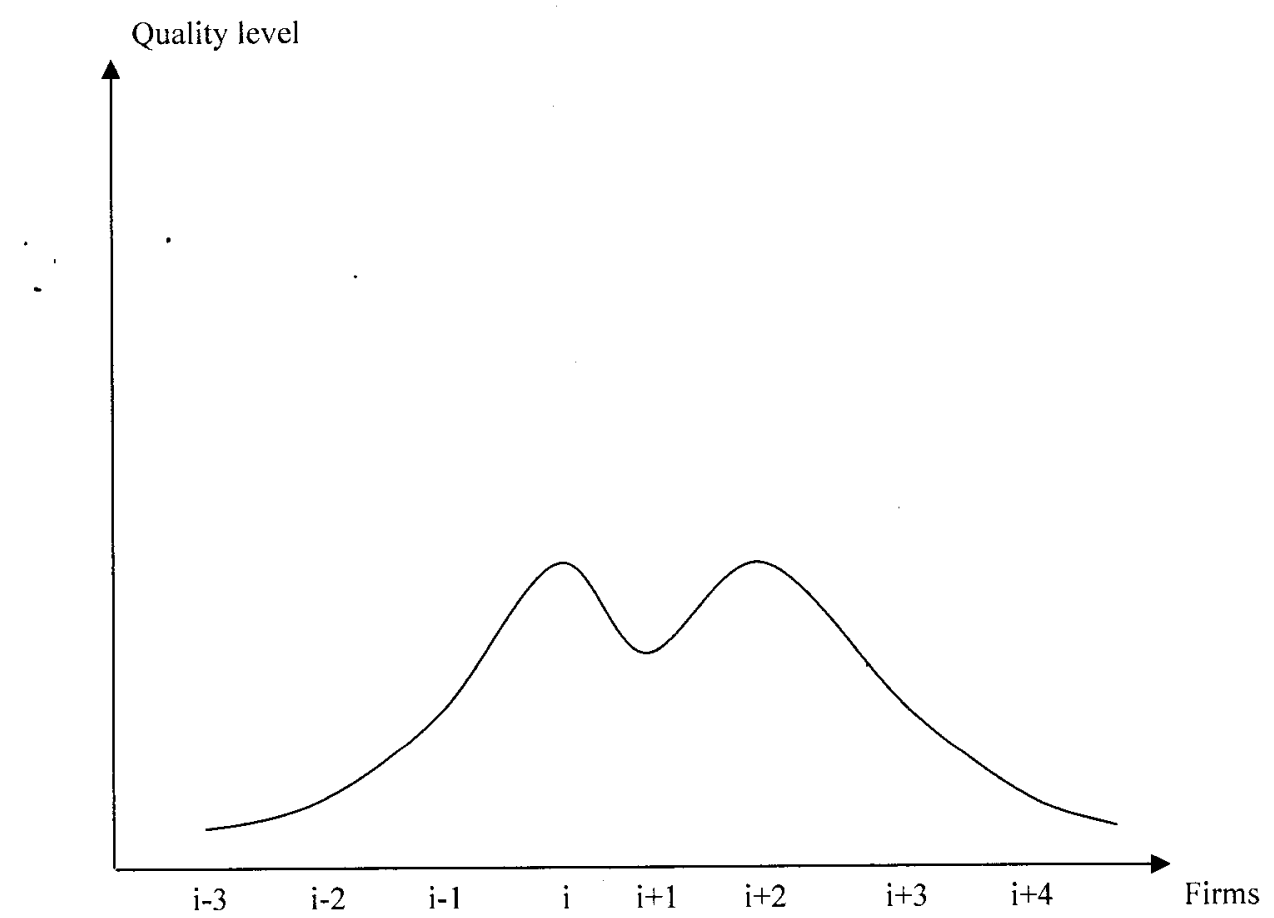

Figure 4.2(B): The general shape of the asymmetric Stackelberg equilibrium quality function: non-neighbour merged firm 
equations (4.4) and (4.6), produces identical equilibrium quality levels for all pairwise non-merged firms equi-distant from the Stackelberg leader's two locally monopolistic market areas, where $a^{M}<a_{k(1)}{ }^{F}>a_{k(2)}{ }^{l}>a_{k(3)}{ }^{F}>\ldots$, if $n \geq 4$. If there are an odd number of firms within the industry, then there is at most, two outside competitors with the lowest (identical) quality levels. For an even number of firms, there is at most one non-merged firm offering the lowest quality level for its single-product variant in the market. Figure 4.2(B) shows the general shape of the Stackelberg post-merger quality levels for all firms $(n \geq 4)$ in the industry.

The following corollary characterizes the outcome of the Stackelberg price-quality equilibrium market shares for the Stackelberg leader, firm $M$, and the remaining $q$ follower-competitor firms.

\section{Pattern of the Stackelberg Equilibrium Market Shares:}

Corollary 4.1(A): The Stackelberg price-quality equilibrium outcome for the market shares or the consumers' demands of the bi-variant firm M's product variants, and of the follower-competitor firms' product variants are given by the following expressions, that is, for the particular case of $n=4$.

\section{The Stackelberg firm $M$ :}

$$
X^{M}=\frac{N\left(3 t L^{2}-8 N\right)}{8\left(t L^{2}-2 N\right)}
$$

\section{The $q=2$ follower-competitor firms:}

$$
X^{F}=\frac{N\left(5 t L^{2}-8 N\right)}{16\left(t L^{2}-2 N\right)}
$$


Corollary 4.1(B): The Stackelberg price-quality equilibrium outcome for the market shares or the consumers' demands of the bi-variant firm M's product variants, and the follower-competitor firms' single-product variants are given by the following expressions, that is, for the particular case of $n=5$.

\section{The Stackelberg firm $M$ :}

$$
X^{M}=\frac{2 N\left[2\left(2 t L^{2}-5 N\right)\left(3 t L^{2}-5 N\right)+\left(t L^{2}-5 N\right)\left(7 t L^{2}-15 N\right)\right]}{5\left[4\left(2 t L^{2}-5 N\right)\left(3 t L^{2}-5 N\right)-5 N\left(7 t L^{2}-15 n\right)\right]}
$$

2. The $q=3$ follower-competitor firms:

$$
\begin{aligned}
& X_{k(1)}^{F}=\frac{N t L^{2}}{5\left(2 t L^{2}-5 N\right)}+\frac{N\left[2\left(2 t L^{2}-5 N\right)\left(3 t L^{2}-5 N\right)-5 N\left(7 t L^{2}-15 N\right)\right][u]}{5\left(2 t L^{2}-5 N\right)\left(7 t L^{2}-15 N\right)[l]} \\
& X_{k(2)}^{F}=\frac{2 N t L^{2}}{5\left(3 t L^{2}-5 N\right)}+\frac{N\left[2\left(2 t L^{2}-5 N\right)\left(3 t L^{2}-5 N\right)-5 N\left(7 t L^{2}-15 N\right)\right][u]}{5\left(3 t L^{2}-5 N\right)\left(7 t L^{2}-15 N\right)[l]}
\end{aligned}
$$

The above equilibrium expressions contain the term $[u]=2\left(2 t L^{2}-5 N\right)\left(3 t L^{2}-5 N\right)+\left(t L^{2}\right.$ $-5 N)\left(7 t L^{2}-15 N\right)$ and $[l]=4\left(2 t L^{2}-5 N\right)\left(3 t L^{2}-5 N\right)-5 N\left(7 t L^{2}-15 N\right)$.

Corollary 4.1(C): The Stackelberg price-quality equilibrium outcome for the market shares or the consumers' demands of the bi-variant firm M's product variants, and the follower-competitor firms' single-product variants are given by the following expressions, that is, for the particular case of $n=6$.

\section{The Stackelberg firm $M$ :}

$$
X^{M}=\frac{3 N\left(t L^{2}-2 N\right)\left(t L^{2}-4 N\right)\left(5 t L^{2}-18 N\right)}{4\left(t L^{2}-3 N\right)\left[8\left(t L^{2}-3 N\right)^{2}-\left(t L^{2}-6 N\right)^{2}\right]}
$$


$-\frac{3 N\left(t L^{2}-2 N\right)\left(t L^{2}-4 N\right)\left(t L^{2}-6 N\right)\left(5 t L^{2}-18 N\right)[u]}{4\left(t L^{2}-3 N\right)\left[8\left(t L^{2}-3 N\right)^{2}-\left(t L^{2}-6 N\right)^{2}\right][l]}$

2. The $q=.4$ follower-competitor firms:

$$
\begin{aligned}
& X_{k(1)}^{F}=\frac{N t L^{2}}{12\left(t L^{2}-3 N\right)}+\frac{3 N\left(t L^{2}-2 N\right)\left(t L^{2}-4 N\right)\left(t L^{2}-6 N\right)\left(5 t L^{2}-18 N\right)[u]}{\left.4\left(t L^{2}-3 N\right)\left[16\left(t L^{2}-3 N\right)^{2}+t L^{2}\left(t L^{2}-6 N\right)\right] l\right]} \\
& X_{k(2)}^{F}=\frac{N t L^{2}\left(5 t L^{2}-18 N\right)}{6\left[8\left(t L^{2}-3 N\right)^{2}-\left(t L^{2}-6 N\right)^{2}\right]} \\
& +\frac{3 N\left(t L^{2}-2 N\right)\left(t L^{2}-3 N\right)\left(t L^{2}-4 N\right)\left(t L^{2}-6 N\right)\left(5 t L^{2}-18 N\right)[u]}{\left[8\left(t L^{2}-3 N\right)^{2}-\left(t L^{2}-6 N\right)^{2}\right]\left[16\left(t L^{2}-3 N\right)^{2}+t L^{2}\left(t L^{2}-6 N\right)\right][l]} \\
& X_{k(3)}^{F}=\frac{N t L^{2}\left(t L^{2}-4 N\right)}{\left[8\left(t L^{2}-3 N\right)^{2}-\left(t L^{2}-6 N\right)^{2}\right]} \\
& +\frac{3 N\left(t L^{2}-2 N\right)\left(t L^{2}-4 N\right)\left(t L^{2}-6 N\right)^{2}\left(5 t L^{2}-18 N\right)[u]}{\left[8\left(t L^{2}-3 N\right)^{2}-\left(t L^{2}-6 N\right)^{2}\right]\left[16\left(t L^{2}-3 N\right)^{2}+t L^{2}\left(t L^{2}-6 N\right)\right][l]}
\end{aligned}
$$

The above equilibrium expressions contain the term $[u]=8\left(t L^{2}-3 N\right)^{2}+3\left(t L^{2}-4 N\right)\left(2 t L^{2}\right.$ $-3 N)$ and $[l]=4\left(t L^{2}-3 N\right)[]-.3 N\left[16\left(t L^{2}-3 N\right)^{2}+t L^{2}\left(t L^{2}-6 N\right)\right]$.

For all cases of $n$, the Stackelberg firm $M$ 's symmetric market shares $X_{l}^{M}=X_{2}^{M}$ are proportionately greater than the market shares of its follower-competitors. The market share of the "isolated" follower-competitor $X_{k(l)}$, i.e., the firm situated between the two Stackelberg firms, is proportionately greater than any of the other follower- 
competitor firms, for all $n$. In general, then $X_{1}^{M}=X_{2}^{M}>X_{k(l)}{ }^{l i}>X_{k(2)}{ }^{l i}>X_{k(3)}{ }^{l i}$. Thus, by moving first, the Stackelberg leader gains control over a relatively large proportion of the global market share.

The next corollary describes the Stackelberg equilibrium outcome of the profit levels of all firms in the post-merger industry. The analytical expressions for the equilibrium profits are derived by using the equilibrium outcomes of Proposition (4.1), and Corollary (4.1).

\section{Pattern of the Stackelberg Equilibrium Profit Shares:}

Corollary 4.2: The Stackelberg price-quality equilibrium outcome for the post-merger profit levels of the merged firm $M$, and the follower-competitor firms are given by the following expressions, that is, for each particular cases of $n=4$ and 5 .

1. The case of $(n=4)$ industry firms $(q=2$ follower-competitors):

$$
\begin{aligned}
& \pi^{M}=2\left(p^{M}\right) X^{M}-\left(a^{M}\right)^{2}-2 f=\frac{N\left(t L^{2}-2 N\right)\left(3 t L^{2}-8 N\right)^{2}}{128\left(t L^{2}-3 N\right)^{2}}-2 f \\
& \pi_{k}^{F}=\left(p_{k}^{F}\right) X_{k}^{F}-\frac{1}{2}\left(a_{k}^{F}\right)^{2}-f=\frac{N\left(5 t L^{2}-8 N\right)^{2}}{1024\left(t L^{2}-2 N\right)}-f ; \quad k=1,2
\end{aligned}
$$

\section{The case of $(n=5)$ industry firms ( $q=3$ follower-competitors):}

$$
\pi^{M}=\frac{N\left[2\left(2 t L^{2}-5 N\right)\left(3 t L^{2}-5 N\right)+\left(t L^{2}-5 N\right)\left(7 t L^{2}-15 N\right)\right]^{2}}{125\left(7 t L^{2}-15 N\right)\left[4\left(2 t L^{2}-5 N\right)\left(3 t L^{2}-5 N\right)-5 N\left(7 t L^{2}-15 N\right)\right]}-2 f
$$

3. The case of $(n=6)$ industry firms ( $q=4$ follower-competitors): 


$$
\pi^{M}=\frac{3 N\left(t L^{2}-2 N\right)^{2}\left(t L^{2}-4 N\right)^{2}\left(5 t L^{2}-18 N\right)^{2}}{16\left[16\left(t L^{2}-3 N\right)^{2}+t L^{2}\left(t L^{2}-6 N\right)\right][l]}
$$

The above equilibrium expression contains the term $[l]=4\left(t L^{2}-3 N\right)[]-.3 N\left[16\left(t L^{2}-\right.\right.$ $3 N)^{2}+t L^{2}\left(t L^{2}-6 N\right)$ and $[]=.8\left(t L^{2}-3 N\right)^{2}-\left(t L^{2}-6 N\right)^{2}$.

The equilibrium profit expressions of the competitor-follower firms for the respective cases of $n=5$ and $n=6$ are not included in the above corollary because the written algebraic terms are too lengthy.

The symmetric joint post-merger profit of the Stackelberg leader is proportionately greater than any of its follower-competitors, for all $n \geq 4$. Thus, a twofirm, non-neighbour Stackelberg price-quality merger increases the post-merger profits of all firms in the industry such that $\pi^{M}>\pi_{k(1)}{ }^{F}>\pi_{k(2)}^{F^{F}}>\pi_{k(3)}{ }^{F}>\ldots$, and all non-merged firms earn less profits than each party to the merged entity. This result is contrary to that of the standard (non-spatial) oligopoly Stackelberg merger with price leadership only, where the post-merger profits exhibit the "free-rider problem", $\pi^{M}<\pi_{k_{(1)}{ }^{l}}<\pi_{k(2)}{ }^{l}<\ldots$, so that the merger increases the post-merger profits of all the rival, or competitor firms [d' Aspremont et al. (1983)]. Thus, for a given $n \geq 4$, the "free-rider problem" is absent for the spatial Stackelberg price-quality merger model.

\subsection{AN ANALYSIS OF THE STACKELBERG PRICE-QUALITY (NON- NEIGHBOUR) MERGER EQUILIBRIUM OUTCOME AND THE POTENTIAL FOR ANTI-COMPETITIVE EFFECTS}

To analyze the potential for anti-competitive effects of a two (non-neighbour) firm 
Stackelberg price-quality merger, it is instructive to first discuss the analytical results of the Stackelberg price-quality equilibrium described in Proposition 4.1(A), 4.1(B) and 4.1(C), and the respective Corollaries 4.1(A), 4.(B), 4.2(A), and 4.2(B). Secondly, the numerical simulation of the Stackelberg price-quality equilibrium outcome for the postmerger prices, quality levels, quantity sold, and the profits of all firms are solved for the industry sizes of $n=4,5$, and 6 . These numerical simulation results show the postmerger pattern, magnitude and direction of the strategic variables, and the total welfare effects, relative to the pre-merger Nash price-quality equilibrium outcome of an $n$-firm oligopoly, of a Stackelberg merger of two non-neighbouring firms.

For the following first three sections, a description of the Stackelberg price-quality equilibrium outcome is presented first, followed by the welfare analysis of the numerical simulation results, for each of the cases, $q=2,3$, and 4 follower firms of a two, nonneighbour Stackelberg firm merger. The final section examines the numerical differences between the equilibrium outcomes of the two-firm, non-neighbour Stackelberg centralized merger with $q=4$ follower firms to that of the two-firm merger under centralized Nash behaviour with $q=4$ competitor firms.

\section{The Stackelberg Two, Non-Neighbour Firm Merger with Two Outside Competitors}

The Stackelberg merged firm $M$ sets an identical post-merger equilibrium price $p^{M}$, and an identical equilibrium quality level $a^{M}$, for its two product variants sold in physically-separated markets. Both the identical, post-merger price $p^{F}$, and the quality level $a^{F}$, of its two competitive neighbours' variants are such that $p^{M}<p^{l}$ and $a^{M}<a^{l}$. The Stackelberg leader knows that acting in such a strategic manner effectively captures 
the consumers of its two isolated competitors' markets in a post-merger industry with only two remaining non-merged members. Since there are only followers located on either side of the Stackelberg leader's firm sites, the merged firm $M$ knows that it can effectively lure away all consumers from its two competitors' market area by setting such a price-quality strategy. Thus, it effectively gains the largest global market share.

The two follower firms remaining in the post-merger industry know that the identical lower price $p^{M}$, and identical lower quality level $a^{M}$, chosen in equilibrium, by the leader's two firms may effectively capture consumers away from them. Thus, they realize that their market areas closest to the merged firms' sites are vulnerable and, acting independently, chose an identical higher price $p^{F}$, and quality level $a^{l *}$, at equilibrium for their single-product variants. By choosing such a price-quality strategy, the two physically isolated follower firms gain the highest possible symmetric market shares $X^{i^{\prime}}$, and thus identical profits $\pi^{F}$, from those consumers located in the market areas adjacent to them.

With lower post-merger prices and qualities offered in its two disconnected markets, the leader sells a greater quantity of its bi-variants than either of its competitorfollowers, $X^{M}>X^{i}$. This symmetric Stackelberg price-quality policy results in a joint post-merger profit greater than that of its neighbours, or $\pi^{M}>\pi^{*}$. This particular case of a two firm, non-neighbour Stackelberg merger in a "captured" industry demonstrates that a simultaneously set price-quality strategy induces its Nash-follower competitors to increase their prices and qualities.

The symmetric Stackelberg price-quality equilibrium strategy of the bi-variant 
product firm $M$, may be compared with the symmetric pre-merger price-quality equilibrium outcome of an $n$-firm oligopoly. The pre-merger price is $p^{*}=t L^{2} /\left(n^{*}\right)^{2}(c=0)$ and $n^{*}=n+q$, the pre-merger quality level is $a^{*}=N / n^{*}$, the pre-merger market share is $X^{*}=N / n^{*}$, and the pre-merger profit of a firm is $\pi^{*}=N\left(2 t L^{2}-n^{*} N\right) / 2\left(n^{*}\right)^{3}$. Suppose that the number of pre-merger firms is $n^{*}=4$, so that $p^{*}=t L^{2} / 16$ and $a^{*}=N / 4$. Then $p^{M}$ $>p^{*} \Leftrightarrow t>3 N / L^{2}$ and $a^{M}<a^{*}=N / 4 \Leftrightarrow t>4 N / L^{2}$. The post-merger price of the Stackelberg leader is greater than the pre-merger price while the post-merger quality level of the bi-variant firm is lower than that of the pre-merger quality level. For the two follower firms, the post-merger price $p^{F}>p^{*} \Leftrightarrow t>3 N / L^{2}$, and the post-merger quality level $a^{F}>a^{*}=N / 4$. Thus, for the two competitors, the post-merger quality levels are greater than the pre-merger quality levels, and the post-merger prices of the competitors are greater than their pre-merger prices.

Table 4.1 shows the simulation results for a three-firm post-merger industry with parameter values of $N=L=1$, and a transport cost of $t=5$. The consumers' surplus, $C S$ is calculated as the sum of the aggregate income $N y$, plus the area under the inelastic demand curve, or $C S=N(a-p)$, minus the total traveling costs incurred.. The traveling costs consumers assume are evaluated by calculating the total area with respect to each set of asymmetric prices since the consumers" "indifference point" is not midway between two firms, in contrast to the symmetric pre-merger Nash prices. Total travel costs in the pre-merger Nash equilibrium are equivalent to $-t N L^{2} / 12 n^{2}=-0.026$ and are greater than those incurred in the Stackelberg model (-0.0157). Note that since consumers either purchase one or none of a product variant, then $C S>0$. The difference 
between the numerical values of post-merger Stackelberg equilibrium variables to that of the pre-merger Nash price-quality equilibrium of an $n$-firm oligopoly are denoted by $\Delta(C S)$, for consumers' surplus, $\Delta(P S)$ for producers' surplus, and $\Delta(T W)$, for total welfare.

Table 4.1: Total Welfare Simulation Results - Stackelberg (Non-Neighbour) Merger $(q=2)$

$(\mathrm{n}=2$ and $\mathrm{q}=2$ ) and $\mathrm{N}=\mathrm{L}=1(\mathrm{t}=5)$

\begin{tabular}{lcccc}
\hline $\mathrm{p}^{*}=0.3125$ & $\mathrm{a}^{*}=0.25$ & $\pi^{*}=0.046875-\mathrm{f}$ & $\mathrm{CS}^{*}=\mathrm{y}-0.0885$ & $\mathrm{PS}^{*}=0.1875-4 \mathrm{f}$ \\
\hline \hline $\mathrm{p}^{\mathrm{M}}(\mathrm{t}=5)=0.33$ & $\mathrm{a}^{\mathrm{M}}(\mathrm{t}=5)=0.22$ & $\mathrm{X}^{\mathrm{M}}(\mathrm{t}=5)=0.2916$ & $\pi^{\mathrm{M}}(\mathrm{t}=5)=0.287-2 \mathrm{f}$ \\
$\mathrm{p}_{\mathrm{k}(1)}{ }^{\mathrm{F}}(\mathrm{t}=5)=0.44$ & $\mathrm{a}_{\mathrm{k}(1)}^{\mathrm{F}}(\mathrm{t}=5)=0.35$ & $\mathrm{X}_{\mathrm{k}(1)}^{\mathrm{F}}(\mathrm{t}=5)=0.35416$ & $\pi_{\mathrm{k}(1)}^{\mathrm{F}}(\mathrm{t}=5)=0.094-\mathrm{f}$ \\
\hline $\mathrm{CS}(\mathrm{t}=5)=\mathrm{y}-0.228$ & $\mathrm{PS}(\mathrm{t}=5)=0.475-4 \mathrm{f}$ & $\mathrm{TW}(\mathrm{t}=5)=\mathrm{y}+0.247-4 \mathrm{f}>0$ \\
$\Delta(\mathrm{CS})_{\mathrm{t}=5}=-0.1398$ & $\Delta(\mathrm{PS})_{\mathrm{t}=5}=0.2876$ & $\Delta(\mathrm{TW})_{\mathrm{t}=5}=0.1478>0$
\end{tabular}

As the consumer demand function is perfectly inelastic, an increase in prices due to a merger serves not only to redistribute the total welfare of the economy, but any distortions in quality levels must be considered as a source of "deadweight welfare loss". The travel costs incurred by consumers to purchase their preferred variant are not numerically equivalent under either a pre-merger (four firm oligopoly) economy and therefore, a distortion of the quality levels exists among the post-merger firms. For example, the numerical simulation results for this model indicate that this merger is welfare enhancing, since $\Delta(T W)>0$. The fact that this merger is socially efficient is due to the greater, absolute amount of producers' surplus gained, relative to the consumers' surplus loss.

\section{The Stackelberg Two, Non-Neighbour Firm Merger with Three Outside Competitors}

The Stackelberg equilibrium prices of a post-merger industry consisting of four 
post-merger firms in the market offers their product variants at prices $p^{M}>p_{k(1)}^{{ }^{F}}>p_{k(2)}{ }^{F}$, while the Stackelberg leader's bi-variants consist of the lowest quality in its two, separate and locally monopolistic markets. The three followers' variant's quality is produced at a higher level, where $a^{M}<a_{k(I)}^{F}>a_{k(2)}^{F}$. The merged firm $M$, at equilibrium, sets a higher price and a lower quality level in its two physically disconnected markets to capture the largest market share over its three competitors, relative to the pre-merger equilibrium. Since the quantity sold of its bi-variants is such that $X^{M}>X_{k(1)}{ }^{F}>X_{k(2)}{ }^{l}$, they also gain the largest profit share in the post-merger industry. Table 4.2 gives the simulation results for a four firm post-merger industry for which the unit transport costs are $t=6$, and with parameter values of $N=L=1$.

The Stackelberg leader's symmetric price-quality policy, for $n \geq 5$ firms, is to set a higher price and a lower quality level for its two variants which induces all followers to set both higher prices and qualities for each of the variants sold in their local markets. The two-firm merged entity, acting as a Stackelberg leader in each of its two disjoint markets, knows that by increasing the symmetric price and decreasing the symmetric quality level of its bi-variants insures that each firm benefits itself and its partner by inducing the "isolated" follower firm between them, located at $x_{i 11}$, to increase the price and quality of its product at an amount greater than that of its two other member competitor-followers. The "isolated" follower firm knows the leader's price-quality strategy, and acting independently, takes advantage of its position by choosing a high price and a high quality level for its single-product variant since its total market area is in direct competition only with the Stackelberg leader's two firms. 
The remaining competitor-followers located at an equi-distant area on the other side of the merged firm $M$ 's physically separated local markets are both induced to set least highest, but identical post-merger prices and quality levels for their single-product variants as they both share a portion of their respective market areas with the leader, and each other. These two followers, acting independently, each choose a price-quality strategy that reflects the dependence of their respective market areas by competition with a merged firm and a follower-competitor. Competition for consumers is greatest for the isolated non-merged firm, $x_{i+1}$, and its independently chosen highest competitor-follower price-quality strategy results in a greater quantity sold of its variant, $X_{k(l)}{ }^{l i}>X_{k(2)}{ }^{l}$, than its two member follower-competitors.

\section{Table 4.2: Total Welfare Simulation Results - Stackelberg (Non-Neighbour)}

\section{Merger $(q=3)$}

$(\mathrm{n}=2$ and $\mathrm{q}=3$ ) and $\mathrm{N}=\mathrm{L}=1(\mathrm{t}=6)$

\begin{tabular}{|c|c|}
\hline $\mathrm{p}^{*}=0.24$ & $\mathrm{a}^{*}=0.2$ \\
\hline
\end{tabular}

\begin{tabular}{llll}
\hline \hline $\mathrm{p}^{\mathrm{M}}(\mathrm{t}=6)=0.417$ & $\mathrm{a}^{\mathrm{M}}(\mathrm{t}=6)=0.1825$ & $\mathrm{X}^{\mathrm{M}}(\mathrm{t}=6)=0.365$ & $\pi^{\mathrm{M}}(\mathrm{t}=6)=0.1190-2 \mathrm{f}$ \\
$\mathrm{p}_{\mathrm{k}(1)}{ }^{\mathrm{F}}(\mathrm{t}=6)=0.298$ & $\mathrm{a}_{\mathrm{k}(1)}{ }^{\mathrm{F}}(\mathrm{t}=6)=0.248$ & $\mathrm{X}_{\mathrm{k}(1)}{ }^{\mathrm{F}}(\mathrm{t}=6)=0.216$ & $\pi_{\mathrm{k}(1)}{ }^{\mathrm{F}}(\mathrm{t}=6)=0.0337-\mathrm{f}$ \\
$\mathrm{p}_{\mathrm{k}(2)}{ }^{\mathrm{F}}(\mathrm{t}=6)=0.271$ & $\mathrm{a}_{\mathrm{k}(2)}{ }^{\mathrm{F}}(\mathrm{t}=6)=0.226$ & $\mathrm{X}_{\mathrm{k}(2)}{ }^{\mathrm{F}}(\mathrm{t}=6)=0.209$ & $\pi_{\mathrm{k}(2)}{ }^{\mathrm{F}}(\mathrm{t}=6)=0.0312-\mathrm{f}$ \\
\hline $\mathrm{CS}(\mathrm{t}=6)=\mathrm{y}-0.2112$ & $\mathrm{PS}(\mathrm{t}=6)=0.2151-5 \mathrm{f}$ & $\mathrm{TW}(\mathrm{t}=6)=\mathrm{y}+0.0039-5 \mathrm{f}>0$ \\
$\Delta(\mathrm{CS})_{\mathrm{t}=6}=-0.15125$ & $\Delta(\mathrm{PS})_{\mathrm{t}=6}=0.0752$ & $\Delta(\mathrm{TW})_{\mathrm{t}=6}=-0.07608<0$ \\
\hline
\end{tabular}

The post-merger profits indicate an absence of the free-rider problem for a Stackelberg price-quality merger with a $(n=5)$ firm pre-merger industry, since an increase in all firms' post-merger equilibrium profits are such that $\pi^{M}>\pi_{k(1)}^{F}>\pi_{k(2)}{ }^{l}$. While consumers experience a decline in their surplus, this decrease is not offset by the 
absolute gain in producers' surplus resulting in a socially inefficient merger for the economy as the change in total welfare is $\Delta(T W)<0$. Total calculated travel costs of 0.00856 for consumers are less than those incurred under the pre-merger case $(-0.02)$.

\section{The Stackelberg Two, Non-Neighbour Firm Merger with Four Outside Competitors}

In the case of a pre-merger industry consisting of six firms, a similar pattern for the outcome of the Stackelberg equilibrium prices, qualities and profits for both the leader, and the followers, occurs compared to the post-merger industry with five firms. The Stackelberg equilibrium outcome for prices are such that $p^{M}>p_{k(l)}^{l i}>p_{k(2)}^{l i}>p_{k(3)}^{l i}$, while the decentralized quality levels are such that $a^{M}<a_{k(1)}{ }^{F}>a_{k(2)}{ }^{F}>a_{k(3)}{ }^{l i}$. Competition for consumers is most intense for the isolated non-merged firm physically situated between the two disjointed market areas of the Stackelberg firm $M$. The follower firm located at $x_{i+4}$ on $C$ offers the lowest price and quality level for its single-product variant as it receives direct competition only from two neighbours that are independent member follower firms.

The symmetric price-quality equilibrium policy of the bi-variant Stackelberg firm $M$ may first be compared with the symmetric pre-merger price $p^{*}=t L^{2} /\left(n^{*}\right)^{2}$, and quality level $a^{*}=N / n^{*}$, where $n^{*}$ denotes the total number of (pre-merger) industry firms. For the case of $n^{*}=6$ pre-merger firms and $(t=8)$ for example, then $p^{M}=0.46>p^{*}=0.22$ and $a^{M}=0.148<a^{*}=0.167$. The identical post-merger price for the bi-variants of the Stackelberg firm $M$ is greater than the pre-merger price, while the post-merger centralized quality level of the bi-variant firm $M$ is less than the pre-merger quality level, given $q \geq 3$ number of follower-competitors. 
If there are four competitor-follower firms and if the unit transport cost is $t=8$ for example, then $p_{k(l)}^{F}=0.43>p_{k(2)}^{F}=0.32>p_{k(3)}^{F}=0.24>p^{*}=0.22$, and $a_{k(l)}{ }^{F}=0.32>$ $a_{k(2)}^{F}=0.24>a_{k(3)}^{F}=0.18>a^{*}=0.167$. The post-merger quality levels of the four competitive-follower firms are greater than the pre-merger quality level, and the postmerger prices of the same follower firms are greater than their pre-merger prices.

Table 4.3 gives the simulation results of a five firm post-merger industry for which the unit transport costs are $t=7$ and 8 , with parameter values of $N=L=1$. The post-merger profits indicate an absence of the "free-rider problem" for a two-firm, nonneighbour Stackelberg merger with four competitor-follower firms, where an increase in all firms' equilibrium profits are such that $\pi^{M}>\pi_{k(1)}^{F}>\pi_{k(2)}^{F}>\pi_{k(3)}^{F}$. The simulation results show that the loss in consumers' surplus is greater than the gain to producers' surplus, and increases as the unit transport cost, $t$, increases. Since $\Delta(T W)<0$, a Stackelberg price-quality merger of two non-neighbouring firms with four competitorfollower rivals results in a socially inefficient merger as total welfare is non-positive.

Given the impact of the Stackelberg merger on post-merger prices, and quality levels, it is easy to see that this type of merger reduces consumers' surplus. Total travel costs incurred by consumers are -0.0369 , if $t=7$ for example, and are greater than the pre-merger travel costs $(-0.0162)$. A socially efficient merger occurs if the number of follower firms is small $(q=2)$ as total welfare is positive. The gain in producers' surplus increases significantly if the number of outside competitors is $q>3$, and this results in a socially inefficient merger. 
Table 4.3: Total Welfare Simulation Results - Stackelberg (Non-Neighbour)

\section{$\operatorname{Merger}(q=4)$}

$(\mathrm{n}=2$ and $\mathrm{q}=4)$ and $\mathrm{N}=\mathrm{L}=1(\mathrm{t}=7$ and 8$)$

\begin{tabular}{|c|c|c|c|}
\hline $\begin{array}{l}(\mathrm{t}=7) \mathrm{p}^{*}=0.194 \\
(\mathrm{t}=8) \mathrm{p}^{*}=0.222\end{array}$ & \multicolumn{3}{|c|}{$\begin{array}{l}\mathrm{a}^{*}=0.167 \pi^{*}=0.01852-\mathrm{f} \mathrm{PS}^{*}=0.111-6 f \mathrm{CS}^{*}=\mathrm{y}-0.0432 \\
\mathrm{a}^{*}=0.167 \pi^{*}=0.02315-\mathrm{f} \mathrm{PS}^{*}=0.138-6 f \mathrm{CS}^{*}=\mathrm{y}-0.0735\end{array}$} \\
\hline $\mathrm{p}^{\mathrm{M}}(\mathrm{t}=7)=0.40$ & $\mathrm{a}^{\mathrm{M}}(\mathrm{t}=7)=0.154$ & $\mathrm{X}^{\mathrm{M}}(\mathrm{t}=7)=0.308$ & $\overline{\pi^{\mathrm{M}}(\mathrm{t}=7)=0.0994-2 \mathrm{f}}$ \\
\hline $\mathrm{p}^{\mathrm{M}}(\mathrm{t}=8)=0.46$ & $\mathrm{a}^{\mathrm{M}}(\mathrm{t}=8)=0.148$ & $\mathrm{X}^{\mathrm{M}}(\mathrm{t}=8)=0.296$ & $\pi^{\mathrm{M}}(\mathrm{t}=8)=0.1161-2 \mathrm{f}$ \\
\hline$\overline{p_{k(1)}} \cdot \mathrm{F}(\mathrm{t}=7) \doteq 0.38$ & $\mathrm{a}_{\mathrm{k}(1)}{ }^{\mathrm{F}}(\mathrm{t}=7)=0.33$ & $X_{k(1)}^{F}(t=7)=0.179$ & $\pi_{\mathrm{k}(1)}^{\mathrm{F}}(\mathrm{t}=7)=0.0562-\mathrm{f}$ \\
\hline $\mathrm{p}_{\mathrm{k}(1)}{ }^{\mathrm{F}}(\mathrm{t}=8)=0.43$ & $\mathrm{a}_{\mathrm{k}(1)}{ }^{\mathrm{F}}(\mathrm{t}=8)=0.32$ & $X_{k(1)}^{F}(t=8)=0.184$ & $\pi_{\mathrm{k}(1)}{ }^{\mathrm{F}}(\mathrm{t}=8)=0.0280-\mathrm{f}$ \\
\hline $\mathrm{p}_{\mathrm{k}(2)}^{\mathrm{F}}(\mathrm{t}=7)=0.29$ & $a_{k(2)}{ }^{F}(t=7)=0.247$ & $\mathrm{X}_{\mathrm{k}(2)}^{\mathrm{F}}(\mathrm{t}=7)=0.173$ & $\pi_{\mathrm{k}(2)}^{\mathrm{F}}(\mathrm{t}=7)=0.0196-\mathrm{f}$ \\
\hline $\mathrm{p}_{\mathrm{k}(2)}^{\mathrm{F}}(\mathrm{t}=8)=0.32$ & $a_{k(2)}^{F}(t=8)=0.244$ & $\mathrm{X}_{\mathrm{k}(2)}{ }^{\mathrm{F}}(\mathrm{t}=8)=0.175$ & $\pi_{\mathrm{k}(2)}^{\mathrm{F}}(\mathrm{t}=8)=0.0260-\mathrm{f}$ \\
\hline $\mathrm{p}_{\mathrm{k}(3)}^{\mathrm{F}}(\mathrm{t}=7)=0.21$ & $a_{k(3)}{ }^{\mathrm{F}}(t=7)=0.177$ & $\mathrm{X}_{\mathrm{k}(3)}^{\mathrm{F}}(\mathrm{t}=7)=0.170$ & $\pi_{k(3)}^{F}(t=7)=0.0193-f$ \\
\hline $\mathrm{p}_{\mathrm{k}(3)}{ }^{\mathrm{F}}(\mathrm{t}=8)=0.24$ & $a_{k(3)}{ }^{F}(t=8)=0.182$ & $\mathrm{X}_{\mathrm{k}(3)}{ }^{\mathrm{F}}(\mathrm{t}=8)=0.173$ & $\pi_{k(3)}^{F}(t=8)=0.0250-f$ \\
\hline $\operatorname{PS}(t=7)=0.215-6 f$ & $\mathrm{CS}(\mathrm{t}=7)=$ & .412 & $7)=y-0.197-6 f>0$ \\
\hline $\operatorname{PS}(\mathrm{t}=8)=0.222-6 \mathrm{f}$ & $\mathrm{CS}(\mathrm{t}=8)=\mathrm{y}$ & 0.517 & $8)=y-0.295-6 f>0$ \\
\hline$\Delta(\mathrm{PS})_{\mathrm{t}=7}=0.077$ & $\Delta(\mathrm{CS})_{\mathrm{t}=7}=$ & 3688 & $t=7=-0.2918<0$ \\
\hline$\Delta(\mathrm{PS})_{\mathrm{t}=8}=0.111$ & $\Delta(\mathrm{CS})_{\mathrm{t}=8}=$ & 4435 & $t_{t=8}=-0.3325<0$ \\
\hline
\end{tabular}

\section{A Comparison of the Simulation Merger Results: Nash and Stackelberg Non-}

\section{Neighbour}

A comparison between the two-firm, neighbour centralized Nash price-quality merger and the two-firm, non-neighbour Stackelberg centralized price-quality merger, where each merged firm faces four single-product competitors, is made between the postmerger prices, quality levels, and profit shares. The numerical simulations of the total welfare are analyzed for the same set of parameter values of $N=L=2$, for the unit transport costs of $t=7$, for all post-merger firms [see Table 3.4 for the two-firm Nash 
merger]. Table 4.4 provides the numerical simulation results for the Stackelberg twofirm, non-neighbour merger with four outside competitors based on these parameter values.

The post-merger prices, and the centralized quality levels of the Stackelberg leader are larger than those for a merged firm under centralized Nash behaviour. This results in significantly higher profits, and total producers' surplus for a Stackelberg nonneighbour merger. Not surprisingly, the loss of consumers' surplus under a Nash twofirm, neighbour merger is significantly less than that loss for consumers under a Stackelberg, two-firm, non-neighbour merger. However, the total loss in welfare to the economy is larger under a Stackelberg merger which may be explained, in part, by the increased levels in prices of the two variants produced by the non-neighbouring Stackelberg firms, and the significant increase in producers' surplus. However, there is also an increase in transport costs, given the same value of $t$, that consumers must bear. For example, if $t=7$ then total transport costs are (-0.388), and if $t=8$ then these costs are calculated as $(-0.4148)$.

Table 4.4: Total Welfare Simulation Results - Stackelberg (Non-Neighbour)

\section{$\operatorname{Merger}(q=4)$}

$(\mathrm{n}=2$ and $\mathrm{q}=4)$ and $\mathrm{N}=\mathrm{L}=2(\mathrm{t}=7$ and 8$)$

\begin{tabular}{lllll}
\hline$(\mathrm{t}=7) \mathrm{p}^{*}=0.77$ & $\mathrm{a}^{*}=0.33$ & $\pi^{*}=0.204-\mathrm{f}$ & $\mathrm{PS}^{*}=1.22-6 f$ & $\mathrm{CS}^{*}=2 \mathrm{y}-1.009$ \\
$(\mathrm{t}=8) \mathrm{p}^{*}=0.88$ & $\mathrm{a}^{*}=0.33$ & $\pi^{*}=0.240-\mathrm{f}$ & $\mathrm{PS}^{*}=1.44-6 f$ & $\mathrm{CS}^{*}=2 \mathrm{y}-1.259$ \\
\hline \hline $\mathrm{p}^{\mathrm{M}}(\mathrm{t}=7)=1.802$ & $\mathrm{a}^{\mathrm{M}}(\mathrm{t}=7)=0.278$ & $\mathrm{X}^{\mathrm{M}}(\mathrm{t}=7)=0.5566$ & $\pi^{\mathrm{M}}(\mathrm{t}=7)=0.9257-2 \mathrm{f}$ \\
$\mathrm{p}^{\mathrm{M}}(\mathrm{t}=8)=2.095$ & $\mathrm{a}^{\mathrm{M}}(\mathrm{t}=8)=0.276$ & $\mathrm{X}^{\mathrm{M}}(\mathrm{t}=8)=0.5529$ & $\pi^{\mathrm{M}}(\mathrm{t}=8)=1.0822-2 \mathrm{f}$ \\
\hline $\mathrm{p}_{\mathrm{k}(1)}{ }^{\mathrm{F}}(\mathrm{t}=7)=1.464$ & $\mathrm{a}_{\mathrm{k}(1)}{ }^{\mathrm{F}}(\mathrm{t}=7)=0.627$ & $\mathrm{X}_{\mathrm{k}(1)}{ }^{\mathrm{F}}(\mathrm{t}=7)=0.3819$ & $\pi_{\mathrm{k}(1)}{ }^{\mathrm{F}}(\mathrm{t}=7)=0.3626-\mathrm{f}$ \\
$\mathrm{p}_{\mathrm{k}(1)}{ }^{\mathrm{F}}(\mathrm{t}=8)=1.702$ & $\mathrm{a}_{\mathrm{k}(1)}{ }^{\mathrm{F}}(\mathrm{t}=8)=0.638$ & $\mathrm{X}_{\mathrm{k}(1)}{ }^{\mathrm{F}}(\mathrm{t}=8)=0.3830$ & $\pi_{\mathrm{k}(1)}{ }^{\mathrm{F}}(\mathrm{t}=8)=0.4484-\mathrm{f}$
\end{tabular}




\begin{tabular}{llll}
$\mathrm{p}_{\mathrm{k}(2)}{ }^{\mathrm{F}}(\mathrm{t}=7)=1.145$ & $\mathrm{a}_{\mathrm{k}(2)}{ }^{\mathrm{F}}(\mathrm{t}=7)=0.490$ & $\mathrm{X}_{\mathrm{k}(2)}^{\mathrm{F}}(\mathrm{t}=7)=0.3594$ & $\pi_{\mathrm{k}(2)}^{\mathrm{F}}(\mathrm{t}=7)=0.2914-\mathrm{f}$ \\
$\mathrm{p}_{\mathrm{k}(2)}{ }^{\mathrm{F}}(\mathrm{t}=8)=1.303$ & $\mathrm{a}_{\mathrm{k}(2)}{ }^{\mathrm{F}}(\mathrm{t}=8)=0.506$ & $\mathrm{X}_{\mathrm{k}(2)}{ }^{\mathrm{F}}(\mathrm{t}=8)=0.3602$ & $\pi_{\mathrm{k}(2)}^{\mathrm{F}}(\mathrm{t}=8)=0.3412-\mathrm{f}$ \\
$\mathrm{p}_{\mathrm{k}(3)}{ }^{\mathrm{F}}(\mathrm{t}=7)=0.749$ & $\mathrm{a}_{\mathrm{k}(3)}{ }^{\mathrm{F}}(\mathrm{t}=7)=0.409$ & $\mathrm{X}_{\mathrm{k}(3)}{ }^{\mathrm{F}}(\mathrm{t}=7)=0.3426$ & $\pi_{\mathrm{k}(3)}{ }^{\mathrm{F}}(\mathrm{t}=7)=0.1730-\mathrm{f}$ \\
$\mathrm{p}_{\mathrm{k}(3))}{ }^{\mathrm{F}}(\mathrm{t}=8)=1.050$ & $\mathrm{a}_{\mathrm{k}(3)}{ }^{\mathrm{F}}(\mathrm{t}=8)=0.394$ & $\mathrm{X}_{\mathrm{k}(3)}{ }^{\mathrm{F}}(\mathrm{t}=8)=0.3436$ & $\pi_{\mathrm{k}(3)}{ }^{\mathrm{F}}(\mathrm{t}=8)=0.2832-\mathrm{f}$ \\
\hline $\mathrm{PS}(\mathrm{t}=7)=2.044-6 \mathrm{f}$ & $\mathrm{CS}(\mathrm{t}=7)=2 \mathrm{y}-6.568$ & $\mathrm{TW}(\mathrm{t}=7)=2 \mathrm{y}-4.524-6 \mathrm{f}$ \\
$\mathrm{PS}(\mathrm{t}=8)=2.496-6 \mathrm{f}$ & $\mathrm{CS}(\mathrm{t}=8)=2 \mathrm{y}-9.083$ & $\mathrm{TW}(\mathrm{t}=8)=2 \mathrm{y}-6.587-6 \mathrm{f}$ \\
\hline$\Delta(\mathrm{PS})_{\mathrm{t}=7}=0.824$ & $\Delta(\mathrm{CS})_{\mathrm{t}=7}=-5.559$ & $\Delta(\mathrm{TS})_{\mathrm{t}=7}=-4.735<0$ \\
$\Delta(\mathrm{PS})_{\mathrm{t}=8}=1.056$ & $\Delta(\mathrm{CS})_{t=8}=-7.824$ & $\Delta(\mathrm{TS})_{\mathrm{t}=8}=-6.768<0$
\end{tabular}

\subsection{CONCLUDING REMARKS}

Two merging firms that act as a Stackelberg price-quality leader decrease both the price and quality levels of their two product variants relative to the price and quality levels of the two followers, even if they operate from physically separate sites, because they take into account the fact that each firm, by decreasing price and quality, benefits itself and its partner by inducing the neighbours between them to increase both price and quality. Although the post-merger prices and qualities of the Stackelberg merged firm $M$ are lower than that of its two competitors, the numerical change in producers' surplus exceeds the numerical change in consumers' surplus, relative to the pre-merger Nash equilibrium values, to result in a socially efficient or welfare enhancing merger.

The two-firm non-neighbour Stackelberg leader facing four competitor-follower firms, increases the price and decreases the quality levels of its two product brands because they take into account the fact that each firm, by increasing the price and decreasing quality, again benefits itself and its member-firm by inducing the isolated competitor-follower between them to increase both the price and quality of its variant, 
relative to the pre-merger levels. The price and quality level set by the isolated competitor-follower firm is lower than that set by the Stackelberg leader, but is higher than the prices and qualities chosen, in equilibrium, by the remaining single-product follower firms in the industry. The numerical simulation results indicate such mergers have a socially inefficient impact on an economy since the numerical change in value of the loss in consumers' surplus outweighs the numerical change in value gained in producers' surplus, relative to the pre-merger Nash equilibrium values.

A natural extension of the Stackelberg non-neighbour merger model would be to consider a leader firm $M$, comprised of a set of three-or-more non-neighbouring firms. There must be at least $n \geq 6$ number of pre-merger firms to participate in a merger configuration type where one follower firm is situated between each of the three, for example, non-neighbouring merging firms. For $n=6$ pre-merger firms, then a Stackelberg merger equilibrium outcome of three firms appears analogous to a two-firm non-neighbour Stackelberg merger equilibrium outcome with two follower firms $(n+q=$ 4). In other words, given $n=6$ pre-merger firms where a two-firm Stackelberg merged firm exists, is there an incentive for the leader to acquire one more firm, or one more product variety?

Although not formally shown, the Stackelberg leader of three non-neighbouring firms would likely follow a price-quality policy like that of the two-firm Stackelberg merger with two followers where $p^{M}<p^{F}$ and $a^{M}<a^{F}$. Since $X^{M}>X^{I^{\prime}}$ then $\pi^{M}>\pi^{F}$. Note that for both of these Stackelberg mergers, the industry is "captured", or completely "surrounded". The numerical simulation results of the two-firm Stackelberg merger with 
$q=2$ followers indicate a socially efficient merger based on the total welfare criterion. If the two-firm Stackelberg leader acquires another firm, then an additional product variety would more than likely increase prices and qualities for all varieties, and thus producers' surplus so that $T W>0$. If there are $n \geq 7$ pre-merger firms, then a Stackelberg merger of three non-neighbour firms would isolate two follower firms. The price-quality policy of this type of leader would appear to be similar to that of the two-firm Stackelberg firm where there are $n=5$ pre-merger firms. Whether or not the industry is completely "bought out" or not, it appears, on the basis of the reasoning given, that the incentive is present for Stackelberg non-neighbour mergers to extend to three firms, and beyond. 


\subsection{THE GENERALIZED STACKELBERG PRICE-QUALITY MERGER MODEL}

This section contains the main existence and uniqueness results of the generalized Stackelberg price-quality game $\Gamma^{S}$. The Stackelberg equilibrium outcome for the postmerger prices and the quality levels of all firms are characterized with respect to the $q$ outside competitors, or followers for an n-neighbour firm Stackelberg merger. The section commences with a description of the game-theoretic model of the industrial market structure.

The description of the Stackelberg price-quality game $\Gamma^{S}$ :

The industrial market structure consists of $n+q \geq 4$ firms symmetrically situated around a circle $C$ of length $L$. The (fixed) firms sites located at $x_{1}, x_{2}, \ldots, x_{n}, x_{n+1}, \ldots, x_{n+q}$ on $C$ are physically and symmetrically separated by an equivalent distance of $L /(n+q)$ units. Suppose that there is a merger among $n$ firms belonging to the corporate entity, a multiproduct firm $M$, which jointly produces a set of $M=\{1, \ldots, n\}$ product variants. The $q$ outside firms, or followers, belonging to the set $F=\{n+1, n+2, \ldots, n+k, \ldots, n+q\}$ remain outside to such merger activity, and each firm produces a single product variant. The multi-product firm $M$, acting as a leader, maximizes its joint profits $\Pi_{M}^{S}($.$) by choosing$ a set of prices $\left\{p_{I}^{M}, \ldots, p_{n}^{M}\right\}$, and decentralizes the choice of a set of quality levels $\left\{a_{1}^{M}, \ldots, a_{n}{ }^{M}\right\}$ to its $n$-firm members, subject to the $q$ firms' (followers) independent, but simultaneous choices of prices $\left\{p_{l}^{F}, \ldots, p_{q}^{F}\right\}$, and quality levels $\left\{a_{I}^{F}, \ldots, a_{q}^{F}\right\}$, of their respective single-product variants. Once the $q$ single-product followers have observed the Stackelberg merged firm $M$ 's price-quality decision, they continue to act in an 
independent Nash manner and choose their price-quality choices.

The Stackelberg price-quality equilibrium of the spatial game between the $q+1$ players, the leader, or the multi-product firm $M$, and the set of $q$ rival competitor firms (followers), is solved by using the backward induction method. In the second stage of the game, after viewing the joint price-quality choice made by the leader, each of the $q$ follower firms maximizes their profits by simultaneously choosing a price and quality level for its single-product variant, which is independent of the choices made by the leader, firm $M$, and all other follower firms. In the first stage of the game, the Stackelberg multi-product firm $M$, aticipates the price-quality decisions of the $q$ follower firms and maximizes the joint profits of its n-neighbour firm members by the simultaneous choice of prices made by the corporate authority, and the decentralized quality levels chosen by the $n$-firm members, of their $n$ multi-product variants.

The existence of a pure strategy Stackelberg price-quality equilibrium depends on the assumption that $n+q \geq 4$ firms participate in the game. The Stackelberg leader, firm $M$ controls a total joint market size of length $n L /(n+q)$ over its set of $n$ multi-variant products. Each of the non-merged firms has an identical market size of length $L /(n+q)$ over its single-product variant. The Stackelberg price-quality game $\Gamma^{S}$ is played between $q+1$ firms: a leader, the multi-product firm $M$, and the $q$ followers, which compete against each other in Nash prices and qualities, after viewing the leader's price-quality choice.

\section{Best-response Stackelberg price and quality functions of the qfollower firms:}

The general solution of the $(2 q)$ price-quality difference equations of the outside 
competitor firms is given by equations (A.25) and (A.20), respectively [see Appendix A], where the marginal cost of production is set at $c=0$. The general price-quality solution for $k=1, \ldots, q$ follower firms is given as $p_{n+k}{ }^{F}=c_{l} \alpha^{k}+c_{2} \beta^{k}+t L^{2} /(n+q)^{2}$ and $a_{n+k}{ }^{F}=$ $N(n+q) / t L^{2}\left(p_{n+k}{ }^{F}\right)$, respectively. The solution for the "undetermined coefficients" $c_{1}$ and $c_{2}$ (as both are functions of $p_{1}^{M}$ and $\left.a_{l}^{M}\right)$, are determined once the Stackelberg prices and quality levels are solved [see Appendix B].

\section{Best-response Stackelberg price and quality functions of the multi-product firm $M$ :}

The best-response functions of the merged firm $M$ are found by solving the $2 n$ first-order conditions, i.e., for the set of $n$ prices $\left(p_{l}{ }^{M}, \ldots, p_{n}{ }^{M}\right)$ found by the corporate authority of the leader, firm $M$, and for the set of $n$ decentralized qualities $\left(a_{l}^{M}, \ldots, a_{n}{ }^{M}\right)$, by maximizing the following joint profit objective function;

$\max \Pi_{M}=\max \sum_{i=1}^{n} \pi_{i}\left(p_{1}^{M}, \ldots, p_{n}^{M}, a_{1}^{M}, \ldots, a_{n}^{M} ; p_{n+1}^{F}, \ldots, p_{n+q}^{F}, a_{n+1}^{F}, \ldots, a_{n+q}^{F}\right)$

subject to the simultaneous choice of prices $\left(p_{n+1}{ }^{F}, \ldots, p_{n+q}{ }^{F}\right)$, and quality levels

$\left(a_{n+l}{ }^{F}, \ldots, a_{n+q}^{F}\right)$ chosen by the $q$ outside competitor-follower firms. The general solution of the (2q) price-quality difference equations of the outside competitive firms for the equilibrium outcome is given by the above respective equations as $p_{n+k}{ }^{F}=c_{1} \alpha^{k}+c_{2} \beta^{k}+$ $t L^{2} /(n+q)^{2}$ and $a_{n+k}{ }^{F}=N(n+q) / t L^{2}\left(p_{n+k}{ }^{F}\right)$, for $k=1, \ldots, q$.

The joint profit function of the Stackelberg merged firm $M$ is written as the sum of three terms to reflect the nature of the functional dependence of its own two peripheral members' profit on the two, adjacent outside competitors' prices and qualities;

$$
\Pi_{M}=\left(p_{1}{ }^{M}\right) \frac{N}{L}\left[\frac{\left(p_{2}{ }^{M}-a_{2}{ }^{M}\right)-2\left(p_{1}{ }^{M}-a_{1}{ }^{M}\right)+\left(p_{n+q}^{F}-a_{n+q}^{F}\right)}{2 t L /(n+q)}+\frac{L}{n+q}\right]-\frac{1}{2}\left(a_{1}{ }^{M}\right)^{2}-f+
$$


$\sum_{i=2}^{n-1}\left(p_{i}{ }^{M}\right) \frac{N}{L}\left[\frac{\left(p_{i+1}^{M}-a_{i+1}^{M}\right)-2\left(p_{i}^{M}-a_{i}^{M}\right)+\left(p_{i-1}^{M}-a_{i-1}^{M}\right)}{2 t L /(n+q)}+\frac{L}{n+q}\right]-\frac{1}{2} \sum_{i=2}^{n-1}\left(a_{i}{ }^{M}\right)^{2}-(n+q-2) f$

$+\left(p_{n}^{M}\right) \frac{N}{L}\left[\frac{\left(p_{n+1}^{F}-a_{n+1}^{F}\right)-2\left(p_{n}^{M}-a_{n}^{M}\right)+\left(p_{n-1}^{M}-a_{n-1}^{M}\right)}{2 t L /(n+q)}+\frac{L}{n+q}\right]-\frac{1}{2}\left(a_{n}^{M}\right)^{2}-f$

where the following equations [see equations (A.26) and (A.27)Appendix 3(A)] for $\left(p_{n+1}{ }^{F}\right.$ $\left.-a_{n+1}{ }^{F}\right)$ and $\left(p_{n+q}^{F}-a_{n+q}{ }^{F}\right)$, respectively, are substituted into the above equation (4.9) to arrive at the reduced-form profit function of the multi-product Stackelberg firm M:

$$
\begin{aligned}
& p_{n+1}^{F}-a_{n+1}^{F}=\frac{\left(\alpha^{2} l-\alpha^{2} r\right)\left[t L^{2}-N(n+q)\right]}{\left(\alpha^{q} l^{2}-\alpha^{2} r^{2}\right)}\left[\left(p_{1}^{M}-a_{1}^{M}\right)-\frac{\left[t L^{2}-N(n+q)\right]}{(n+q)^{2}}\right]+\frac{\left[t L^{2}-N(n+q)\right]}{(n+q)^{2}} \\
& +\frac{\left(\alpha^{2} l-\alpha^{2} r\right)\left[t L^{2}-N(n+q)\right]}{\alpha^{3}\left(\alpha^{q} l^{2}-\alpha^{2}-\alpha^{2} r^{2}\right)}\left[\left(p_{n}^{M}-a_{n}^{M}\right)-\frac{\left[t L^{2}-N(n+q)\right]}{(n+q)^{2}}\right] \\
& p_{n+q}^{F}-a_{n+q}^{F}=\frac{\alpha^{q-1}\left(\alpha^{2} l-\alpha^{2} r\right)\left[t L^{2}-N(n+q)\right]}{\left(\alpha^{q} l^{2}-\alpha^{2} r^{2}\right)}\left[\left(p_{1}^{M}-a_{1}^{M}\right)-\frac{\left[t L^{2}-N(n+q)\right]}{(n+q)^{2}}\right]+\frac{\left[t L^{2}-N(n+q)\right]}{(n+q)^{2}} \\
& +\frac{\left(\alpha^{q} l-\alpha^{2} r\right)\left[t L^{2}-N(n+q)\right]}{\alpha^{q+2}\left(\alpha^{q} l^{2}-\alpha^{2} r^{2}\right)}\left[\left(p_{n}^{M}-a_{n}^{M}\right)-\frac{\left[t L^{2}-N(n+q)\right]}{(n+q)^{2}}\right]
\end{aligned}
$$

The above expressions contain the terms $l=(4 \alpha-1) t L^{2}-(2 \alpha-1) N(n+q)$ and $r=(4-$ $\alpha) t L^{2}-(2-\alpha) N(n+q)$.

The first-order conditions for prices are characterized by the following set of $n$ equations: 


$$
\begin{aligned}
& p_{1}{ }^{M}=\frac{\left(\alpha^{q} l^{2}-\alpha^{2} r^{2}\right)\left[3 t L^{2}-N(n+q)\right]}{2(n+q)^{2}\left[d_{1}\right]}-\frac{\left(\alpha^{q} l-\alpha^{2} r\right)\left[t L^{2}-N(n+q)\right]^{2}\left(1+\alpha^{2 q+1}\right)}{2 \alpha^{2 q+1}(n+q)^{2}\left[d_{1}\right]}+\frac{1}{2} a_{1}^{M} \\
& +\frac{\left(\alpha^{q} l^{2}-\alpha^{2} r^{2}\right) p_{2}^{M}}{\left[d_{1}\right]}-\frac{\left(\alpha^{q} l^{2}-\alpha^{2} r^{2}\right) a_{2}^{M}}{\left[2 d_{1}\right]}+\frac{\left(\alpha^{q} l-\alpha^{2} r\right)\left[t L^{2}-N(n+q)\right]\left(1+\alpha^{q+2}\right) p_{n}^{M}}{2 \alpha^{q+2}\left[d_{1}\right]} \\
& -\frac{\left(\alpha^{q} l-\alpha^{2} r\right)\left[t L^{2}-N(n+q)\right] a_{n}^{M}}{2 \alpha^{q+2}\left[d_{1}\right]} \\
& p_{i}^{M}=\frac{1}{2}\left(p_{i+1}^{M}+p_{i-1}^{M}\right)+\frac{1}{2} a_{i}^{M}-\frac{1}{4}\left(a_{i+1}^{M}-a_{i-1}^{M}\right)+\frac{t L^{2}}{2(n+q)^{2}} ; \quad i=2,3, \ldots, n-1 \\
& p_{n}^{M}=\frac{\alpha^{3}\left(\alpha^{q} l^{2}-\alpha^{2} r^{2}\right)\left[3 t L^{2}-N(n+q)\right]}{2(n+q)^{2}\left[d_{3}\right]}-\frac{\left(\alpha^{q} l-\alpha^{2} r\right)\left[t L^{2}-N(n+q)\right]^{2}\left(1+\alpha^{3}\right)}{2(n+q)^{2}\left[d_{3}\right]}+\frac{1}{2} a_{n}^{M} \\
& +\frac{\alpha^{3}\left(\alpha^{q} l^{2}-\alpha^{2} r^{2}\right) p_{n-1}^{M}}{\left[d_{3}\right]}-\frac{\alpha^{3}\left(\alpha^{q} l^{2}-\alpha^{2} r^{2}\right) a_{n-1}^{M}}{2\left[d_{3}\right]}+\frac{\alpha^{3}\left(\alpha^{q} l-\alpha^{2} r\right)\left[t L^{2}-N(n+q)\right]\left(1+\alpha^{q+2}\right) p_{1}^{M}}{2 \alpha^{q+2}\left[d_{3}\right]} \\
& -\frac{\alpha^{3}\left(\alpha^{q} l-\alpha^{2} r\right)\left[t L^{2}-N(n+q)\right] a_{1}^{M}}{2\left[d_{3}\right]}
\end{aligned}
$$

The above equations contain the terms $\left[d_{l}\right]=2\left(\alpha^{A} l^{2}-\alpha^{2} r^{2}\right)-\alpha^{q-1}\left[t L^{2}-N(n+q)\right]\left(\alpha^{q} l-\alpha^{2} r\right)$ and $\left[d_{3}\right]=2 \alpha^{3}\left(\alpha^{q} l^{2}-\left[t L^{2}-N(n+q)\right]\left(\alpha^{q} l-\alpha^{2} r\right)\right.$. 
The first-order conditions for the quality levels are characterized by the following set of $n$ equations:

$a_{1}^{M}=\frac{N(n+q)}{2 t L^{2}\left(\alpha^{q} l^{2}-\alpha^{2} r^{2}\right)}\left[2\left(\alpha^{q} l^{2}-\alpha^{2} r^{2}\right)-\alpha^{q-1}\left(\alpha^{q} l-\alpha^{2} r\right)\left[t L^{2}-N(n+q)\right]\right] p_{1}^{M}$

$a_{i}^{M}=\frac{N(n+q)}{t L^{2}}\left(p_{i}{ }^{M}\right) ; \quad i=2, \ldots, n-1$.

$a_{n}^{M}=\frac{N(n+q)}{2 t L^{2} \alpha^{3}\left(\alpha^{q} l^{2}-\alpha^{2} r^{2}\right)}\left[2 \alpha^{3}\left(\alpha^{q} l^{2}-\alpha^{2} r^{2}\right)-\left(\alpha^{q} l-\alpha^{2} r\right)\left[t L^{2}-N(n+q)\right]\right] p_{n}^{M}$

The first-order conditions for prices, after appropriate substitutions of equations (4.13) to (4.15) for the Stackelberg merged-firm $M$ quality variables, is written as the following general system of $n$ linear, recursive non-homogeneous second-order difference equations with constant coefficients:

$$
\begin{aligned}
& p_{1}^{M}=\frac{2 t L^{2} \alpha^{q+5}\left[3 t L^{2}-N(n+q)\right]\left(\alpha^{q} l^{2}-\alpha^{2} r^{2}\right)^{2}}{(n+q)^{2}\left[d_{1}^{*}\right]}+\frac{2 \alpha^{q+5}\left(\alpha^{q} l^{2}-\alpha^{2} r^{2}\right)^{2}\left[2 t L^{2}-N(n+q)\right]}{\left[d_{1}^{*}\right]} \\
& -\frac{2 t L^{2} \alpha^{3}\left(1+\alpha^{2 q+1}\right)\left(\alpha^{q} l-\alpha^{2} r\right)\left(\alpha^{q} l^{2}-\alpha^{2} r^{2}\right)\left[t L^{2}-N(n+q)\right]^{2}}{(n+q)^{2}\left[d_{1}^{*}\right]} \\
& p_{i}^{M}=\frac{1}{2}\left(p_{i-1}^{M}+p_{i+1}^{M}\right)+\frac{\left(t L^{2}\right)^{2}}{(n+q)^{2}\left[2 t L^{2}-N(n+q)\right]} ; \quad i=2, \ldots, n-1
\end{aligned}
$$


$p_{n}{ }^{M}=\frac{2 t L^{2} \alpha^{q+6}\left(\alpha^{q} l^{2}-\alpha^{2} r^{2}\right)^{2}\left[3 t L^{2}-N(n+q)\right]}{(n+q)^{2}\left[d_{2}^{*}\right]}+\frac{2 \alpha^{q+6}\left(\alpha^{q} l^{2}-\alpha^{2} r^{2}\right)^{2}\left[2 t L^{2}-N(n+q)\right] p_{n-1}^{M}}{\left[d_{2}^{*}\right]}$

$-\frac{2 t L^{2} \alpha^{q+3}\left(1+\alpha^{3}\right)\left(\alpha^{q} l-\alpha^{2} r\right)\left(\alpha^{q} l^{2}-\alpha^{2} r^{2}\right)\left[t L^{2}-N(n+q)\right]^{2}}{(n+q)^{2}\left[d_{2}^{*}\right]}$

The above expressions contain the terms $\left[d_{2}\right]=2\left(\alpha^{A} l^{2}-\alpha^{2} r^{2}\right)\left[2 t L^{2}-N(n+q)\right]-\alpha^{q-l}\left(\alpha^{4} l-\right.$ $\left.\alpha^{2} r\right) N(n+q)\left[t L^{2}-N(n+q)\right]$ and $\left[d_{4}\right]=4 t L^{2} \alpha^{3}\left(\alpha^{q} l^{2}-\alpha^{2} r^{2}\right)-N(n+q)\left[d_{3}\right]$.

The above expressions also contain the terms $\left[d_{1}^{*}\right]=\alpha^{q+5}\left[d_{1}\right]\left[d_{2}\right]-\left(\alpha^{q} l-\alpha^{2} r\right)\left[t L^{2}-\right.$ $N(n+q)]\left[2 t L^{2}\left(\alpha^{q} l^{2}-\alpha^{2} r^{2}\right) \alpha^{3}\left(1+\alpha^{q+2}\right)-N(n+q)\left[d_{3}\right]\right]$ and $\left[d_{2}^{*}\right]=\alpha^{q}\left[d_{3}\right]\left[d_{t}\right]-\alpha^{4}\left(\alpha^{q} l-\alpha^{2} r\right)$ $\left[t L^{2}-N(n+q)\right]\left[2 t L^{2}\left(1+\alpha^{q}{ }^{2}\right)\left(\alpha^{q} l^{2}-\alpha^{2} r^{2}\right)-N(n+q)\left[d_{1}\right]\right]$. The set of equations, (4.16) to (4.18), represent a system of $n$ linear recursive non-homogeneous second-order price difference equations with constant coefficients. The equations (4.16) and (4.18) represent the boundary, or initial conditions and determine the remaining $(n-2)$ price difference equations. Each of the initial conditions is a function of the price $\left(p_{2}{ }^{M}\right.$ and $\left.p_{n-1}{ }^{M}\right)$ respectively, of their own nearest member firm. The $(n-2)$ price difference equations (4.17) of the system are each solely a function of their two respective members firms' prices. The following proposition characterizes the price-quality Stackelberg equilibrium of an n-neighbour firm merger.

\section{The Stackelberg Equilibrium of the Price-Quality Game $\Gamma^{s}$ :}

Proposition 4.2(A): The price-quality Stackelberg equilibrium pairs of the game $\Gamma^{S}$ for the multi-product firm Mare given by their respective strategic variable solutions of the 
system of non-homogeneous, linear and recursive, second-order difference equations as the following expressions:

$p_{i}^{M}=a^{*}+b^{*} i-\frac{i^{2}\left(t L^{2}\right)^{2}}{(n+q)^{2}\left[2 t L^{2}-N(n+q)\right]} ; \quad$ for $i=1,2, \ldots, n$

The solutions of the "undetermined coefficients", $a^{*}$ and $b^{*}$, respectively, are given in the Appendix 4(B).

Proof: see Appendix 4(B) for the solutions of the strategic game variables.

Proposition 4.2(B): The price-quality Stackelberg equilibrium pairs of the game $\Gamma^{S}$ for the outside competitors $k \epsilon F$ are the strategic variable solutions of the system of nonhomogeneous, linear and recursive second-order difference equations as the following expressions:

$p_{n+k}^{F}=c_{1}^{*}(\alpha)^{k}+c_{2}^{*}(\beta)^{k}+\frac{t L^{2}}{(n+q)^{2}}$ for $k=1, \ldots, q$

where the solution of the "undetermined coefficients", $c_{1}{ }^{*}$ and $c_{2}{ }^{*}$, are given by the following equations:

$$
\begin{aligned}
& c_{1}^{*}=\frac{\left(\alpha^{q} l-\alpha^{2} r\right)\left[t L^{2}-N(n+q)\right]}{\alpha\left(\alpha^{q} l^{2}-\alpha^{2} r^{2}\right)}\left[(n+q)^{2}\left(a^{*}+b^{*}\right)-\frac{t L^{2}\left[t L^{2}-N(n+q)\right]}{\left[2 t L^{2}-N(n+q)\right]}\right] \\
& c_{2}^{*}=\left(\alpha^{-1}\right) c_{1}^{*} \\
& a_{n+k}^{F}=\frac{N(n+q)}{t L^{2}}\left(p_{n+k}^{F}\right) \text { for } k=1, \ldots, q
\end{aligned}
$$


Proof: see Appendix 4(B) for the solutions of the strategic game variables.

The following corollary characterizes the outcome of the Stackelberg price-quality equilibrium market shares for the Stackelberg leader, firm $M$, and the $q$ competitorfollower firms:

\section{Pattern of the Stackelberg Equilibrium Market Shares:}

Corollary 4.2(A): The price-quality Stackelberg equilibrium outcomes for the market shares, or the quantity sold by the multi-product leader, firm $M$, are given by the following expressions:

$$
\begin{aligned}
& X_{1}^{M}=X_{n}^{M}=\frac{N}{(n+q)}-\frac{N^{2}\left[t L^{2}-N(n+q)\right]}{2 t L^{2}\left[2 t L^{2}-N(n+q)\right]}+\frac{N(n+q)\left[t L^{2}-N(n+q)\right]}{2\left(t L^{2}\right)^{2}}\left[c_{1}^{*}\left(1+\alpha^{-2}\right)-a^{*}\right] \\
& X_{2}^{M}=X_{n-1}^{M}=\frac{N\left[t L^{2}-N(n+q)\right]}{(n+q) t L^{2}}+\frac{N(n+q)\left[t L^{2}-N(n+q)\right]}{2\left(t L^{2}\right)^{2}}\left[b^{*}-a^{*}+c_{1}^{*}\left(\alpha^{2}+\alpha^{-3}\right)\right] \\
& X_{i}^{M}=\frac{N t L^{2}}{(n+q)\left[2 t L^{2}-N(n+q)\right]} \text { for } i=3, \ldots, n-2
\end{aligned}
$$

Corollary 4.2(B): The price-quality Stackelberg equilibrium outcomes for the market shares, or the quantity sold by the q competitor-followers are given by the following expressions:

$$
X_{n+1}^{F}=X_{n+q}^{F}=\frac{N}{(n+q)}-\frac{N\left[t L^{2}-N(n+q)\right]\left[3 t L^{2}-N(n+q)\right]}{2(n+q) t L^{2}\left[2 t L^{2}-N(n+q)\right]}
$$


$+\frac{N(n+q)\left[t L^{2}-N(n+q)\right]}{2\left(t L^{2}\right)^{2}}\left[a^{*}+b^{*}-c_{1}^{*}\left[\alpha(2-\alpha)+\alpha^{-3}(2 \alpha-1)\right]\right]$

$$
X_{n+k}^{F}=\frac{N}{(n+q)}+\frac{N(n+q)\left[t L^{2}-N(n+q)\right]}{2\left(t L^{2}\right)^{2}}\left[c_{1}^{*}(\alpha-1)^{2} \alpha^{k-3}\left(\alpha^{2}-1\right)\right] \text { for } k=2, \ldots, q-1
$$

The general solution of the Stackelberg price-quality equilibrium outcome of the postmerger profit levels of all firms is too complicated to allow for an analysis of the effects of a merger for the general model. Thus, the numerical simulations of the general model provided in the next section (4.6) of the chapter demonstrate such merger effects for a special case of a two-neighbour firm merger with four follower-competitors. 


\subsection{AN ANALYSIS OF THE STACKELBERG PRICE-QUALITY (NEIGHBOUR) TWO-FIRM MERGER MODEL AND THE POTENTIAL FOR ANTI-} COMPETITIVE EFFECTS

To analyze the potential for anti-competitive effects of a two-neighbour firm Stackelberg price-quality merger, the numerical simulation of the equilibrium outcome for the post-merger prices, quality levels, quantity sold, and the profits of all firms are solved for the post-merger industry structure with four outside, competitor-followers [see Table 4.5]. These numerical results show the post-merger pattern, and the relative magnitude of the equilibrium outcome, and the total welfare effects of a Stackelberg merger of two neighbouring firms.

In the case of a pre-merger industry with six firms, a similar pattern of the equilibrium outcome for the prices, quality levels, and profit shares for both the twoneighbour firm leader, and the four followers, results as compared with a two-firm nonneighbour Stackelberg merger. Competition for consumers is least intense for the two follower firms physically located equi-distantly near the bi-variant firm $M$ 's market periphery. The intensity of the price-quality competition is as the highest level for the two outside competitors located furthest from the leader's joint market areas and is reflected in the lowest (identical) post-merger equilibrium price and quality set by these firms. Suppose that the firms located at $x_{1}$ and $x_{2}$ on $C$ merge, then the follower members located at $x_{+}$and $x_{5}$, offer consumers the lowest price, and quality level as its direct competition is only from two independent competitors.

Table 4.5 provides the simulation results of a five-firm post-merger industry for 
which the unit transport costs are $t=7$ and 8 , with parameter values set at $N=L=1$. If the unit transport cost $t$ increases, the post-merger prices, market shares, quality levels and profits all increase for the two-neighbour Stackelberg leader. Similarly, if the unit transport cost $t$ increases, the post-merger prices, and the profit level of all four outside competitors increases, while the quality levels and the quantity sold of the independent variants all decrease. The leader, however, sells a greater quantity of its two product variants than any of its competitors, but at quality levels less than the outside competition.

The numerical simulation results show that a two-neighbour firm Stackelberg price-quality merger with four follower-competitors, increases the post-merger profits of all firms in the industry such that $\pi^{M}>\pi_{k(l)}{ }^{F}>\pi_{k(2)}{ }^{F}$, and all non-merged firms earn less profits than each party to the merged firm $M$. This result is contrary to that of the standard (non-spatial) oligopoly Stackelberg merger with price leadership only, where the post-merger profits display the "free-rider problem", or $\pi^{M}<\pi_{k(1)}{ }^{F}<\pi_{k(2)}{ }^{F}$, so that a merger increases the post-merger profits in such a manner. Thus, the free-rider problem is absent for a spatial Stackelberg price-quality merger of two neighbouring firms.

The simulation results show that the loss in consumers' surplus is less than the gain to producers' surplus and consequently total welfare is positive for each unit value of ı. Since $\Delta(T W)>0$, measured relative to the pre-merger Nash price-quality equilibrium values, a Stackelberg merger of two neighbouring firms with four competitor-follower firms results in a socially efficient merger as the change in the total welfare value is positive. 
Table 4.5: Total Welfare Simulation Results - Stackelberg Two-Firm

\section{(Neighbour) Merger}

( $\mathrm{n}=2$ and $\mathrm{q}=4)$ and $\mathrm{N}=\mathrm{L}=1(\mathrm{t}=7$ and 8$)$

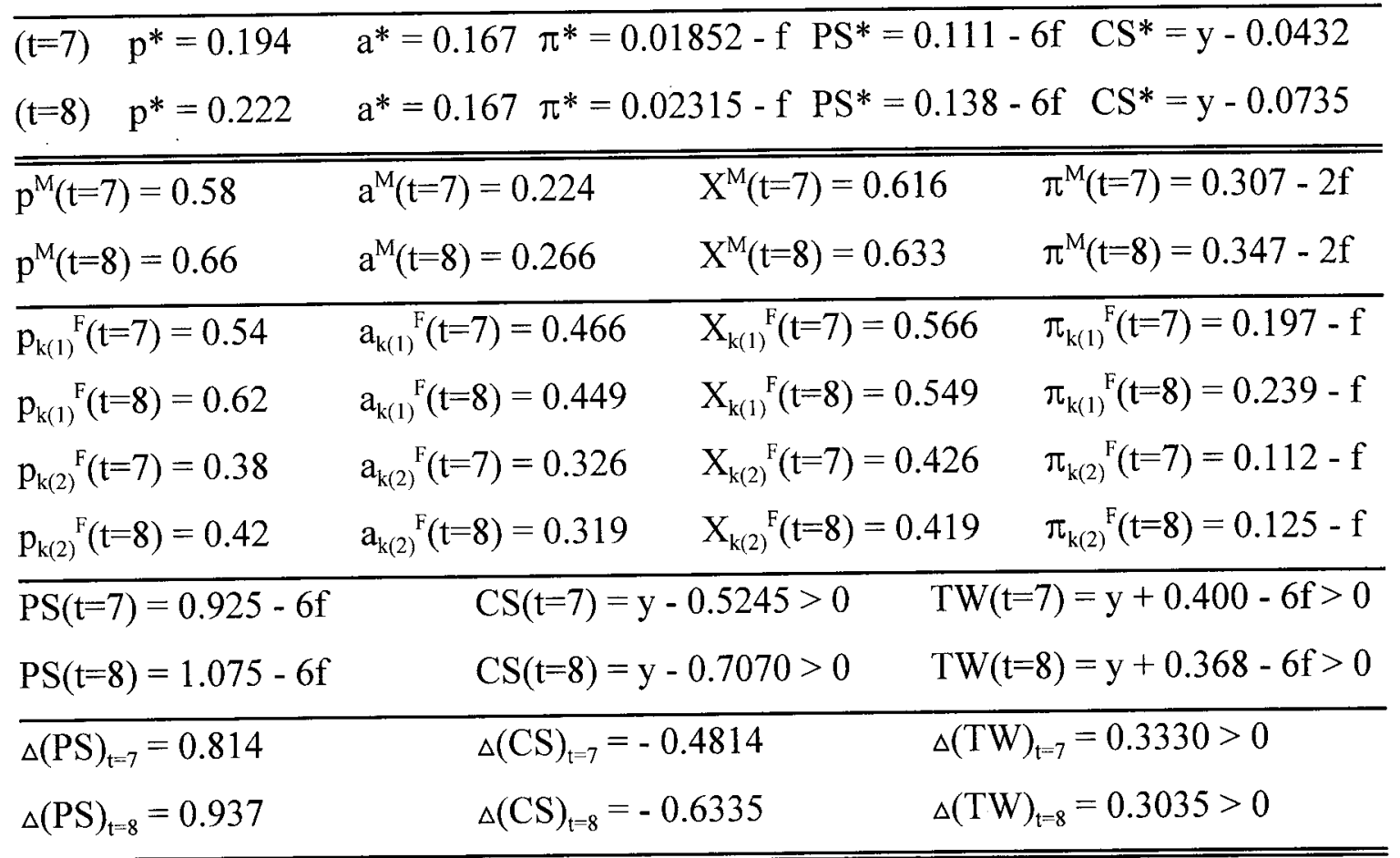

A comparison between the two-firm, neighbour, and the non-neighbour

Stackelberg merger on the post-merger prices, quality levels, profit shares, and total welfare can be described for the same set of parameter values [see Table 4.3 and Table 4.5]. The price-quality equilibrium strategy chosen by that of a leader with two neighbouring firms indicates that the significantly greater gain in profits are a result of higher prices and quality levels for its two jointly produced variants. Consumers who purchase their preferred variants from competitive rivals gain under a merger of two nonneighbouring firms since post-merger prices are lower but with corresponding lower product qualities. Not surprisingly then, the loss in consumers' surplus is significantly 
less under a two-firm non-neighbour merger. However, the total transport costs incurred by consumers is calculated as $(-0.032)$ if $t=7$, and they are less than the total costs (0.045 ) incurred by consumers under a Stackelberg merger of two non-neighbouring firms with four follower-competitive firms, and the same parameter model values. The total gain in the change in welfare to the economy is significantly greater under a Stackelberg merger of two neighbouring firms. 


\section{APPENDIX: CHAPTER THREE}

\section{(I) Proof: A Two-Firm Merger of Non-Neighbouring Firms}

Suppose that a merger occurs between two non-neighbouring firms $i$, and $i+2$, where $i \neq i+2$, or $i$ itself. The joint profit-maximizing function of the multi-product firm $M$ that simultaneously chooses prices $\left\{p_{i}^{M}, p_{i+2}{ }^{M}\right\}$, and quality levels $\left\{a_{i}^{M}, a_{i+2}{ }^{M}\right\}$, is given by the following:

$$
\pi^{M}=\pi_{i}^{M}+\pi_{i+2}^{M}=\left(p_{i}^{M}-c\right) \frac{N}{L} X_{i}^{M}-\frac{1}{2}\left(a_{i}^{M}\right)^{2}+\left(p_{i+2}^{M}-c\right) \frac{N}{L} X_{i+2}^{M}-\frac{1}{2}\left(a_{i+2}^{M}\right)^{2}-2 f .
$$

The necessary conditions with respect to prices $p_{i}^{M}$ and $p_{i+2}{ }^{M}$, respectively, are given by $\partial \pi^{M} / \partial p_{i}^{M}=0$ and $\partial \pi^{M} / \partial p_{i+2}{ }^{M}=0$, and produce the two reaction functions;

$$
\begin{aligned}
& p_{i}^{M}=\frac{1}{4}\left(p_{i+1}^{F}-a_{i+1}^{F}\right)+\frac{1}{4}\left(p_{i-1}^{F}-a_{i-1}^{F}\right)+\frac{1}{2} t\left(\frac{L}{n}\right)^{2}+\frac{1}{2}\left(a_{i}^{M}+c\right) \\
& p_{i+2}^{M}=\frac{1}{4}\left(p_{i+3}^{F}-a_{i+3}^{F}\right)+\frac{1}{4}\left(p_{i+1}^{F}-a_{i+1}^{F}\right)+\frac{1}{2} t\left(\frac{L}{n}\right)^{2}+\frac{1}{2}\left(a_{i+2}^{M}+c\right)
\end{aligned}
$$

Note that the equations (3.i) and (3.ii) are symmetric since the prices $p_{i-1}{ }^{F}=p_{i+1}{ }^{F}=p_{i \mid 3}{ }^{F} \equiv$ $p_{k(l)}{ }^{F}$, and the quality levels ${a_{i-1}}^{F}=a_{i+1}{ }^{F}=a_{i+3}{ }^{F} \equiv a_{k(l)}{ }^{F}$, are treated as fixed parameters of the outside competitor, or single-product firms. Further, if the merged entity $M$ sets identical quality levels $a_{i}{ }^{M}=a_{i+2}{ }^{M} \equiv a^{M}$, then $p_{i}^{M}=p_{i^{+2}}{ }^{M} \equiv p^{M}$ so that the multi-product firm $M$ sets identical post-merger prices.

The necessary conditions $\partial \pi^{M} / \partial a_{i}^{M}=0$ and $\partial \pi^{M} / \partial a_{i+2}{ }^{M}=0$, with respect to the qualities $a_{i}^{M}$ and $a_{i+2}{ }^{M}$, produce the following reaction functions, respectively; 
$a_{i}^{M}=\left(\frac{n \dot{N}}{t L^{2}}\right)\left(p_{i}^{M}-c\right)$

$a_{i+2}^{M}=\left(\frac{n N}{t L^{2}}\right)\left(p_{i+2}^{M}-c\right)$

Since $p_{i}^{M}=p_{i+2}{ }^{M} \equiv p^{M}$, then equations (3.iii) and (3.iv) imply that quality levels $a_{i}^{M}=$ $a_{i, 2}{ }^{M} \equiv a^{M}$. Further more, equations (3.i) and (3.ii) are independent. Thus, the pricereaction function of each of the merged parties is, respectively, identical to equation (2.4) [see Chapter 2], which is a firm i's price-reaction function in a pre-merger simultaneous Nash price-quality equilibrium. As all outside competitor firms possess price-reaction functions given by equation (2.4), the pre-merger prices are identical to the post-merger prices. Hence, such a firm site configuration is not a profit-maximizing strategy. 


\section{A. THE GENERALIZED PRICE-QUALITY MERGER MODEL}

\section{Proof of Proposition 3.1:}

\section{A. Best-response price and quality functions of the merged firm:}

The set $M=\{1, \ldots, n\}$ denotes the corporate merged entity which is comprised of $n$ member firms, and the set $F=\{1, \ldots, q\}$ represents the number of $q$ non-merged, or singleproduct firms. The industry contains a total of $n+q$ firms. The best-response functions of the merged firm $M$ are found by solving the $2 n$ first-order conditions, i.e., for the set of $n$ prices $\left(p_{l}^{M}, \ldots, p_{n}{ }^{M}\right)$, and for the set of $n$ qualities $\left(a_{l}^{M}, \ldots, a_{n}{ }^{M}\right)$ independently chosen by the $n$-firms. The multi-product firm $M$ maximizes the following joint profit objective function with respect to the set of $n$ prices only;

$\max \Pi_{M}=\max \sum_{i=1}^{n} \pi_{i}\left(p_{1}^{M}, \ldots, p_{n}^{M}, a_{1}^{M}, \ldots, a_{n}^{M} ; p_{n+1}^{F}, \ldots, p_{n+q}^{F}, a_{n+1}^{F}, \ldots, a_{n+q}^{F}\right)$

The joint profit function of the merged firm $M$ is written as the sum of three terms to reflect the nature of the functional dependence of its own two peripheral members' profit on the two adjacent, outside competitors' prices and qualities;

$\Pi_{M}=\left(p_{1}^{M}-c\right) \frac{N}{L}\left[\frac{\left(p_{2}^{M}-a_{2}^{M}\right)-2\left(p_{1}^{M}-a_{1}^{M}\right)+\left(p_{n+q}^{F}-a_{n+q}^{F}\right)}{2 t L /(n+q)}+\frac{L}{n+q}\right]-\frac{1}{2}\left(a_{1}^{M}\right)^{2}-f+$

$\sum_{i=2}^{n-1}\left(p_{i}{ }^{M}-c\right) \frac{N}{L}\left[\frac{\left(p_{i+1}^{M}-a_{i+1}^{M}\right)-2\left(p_{i}{ }^{M}-a_{i}{ }^{M}\right)+\left(p_{i-1}^{M}-a_{i-1}{ }^{M}\right)}{2 t L /(n+q)}+\frac{L}{n+q}\right]-\frac{1}{2} \sum_{i=2}^{n-1}\left(a_{i}{ }^{M}\right)^{2}-(n+q-2) f$

$+\left(p_{n}^{M}-c\right) \frac{N}{L}\left[\frac{\left(p_{n+1}^{F}-a_{n+1}^{F}\right)-2\left(p_{n}^{M}-a_{n}^{M}\right)+\left(p_{n-1}^{M}-a_{n-1}^{M}\right)}{2 t L /(n+q)}+\frac{L}{n+q}\right]-\frac{1}{2}\left(a_{n}^{M}\right)^{2}-f$ 
The first-order conditions for prices are characterized by the following set of $n$ equations:

$$
\begin{aligned}
& p_{1}^{M}=\frac{1}{2} p_{2}^{M}+\frac{1}{4} c+\frac{1}{4} p_{n+q}^{F}+\frac{1}{2} a_{1}^{M}-\frac{1}{4}\left(a_{2}^{M}+a_{n+q}^{F}\right)+\frac{t L^{2}}{2(n+q)^{2}} \\
& p_{i}^{M}=\frac{1}{2}\left(p_{i+1}^{M}+p_{i-1}^{M}\right)+\frac{1}{2} a_{i}^{M}-\frac{1}{4}\left(a_{i+1}^{M}+a_{i-1}^{M}\right)+\frac{t L^{2}}{2(n+q)^{2}} ; \quad i=2,3, \ldots, n-1 \\
& p_{n}^{M}=\frac{1}{2} p_{n-1}^{M}+\frac{1}{4} c+\frac{1}{4} p_{n+1}^{F}+\frac{1}{2} a_{n}^{M}-\frac{1}{4}\left(a_{n+1}^{F}+a_{n-1}^{M}\right)+\frac{t L^{2}}{2(n+q)^{2}}
\end{aligned}
$$

The multi-product firm $M$ decentralizes the decision regarding choice of quality levels of its $n$ product variants to the member firms [otherwise; the corporate entity faces the simultaneous solution of fourth-order, recursive, non-homogeneous difference equations for the set of $n$ prices and the set of $n$ quality levels]. Thus, the $n$-firms act independently in their choice of quality level for their particular product variant.

The first-order conditions for quality levels are characterized by the following set of $n$ equations:

$$
\begin{aligned}
& a_{1}^{M}=\frac{N(n+q)}{t L^{2}}\left(p_{1}^{M}-c\right) \\
& a_{i}^{M}=\frac{N(n+q)}{t L^{2}}\left(p_{i}^{M}-c\right) ; \quad i=2, \ldots, n-1 . \\
& a_{n}^{M}=\frac{N(n+q)}{t L^{2}}\left(p_{n}^{M}-c\right)
\end{aligned}
$$


The joint profit function $\Pi_{M}($.$) is strictly concave in the variables \left(p_{I}{ }^{M}, \ldots, p_{n}{ }^{M}\right)$ and $\left(a_{l}{ }^{M}, \ldots, a_{n}{ }^{M}\right)$ and has a unique maximum if and only if it satisfies the following secondorder condition:

$$
\frac{\partial^{2} \Pi_{M}}{\partial p_{i}^{2}}=\frac{-N(n+q)}{t L^{2}}<0 ; \frac{\partial^{2} \Pi_{M}}{\partial a_{i}^{2}}=-1<0 ; \frac{\partial^{2} \Pi_{M}}{\partial p_{i} \partial a_{i}}=\frac{N(n+q)}{t L^{2}}>0
$$

These partial derivatives must also satisfy the following inequality,

$$
\begin{aligned}
& \left(\partial^{2} \Pi_{M} / \partial p_{i}^{2}\right)\left(\partial^{2} \Pi_{M} / \partial a_{i}^{2}\right)-\left(\partial^{2} \Pi_{M} / \partial p_{i} \partial a_{i}\right)^{2}>0 \Leftrightarrow \\
& {\left[-2 N(n+q) / t L^{2}\right][-1]-\left[N(n+q) / t L^{2}\right]^{2}>0 \Leftrightarrow t>N(n+q) / 2 L^{2} .}
\end{aligned}
$$

The first-order conditions for prices, after appropriate substitutions of equations (A.6) to (A.8) for the merged-firm quality variables, may be written as the following general system of $n$ linear, recursive non-homogeneous second-order difference equations with constant coefficients:

$$
\begin{aligned}
& p_{1}{ }^{M}=\frac{1}{2} p_{2}{ }^{M}+\frac{t L^{2}\left(p_{n+q}^{F}-a_{n+q}^{F}\right)}{2\left[2 t L^{2}-N(n+q)\right]}+\frac{\left(t L^{2}\right)^{2}}{(n+q)^{2}\left[2 t L^{2}-N(n+q)\right]}+\frac{\left[t L^{2}-N(n+q)\right] c}{2\left[2 t L^{2}-N(n+q)\right]} \\
& p_{i}{ }^{M}=\frac{1}{2}\left(p_{i-1}^{M}+p_{i+1}^{M}\right)+\frac{\left(t L^{2}\right)^{2}}{(n+q)^{2}\left[2 t L^{2}-N(n+q)\right]} ; \quad i=2, \ldots, n-1
\end{aligned}
$$

$$
p_{n}^{M}=\frac{1}{2} p_{n-1}^{M}+\frac{t L^{2}\left(p_{n+1}^{F}-a_{n+1}^{F}\right)}{2\left[2 t L^{2}-N(n+q)\right]}+\frac{\left(t L^{2}\right)^{2}}{(n+q)^{2}\left[2 t L^{2}-N(n+q)\right]}+\frac{\left[t L^{2}-N(n+q)\right] c}{2\left[2 t L^{2}-N(n+q)\right]}
$$


The set of equations, (A.10 to (A.12), represent a system of $n$ linear recursive nonhomogeneous second-order difference equations with constant coefficients. The equations (A.10) and (A.12) represent the boundary, or initial conditions. The general solution of the system of $n$ equations is determined by solving for a solution to the homogeneous system of equations \{i.e., without the constant term $\mathrm{tL}^{2}\left[\mathrm{tL}^{2}\right] /(\mathrm{n}+\mathrm{q})^{2}\left[2 \mathrm{tL}^{2}-\right.$ $\mathrm{N}(\mathrm{n}+\mathrm{q})]$ in equation (A.11) $\}$, plus a particular solution associated with the nonhomogeneous system \{i.e., equation (A.11) with the previously noted constant term\}. Thus, the general solution to the homogeneous system of price equations may be written as $r+s i$ for $i=1, \ldots, n$ and, where $r$ and $s$ are known as the "undetermined coefficients". A particular solution to the general system of price equations is of the form $p_{i}=-$ $i^{2} t L^{2}\left[t L^{2}\right] /(n+q)^{2}\left[2 t L^{2}-N(n+q)\right]$ for $i=1,2, \ldots, n$. Hence, the general solution to the system of $n$ price equations (A.10) to (A.12) is of the following form:

$p_{i}^{M}=r+s i-\frac{i^{2}\left(t L^{2}\right)^{2}}{(n+q)^{2}\left[2 t L^{2}-N(n+q)\right]} ;$ for $i=1,2, \ldots, n$

The solution of the "undetermined coefficients" $r$ and $s$, respectively, are determined by the boundary conditions, equations (A.10) and (A.12), along with equation (A.13), and they are given by the following expressions:

$$
\begin{aligned}
& r=\frac{t L^{2}\left(p_{n+q}^{F}-a_{n+q}^{F}\right)}{\left[2 t L^{2}-N(n+q)\right]}+\frac{\left[t L^{2}-N(n+q)\right] c}{\left[2 t L^{2}-N(n+q)\right]} \\
& s=\frac{(n+1)\left(t L^{2}\right)^{2}}{(n+q)^{2}\left[2 t L^{2}-N(n+q)\right]}
\end{aligned}
$$


Thus, the set of best-response price functions with respect to the price variable $p_{n: q}{ }^{F}$, and the quality variable $a_{n^{+} q}{ }^{F}$, of the $(n+q)$-th outside competitor, is given by the following equation:

$p_{i}^{M}=\frac{t L^{2}\left(p_{n+q}^{F}-a_{n+q}^{F}\right)}{\left[2 t L^{2}-N(n+q)\right]}+\frac{\left[t L^{2}-N(n+q)\right] c}{\left[2 t L^{2}-N(n+q)\right]}+\frac{i(n+1)\left(t L^{2}\right)^{2}}{(n+q)^{2}\left[2 t L^{2}-N(n+q)\right]}$

$-\frac{i^{2}\left(t L^{2}\right)^{2}}{(n+q)^{2}\left[2 t L^{2}-N(n+q)\right]} ; \quad i=1,2, \ldots, n$.

\section{B. Best-response price and quality functions of the qoutside competitors (single-product}

firms):

The set of outside competitors, or non-merged firms is represented by $F=\{n+1, n+2, \ldots$, $n+k, \ldots, n+q\}$, where $k=1,2, \ldots, q$. Each non-merged firm independently chooses a price and quality level from the other members of this group, as well as the merged firm $M$, so as to maximize its own profit. The mathematical optimization problem of the $(n+k)-t h$ firm is given by the following;

$\operatorname{Max} \pi_{n+k}\left(p_{n+k-1}^{F}, p_{n+k}^{F}, p_{n+k+1}^{F} ; a_{n+k-1}^{F}, a_{n+k}^{F}, a_{n+k+1}^{F}\right)=$ $\left(p_{n+k}^{F}-c\right) \frac{N}{L}\left[\frac{\left(p_{n+k+1}^{F}-a_{n+k+1}^{F}\right)-2\left(p_{n+k}^{F}-a_{n+k}^{F}\right)+\left(p_{n+k-1}^{F}-a_{n+k-1}^{F}\right)}{2 t L /(n+q)}+\frac{L}{(n+q)}\right]-\frac{1}{2}\left(a_{n+k}^{F}\right)^{2}-f$

for the set of $q$ prices $\left(p_{n+l}{ }^{F}, \ldots, p_{n}, q^{F}\right)$, and for the set of $q$ quality levels $\left(a_{n+1}{ }^{F}, \ldots, a_{n+q}{ }^{l i}\right)$.

The necessary conditions of the problem give the following system of $q$ linear recursive 
non-homogeneous second-order difference equations:

$$
\begin{aligned}
& p_{n+1}^{F}=\frac{1}{4}\left(p_{n}^{M}+p_{n+2}^{F}\right)+\frac{1}{2} c+\frac{1}{2} a_{n+1}^{F}-\frac{1}{4}\left(a_{n}^{M}+a_{n+2}^{F}\right)+\frac{t L^{2}}{2(n+q)^{2}} \\
& p_{n+k}^{F}=\frac{1}{4}\left(p_{n+k+1}^{F}+p_{n+k-1}^{F}\right)+\frac{1}{2} c+\frac{1}{2} a_{n+k}^{F}-\frac{1}{4}\left(a_{n+k+1}^{F}+a_{n+k-1}^{F}\right)+\frac{t L^{2}}{2(n+q)^{2}} ;
\end{aligned}
$$

for $k=2,3, \ldots, q-1$.

$$
p_{n+q}^{F}=\frac{1}{4}\left(p_{1}^{M}+p_{n+q-1}^{F}\right)+\frac{1}{2} c+\frac{1}{2} a_{n+q}^{F}-\frac{1}{4}\left(a_{1}^{M}+a_{n+q-1}^{F}\right)+\frac{t L^{2}}{2(n+q)^{2}}
$$

The first-order conditions for the quality levels are characterized by the following equations:

$$
a_{n+k}^{F}=\frac{N(n+q)}{t L^{2}}\left(p_{n+k}^{F}-c\right) ; \quad k=1,2, \ldots, q
$$

The first-order conditions for prices, after the appropriate substitution of the quality variables $a_{n \nmid k}{ }^{F}$ from equation (A.20), are written as the following system of $q$ linear recursive non-homogeneous second-order difference equations:

$$
\begin{aligned}
& p_{n+1}^{F}=\frac{\left[t L^{2}-N(n+q)\right] p_{n+2}^{F}}{2\left[2 t L^{2}-N(n+q)\right]}+\frac{t L^{2}\left(p_{n}^{M}-a_{n}^{M}\right)}{2\left[2 t L^{2}-N(n+q)\right]}+\frac{\left(t L^{2}\right)^{2}}{(n+q)^{2}\left[2 t L^{2}-N(n+q)\right]}+\frac{1}{2} c \\
& p_{n+k}^{F}=\frac{\left[t L^{2}-N(n+q)\right] p_{n+k-1}^{F}}{2\left[2 t L^{2}-N(n+q)\right]}+\frac{\left[t L^{2}-N(n+q)\right] p_{n+k+1}^{F}}{2\left[2 t L^{2}-N(n+q)\right]}+\frac{t L^{2}\left[c(n+q)^{2}+t L^{2}\right]}{(n+q)^{2}\left[2 t L^{2}-N(n+q)\right]}
\end{aligned}
$$


$p_{n+q}^{F}=\frac{\left[t L^{2}-N(n+q)\right] p_{n+q-1}^{F}}{2\left[2 t L^{2}-N(n+q)\right]}+\frac{t L^{2}\left(p_{1}^{M}-a_{1}^{M}\right)}{2\left[2 t L^{2}-N(n+q)\right]}+\frac{\left(t L^{2}\right)^{2}}{(n+q)^{2}\left[2 t L^{2}-N(n+q)\right]}+\frac{1}{2} c$

A particular solution to the system of equations (A.21) to (A.23) is given by $p_{k}=\left[c(n+q)^{2}\right.$ $\left.+t L^{2}\right] /(n+q)^{2}=c+t L^{2} /(n+q)^{2}$. The solution to the associated homogeneous system of price equations with the "undetermined coefficients", $c_{l}$ and $c_{2}$, is of the following form;

$p_{n+k}^{F}=c_{1}(\alpha)^{k}+c_{2}(\beta)^{k} ; \quad k=1,2, \ldots, q$

$$
=c_{1}\left[\frac{2 t L^{2}-N(n+q)+\sqrt{t L^{2}\left[3 t L^{2}-2 N(n+q)\right]}}{\left[t L^{2}-N(n+q)\right]^{k}}\right]^{k}+c_{2}\left[\frac{2 t L^{2}-N(n+q)-\sqrt{t L^{2}\left[3 t L^{2}-2 N(n+q)\right]}}{\left[t L^{2}-N(n+q)\right]^{k}}\right]^{k}
$$

The two distinct and real roots ( $\alpha$ and $\beta$ ) of the auxiliary equation $m^{2}-2\left[2 t L^{2}-N(n+q)\right] m$ $/\left[t L^{2}-N(n+q)\right]+1=0$ associated with the second-order homogeneous equation are given by the following expressions:

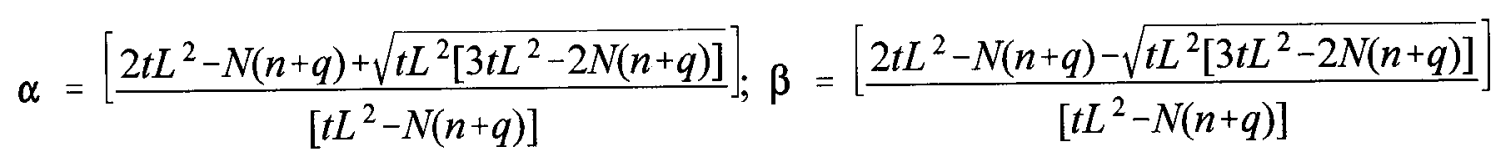

The general solution to the system (A.21) to (A.23) of $q$ difference equations is therefore given by;

$$
p_{n+k}^{F}=c_{1}(\alpha)^{k}+c_{2}(\beta)^{k}+\frac{\left[c(n+q)^{2}+t L^{2}\right]}{(n+q)^{2}} \text { for } k=1,2, . ., q .
$$

Note that since $\alpha \beta=1$ then $0<|\alpha| \leq 1$ or $0<|\beta| \leq 1 \leftrightarrow t \geq N(n+q) / 2 L^{2}$. Using the boundary conditions of equations (A.21) and (A.23) in equation (A.22), we can solve for 
the solutions of the "undetermined coefficients", $c_{1}$ and $c_{2}$, respectively, as functions of $p_{1}{ }^{M}, p_{n}{ }^{M}, a_{1}{ }^{M}$, and $a_{n}{ }^{M}$. They are denoted as equations (A.26) and (A.27), respectively;

$$
\begin{aligned}
& c_{1}=\frac{t L^{2}\left(\alpha^{q} l-\alpha^{2} r\right)}{\alpha\left(\alpha^{q} l^{2}-\alpha^{2} r^{2}\right)}\left[\left(p_{1}^{M}-a_{1}^{M}\right)-\frac{\left[t L^{2}-N(n+q)\right]}{(n+q)^{2}}-c\right] \\
& c_{2}=\frac{t L^{2}\left(\alpha^{q} l-\alpha^{2} r\right)}{\alpha^{2}\left(\alpha^{q} l^{2}-\alpha^{2} r^{2}\right)}\left[\left(p_{n}^{M}-a_{n}^{M}\right)-\frac{\left[t L^{2}-N(n+q)\right]}{(n+q)^{2}}-c\right] .
\end{aligned}
$$

where the fact that $\alpha \beta=1$ has been employed and $l=\left[(4 \alpha-1) t L^{2}-(2 \alpha-1) N(n+q)\right]$ and $r=\left[(4-\alpha) t L^{2}-(2-\alpha) N(n+q)\right]$. The symmetry of the equilibrium conditions for the set of prices of the merged firm, and for the set of prices of the non-merged firms, implies that $p_{l}^{M}=p_{n}^{M}, p_{2}^{M}=p_{n-1}^{M}, \ldots$, etc., and $p_{n+1}^{F}=p_{n+q}{ }^{F}, p_{n+2}{ }^{F}=p_{n+q-l}{ }^{l}, \ldots$, etc., so that bequations (A.10) and (A.12) may be rewritten as the following equation;

$$
p_{1}^{M}=p_{n}^{M}=\frac{t L^{2}\left(p_{n+1}^{F}-a_{n+1}^{F}\right)}{\left[2 t L^{2}-N(n+q)\right]}+\frac{n\left(t L^{2}\right)^{2}}{(n+q)^{2}\left[2 t L^{2}-N(n+q)\right]}+\frac{\left[t L^{2}-N(n+q)\right] c}{\left[2 t L^{2}-N(n+q)\right]}
$$

Similarly, equations (A.21) and (A.23) may be rewritten as the following equation (A.28);

$$
\begin{gathered}
p_{n+1}^{F}=p_{n+q}^{F}=\frac{\left[t L^{2}-N(n+q)\right]^{2}\left(c_{1} \alpha+c_{2} \beta\right)}{2\left[2 t L^{2}-N(n+q)\right]^{2}}+\frac{\left[t L^{2}-N(n+q)\right]\left(c_{1} \alpha^{2}+c_{2} \beta^{2}\right)}{2\left[2 t L^{2}-N(n+q)\right]}+c \\
+\frac{t L^{2}\left[t L^{2}-N(n+q)\right]^{2}}{2(n+q)^{2}\left[2 t L^{2}-N(n+q)\right]^{2}}+\frac{t L^{2}\left[3 t L^{2}-N(n+q)\right]}{2(n+q)^{2}\left[2 t L^{2}-N(n+q)\right]}+\frac{n\left(t L^{2}\right)^{2}\left[t L^{2}-N(n+q)\right]}{2(n+q)^{2}\left[2 t L^{2}-N(n+q)\right]^{2}}
\end{gathered}
$$

Thus, after appropriate substitutions of the variables, the equilibrium price $p_{l}{ }^{M}=p_{n}{ }^{M}$, of 
the merged firm $M$, is given by the following expression:

$$
\begin{aligned}
& p_{1}{ }^{M}=p_{n}{ }^{M}=\frac{\left[t L^{2}-N(n+q)\right]\left(c_{1} \alpha+c_{2} \beta\right)}{\left[2 t L^{2}-N(n+q)\right]}+\frac{n\left(t L^{2}\right)^{2}}{(n+q)^{2}\left[2 t L^{2}-N(n+q)\right]}+c \\
& +\frac{t L^{2}\left[t L^{2}-N(n+q)\right]}{(n+q)^{2}\left[2 t L^{2}-N(n+q)\right]}
\end{aligned}
$$

Hence, equation (A.14) may be written as the following expression for the general solution of the multi-product firm $M$ 's prices:

$$
r=c+\frac{\left[t L^{2}-N(n+q)\right]\left(c_{1} \alpha+c_{2} \beta\right)}{\left[2 t L^{2}-N(n+q)\right]}+\frac{t L^{2}\left[t L^{2}-N(n+q)\right]}{(n+q)^{2}\left[2 t L^{2}-N(n+q)\right]}
$$

Finally, the expression for the general system of $n$ equilibrium merged-firm prices for $i=$ $1,2, \ldots, n$ is given by the equation;

$$
\begin{aligned}
& p_{i}{ }^{M}=c+\frac{\left[t L^{2}-N(n+q)\right]\left(c_{1} \alpha+c_{2} \beta\right)}{\left[2 t L^{2}-N(n+q)\right]}+\frac{t L^{2}\left[t L^{2}-N(n+q)\right]}{(n+q)^{2}\left[2 t L^{2}-N(n+q)\right]} \\
& +\frac{i(n+1)\left(t L^{2}\right)^{2}}{(n+q)^{2}\left[2 t L^{2}-N(n+q)\right]}-\frac{i^{2}\left(t L^{2}\right)^{2}}{(n+q)^{2}\left[2 t L^{2}-N(n+q)\right]} .
\end{aligned}
$$

Finally, by symmetry of the quality level equilibrium conditions of the merged entity $M$, the equations (A.6) and (A.8) then imply that $a_{l}^{M}=a_{n}{ }^{M}$. Thus, the Nash equilibrium outcomes for $a_{l}^{M}=a_{n}^{M}$ and $a_{i}^{M}$ for $i=2,3, \ldots, n-1$ are given by the following expressions: 


$$
\begin{aligned}
& a_{1}^{M}=a_{n}^{M}=\frac{N(n+q)}{t L^{2}}\left[r+s-\frac{\left(t L^{2}\right)^{2}}{(n+q)^{2}\left[2 t L^{2}-N(n+q)\right]}-c\right] \\
& a_{i}^{M}=\frac{N(n+q)}{t L^{2}}\left[r+s i-\frac{i^{2}\left(t L^{2}\right)^{2}}{(n+q)^{2}\left[2 t L^{2}-N(n+q)\right]}-c\right]
\end{aligned}
$$

Finally, the solutions of the "undetermined coefficients", $c_{l}$ and $c_{2}$, respectively, from equation (A.25) may be written as the expressions, where $[d]=\left(b_{1}\right)\left(b_{2}\right)-\left(\alpha^{q} l-\alpha^{2} r\right)^{2}\left[t L^{2}-\right.$ $N(n+q) 7^{2}$ so that the coefficients $c_{1}^{*}$ and $c_{2}{ }^{*}$ are given by the following equations:

$$
\begin{aligned}
& c_{1}^{*}=\frac{t L^{2}\left(\alpha^{q} l-\alpha^{2} r\right)\left[t L^{2}-N(n+q)\right]\left[2 t L^{2}-N(n+q)\right]}{\alpha^{4}(n+q)^{2}[d]}\left[\frac{n\left(t L^{2}\right)^{2}}{\left[2 t L^{2}-N(n+q)\right]}\right. \\
& \left.-\left[t L^{2}-N(n+q)\right]-1\right] \\
& c_{2}^{*}=\left(\alpha^{2}\right) c_{1}^{*}
\end{aligned}
$$

The above equations contain the terms $\left(b_{\nu}\right)=\left(\alpha^{q} l^{2}-\alpha^{2} r^{2}\right)\left[2 t L^{2}-N(n+q)\right]-\left(\alpha^{q} l-\alpha^{2} r\right)\left[t L^{2}-\right.$ $N(n+q)]$ and $\left(b_{2}\right)=\alpha^{3}\left(\alpha^{q} l^{2}-\alpha^{2} r^{2}\right)\left[2 t L^{2}-N(n+q)\right]-\left(\alpha^{q} l-\alpha^{2} r\right)\left[t L^{2}-N(n+q)\right]$ and $[d]=$ $\alpha^{3}\left(\alpha^{4} l^{2}-\alpha^{2} r^{2}\right)\left[2 t L^{2}-N(n+q)\right]\left[2 t L^{2}\left\{\alpha^{q} l(l-1)-\alpha^{2} r(r-1)\right\}-N(n+q)\left\{\alpha^{q} l(l-2)-\alpha^{2} r(r-2)\right\}\right]$. The equivalent general expression of the $q$ Nash equilibrium non-merged firm prices $p_{n, k}{ }^{F}$ for $k=1, \ldots, q$ is given by the following equation;

$p_{n+k}^{F}=c_{1}^{*}\left(\alpha^{k}\right)+c_{2}^{*}\left(\beta^{k}\right)+c+t L^{2} /(n+q)^{2} \quad$ for $k=1,2, \ldots, q$

The Nash equilibrium quality levels $a_{n+k}{ }^{F}$ for $k=1,2, \ldots, q$ of the non-merged firms is given by the following equation; 
$a_{n+k}^{F}=\frac{N(n+q)}{t L^{2}}\left[c_{1}^{*}\left(\alpha^{k}\right)+c_{2}^{*}\left(\beta^{k}\right)+\frac{t L^{2}}{(n+q)^{2}}\right]$ for $k=1, \ldots, q$

The equivalent general expression of the $n$ Nash equilibrium multi-product firm M's prices $p_{i}^{M}$ for $i=1, \ldots, n$ is given by the following equation;

$p_{i}{ }^{M}=r^{*}+i s^{*}-\frac{i^{2}\left(t L^{2}\right)^{2}}{(n+q)^{2}\left[2 t L^{2}-N(n+q)\right]} \quad$ for $i=1, \ldots, n$

Similarly, the equation (A.32) for the $n$ Nash equilibrium multi-product firm M's quality levels $a_{i}^{M}$ for $i=2, \ldots, n-1$ is appropriately substituted for the solutions of the "undetermined coefficients", $c_{1}{ }^{*}$ and $c_{2}{ }^{*}$, as given above.

The Nash equilibrium profits for the multi-product firm $M$ are given by the following expressions:

$$
\begin{aligned}
& \pi_{1}^{M}=\frac{N\left(p_{1}^{M}-c\right)}{2\left[2 t L^{2}-N(n+q)\right]}\left[\frac{(n+q)\left[t L^{2}-N(n+q)\right]^{2}}{\left(t L^{2}\right)^{2}}\left(c_{1}^{*} \alpha+c_{2}^{*} \beta\right)+\frac{\left[t L^{2}-N(n+q)\right]\left[3 t L^{2}-N(n+q)\right]}{t L^{2}(n+q)}\right. \\
& \left.\quad+\frac{N[2-n(n+q)]}{(n+q)}\right]-f ; \text { where } \\
& p_{1}^{M}-c=\frac{\left[t L^{2}-N(n+q)\right]}{\left[2 t L^{2}-N(n+q)\right]}\left(c_{1}^{*} \alpha+c_{2}^{*} \beta\right)+\frac{t L^{2}\left[t L^{2}-N(n+q)\right]}{(n+q)^{2}\left[2 t L^{2}-N(n+q)\right]}+\frac{n\left(t L^{2}\right)^{2}}{(n+q)^{2}\left[2 t L^{2}-N(n+q)\right]} \\
& \pi_{2}^{M}=\frac{N\left(p_{2}^{M}-c\right)}{2\left[2 t L^{2}-N(n+q)\right]}\left[\frac{2\left[t L^{2}-(n-1) N(n+q)\right]}{(n+q)}-\frac{N(n+q)^{2}\left[t L^{2}-N(n+q)\right]}{\left(t L^{2}\right)^{2}}\left(c_{1}^{*} \alpha+c_{2}^{*} \beta\right)\right.
\end{aligned}
$$




$$
\left.-\frac{\left.N\left[t L^{2}-N(n+q)\right]\right]}{t L^{2}}\right]-f ; \text { where }
$$

$$
\begin{aligned}
& p_{2}^{M}-c=\frac{\left[t L^{2}-N(n+q)\right]}{\left[2 t L^{2}-N(n+q)\right]}\left(c_{1}^{*} \alpha+c_{2}^{*} \beta\right)+\frac{t L^{2}\left[t L^{2}-N(n+q)\right]}{(n+q)^{2}\left[2 t L^{2}-N(n+q)\right]}+\frac{2(n-1)\left(t L^{2}\right)^{2}}{(n+q)^{2}\left[2 t L^{2}-N(n+q)\right]} \\
& \pi_{i}^{M}=\frac{N\left(p_{i}{ }^{M}-c\right)}{2\left[2 t L^{2}-N(n+q)\right]}\left[\frac{\left[t L^{2}-N(n+q)\right]\left[2 t L^{2}-N(n+q)\right]}{t L^{2}(n+q)}-\frac{N(n+q)^{2}\left[t L^{2}-N(n+q)\right]}{\left(t L^{2}\right)^{2}}\left(c_{1}^{*} \alpha+c_{2}^{*} \beta\right)\right. \\
& p_{i}{ }^{2}-c=\frac{\left[t L^{2}-N(n+q)\right]}{\left[2 t L^{2}-N(n+q)\right]}\left(c_{1}^{*} \alpha+c_{2}^{*} \beta\right)+\frac{t L^{2}\left[t L^{2}-N(n+q)\right]}{(n+q)^{2}\left[2 t L^{2}-N(n+q)\right]}+\frac{i\left(t L^{2}\right)^{2}[(n+1)-i]}{(n+q)^{2}\left[2 t L^{2}-N(n+q)\right]} \\
& \text { for } i=3,4, \ldots, n-2 \\
& \text { B. THE "SYMMETRIC CASCADING EFFECT" OF EQUILIBRIUM PRICES } \\
& \text { AND QUALITIES }
\end{aligned}
$$

\section{AND QUALITIES}

Proof of Inequalities:

$$
\begin{aligned}
& \frac{\partial p_{i}{ }^{M}}{\partial i}=s^{*}-\frac{2 i\left(t L^{2}\right)^{2}}{(n+q)^{2}\left[2 t L^{2}-N(n+q)\right]}=0 \Leftrightarrow \\
& \frac{(n+1)\left(t L^{2}\right)^{2}}{(n+q)^{2}\left[2 t L^{2}-N(n+q)\right]}-\frac{2 i\left(t L^{2}\right)^{2}}{(n+q)^{2}\left[2 t L^{2}-N(n+q)\right]}=0
\end{aligned}
$$


$\Leftrightarrow i_{\max }=1 / 2(n+1) ; \quad \therefore \quad \frac{\partial p_{i}{ }^{M}}{\partial i}>0 \Leftrightarrow i<1 / 2(n+1) \quad \therefore \quad \frac{\partial p_{i}{ }^{M}}{\partial i}<0 \Leftrightarrow i>1 / 2(n+1)$

Similarly, to establish the pattern of the Nash equilibrium quality levels of the merged firm $M$,

$$
\begin{aligned}
& \frac{\partial a_{i}{ }^{M}}{\partial i}=\frac{N(n+q)}{t L^{2}} \frac{\partial p_{i}{ }^{M}}{\partial i}=0 \leftrightarrow i_{\max }=1 / 2(n+1) \\
& \therefore \frac{\partial a_{i}^{M}}{\partial i}>0 \Leftrightarrow i<1 / 2(n+1) \quad \therefore \frac{\partial a_{i}{ }^{M}}{\partial i}<0 \Leftrightarrow i>1 / 2(n+1)
\end{aligned}
$$

The condition needed for the outside single-product firms' prices and qualities, is given as the following "reduced expression" of the respective derivatives. The "reduced expression" simply deletes a common term which is multiplied by the following expression for $\partial p_{n+k} F / \partial k=0$.

$$
\begin{aligned}
& \frac{\partial p_{n+k}^{F}}{\partial k}=k c_{1}^{*}\left(\alpha^{k-1}-\alpha^{-k+1}\right)=0 \text { since } \frac{\partial c_{1}^{*}}{\partial k}=0 \text { where } c_{2}^{*}=\left(\alpha^{2}\right) c_{1}^{*} \\
& \therefore \frac{\partial p_{n+k}^{F}}{\partial k}<0 \Leftrightarrow \frac{d}{d k}\left[\alpha^{k-1}\left(\alpha^{2} r-l\right)+\alpha^{-(k-1)}\left(\alpha^{q} l-\alpha^{2} r\right)\right]<0 \leftrightarrow-2 \ln (\alpha)<q \ln (\alpha) \leftrightarrow-2<q \\
& \Leftrightarrow|\alpha|>1 .
\end{aligned}
$$


$\therefore \frac{\partial p_{n+k}^{F}}{\partial k}>0 \Leftrightarrow q \ln (\alpha)>-2 \ln (\alpha) \Leftrightarrow q>-2 ;$ for $q \geq 3 \Leftrightarrow 0<|\alpha| \leq 1$

The above derivatives contain the terms $\mathrm{r}=2\left[2 \mathrm{tL}^{2}-\mathrm{N}(\mathrm{n}+\mathrm{q})\right]-\alpha[\mathrm{tL}-\mathrm{N}(\mathrm{n}+\mathrm{q})]$ and $\mathrm{l}=$ $2 \alpha\left[2 \mathrm{tL}^{2}-\mathrm{N}(\mathrm{n}+\mathrm{q})\right]-\left[\mathrm{tL}^{2}-\mathrm{N}(\mathrm{n}+\mathrm{q})\right]$, and the global minimum, denoted by $k_{\text {min }}$, of the function $p_{n+k}{ }^{F}$ must satisfy the following:

$$
\begin{aligned}
& \frac{\partial^{2} p_{n+k}^{F}}{\partial k^{2}}>0 \Leftrightarrow\left(\alpha^{k-1}-\alpha^{-k+1}\right)+k\left[(k-1) \alpha^{k-2}-(-k+1) \alpha^{-k}\right]>0 \Leftrightarrow \\
& k>\alpha^{-k} \Leftrightarrow|\alpha|>1 .
\end{aligned}
$$

To establish the pattern of the Nash equilibrium profit levels for the inner core set $c_{m}$ of member-firms belonging to the multi-product firm $M$,

$$
\begin{aligned}
& \pi_{i}^{M}=\left(p_{i}{ }^{M}-c\right) X_{i}^{M}-1 / 2\left(a_{i}{ }^{M}\right)^{2}-f=\left(p_{i}{ }^{M}-c\right) \frac{N}{(n+q)}-\frac{N^{2}(n+q)^{2}}{2\left(t L^{2}\right)^{2}}\left(p_{i}{ }^{M}-c\right)^{2}-f \\
& \frac{\partial \pi_{i}^{M}}{\partial i}=\frac{N}{(n+q)} \frac{\partial\left(p_{i}{ }^{M}-c\right)}{\partial i}-\frac{N^{2}(n+q)^{2}}{\left(t L^{2}\right)^{2}}\left(p_{i}{ }^{M}-c\right) \frac{\partial\left(p_{i}{ }^{M}-c\right)}{\partial i}=0 \Leftrightarrow \\
& \frac{\partial\left(p_{i}{ }^{M}-c\right)}{\partial i}\left[\frac{N}{(n+q)}-\frac{N^{2}(n+q)^{2}}{\left(t L^{2}\right)^{2}}\left(p_{i}{ }^{M}-c\right)\right]=0 \Leftrightarrow \frac{\partial\left(p_{i}{ }^{M}-c\right)}{\partial i}=0 \Leftrightarrow i_{\max }=1 / 2(n+1) \\
& \therefore \frac{\partial \pi_{i}^{M}}{\partial i}>0 \Leftrightarrow i<1 / 2(n+1) \therefore \frac{\partial \pi_{i}^{M}}{\partial i}<0 \Leftrightarrow i>1 / 2(n+1) \text { for } i=3,4, \ldots, n-2 .
\end{aligned}
$$


To establish the pattern of the Nash equilibrium profit levels of the single-product competitor firms $k=1, \ldots, q$ :

$$
\begin{aligned}
& \pi_{n+k}^{F}=\left(p_{n+k}^{F}-c\right) X_{n+k}^{F}-1 / 2\left(a_{n+k}^{F}\right)^{2}-f=\left(p_{n+k}^{F}-c\right) X_{n+k}^{F}-\frac{N^{2}(n+q)^{2}}{2\left(t L^{2}\right)^{2}}\left(p_{n+k}^{F}-c\right)^{2}-f \\
& \frac{\partial \pi_{n+k}^{F}}{\partial k}=\left(p_{n+k}^{F}-c\right) \frac{\partial X_{n+k}^{F}}{\partial k}+X_{n+k}^{F} \frac{\partial\left(p_{n+k}^{F}-c\right)}{\partial k}-\frac{N^{2}(n+q)^{2}}{\left(t L^{2}\right)^{2}}\left(p_{n+k}^{F}-c\right) \frac{\partial\left(p_{n+k}^{F}-c\right)}{\partial k}<0
\end{aligned}
$$

Since $X_{n+k}^{F}=\frac{N}{(n+q)}+\frac{N(n+q)}{2\left(t L^{2}\right)^{2}}\left[t L^{2}-N(n+q)\right]\left[p_{n+k+1}^{F}-2 p_{n+k}^{F}+p_{n+k-1}^{F}\right]=\frac{N}{(n+q)}+$

$$
\begin{aligned}
& \frac{N(n+q)}{2\left(t L^{2}\right)^{2}}\left[t L^{2}-N(n+q)\right] c_{1}^{*}\left[\alpha^{k+1}+\alpha^{-k+3}+\alpha^{k-1}+\alpha^{-k+1}-2\left(\alpha^{k}+\alpha^{-k+2}\right)\right] \\
& \therefore \frac{\partial \pi_{n+k}^{F}}{\partial k}<0 \Leftrightarrow t L^{2}\left[t L^{2}-N(n+q)\right]\left[(k+1) \alpha^{k}+(1-k) \alpha^{-k}+(k-1) \alpha^{k-2}+(3-k) \alpha^{-k+2}-4 \alpha^{-k+1}\right] \\
& +2 k t L^{2} c_{1}^{*}(n+q)^{2}\left[\alpha^{-2 k+3}-\alpha^{2 k-1}\right]+ \\
& c_{1}^{*}(n+q)^{2}\left[t L^{2}-N(n+q)\right]\left[(2 k+1) \alpha^{2 k}+(2 k-1) \alpha^{2 k-2}+(1-2 k) \alpha^{-2 k+2}+(3-2 k) \alpha^{-2 k+4}-2 k \alpha^{2 k-1}\right. \\
& \left.+2(k-2) \alpha^{-2 k+3}+(k-1)-(k+3) \alpha+4 \alpha^{2}\right]<0 \Leftrightarrow \alpha^{k+4}<\frac{4}{3} \leftrightarrow 0<|\alpha|<1 \quad \text { for } k=1, \ldots, q \\
& \therefore \frac{\partial \pi_{n+k}^{F}}{\partial k}>0 \Leftrightarrow \alpha^{k+4}>\frac{4}{3} \leftrightarrow|\alpha|>1 \text { for } k=1, \ldots, q
\end{aligned}
$$




\section{THE COMPARATIVE STATIC RESULT}

\section{Proof of Comparative Static Equation:}

By using equation (A.30), the total price differential locus is calculated as the following:

$d p_{i}{ }^{M}=\frac{\partial p_{i}{ }^{M}}{\partial n} d n+\frac{\partial p_{i}{ }^{M}}{\partial q} d q ;$ subject to $\mathrm{dn}+\mathrm{dq}=0$, so that $\mathrm{dq}=-\mathrm{dn}$

$$
\therefore \frac{d p_{i}{ }^{M}}{d n}=\frac{\partial p_{i}{ }^{M}}{\partial n}-\frac{\partial p_{i}{ }^{M}}{\partial q}=\frac{i\left(t L^{2}\right)^{2}}{(n+q)^{2}\left[2 t L^{2}-N(n+q)\right]}+\frac{\left(t l^{2}\right)^{2}\left[t L^{2}-N(n+q)\right]^{2}}{2(n+q)^{2}\left[2 t L^{2}-N(n+q)\right]^{2}}
$$

D. THE NASH PRICE-QUALITY EQUILIBRIUM RESULTS: A SINGLE, TWO-

\section{NEIGHBOUR FIRM MERGER (QUALITY LEVELS DECENTRALIZED)}

\section{Number of Firms $(n=2$ and $q=2) ;$ sufficient condition $t>2 N / L^{2}$}

$$
p^{M}=c+\frac{t L^{2}\left(t L^{2}-2 N\right)}{2\left(5 t L^{2}-12 N\right)} ; \quad p^{F}=c+\frac{t L^{2}\left(3 t L^{2}-8 N\right)}{8\left(5 t L^{2}-12 N\right)} ; \quad X^{M}=\frac{2 N\left(t L^{2}-2 N\right)}{\left(5 t L^{2}-12 N\right)}
$$

$$
\begin{aligned}
& a^{M}=\frac{2 N\left(t L^{2}-2 N\right)}{\left(5 t L^{2}-12 N\right)} ; \quad a^{F}=\frac{N\left(3 t L^{2}-8 N\right)}{2\left(5 t L^{2}-12 N\right)} ; \quad X_{k(1)}^{F}=\frac{N\left(3 t L^{2}-8 N\right)}{2\left(5 t L^{2}-12 N\right)} \\
& \pi^{M}=\frac{N\left(t L^{2}-2 N\right)^{2}\left(t L^{2}-4 N\right)}{\left(5 t L^{2}-12 N\right)^{2}}-2 f ; \quad \pi^{F}=\frac{N\left(3 t L^{2}-8 N\right)^{2}\left(t L^{2}-2 N\right)}{16\left(5 t L^{2}-12 N\right)^{2}}-f
\end{aligned}
$$

2. Number of Firms $\left(n=2\right.$ and $q=3$ ): sufficient condition $t>5 N / 2 L^{2}$

$$
p^{M}=c+\frac{2\left(t L^{2}\right)^{2}}{25\left(2 t L^{2}-5 N\right)}+\frac{t L^{2}\left(7 t L^{2}-25 N\right)\left(t L^{2}-5 N\right)}{50\left(2 t L^{2}-5 N\right)\left(3 t L^{2}-10 N\right)} ; \quad p^{M}>p_{k(1)}^{F} \Leftrightarrow t>\frac{3 N}{L^{2}}
$$




$$
\begin{aligned}
& a^{M}=\frac{2 N t L^{2}}{5\left(2 t L^{2}-5 N\right)}+\frac{N\left(t L^{2}-5 N\right)\left(7 t L^{2}-25 N\right)}{10\left(2 t L^{2}-5 N\right)\left(3 t L^{2}-10 N\right)} \\
& X^{M}=\frac{2 N}{5}-\frac{N\left(t L^{2}-5 N\right)\left(t L^{2}-3 N\right)}{2\left(2 t L^{2}-5 N\right)\left(3 t L^{2}-10 N\right)} \\
& p_{k(1)}^{F}=c+\frac{t L^{2}\left(7 t L^{2}-25 N\right)}{50\left(3 t L^{2}-10 N\right)} ; \quad a_{k(1)}^{F}=\frac{N\left(7 t L^{2}-25 N\right)}{10\left(3 t L^{2}-10 N\right)} ; \quad X_{k(1)}^{F}=\frac{N\left(7 t L^{2}-25 N\right)}{10\left(3 t L^{2}-10 N\right)}
\end{aligned}
$$

$$
p_{k(2)}^{F}=c+\frac{\left(t L^{2}\right)^{2}}{25\left(2 t L^{2}-5 N\right)}+\frac{t L^{2}\left(t L^{2}-5 N\right)\left(7 t L^{2}-25 N\right)}{50\left(2 t L^{2}-5 N\right)\left(3 t L^{2}-10 N\right)}
$$

$$
a_{k(2)}^{F}=\frac{N t L^{2}}{5\left(2 t L^{2}-5 N\right)}+\frac{N\left(t L^{2}-5 N\right)\left(7 t L^{2}-25 N\right)}{10\left(2 t L^{2}-5 N\right)\left(3 t L^{2}-10 N\right)}
$$

$$
X_{k(2)}^{F}=\frac{N}{5}+\frac{N\left(t L^{2}-5 N\right)^{2}}{10\left(2 t L^{2}-5 N\right)\left(3 t L^{2}-10 N\right)}
$$

$$
\pi^{M}=\frac{N\left[4\left(2 t L^{2}-5 N\right)\left(3 t L^{2}-10 N\right)-5\left(t L^{2}-5 N\right)\left(t L^{2}-3 N\right)\right]^{2}}{500\left(2 t L^{2}-5 N\right)\left(3 t L^{2}-10 N\right)^{2}}-2 f
$$

$$
\pi_{k(1)}^{F}=\frac{N\left(2 t L^{2}-5 N\right)\left(7 t L^{2}-25 N\right)^{2}}{1000\left(3 t L^{2}-10 N\right)^{2}}-f ; \pi_{k(2)}^{F}=\frac{N\left[\left(2 t L^{2}-5 N\right)\left(7 t L^{2}-25 N\right)-t L^{2}\left(t L^{2}-5 N\right)\right]^{2}}{1000\left(2 t L^{2}-5 N\right)\left(3 t L^{2}-10 N\right)^{2}}-f
$$

3. Number of Firms ( $n=2$ and $q=6)$; sufficient condition $t>3 N / L^{2}$ 


$$
\begin{aligned}
& p^{M}=c+\frac{t L^{2}\left(t L^{2}-2 N\right)\left(5 t L^{2}-18 N\right)}{6[\cdot]} ; \quad a^{M}=\frac{N\left(t L^{2}-2 N\right)\left(5 t L^{2}-18 N\right)}{[\cdot]} \\
& X^{M}=\frac{N\left(t L^{2}-2 N\right)\left(5 t L^{2}-18 N\right)}{[\cdot]} ; \quad X_{k(1)}^{F}=\frac{N\left[3\left(t L^{2}-2 N\right)\left(t L^{2}-6 N\right)+8\left(t L^{2}-3 N\right)^{2}\right]}{3[\cdot]}
\end{aligned}
$$$$
p_{k(1)}^{F}=c+\frac{t L^{2}\left[3\left(t L^{2}-2 N\right)\left(t L^{2}-6 N\right)+8\left(t L^{2}-3 N\right)^{2}\right]}{18[\cdot]}
$$

$$
a_{k(1)}^{F}=\frac{N\left[3\left(t L^{2}-2 N\right)\left(t L^{2}-6 N\right)+8\left(t L^{2}-3 N\right)^{2}\right]}{3[\cdot]} ; \quad p_{k(1)}^{F}>p_{k(2)}^{F} \Leftrightarrow t>\frac{6 N}{L^{2}}
$$

$$
p_{k(2)}^{F}=c+\frac{t L^{2}\left(t L^{2}-3 N\right)\left(5 t L^{2}-18 N\right)}{9[\cdot]} ; \quad a_{k(2)}^{F}=\frac{2 N\left(t L^{2}-3 N\right)\left(5 t L^{2}-18 N\right)}{3[\cdot]}
$$

$$
X_{k(2)}^{F}=\frac{2 N\left(t L^{2}-3 N\right)\left(5 t L^{2}-18 N\right)}{3[\cdot]} ; \quad \pi_{k(2)}^{F}=\frac{2 N\left(t L^{2}-3 N\right)\left(5 t L^{2}-18 N\right)^{2}}{27[\cdot]^{2}}-f
$$

$$
\pi^{M}=\frac{N\left(t L^{2}-2 N\right)^{2}\left(5 t L^{2}-18 N\right)^{2}\left(t L^{2}-6 N\right)}{6[\cdot]^{2}}-2 f
$$

$$
\pi_{k(1)}^{F}=\frac{N\left(t L^{2}-3 N\right)\left[3\left(t L^{2}-2 N\right)\left(t L^{2}-6 N\right)+8\left(t L^{2}-3 N\right)^{2}\right]^{2}}{54[\cdot]^{2}}-f
$$

The above equations contain the term $[]=.3\left(t L^{2}-2 N\right)\left(t L^{2}-6 N\right)+16\left(t L^{2}-3 N\right)^{2}$. 


\section{E. THE NASH PRICE-QUALITY MERGER EQUILIBRIUM RESULTS: A}

\section{SINGLE, TWO-NEIGHBOUR FIRM MERGER (CENTRALIZED QUALITY}

\section{LEVELS)}

Suppose there is a merger between two-neighbour firms, located at $x_{i}$ and $x_{i+1}$, respectively. The corporate authority of the bi-variant firm $M$ simultaneously chooses prices $\left\{p_{i}^{M}, p_{i+1}{ }^{M}\right\}$, and quality levels $\left\{a_{i}^{M}, a_{i+1}{ }^{M}\right\}$, so as to maximize the joint profit, $\pi^{\mathcal{M}}=$ $\pi_{i}^{M}+\pi_{i+1}{ }^{M}$, of its two member firms. The corporate authority of the merged firm $M$ assumes that its price-quality choice is not reflected in the simultaneous choice of price and quality independently set by each of the remaining (n-2) single-product competitors in the industry, given $n \geq 4$ pre-merger firms.

The joint profit function of the two-neighbour firm merger is given by the following expression:

$$
\pi^{M}=\pi_{i}^{M}+\pi_{i+1}^{M}=\left(p_{i}^{M}-c\right) X_{i}^{M}-\frac{1}{2}\left(a_{i}^{M}\right)^{2}+\left(p_{i+1}^{M}-c\right) X_{i+1}^{M}-\frac{1}{2}\left(a_{i+1}^{M}\right)^{2}-2 f
$$

From the necessary conditions with respect to prices for $i=1, \ldots, n, \partial \pi^{M} / \partial p_{i}^{M}=0$ and $\partial \pi^{M} / \partial p_{i+1}{ }^{M}=0$, respectively, the following best-response price functions for the merged firm $M$ are derived as:

$$
\begin{aligned}
& p_{i}^{M}=\frac{1}{2}\left(p_{i+1}^{M}+p_{i-1}^{F}\right)+\frac{1}{2} a_{i}^{M}-\frac{1}{4} a_{i+1}^{M}-\frac{1}{4} a_{i-1}^{F}+\frac{t L^{2}}{2 n^{2}} \\
& p_{i+1}^{M}=\frac{1}{2}\left(p_{i}^{M}+p_{i+2}^{F}\right)+\frac{1}{2} a_{i+1}^{M}-\frac{1}{4} a_{i}^{M}-\frac{1}{4} a_{i+2}^{F}+\frac{t L^{2}}{2 n^{2}}
\end{aligned}
$$


From the necessary conditions with respect to quality levels for $i=1, \ldots, n, \partial \pi^{M} / \partial a_{i}^{M}=0$ and $\partial \pi^{M} / \partial a_{i+1}{ }^{M}=0$, respectively, the following best-response quality functions for the merged firm $M$ are derived as:

$a_{i}^{M}=\frac{n N}{2 t L^{2}}\left(2 p_{i}^{M}-p_{i+1}^{M}-c\right)$

$a_{i+1}^{M}=\frac{n N}{2 t L^{2}}\left(2 p_{i+1}^{M}-p_{i}^{M}-c\right)$

The market shares, $X_{i}^{M}$ and $X_{i: 1}{ }^{M}$, respectively, are functions of the nearest outside competitors' price and quality level. Since $p_{i-1}{ }^{F}=p_{i+2}^{F} \equiv p_{k(l)}^{F}$, and $a_{i-1}^{F}=a_{i+2}{ }^{F} \equiv a_{k(l)}{ }^{F}$ in the expression for joint profit $\pi^{M}$, and they are fixed for the nearest equi-distant singleproduct rival firms, and if $a_{i}^{M}=a_{i+l}{ }^{M} \equiv a^{M}$, then equations (E.0) and (E.1) are symmetric, and the bi-variant firm $M$ will set, in equilibrium, identical prices $p_{i}^{M}=p_{i+1}^{M} \equiv p^{M}$, and quality levels $a_{i}^{M}=a_{i+l}{ }^{M} \equiv a^{M}$.

The best-response price and quality functions for each of the $(n-2)$ single-product competitors are solved from the first-order conditions, and they are each determined separately, and recursively, for those firms located at $x_{i+2}\left(\right.$ or $\left.x_{i-1}\right), x_{i+3}, \ldots, x_{i-2}$ on $C$, given $n \geq 4$. For example, the best-response price function $p_{i+2}{ }^{F}$, and quality function $a_{i+2}{ }^{k}$, of the firm $x_{i+2}$, are determined from the following profit-maximization problem:

$$
\pi_{i+2}^{F}=\left(p_{i+2}^{F}-c\right) \frac{N}{L}\left[\frac{\left(p_{i+3}^{F}-a_{i+3}^{F}\right)-2\left(p_{i+2}^{F}-a_{i+2}^{F}\right)+\left(p_{i+1}^{M}-a_{i+1}^{M}\right)}{2 t L / n}+\frac{L}{n}\right]-\frac{1}{2}\left(a_{i+3}^{F}\right)^{2}-f
$$


$p_{i+2}^{F}=\frac{1}{4}\left(p_{i+1}^{M}-a_{i+1}^{M}\right)+\frac{1}{4}\left(p_{i+3}^{F}-a_{i+3}^{F}\right)+\frac{1}{2} a_{i+2}^{F}+\frac{t L^{2}}{2 n^{2}}$

$a_{i+2}^{F}=\frac{n N}{t L^{2}}\left(p_{i+2}^{F}-c\right)$

Substituting equations (E.2), (E.3), (E.5) and (E.6) into equation (E.0) gives the postmerger equilibrium price function $p^{M}$ :

$$
p^{M}=\frac{\left(2 t L^{2}-n N\right) p_{k(1)}^{F}}{\left(4 t L^{2}-n N\right)}+\frac{4\left(t L^{2}\right)^{2}}{n^{2}\left(4 t L^{2}-n N\right)}+\frac{\left(2 t L^{2}+n N\right) c}{\left(4 t L^{2}-n N\right)}
$$

Note that $p^{M}$ is not only a function of the parameters $t, L, n$, and $N$, but is also a function of $p_{k(l)}{ }^{F}$, the price of the two nearest equi-distant non-merged firms' variants. The solution of $p_{k(j)}{ }^{F}$ and $a_{k(j)}{ }^{F}$, for $j=1,2, \ldots$, is determined recursively by each independent Nash profit-maximization problem, for a given $n \geq 4$, and is symmetric with respect to the prices (and quality levels) of the neighbouring firms. For example, if there are $n=4$ pre-merger firms, suppose that firms 1 and 2 merge. Then firms 3 and 4 are the nearest equi-distant rivals located on either side of the merged firm $M$, and these singleproduct firms set, in equilibrium, identical prices $p_{k(l)}{ }^{F}$, and identical quality levels $a_{k(l)}{ }^{l}$. The price $p_{k(l)}^{F}$ is a function of the price $p^{M}$ of the bi-variant firm $M$.

If there are $n=5$ pre-merger firms, then the next nearest neighbours' prices to the merged firm $M$ are given by $p_{3}^{F}=p_{5}^{F}=p_{k(l)}^{F}$, and $p_{+}^{F}=p_{k(2)}{ }^{F}$. The price $p_{k(2)}^{F}$ is a function of $p_{k(l)}{ }^{r}$ only. Thus, by the recursive solution of the single-product firms' 
equilibrium prices and qualities, then all pair-wise non-merged firms equi-distant from the merged firm $M$ will set, in equilibrium, identical prices such that, in general, $p^{M}>$ $p_{k(1)}^{F}>p_{k(2)}^{F}>\ldots$ if and only if $t>n N / 2 L^{2}$. As an example, the profit function (E.4) contains the variables, $p_{i+3}{ }^{F}$ and $a_{i+3}{ }^{F}$. If there are $n=5$ pre-merger firms, then the outermost single-product firm is located at $x_{i+3}$ on $C$. Then a separate profit-maximizing problem must be solved for the Nash equilibrium values, $p_{i+3}{ }^{F}=p_{k(2)}{ }^{F}$ and $a_{i+3}{ }^{F}=a_{k(2)}{ }^{F}$. The Nash equilibrium values are then substituted into (E.4) to solve for the equilibrium values, $p_{k(l)}{ }^{F}$ and $a_{k(l)}{ }^{F}$, respectively.

The equilibrium outcome for quality levels is such that, in general, the bi-variant firm $M$ will set a lower level of quality $a^{M}<a_{k(l)}{ }^{F}>a_{k(2)}{ }^{F}>\ldots$ if and only if $t>n N / 2 L^{2}$, for its variants than will its single-product competitors. It can be shown that the twoneighbour firm merger increases the post-merger profits in the industry, given $n \geq 4$, such that $\pi^{M}>\pi_{k(l)}^{F}>\pi_{k(2)}^{F}>\ldots$, and all single-product firms earn less profits than each party to the merged firm $M$. The equilibrium outcome solutions of a two-neighbour firm merger for the prices, the quality levels, and the profits are given below for each of the cases $n=4,5$, and 6 post-merger firms within an industry.

\section{$1:$ Number of Firms $(n=2$ and $q=2):$ sufficient condition $t>2 N / L^{2}$}

$$
\begin{aligned}
& \hline p^{M}=c+\frac{t L^{2}\left(t L^{2}-2 N\right)}{2\left(5 t L^{2}-8 N\right)} ; \quad p^{F}=c+\frac{t L^{2}\left(3 t L^{2}-4 N\right)}{8\left(5 t L^{2}-8 N\right)} ; \quad p^{M}>P_{k(1)}^{F} \Leftrightarrow t>4 N / L^{2} \\
& a^{M}=\frac{N\left(t L^{2}-2 N\right)}{\left(5 t L^{2}-8 N\right)} ; \quad a^{F}=\frac{N\left(3 t L^{2}-4 N\right)}{2\left(5 t L^{2}-8 N\right)} ; \quad X^{M}=\frac{2 N\left(t L^{2}-2 N\right)}{\left(5 t L^{2}-8 N\right)} ; \quad X^{F}=\frac{N\left(3 t L^{2}-4 N\right)}{2\left(5 t L^{2}-18 N\right)}
\end{aligned}
$$




$$
\pi^{M}=\frac{N\left(t L^{2}-2 N\right)^{2}\left(t L^{2}-N\right)}{\left(5 t L^{2}-8 N\right)^{2}}-2 f ; \quad \pi^{F}=\frac{N\left(3 t L^{2}-4 N\right)^{2}\left(t L^{2}-2 N\right)}{16\left(5 t L^{2}-8 N\right)^{2}}-f
$$

2: Number of Firms $(n=2$ and $q=3):$ sufficient condition $t>5 N / 2 L^{2}$

$$
p^{M}=c+\frac{2 t L^{2}\left[2\left(2 t L^{2}-5 N\right)\left(3 t L^{2}-5 N\right)+\left(t L^{2}-5 N\right)^{2}\right]}{25\left(3 t L^{2}-5 N\right)\left(8 t L^{2}-25 N\right)}
$$

$$
a^{M}=\frac{N\left[2\left(2 t L^{2}-5 N\right)\left(3 t L^{2}-5 N\right)+\left(t L^{2}-5 N\right)^{2}\right]}{5\left(3 t L^{2}-5 N\right)\left(8 t L^{2}-25 N\right)}
$$

$p_{k(1)}^{F}=c+\frac{t L^{2}\left[4\left(2 t L^{2}-5 N\right)\left(3 t L^{2}-5 N\right)+\left(t L^{2}-5 N\right)\left(4 t L^{2}-5 N\right)\right]}{25\left(3 t L^{2}-5 N\right)\left(8 t L^{2}-25 N\right)}$

$$
\begin{aligned}
& a_{k(1)}^{F}=\frac{N\left[4\left(2 t L^{2}-5 N\right)\left(3 t L^{2}-5 N\right)+\left(t L^{2}-5 N\right)\left(4 t L^{2}-5 N\right)\right]}{5\left(3 t L^{2}-5 N\right)\left(8 t L^{2}-25 N\right)} \\
& p_{k(2)}^{F}=c+\frac{t L^{2}\left[\left(2 t L^{2}-5 N\right)\left(7 t L^{2}-5 N\right)+4\left(t L^{2}-5 N\right)\left(3 t L^{2}-5 N\right)\right]}{25\left(3 t L^{2}-5 N\right)\left(8 t L^{2}-25 N\right)}
\end{aligned}
$$

$$
\begin{aligned}
& a_{k(2)}^{F}=\frac{N\left[4\left(t L^{2}-5 N\right)\left(3 t L^{2}-5 N\right)+\left(2 t L^{2}-5 N\right)\left(7 t L^{2}-5 N\right)\right]}{5\left(3 t L^{2}-5 N\right)\left(8 t L^{2}-25 N\right)} \\
& \pi^{M}=\frac{N\left(4 t L^{2}-5 N\right)\left[2\left(3 t L^{2}-5 N\right)\left(3 t L^{2}-10 N\right)+\left(t L^{2}-5 N\right)^{2}\right]^{2}}{125\left(3 t L^{2}-5 N\right)^{2}\left(8 t L^{2}-25 N\right)^{2}}-2 f
\end{aligned}
$$




$$
\begin{aligned}
& \pi_{k(1)}^{F}=\frac{N\left(2 t L^{2}-5 N\right)\left[\left(t L^{2}-5 N\right)\left(4 t L^{2}-5 N\right)+4\left(2 t L^{2}-5 N\right)\left(3 t L^{2}-5 N\right)\right]^{2}}{250\left(3 t L^{2}-5 N\right)^{2}\left(8 t L^{2}-25 N\right)^{2}}-f \\
& \pi_{k(2)}^{F}=\frac{N\left(2 t L^{2}-5 N\right)\left[4\left(t L^{2}-5 N\right)\left(3 t L^{2}-5 N\right)+\left(2 t L^{2}-5 N\right)\left(7 t L^{2}-5 N\right)\right]^{2}}{250\left(3 t L^{2}-5 N\right)^{2}\left(8 t L^{2}-25 N\right)^{2}}-f
\end{aligned}
$$

3: Number of Firms $(n=2$ and $q=4)$ : sufficient condition $t>3 N / L^{2}$

$$
\begin{aligned}
& p^{M}=c+\frac{t L^{2}\left(t L^{2}-2 N\right)\left(5 t L^{2}-18 N\right)}{6[\cdot]} ; \quad a^{M}=\frac{N\left(t L^{2}-2 N\right)\left(5 t L^{2}-18 N\right)}{2[\cdot]} \\
& p^{M}>p_{k(1)}^{F} \Leftrightarrow t \geq 6 N / L^{2}: \quad p^{M}>p_{k(2)}^{F} \Leftrightarrow t>3 N / L^{2} \\
& p_{k(1)}^{F}=c+\frac{t L^{2}\left(t L^{2}-3 N\right)\left(11 t L^{2}-18 N\right)}{18[\cdot]} ; \quad a_{k(1)}^{F}=\frac{N\left(t L^{2}-3 N\right)\left(11 t L^{2}-18 N\right)}{3[\cdot]} \\
& p_{k(2)}^{F}=c+\frac{t L^{2}\left(2 t L^{2}-3 N\right)\left(5 t L^{2}-18 N\right)}{18[\cdot]} ; \quad a_{k(2)}^{F}=\frac{N\left(2 t L^{2}-3 N\right)\left(5 t L^{2}-18 N\right)}{3[\cdot]} \\
& \pi^{M}=\frac{N\left(2 t L^{2}-3 N\right)\left(t L^{2}-2 N\right)^{2}\left(5 t L^{2}-18 N\right)^{2}}{12[\cdot]^{2}}-2 f \\
& \pi_{k(1)}^{F}=\frac{N\left(t L^{2}-3 N\right)^{3}\left(11 t L^{2}-18 N\right)^{2}}{54[\cdot]^{2}}-f \\
& \pi_{k(2)}^{F}=\frac{N\left(t L^{2}-3 N\right)\left(2 t L^{2}-3 N\right)^{2}\left(5 t L^{2}-18 N\right)^{2}}{54[\cdot]^{2}}-f
\end{aligned}
$$


$-214-$

The above expressions contain the term $[]=.\left(2 t L^{2}-3 N\right)\left(5 t L^{2}-18 N\right)+9\left(t L^{2}-2 N\right)\left(t L^{2}-\right.$ $3 N)$. 


\section{APPENDIX: CHAPTER FOUR}

\section{A. THE STACKELBERG LEADER-FOLLOWER (NON-NEIGHBOUR) FIRM}

\section{MERGER MODEL}

\section{Proof of Proposition 4.1:}

\section{A. Best-response Stackelberg price-quality functions of the outside firms:}

The industry consists of $n \geq 4$ firms located at $x_{i}, x_{i+1}, x_{i+2}, \ldots, x_{i-1}$, on $C$, where $i \epsilon$ $\{1, \ldots, n\}$. Suppose that there is a merger between two non-neighbouring firms located at $x_{i}$ and $x_{i+2}$, on $C$, respectively. The remaining firms are known as the "followers", or the outside competition, which are located at $x_{i+1}, x_{i+3}, x_{i+4}, \ldots, x_{i-2}, x_{i-1}$, on $C$, respectively. The merged entity $M$, as the leader, maximizes its joint profits by simultaneously choosing a set of prices $\left\{p_{i}^{M}, p_{i+2}{ }^{M}\right\}$, and a set of quality levels $\left\{a_{i}^{M}, a_{i+2}{ }^{M}\right\}$, subject to the followers simultaneous choice of prices $\left\{p_{i+1}^{F}, p_{i+3}^{F}, \ldots, p_{i-1}{ }^{F}\right\}$, and qualitites $\left\{a_{i+1}{ }^{F}, a_{i},{ }^{l}, \ldots\right.$ , $\left.a_{i-1}^{F}\right\}$, that are individually chosen by each of the (n-2) outside competitive-follower firms.

The Stackelberg price-quality equilibrium of the spatial game between the two players, the leader, or the merged firm $M$, and the set of $(n-2)$ outside firms, or followers, is determined by the backward induction method. Firstly, after viewing the price-quality choice of the merged firm $M$, each of the (n-2) competitor-follower firms maximize their profits by the simultaneous choice of price and quality level of its product variant independently of the choices made by both the merged firm $M$, and all other follower firms. Secondly, the merged firm $M$, knowing the price-quality choices of the outside competitors, maximizes the joint profits of its two non-neighbour firm members by the 
simultaneous choice of prices and qualities of its product variants, i.e., subject to the price-quality choices determined by the outside competitor-followers.

The best-response price, and quality functions of the follower firm members are solved from the first-order conditions and are each determined separately for those firms located at $x_{i+1}, x_{i+3}\left(\right.$ or $\left.x_{i-1}\right)$, and for those firms at $x_{i+\downarrow}, x_{t^{+} 5}, \ldots, x_{i-2}$ on $C$. The best-response functions of the $(i+1)$-th firm are found by solving the two first-order conditions, for the price $p_{i+1}^{F}$ and the quality level $a_{i+l} F$, from the following mathematical optimization problem:

$\max \pi_{i+1}^{F}\left(p_{i+1}^{F}, a_{i+1}^{F}, p_{i}^{M}, p_{i+2}^{M}, a_{i}^{M}, a_{i+2}^{M}\right)=$

$\left(p_{i+1}^{F}\right) \frac{N}{L}\left[\frac{\left(p_{i+2}^{M}-a_{i+2}^{M}\right)-2\left(p_{i+1}^{F}-a_{i+1}^{F}\right)+\left(p_{i}^{M}-a_{i}^{M}\right)}{2 t L / n}+\frac{L}{n}\right]-1 / 2\left(a_{i+1}^{F}\right)^{2}-f$

The first-order conditions for the price $p_{i+l}{ }^{F}$, and the quality level $a_{i+1}{ }^{F}$ determine the bestresponse functions for the $(i+1)$-th firm which are given by the following equations:

$$
\begin{gathered}
p_{i+1}^{F}=1 / 4\left(p_{i}^{M}-a_{i}^{M}\right)+1 / 4\left(p_{i+2}^{M}-a_{i+2}^{M}\right)+1 / 2 a_{i+1}^{F}+\frac{t L^{2}}{2 n^{2}} \\
a_{i+1}^{F}=\frac{n N}{t L^{2}}\left(p_{i+1}^{F}\right)
\end{gathered}
$$

The substitution of $a_{i+1} F$ from equation (A.3) into equation (A.2) gives the best-response function $p_{i+l}{ }^{F}\left(p_{i}^{M}, p_{i+2}{ }^{M}, a_{i}{ }^{M}, a_{i+2}{ }^{M}\right)$ as the following expression: 
$p_{i+1}^{F}=\frac{t L^{2}\left(p_{i}{ }^{M}-a_{i}{ }^{M}\right)}{2\left(2 t L^{2}-n N\right)}+\frac{t L^{2}\left(p_{i+2}{ }^{M}-a_{i+2}{ }^{M}\right)}{2\left(2 t L^{2}-n N\right)}+\frac{\left(t L^{2}\right)^{2}}{n^{2}\left(2 t L^{2}-n N\right)}$

The profit-maximization problem for the outside firm located at $x_{i+3}\left(\right.$ or $\left.x_{i-\nu}\right)$ is to simultaneously determine the price $p_{i+3}{ }^{F}$ and quality level $a_{i+3}{ }^{F}$ that maximizes the following profit function:

$$
\begin{aligned}
& \pi_{i+3}^{F}\left(p_{i+3}^{F}, p_{i+4}^{F}, a_{i+3}^{F}, a_{i+4}^{F}, p_{i+2}^{M}, a_{i+2}^{M}\right)= \\
& \left(p_{i+3}^{F}\right) \frac{N}{L}\left[\frac{\left(p_{i+4}^{F}-a_{i+4}^{F}\right)-2\left(p_{i+3}^{F}-a_{i+3}\right)^{F}+\left(p_{i+2}^{M}-a_{i+2}^{M}\right)}{2 t L / n}+\frac{L}{n}\right]-1 / 2\left(a_{i+3}^{F}\right)^{2}-f
\end{aligned}
$$

The first-order conditions for price $p_{i+3}{ }^{F}$, and quality level $a_{i+3}{ }^{F}$ determine the bestresponse functions for the $(i+3)$-th firm and are given by the following equations:

$p_{i+3}^{F}=1 / 4\left(p_{i+2}^{M}-a_{i+2}^{M}\right)+1 / 4\left(p_{i+4}^{F}-a_{i+4}^{F}\right)+1 / 2 a_{i+3}^{F}+\frac{t L^{2}}{2 n^{2}}$

$a_{i+3}^{F}=\frac{n N}{t L^{2}}\left(p_{i+3}^{F}\right)$

The first-order conditions of the price variables $p_{i+k}^{F}$, and the quality level variables $a_{i \downarrow k}{ }^{l}$, for $k=4, \ldots, n-2$ or $(i-2)$, respectively, determine the best-response functions for the outside firm competitors:

$$
p_{i+k}^{F}=1 / 4\left(p_{i+k+1}^{F}+p_{i+k-1}^{F}\right)+1 / 2 a_{i+k}^{F}-1 / 4\left(a_{i+k+1}^{F}+a_{i+k-1}^{F}\right)+\frac{t L^{2}}{2 n^{2}}
$$


$a_{i+k}^{F}=\frac{n N}{t L^{2}}\left(p_{i+k}^{F}\right)$ for $k=4, \ldots, n-2$

Thus, after appropriate substitution of the quality variables $a_{i+3}{ }^{F}$ and $a_{i+4}{ }^{F}$ into equation (A..6), and $a_{i+k}^{F}$ into equation (A.8), we then have the price reaction functions expressed solely in terms of those prices with respect to their next-door neighbours:

$p_{i+3}^{F}=\frac{t L^{2}\left(p_{i+2}^{M}-a_{i+2}^{M}\right)}{2\left(2 t L^{2}-n N\right)}+\frac{\left(t L^{2}-n N\right) p_{i+4}^{F}}{2\left(2 t L^{2}-n N\right)}+\frac{\left(t L^{2}\right)^{2}}{n^{2}\left(2 t L^{2}-n N\right)}$

$p_{i+k}^{F}=\frac{\left(t L^{2}-n N\right) p_{i+k-1}^{F}}{2\left(2 t L^{2}-n N\right)}+\frac{\left(t L^{2}-n N\right) p_{i+k+1}^{F}}{2\left(2 t L^{2}-n N\right)}+\frac{\left(t L^{2}\right)^{2}}{n^{2}\left(2 t L^{2}-n N\right)}$

Note that the Stackelberg best-response price function given by equation (A.11), is a function of $p_{i+{ }^{F}}$, the price of the $(i+4)$-th competitor-follower firm. The second-stage solution, i.e., the Stackelberg price-quality equilibrium of the non-merged firms must be functions solely of the merged firm $M$ 's prices and qualities, in order to obtain the reduced-form profit function for the Stackelberg merged firm $M$. The system of linear recursive non-homogeneous difference equations, equations (A.4), (A.10) and (A.11), must first be solved individually, for a given value of $n \geq 4$. Once the intermediate solution set for these difference equations is determined for a given value of $n$, the expressions for the follower firms' prices and qualities are then functions of the prices and qualities of the Stackelberg firm $M$.

\section{B. Best-response Stackelberg price-quality functions of the merged firm M:}


Suppose there is a merger between two non-neighbouring firms located on $C$ at $x_{i}$ and $x_{i+2}$. The merged firm $M$, acting as the leader, jointly maximizes its member profits by choosing prices $\left\{p_{i}^{M}, p_{i+2}{ }^{M}\right\}$, and quality levels $\left\{a_{i}^{M}, a_{i+2}{ }^{M}\right\}$ of its two product-variants, subject to those price, and quality decisions made by the followers, i.e., the outside competitor firms. Formally, the mathematical optimization problem for the merged entity $M$ is stated as the following:

$$
\begin{aligned}
& \max \Pi_{M}=\max \left(\pi_{i}^{M}+\pi_{i+2}^{M}\right)= \\
& \left(p_{i}^{M}\right) \frac{N}{L}\left[\frac{\left(p_{i+1}^{F}-a_{i+1}^{F}\right)-2\left(p_{i}^{M}-a_{i}^{M}\right)+\left(p_{i-1}^{F}-a_{i-1}^{F}\right)}{2 t L / n}+\frac{L}{n}\right]-1 / 2\left(a_{i}^{M}\right)^{2}-f+ \\
& \left(p_{i+2}^{M}\right) \frac{N}{L}\left[\frac{\left(p_{i+3}^{F}-a_{i+3}^{F}\right)-2\left(p_{i+2}^{M}-a_{i+2}^{M}\right)+\left(p_{i+1}^{F}-a_{i+1}^{F}\right)}{2 t L / n}+\frac{L}{n}\right]-1 / 2\left(a_{i+2}^{M}\right)^{2}-f
\end{aligned}
$$

subject to $\left\{p_{i-1}{ }^{F}, p_{i+1}{ }^{F}, p_{i+3}{ }^{F}\right\}$ and $\left\{a_{i-1}{ }^{F}, a_{i+1}{ }^{F}, a_{i+3}{ }^{F}\right\}$

The firm $M$ maximizes its joint profit function $\Pi_{M}$, given in equation (A.12), subject to the prices $\left\{p_{i-1}{ }^{F}, p_{i+1}{ }^{F}, p_{i+3}{ }^{F}\right\}$, and the quality levels $\left\{a_{i-1}{ }^{F}, a_{i+1}{ }^{F}, a_{i: 3}{ }^{F}\right\}$ simultaneously, but independently chosen by each of the three $\{i-1, i+1, i-3\}$ follower firms. The reducedform profit function of the merged firm $M$ is determined by the substitution of the intermediate strategic price and quality solutions obtained from the equations (A.4), (A.10) and (A.11), for each value of $n=4,5$, and 6 .

\section{The case of $n=4$ industry firms ( $q=2$ outside competitor-followers):}

The first-order conditions of the follower firms' prices $\left\{p_{i}^{F}, p_{i+3}^{F}\right\}$, and qualities $\left\{a_{i}^{F}, a_{i+3}{ }^{F}\right\}$, 
(not shown) are symmetric with respect to firms $i+1$ and $\mathrm{i}+3$. Hence, $p_{i+1}^{F}=p_{i+3}^{F}=p^{F} \Leftrightarrow$ $a_{i+1}{ }^{F}=a_{i+3}{ }^{F}=a^{F}$. After substitution of the quality variables from equations (A.3) and (A.7) into the equations (A.4) and (A.7), respectively, then the best reply functions for price, and quality, (since, by symmetry, $p_{i}^{M}=p_{i+2}{ }^{M} \equiv p^{M}$, and are fixed) are given by the following expressions for $n=4$ :

$$
\begin{aligned}
& p_{i+1}^{F}=p_{i+3}^{F}=p^{F}=\frac{t L^{2}\left(p^{M}-a^{M}\right)}{2\left(t L^{2}-2 N\right)}+\frac{\left(t L^{2}\right)^{2}}{32\left(t L^{2}-2 N\right)} \\
& a_{i+1}^{F}=a_{i+3}^{F}=a^{F}=\frac{4 N}{t L^{2}}\left(p^{F}\right)
\end{aligned}
$$

The reduced-form profit function of the merged firm $M$ (centralized quality levels) is given by the following equation for which the first-order conditions are symmetric $(n=4)$ :

$$
\begin{aligned}
& \Pi_{M}=\left(p^{M}\right) \frac{8 N}{t L^{2}}\left[\frac{\left(t L^{2}-4 N\right)\left(p^{M}-a^{M}\right)}{2\left(t L^{2}-2 N\right)}-\left(p^{M}-a^{M}\right)+\frac{t L^{2}\left(t L^{2}-4 N\right)}{32\left(t L^{2}-2 N\right)}\right] \\
& +\left(p^{M}\right) \frac{N}{2}-\left(a^{M}\right)^{2}-2 f
\end{aligned}
$$

The first-order condition for $p^{M}$ gives the following best-response price function:

$$
p^{M}=1 / 2 a^{M}+\frac{\left(3 t L^{2}-8 N\right)}{32}
$$

The first-order condition for $a^{M}$ gives the following best-response quality function: 


$$
a^{M}=\frac{2 N}{\left(t L^{2}-2 N\right)}\left(p^{M}\right)
$$

The first-order conditions for the merged firm $M$ 's prices $\left\{p_{i}^{M}, p_{i+2}{ }^{M}\right\}$, and quality levels $\left\{a_{i}{ }^{M}, a_{i \vdash 2}{ }^{M}\right\}$, (not shown) are symmetric which implies that $p_{i}{ }^{M}=p_{i+2}{ }^{M} \equiv p^{M} \Leftrightarrow a_{i}{ }^{M}=a_{i+2}{ }^{M} \equiv$ $a^{M}$. Thus, the merged firm sets a symmetric price and quality policy under Stackelberg behaviour if there are $q=2$ outside competitors. The Stackelberg price-quality equilibrium of the merged firm $M$ is given by the following equations:

$$
\begin{aligned}
& p^{M}=\frac{\left(t L^{2}-2 N\right)\left(3 t L^{2}-8 N\right)}{32\left(t L^{2}-3 N\right)} \\
& a^{M}=\frac{N\left(3 t L^{2}-8 N\right)}{16\left(t L^{2}-3 N\right)}
\end{aligned}
$$

The second-order conditions are given by the following expressions:

$$
\begin{aligned}
& \frac{\partial^{2} \pi^{M}}{\partial\left(p^{M}\right)^{2}}=\frac{-8 N}{\left(t L^{2}-2 N\right)}<0 ; \frac{\partial^{2} \pi^{M}}{\partial\left(a^{M}\right)^{2}}=-2<0 ; \frac{\partial^{2} \pi^{M}}{\partial p^{M} a^{M}}=\frac{4 N}{\left(t L^{2}-2 N\right)}>0 \\
& \therefore\left[\frac{-8 N}{\left(t L^{2}-2 N\right)}\right][-2]-\left[\frac{4 N}{\left(t L^{2}-2 N\right)}\right]^{2}>0 \Leftrightarrow t>\frac{3 N}{L^{2}}
\end{aligned}
$$

Thus, the Stackelberg price-quality equilibrium of the two outside competitor-follower firms is given by the following equations:

$$
p^{F}=\frac{t L^{2}\left(5 t L^{2}-8 N\right)}{64\left(t L^{2}-2 N\right)}
$$




$$
a^{F}=\frac{N\left(5 t L^{2}-8 N\right)}{16\left(t L^{2}-2 N\right)}
$$

\section{The case of $n=5$ industry firms ( $q=3$ outside competitor-followers):}

The best-response price and quality functions for the firms $i+1, i+3$ and $i+4(i-1)$ are given by the following expressions for $n=5$ :

$$
\begin{aligned}
& p_{i+1}^{F}=p_{k(1)}^{F}=\frac{t L^{2}\left(p_{i}^{M}-a_{i}^{M}\right)}{2\left(2 t L^{2}-5 N\right)}+\frac{t L^{2}\left(p_{i+2}^{M}-a_{i+2}^{M}\right)}{2\left(2 t L^{2}-5 N\right)}+\frac{\left(t L^{2}\right)^{2}}{25\left(2 t L^{2}-5 N\right)} ; a_{i+1}^{F}=a_{k(1)}^{F}=\frac{5 N}{t L^{2}}\left(p_{k(1)}^{F}\right) \\
& p_{i+3}^{F}=\frac{t L^{2}\left(p_{i+2}^{M}-a_{i+2}^{M}\right)}{2\left(2 t L^{2}-5 N\right)}+\frac{\left(t L^{2}-5 N\right) p_{i+4}^{F}}{2\left(2 t L^{2}-5 N\right)}+\frac{\left(t L^{2}\right)^{2}}{25\left(2 t L^{2}-5 N\right)} \\
& p_{i+4}^{F}=\frac{t L^{2}\left(p_{i}^{M}-a_{i}^{M}\right)}{2\left(2 t L^{2}-5 N\right)}+\frac{\left(t L^{2}-5 N\right) p_{i+3}^{F}}{2\left(2 t L^{2}-5 N\right)}+\frac{\left(t L^{2}\right)^{2}}{25\left(2 t L^{2}-5 N\right)} \\
& a_{i+3}^{F}=\frac{5 N}{t L^{2}}\left(p_{i+3}^{F}\right) ; \quad a_{i+4}^{F}=\frac{5 N}{t L^{2}}\left(p_{i+4}^{F}\right)
\end{aligned}
$$

Thus, the symmetry of the first-order conditions (not shown) for $p_{i+3}{ }^{F}$ and $p_{i+4}{ }^{F}$ imply that $p_{i+3}{ }^{F}=p_{i+4}{ }^{F}=p_{k(2)}{ }^{F} \Leftrightarrow p_{i}^{M}=p_{i+2}{ }^{M}=p^{M}$, and $a_{i}^{M}=a_{i+2}{ }^{M}=a^{M}$, so that they may be rewritten as the following expressions:

$$
p_{k(1)}^{F}=\frac{\left(t L^{2}\right)^{2}}{25\left(2 t L^{2}-5 N\right)}+\frac{t L^{2}\left(p^{M}-a^{M}\right)}{\left(2 t L^{2}-5 N\right)} ; \quad a_{k(1)}^{F}=\frac{5 N}{t L^{2}}\left(p_{k(1)}^{F}\right)
$$


$p_{k(2)}^{F}=\frac{t L^{2}\left(p^{M}-a^{M}\right)}{\left(3 t L^{2}-5 N\right)}+\frac{\left(t L^{2}\right)^{2}}{25\left(3 t L^{2}-5 N\right)} ; \quad a_{k(2)}^{F}=\frac{5 N}{t L^{2}}\left(p_{k(2)}^{F}\right)$

The reduced-form profit function of the merged firm $M$ (centralized quality levels) is given by the following equation $(n=5)$ :

$\Pi_{M}=\left(p^{M}\right) \frac{5 N}{t L^{2}}\left[\frac{-t L^{2}\left(7 t L^{2}-15 N\right)\left(p^{M}-a^{M}\right)}{\left(2 t L^{2}-5 N\right)\left(3 t L^{2}-5 N\right)}+\frac{t L^{2}\left(t L^{2}-5 N\right)\left(7 t L^{2}-15 N\right)}{25\left(2 t L^{2}-5 N\right)\left(3 t L^{2}-5 N\right)}\right]$

$+\left(p^{M}\right) \frac{2 N}{5}-\left(a^{M}\right)^{2}-2 f$

The first-order conditions for $\left\{p^{M}, a^{M}\right\}$ give the following best-response price, and quality functions (A.24):

$p^{M}=\frac{\left(t L^{2}-50 N\right)}{50}+\frac{\left(3 t L^{2}-5 N\right)\left(3 t L^{2}-10 N\right)}{25\left(7 t L^{2}-15 N\right)}+\frac{1}{2} a^{M} ; a^{M}=\frac{5 N\left(7 t L^{2}-15 N\right)}{2\left(2 t L^{2}-5 N\right)\left(3 t L^{2}-5 N\right)} p^{M}$

The best-response price functions are symmetric which implies that $p_{i}^{M}=p_{i \vdash 2}{ }^{M} \equiv p^{M} \leftrightarrow$ $a_{t}^{M}=a_{i \cdots 2}{ }^{M} \equiv a^{M}$. Thus, the merged firm sets a symmetric price and quality policy under Stackelberg behaviour if there are $q=3$ outside competitors. The Stackelberg pricequality equilibrium of the merged firm $M$ (centralized quality levels) is given by the following equations:

$$
p^{M}=\frac{2\left(2 t L^{2}-5 N\right)\left(3 t L^{2}-5 N\right)\left[2\left(2 t L^{2}-5 N\right)\left(3 t L^{2}-5 N\right)+\left(t L^{2}-5 N\right)\left(7 t L^{2}-15 N\right)\right]}{25\left(7 t L^{2}-15 N\right)\left[4\left(2 t L^{2}-5 N\right)\left(3 t L^{2}-5 N\right)-5 N\left(7 t L^{2}-15 N\right)\right]}
$$




$$
a^{M}=\frac{N\left[2\left(2 t L^{2}-5 N\right)\left(\left(3 t L^{2}-5 N\right)+\left(t L^{2}-5 N\right)\left(7 t L^{2}-15 N\right)\right]\right.}{5\left[4\left(2 t L^{2}-5 N\right)\left(3 t L^{2}-5 N\right)-5 N\left(7 t L^{2}-15 N\right)\right]}
$$

Thus, the Stackelberg price-quality equilibrium of the three outside, competitor-follower firms is given by the following equations (A.26):

$$
\begin{aligned}
& p_{k(1)}^{F}=\frac{\left(t L^{2}\right)^{2}}{25\left(2 t L^{2}-5 N\right)}+\frac{t L^{2}\left[2\left(2 t L^{2}-5 N\right)\left(3 t L^{2}-5 N\right)-5 N\left(7 t L^{2}-15 N\right)\right][u]}{25\left(2 t L^{2}-5 N\right)\left(7 t L^{2}-15 N\right)\left[4\left(2 t L^{2}-5 N\right)\left(3 t L^{2}-5 N\right)-5 N\left(7 t L^{2}-15 N\right)\right]} \\
& a_{k(1)}^{F}=\frac{N t L^{2}}{5\left(2 t L^{2}-5 N\right)}+\frac{N\left[2\left(2 t L^{2}-5 N\right)\left(3 t L^{2}-5 N\right)-5 N\left(7 t L^{2}-15 N\right)\right][u]}{5\left(2 t L^{2}-5 N\right)\left(7 t L^{2}-15 N\right)\left[4\left(2 t L^{2}-5 N\right)\left(3 t L^{2}-5 N\right)-5 N\left(7 t L^{2}-15 N\right)\right]} \\
& p_{k(2)}^{F}=\frac{2\left(t L^{2}\right)^{2}}{25\left(3 t L^{2}-5 N\right)}+\frac{t L^{2}\left[2\left(2 t L^{2}-5 N\right)\left(3 t L^{2}-5 N\right)-5 N\left(7 t L^{2}-15 N\right)\right][u]}{25\left(3 t L^{2}-5 N\right)\left(7 t L^{2}-15 N\right)\left[4\left(2 t L^{2}-5 N\right)\left(3 t L^{2}-5 N\right)-5 N\left(7 t L^{2}-15 N\right)\right]} \\
& a_{k(2)}^{F}=\frac{2 N t L^{2}}{5\left(3 t L^{2}-5 N\right)}+\frac{N\left[2\left(2 t L^{2}-5 N\right)\left(3 t L^{2}-5 N\right)-5 N\left(7 t L^{2}-15 N\right)\right][u]}{5\left(3 t L^{2}-5 N\right)\left(7 t L^{2}-15 N\right)\left[4\left(2 t L^{2}-5 N\right)\left(3 t L^{2}-5 N\right)-5 N\left(7 t L^{2}-15 N\right)\right]}
\end{aligned}
$$

The above equilibrium expressions contain the term $[u]=2\left(2 t L^{2}-5 N\right)\left(3 t L^{2}-5 N\right)+\left(t L^{2}\right.$ $-5 N)\left(7 t L^{2}-15 N\right)$

\section{The case of $n=6$ industry firms ( $q=4$ outside competitor-followers):}

The first-order conditions of the follower firms' prices and qualities are symmetric with

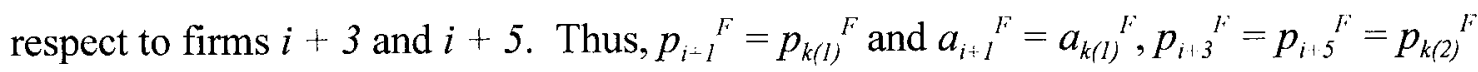
$\Leftrightarrow a_{i+3}{ }^{F}=a_{i+5}{ }^{F}=a_{k(2)}{ }^{F}$, and $p_{i+4}{ }^{F}=p_{k(3)}{ }^{F}$, and $a_{i+4}{ }^{F}=a_{k(3)}{ }^{F}$. By symmetry of the first-order price and quality conditions of the firm $M$, then equation (A.4) for price $p_{k(l)}{ }^{F}$, and 
equation (A.3) for quality level $a_{k(l)}^{l i}$, are given by the following expressions for $n=6$ :

$p_{k(1)}^{F}=\frac{t L^{2}\left(p^{M}-a^{M}\right)}{2\left(t L^{2}-3 N\right)}+\frac{\left(t L^{2}\right)^{2}}{72\left(t L^{2}-3 N\right)} ; \quad a_{k(1)}^{F}=\frac{6 N}{t L^{2}}\left(p_{k(1)}^{F}\right)$

The remaining price and quality best-reply functions are given by the following expressions:

$p_{k(2)}^{F}=\frac{t L^{2}\left(p^{M}-a^{M}\right)}{4\left(t L^{2}-3 N\right)}+\frac{\left(t L^{2}-6 N\right) p_{k(3)}^{F}}{4\left(t L^{2}-3 N\right)}+\frac{\left(t L^{2}\right)^{2}}{72\left(t L^{2}-3 N\right)} ; \quad a_{k(2)}^{F}=\frac{6 N}{t L^{2}}\left(p_{k(2)}^{F}\right)$

$p_{k(3)}^{F}=\frac{\left(t L^{2}-6 N\right) p_{k(2)}^{F}}{2\left(t L^{2}-3 N\right)}+\frac{\left(t L^{2}\right)^{2}}{72\left(t L^{2}-3 N\right)} ; \quad a_{k(3)}^{F}=\frac{6 N}{t L^{2}}\left(p_{k(3)}^{F}\right)$

After eliminating the respective price variables in each of the above equations (A.28), they are rewritten as the following expressions:

$$
\begin{aligned}
& p_{k(2)}^{F}=\frac{2 t L^{2}\left(t L^{2}-3 N\right)\left(p^{M}-a^{M}\right)}{\left[8\left(t L^{2}-3 N\right)^{2}-\left(t L^{2}-6 N\right)^{2}\right]}+\frac{\left(t L^{2}\right)^{2}\left(5 t L^{2}-18 N\right)}{36\left[8\left(t L^{2}-3 N\right)^{2}-\left(t L^{2}-6 N\right)^{2}\right]} \\
& p_{k(3)}^{F}=\frac{t L^{2}\left(t L^{2}-6 N\right)\left(p^{M}-a^{M}\right)}{\left[8\left(t L^{2}-3 N\right)^{2}-\left(t L^{2}-6 N\right)^{2}\right]}+\frac{\left(t L^{2}\right)^{2}\left(t L^{2}-4 N\right)}{6\left[8\left(t L^{2}-3 N\right)^{2}-\left(t L^{2}-6 N\right)^{2}\right]}
\end{aligned}
$$

The reduced-form profit function of the merged firm $M$ (centralized quality levels) is given by the following equation $(n=6)$ :

$$
\Pi^{M}=\frac{6 N}{t L^{2}}\left(p^{M}\right)\left[\frac{2\left(t L^{2}-3 N\right)\left(t L^{2}-6 N\right)\left(p^{M}-a^{M}\right)}{\left[8\left(t L^{2}-3 N\right)^{2}-\left(t L^{2}-6 N\right)^{2}\right]}+\frac{\left(t L^{2}-6 N\right)\left(p^{M}-a^{M}\right)}{2\left(t L^{2}-3 N\right)}+\frac{t L^{2}\left(t L^{2}-6 N\right)}{72\left(t L^{2}-3 N\right)}\right.
$$


$\left.-\frac{12 N}{t L^{2}}\left(p^{M}-a^{M}\right)+\frac{t L^{2}\left(5 t L^{2}-18 N\right)\left(t L^{2}-6 N\right)}{36\left[8\left(t L^{2}-3 N\right)^{2}-\left(t L^{2}-6 N\right)^{2}\right]}\right]+\left(p^{M}\right) \frac{N}{3}-\left(a^{M}\right)^{2}-2 f$

The first-order conditions for price $p^{M}$, and the quality level $a^{M}$, are given by the following expressions:

$$
\begin{aligned}
& p^{M}=\frac{1}{2} a^{M}+\frac{\left(t L^{2}-2 N\right)\left(t L^{2}-4 N\right)\left(5 t L^{2}-18 N\right)}{4\left[8\left(t L^{2}-3 N\right)^{2}+9\left(t L^{2}-2 N\right)\left(t L^{2}-4 N\right)\right]} \\
& a^{M}=\frac{3 N\left[8\left(t L^{2}-3 N\right)^{2}+9\left(t L^{2}-2 N\right)\left(t L^{2}-4 N\right)\right] p^{M}}{2\left(t L^{2}-3 N\right)\left[8\left(t L^{2}-3 N\right)^{2}-\left(t L^{2}-6 N\right)^{2}\right]}
\end{aligned}
$$

Thus, the symmetric Stackelberg price-quality equilibrium outcome for the merged firms' two product variants is given by the following expressions:

$$
\begin{aligned}
& p^{M}=\frac{\left(t L^{2}-2 N\right)\left(t L^{2}-3 N\right)\left(t L^{2}-4 N\right)\left(5 t L^{2}-18 N\right)\left[8\left(t L^{2}-3 N\right)^{2}-\left(t L^{2}-6 N\right)^{2}\right]}{2\left[16\left(t L^{2}-3 N\right)^{2}+t L^{2}\left(t L^{2}-6 N\right)\right][l]} \\
& a^{M}=\frac{3 N\left(t L^{2}-2 N\right)\left(t L^{2}-4 N\right)\left(5 t L^{2}-18 N\right)}{4[l]}
\end{aligned}
$$

The above equilibrium expressions contain the terms $[]=.8\left(t L^{2}-3 N\right)^{2}-\left(t L^{2}-6 N\right)^{2}$, and $[l]=4\left(t L^{2}-3 N\right)[]-.3 N\left[16\left(t L^{2}-3 N\right)^{2}+t L^{2}\left(t L^{2}-6 N\right)\right]$. The equilibrium expressions below contain the term $[u]=8\left(t L^{2}-3 N\right)^{2}+3\left(t L^{2}-4 N\right)\left(2 t L^{2}-3 N\right)$.

The Stackelberg price-quality equilibrium outcome of the four outside follower firms is given by the following expressions for the four product variants: 


$$
\begin{aligned}
& p_{k(1)}^{F}=\frac{\left(t L^{2}\right)^{2}}{72\left(t L^{2}-3 N\right)}+\frac{t L^{2}\left(t L^{2}-2 N\right)\left(t L^{2}-4 N\right)\left(t L^{2}-6 N\right)\left(5 t L^{2}-18 N\right)[u]}{8\left(t L^{2}-3 N\right)\left[16\left(t L^{2}-3 N\right)^{2}+t L^{2}\left(t L^{2}-6 N\right)\right][l]} \\
& a_{k(1)}^{F}=\frac{N t L^{2}}{12\left(t L^{2}-3 N\right)}+\frac{3 N\left(t L^{2}-2 N\right)\left(t L^{2}-4 N\right)\left(t L^{2}-6 N\right)\left(5 t L^{2}-18 N\right)[u]}{4\left(t L^{2}-3 N\right)\left[16\left(t L^{2}-3 N\right)^{2}+t L^{2}\left(t L^{2}-6 N\right)\right][l]} \\
& p_{k(2)}^{F}=\frac{t L^{2}\left(t L^{2}-2 N\right)\left(t L^{2}-4 N\right)\left(t L^{2}-6 N\right)\left(5 t L^{2}-18 N\right)[u]}{2\left[16\left(t L^{2}-3 N\right)^{2}+t L^{2}\left(t L^{2}-6 N\right)\right]\left[8\left(t L^{2}-3 N\right)^{2}-\left(t L^{2}-6 N\right)^{2}\right][l]} \\
& +\frac{\left(t L^{2}\right)^{2}\left(5 t L^{2}-18 N\right)}{36\left[8\left(t L^{2}-3 N\right)^{2}-\left(t L^{2}-6 N\right)^{2}\right]} \\
& a_{k(2)}^{F}=\frac{t L^{2} N\left(5 t L^{2}-18 N\right)}{6\left[8\left(t L^{2}-3 N\right)^{2}-\left(t L^{2}-6 N\right)^{2}\right]}+ \\
& \frac{3 N\left(t L^{2}-2 N\right)\left(t L^{2}-3 N\right)\left(t L^{2}-4 N\right)\left(t L^{2}-6 N\right)\left(5 t L^{2}-18 N\right)[u]}{\left[16\left(t L^{2}-3 N\right)^{2}+t L^{2}\left(t L^{2}-6 N\right)\right]\left[8\left(t L^{2}-3 N\right)^{2}-\left(t L^{2}-6 N\right)^{2}\right][l]} \\
& p_{k(3)}^{F}=\frac{t L^{2}\left(t L^{2}-2 N\right)\left(t L^{2}-4 N\right)\left(t L^{2}-6 N\right)^{2}\left(5 t L^{2}-18 N\right)[u]}{4\left[16\left(t L^{2}-3 N\right)^{2}+t L^{2}\left(t L^{2}-6 N\right)\right]\left[8\left(t L^{2}-3 N\right)^{2}-\left(t L^{2}-6 N\right)^{2}\right][l]} \\
& +\frac{\left(t L^{2}\right)^{2}\left(t L^{2}-4 N\right)}{6\left[8\left(t L^{2}-3 N\right)^{2}-\left(t L^{2}-6 N\right)^{2}\right]} \\
& a_{k(3)}^{F}=\frac{N t L^{2}\left(t L^{2}-4 N\right)}{\left[8\left(t L^{2}-3 N\right)^{2}-\left(t L^{2}-6 N\right)^{2}\right]}+
\end{aligned}
$$


$\frac{3 N\left(t L^{2}-2 N\right)\left(t L^{2}-4 N\right)\left(t L^{2}-6 N\right)^{2}\left(5 t L^{2}-18 N\right)[u]}{2\left[16\left(t L^{2}-3 N\right)^{2}+t L^{2}\left(t L^{2}-6 N\right)\right]\left[8\left(t L^{2}-3 N\right)^{2}-\left(t L^{2}-6 N\right)^{2}\right][l]}$ 


\section{APPENDIX: CHAPTER FOUR}

\section{B. THE GENERALIZED STACKELBERG PRICE-QUALITY (NEIGHBOUR) MERGER MODEL}

\section{Proof of Proposition 4.2:}

\section{A. Best-response price and quality functions of the Stackelberg merged firm $M$ :}

The set $M=\{1, \ldots, n\}$ denotes the corporate merged entity which is comprised of $n$ member firms, and the set $F=\{1, \ldots, q\}$ represents the number of $q$ non-merged, or outside competitor-follower firms. The industry contains a total of $n+q$ firms. The bestresponse functions of the merged firm $M$ are found by solving the $2 n$ first-order conditions, i.e., for the set of $n$ prices $\left(p_{1}{ }^{M}, \ldots, p_{n}{ }^{M}\right)$, where the corporate authority of firm $M$ maximizes the following joint profit objective function with respect to prices only, and decentralizes the $n$ qualities $\left(a_{1}^{M}, \ldots, a_{n}^{M}\right)$ to its $n$ member firms;

$$
\max \Pi_{M}=\max \sum_{i=1}^{n} \pi_{i}\left(p_{1}^{M}, \ldots, p_{n}^{M}, a_{1}^{M}, \ldots, a_{n}^{M} ; p_{n+1}^{F}, \ldots, p_{n+q}^{F}, a_{n+1}^{F}, \ldots, a_{n+q}^{F}\right)
$$

subject to the simultaneous choice of prices $\left(p_{n+l}{ }^{F}, \ldots, p_{n+q}{ }^{F}\right)$, and quality levels

$\left(a_{n+1}^{F}, \ldots, a_{n+q}^{F}\right)$ chosen by the $q$ competitor-follower firms. The general solution of the (2q) price-quality difference equations of the outside competitor firms is given by equation (A.25) of Appendix (A), where the marginal cost of production, $c=0$, as $p_{n+k}{ }^{F}$ $=c_{1} \alpha^{k}+c_{2} \beta^{k}+t L^{2} /(n+q)^{2}$ and $a_{n+k}^{F}=N(n+q) / t L^{2}\left(p_{n+k}{ }^{F}\right)$, for $k=1, \ldots, q$. The joint profit function of the merged firm $M$ is written as the sum of three terms to reflect the nature of the functional dependence of its own two peripheral members' profit on the two, adjacent outside competitors' prices and qualities; 


$$
\begin{aligned}
& \Pi_{M}=\left(p_{1}^{M}\right) \frac{N}{L}\left[\frac{\left(p_{2}^{M}-a_{2}^{M}\right)-2\left(p_{1}{ }^{M}-a_{1}^{M}\right)+\left(p_{n+q}^{F}-a_{n+q}^{F}\right)}{2 t L /(n+q)}+\frac{L}{n+q}\right]-\frac{1}{2}\left(a_{1}^{M}\right)^{2}-f+ \\
& \sum_{i=2}^{n-1}\left(p_{i}{ }^{M}\right) \frac{N}{L}\left[\frac{\left(p_{i+1}^{M}-a_{i+1}^{M}\right)-2\left(p_{i}^{M}-a_{i}{ }^{M}\right)+\left(p_{i-1}^{M}-a_{i-1}{ }^{M}\right)}{2 t L /(n+q)}+\frac{L}{n+q}\right]-\frac{1}{2} \sum_{i=2}^{n-1}\left(a_{i}^{M}\right)^{2}-(n+q-2) f \\
& +\left(p_{n}{ }^{M}\right) \frac{N}{L}\left[\frac{\left(p_{n+1}^{F}-a_{n+1}^{F}\right)-2\left(p_{n}^{M}-a_{n}{ }^{M}\right)+\left(p_{n-1}^{M}-a_{n-1}{ }^{M}\right)}{2 t L /(n+q)}+\frac{L}{n+q}\right]-\frac{1}{2}\left(a_{n}^{M}\right)^{2}-f
\end{aligned}
$$

where the following equations [see equations (A.26) and (A.27) in Appendix 3 (A)] for $\left(p_{n+1}{ }^{F}-a_{n+1}{ }^{F}\right)$ and $\left(p_{n+q}{ }^{F}-a_{n+q}{ }^{F}\right)$, respectively, are substituted into the above equation (B.2) to arrive at the reduced-form profit function of the Stackelberg multi-product firm M:

$$
\begin{aligned}
& p_{n+1}^{F}-a_{n+1}^{F}=\frac{\left(\alpha^{2} l-\alpha^{2} r\right)\left[t L^{2}-N(n+q)\right]}{\left(\alpha^{q} l^{2}-\alpha^{2} r^{2}\right)}\left[\left(p_{1}^{M}-a_{1}^{M}\right)-\frac{\left[t L^{2}-N(n+q)\right]}{(n+q)^{2}}\right]+\frac{\left[t L^{2}-N(n+q)\right]}{(n+q)^{2}} \\
& +\frac{\left(\alpha^{2} l-\alpha^{2} r\right)\left[t L^{2}-N(n+q)\right]}{\alpha^{3}\left(\alpha^{q} l^{2}-\alpha^{2} r^{2}\right)}\left[\left(p_{n}^{M}-a_{n}^{M}\right)-\frac{\left[t L^{2}-N(n+q)\right]}{(n+q)^{2}}\right] \\
& p_{n+q}^{F}-a_{n+q}^{F}=\frac{\left(\alpha^{2} l-\alpha^{2} r\right) \alpha^{q-1}\left[t L^{2}-N(n+q)\right]}{\left(\alpha^{q} l^{2}-\alpha^{2} r^{2}\right)}\left[\left(p_{1}^{M}-a_{1}^{M}\right)-\frac{\left[t L^{2}-N(n+q)\right]}{(n+q)^{2}}\right]+\frac{\left[t L^{2}-N(n+q)\right]}{(n+q)^{2}} \\
& +\frac{\left(\alpha^{q} l-\alpha^{2} r\right)\left[t L^{2}-N(n+q)\right]}{\left(\alpha^{q} l^{2}-\alpha^{2} r^{2}\right) \alpha^{q+2}}\left[\left(p_{n}{ }^{M}-a_{n}^{M}\right)-\frac{\left[t L^{2}-N(n+q)\right]}{(n+q)^{2}}\right]
\end{aligned}
$$

The above expressions contain the terms $l=(4 \alpha-1) t L^{2}-(2 \alpha-1) N(n+q)$ and $r=(4-$ 
$\alpha) t L^{2}-(2-\alpha) N(n+q)$

The first-order conditions for prices are characterized by the following set of $n$ equations:

$$
\begin{aligned}
& p_{1}^{M}=\frac{\left(\alpha^{q} l^{2}-\alpha^{2} r^{2}\right)\left[3 t L^{2}-N(n+q)\right]}{2(n+q)^{2}\left[d_{1}\right]}-\frac{\left(\alpha^{q} l-\alpha^{2} r\right)\left[t L^{2}-N(n+q)\right]^{2}\left(1+\alpha^{2 q+1}\right)}{2 \alpha^{q+2}(n+q)^{2}\left[d_{1}\right]}+\frac{1}{2} a_{1}^{M} \\
& +\frac{\left(\alpha^{q} l^{2}-\alpha^{2} r^{2}\right) p_{2}{ }^{M}}{\left[d_{1}\right]}-\frac{\left(\alpha^{q} l^{2}-\alpha^{2} r^{2}\right) a_{2}^{M}}{2\left[d_{1}\right]}+\frac{\left(\alpha^{q} l-\alpha^{2} r\right)\left[t L^{2}-N(n+q)\right]\left(1+\alpha^{q+2}\right) p_{n}^{M}}{2 \alpha^{q+2}\left[d_{1}\right]} \\
& -\frac{\left(\alpha^{q} l-\alpha^{2} r\right)\left[t L^{2}-N(n+q)\right] a_{n}^{M}}{2 \alpha^{q+2}\left[d_{1}\right]} \\
& p_{i}^{M}=\frac{1}{2}\left(p_{i+1}^{M}+p_{i-1}^{M}\right)+\frac{1}{2} a_{i}^{M}-\frac{1}{4}\left(a_{i+1}^{M}-a_{i-1}^{M}\right)+\frac{t L^{2}}{2(n+q)^{2}} ; \quad i=2,3, \ldots, n-1 \\
& p_{n}^{M}=\frac{\alpha^{3}\left(\alpha^{q} l^{2}-\alpha^{2} r^{2}\right)\left[3 t L^{2}-N(n+q)\right]}{2(n+q)^{2}\left[d_{3}\right]}-\frac{\left(\alpha^{q} l-\alpha^{2} r\right)\left[t L^{2}-N(n+q)\right]^{2}\left(1+\alpha^{3}\right)}{2(n+q)^{2}\left[d_{3}\right]}+\frac{1}{2} a_{n}^{M} \\
& +\frac{\alpha^{3}\left(\alpha^{q} l^{2}-\alpha^{2} r^{2}\right) p_{n-1}^{M}}{\left[d_{3}\right]}-\frac{\alpha^{3}\left(\alpha^{q} l^{2}-\alpha^{2} r^{2}\right) a_{n-1}^{M}}{2\left[d_{3}\right]}+\frac{\alpha^{3}\left(\alpha^{q} l-\alpha^{2} r\right)\left[t L^{2}-N(n+q)\right]\left(1+\alpha^{q+2}\right) p_{1}^{M}}{2\left[d_{3}\right] \alpha^{q+2}} \\
& -\frac{\alpha^{3}\left(\alpha^{q} l-\alpha^{2} r\right)\left[t L^{2}-N(n+q)\right] a_{1}^{M}}{2\left[d_{3}\right]}
\end{aligned}
$$


The above equations contain the terms $\left[d_{l}\right]=2\left(\alpha^{q} l^{2}-\alpha^{2} r^{2}\right)-\alpha^{q-1}\left[t L^{2}-N(n+q)\right]\left(\alpha^{q} l-\alpha^{2} r\right)$ and $\left[d_{3}\right]=2 \alpha^{3}\left(\alpha^{q} l^{2}-\alpha^{2} r^{2}\right)-\left[t L^{2}-N(n+q)\right]\left(\alpha^{q} l-\alpha^{2} r\right)$

The first-order conditions for quality levels are characterized by the following set of $n$ equations:

$$
\begin{aligned}
& a_{1}^{M}=\frac{N(n+q)}{2 t L^{2}\left(\alpha^{q} l^{2}-\alpha^{2} r^{2}\right)} p_{1}^{M}\left[2\left(\alpha^{q} l^{2}-\alpha^{2} r^{2}\right)-\alpha^{q-1}\left(\alpha^{q} l-\alpha^{2} r\right)\left[t L^{2}-N(n+q)\right]\right] \\
& a_{i}^{M}=\frac{N(n+q)}{t L^{2}}\left(p_{i}^{M}\right) ; \quad i=2, \ldots, n-1 \\
& a_{n}^{M}=\frac{N(n+q)}{2 t L^{2} \alpha^{3}\left(\alpha^{q} l^{2}-\alpha^{2} r^{2}\right)} p_{n}^{M}\left[2 \alpha^{3}\left(\alpha^{q} l^{2}-\alpha^{2} r^{2}\right)-\left(\alpha^{q} l-\alpha^{2} r\right)\left[t L^{2}-N(n+q)\right]\right]
\end{aligned}
$$

The joint profit function $\Pi_{M}($.$) is strictly concave in the variables \left(p_{I}{ }^{M}, \ldots, p_{n}{ }^{M}\right)$ and $\left(a_{1}^{M}, \ldots, a_{n}^{M}\right)$ and has a unique maximum if and only if it satisfies the following secondorder condition:

$$
\frac{\partial^{2} \Pi_{M}}{\partial p_{i}^{2}}=\frac{-N(n+q)}{t L^{2}}<0 ; \frac{\partial^{2} \Pi_{M}}{\partial a_{i}^{2}}=-1<0 ; \frac{\partial^{2} \Pi_{M}}{\partial p_{i} \partial a_{i}}=\frac{N(n+q)}{t L^{2}}>0
$$

These partial derivatives must also satisfy the following inequality,

$$
\begin{aligned}
& \left(\partial^{2} \Pi_{M} / \partial p_{i}^{2}\right)\left(\partial^{2} \Pi_{M} / \partial a_{i}^{2}\right)-\left(\partial^{2} \Pi_{M} / \partial p_{i} \partial a_{i}\right)^{2}>0 \Leftrightarrow \\
& {\left[-2 N(n+q) / t L^{2}\right][-1]-\left[N(n+q) / t L^{2}\right]^{2}>0 \Leftrightarrow t>N(n+q) / 2 L^{2} .}
\end{aligned}
$$

The first-order conditions for prices, after appropriate substitutions of equations (B.6) to 
(B.8) for the merged-firm quality variables, may be written as the following general system of $n$ linear, recursive non-homogeneous second-order difference equations with constant coefficients:

$$
\begin{aligned}
& p_{1}^{M}=\frac{2 t L^{2} \alpha^{q+5}\left[3 t L^{2}-N(n+q)\right]\left(\alpha^{q} l^{2}-\alpha^{2} r^{2}\right)^{2}}{(n+q)^{2}\left[d_{1}^{*}\right]}+\frac{2 \alpha^{q+5}\left(\alpha^{q} l^{2}-\alpha^{2} r^{2}\right)^{2}\left[2 t L^{2}-N(n+q)\right] p_{2}^{M}}{\left[d_{1}^{*}\right]} \\
& -\frac{2 t L^{2} \alpha^{3}\left(1+\alpha^{2 q+1}\right)\left(\alpha^{q} l-\alpha^{2} r\right)\left(\alpha^{q} l^{2}-\alpha^{2} r^{2}\right)\left[t L^{2}-N(n+q)\right]^{2}}{(n+q)^{2}\left[d_{1}^{*}\right]} \\
& p_{i}^{M}=\frac{1}{2}\left(p_{i-1}^{M}+p_{i+1}^{M}\right)+\frac{\left(t L^{2}\right)^{2}}{(n+q)^{2}\left[2 t L^{2}-N(n+q)\right]} ; \\
& p_{n}^{M}=\frac{2 t L^{2} \alpha^{q+6}\left[3 t L^{2}-N(n+q)\right]\left(\alpha^{q} l^{2}-\alpha^{2} r^{2}\right)^{2}}{(n+q)^{2}\left[d_{2}^{*}\right]}+\frac{2^{q+6}\left(\alpha^{q} l^{2}-\alpha^{2} r^{2}\right)^{2}\left[2 t L^{2}-N(n+q)\right] p_{n-1}^{M}}{\left[d_{2}^{*}\right]} \\
& -\frac{2 t L^{2} \alpha^{q+3}\left(1+\alpha^{3}\right)\left(\alpha^{q} l-\alpha^{2} r\right)\left(\alpha^{2} l^{2}-\alpha^{2} r^{2}\right)\left[t L^{2}-N(n+q)\right]^{2}}{(n+q)^{2}\left[d_{2}^{*}\right]}
\end{aligned}
$$

The above expressions contain the terms $\left[d_{2}\right]=2\left(\alpha^{q} l^{2}-\alpha^{2} r^{2}\right)\left[2 t L^{2}-N(n+q)\right]-\alpha^{q-1}\left(\alpha^{q} l-\right.$ $\left.\alpha^{2} r\right) N(n+q)\left[t L^{2}-N(n+q)\right]$ and $\left[d_{4}\right]=4 t L^{2} \alpha^{3}\left(\alpha^{q} l^{2}-\alpha^{2} r^{2}\right)-N(n+q)\left[d_{3}\right]$.

The above expressions also contain the terms $\left[d_{1}^{*}\right]=\alpha^{q+5}\left[d_{l}\right]\left[d_{2}\right]-\left(\alpha^{q} l-\alpha^{2} r\right)\left[t L^{2}-\right.$ $N(n+q)]\left[2 t L^{2}\left(\alpha^{q} l^{2}-\alpha^{2} r^{2}\right) \alpha^{3}\left(1+\alpha^{q+2}\right)-N(n+q)\left[d_{3}\right]\right]$ and $\left[d_{2}{ }^{*}\right]=\alpha^{q}\left[d_{3}\right]\left[d_{+}\right]-\alpha^{4}\left(\alpha^{q} l-\right.$ $\left.\alpha^{2} r\right)\left[t L^{2}-N(n+q)\right]\left[2 t L^{2}\left(1+\alpha^{q+2}\right)\left(\alpha^{q} l^{2}-\alpha^{2} r^{2}\right)-N(n+q)\left[d_{l}\right]\right]$. 
The set of equations, (B.10) to (B.12), represent a system of $n$ linear recursive non-homogeneous second-order difference equations with constant coefficients. The equations (B.10) and (B.12) represent the boundary, or initial conditions. The general solution of the system of $n$ equations is determined by solving for a solution to the homogeneous system of equations $\left\{\right.$ i.e., without the constant term $\left(\mathrm{tL}^{2}\right)^{2} /(\mathrm{n}+\mathrm{q})^{2}\left[2 \mathrm{tL}^{2}-\right.$ $\mathrm{N}(\mathrm{n}+\mathrm{q})$ ] in equation (B.11) $\}$, plus a particular solution associated with the nonhomogeneous system \{i.e., equation (B.11) with the previously noted constant term\}. Thus, the general solution to the homogeneous system of price equations may be written as $a+b i$ for $i=1, \ldots, n$ and, where $a$ and $b$ are known as the "undetermined coefficients". A particular solution to the general system of price equations is of the form $p_{i}=-i^{2}\left(t L^{2}\right)^{2} /$ $(n+q)^{2}\left[2 t L^{2}-N(n+q)\right]$ for $i=1,2, \ldots, n$. Hence, the general solution to the system of $n$ price equations (B.10) to (B.12) is of the following form:

$p_{i}^{M}=a^{*}+b^{*} i-\frac{i^{2}\left(t L^{2}\right)^{2}}{(n+q)^{2}\left[2 t L^{2}-N(n+q)\right]} ;$ for $i=1,2, \ldots, n$

The solutions of $a^{*}$, and $b^{*}$ respectively, are determined by the boundary conditions, equations (B.10) and (B.12), along with equation (B.13) and are given by the following equations (B.14) and (B.15), respectively:

$$
\begin{aligned}
& a^{*}=\frac{2 t L^{2} \alpha^{q+5}\left(\alpha^{q} l^{2}-\alpha^{2} r^{2}\right)^{2}\left[3 t L^{2}-N(n+q)\right]}{(n+q)^{2}\left(e_{1}^{*} f_{2}^{*}+f_{1}^{*} e_{2}^{*}\right)}\left(f_{2}^{*}-\alpha e_{2}^{*}\right) \\
& -\frac{2 t L^{2} \alpha^{3}\left(\alpha^{q} l-\alpha^{2} r\right)\left(\alpha^{q} l^{2}-\alpha^{2} r^{2}\right)\left[t L^{2}-N(n+q)\right]^{2}}{(n+q)^{2}\left(e_{1}^{*} f_{2}^{*}+f_{1}^{*} e_{2}^{*}\right)}\left[\left(1+\alpha^{2 q+1}\right) f_{2}^{*}-\alpha^{q}\left(1+\alpha^{3}\right) e_{2}^{*}\right]
\end{aligned}
$$




$$
\begin{aligned}
& +\frac{\left(t L^{2}\right)^{2}\left(d_{1}^{*} f_{2}^{*}-n^{2} d_{2}^{*} e_{2}^{*}\right)}{(n+q)^{2}\left[2 t L^{2}-N(n+q)\right]\left(e_{1}^{*} f_{2}^{*}+f_{1}^{*} e_{2}^{*}\right)}-\frac{2\left(t L^{2}\right)^{2} \alpha^{q+5}\left(\alpha^{q} l^{2}-\alpha^{2} r^{2}\right)}{(n+q)^{2}\left(e_{1}^{*} f_{2}^{*}+f_{1}^{*} e_{2}^{*}\right)}\left[4 f_{2}^{*}-\alpha(n-1)^{2} e_{2}^{*}\right] \\
& b^{*}=\frac{2 t L^{2} \alpha^{q+5}\left(\alpha^{q} l^{2}-\alpha^{2} r^{2}\right)^{2}\left[3 t L^{2}-N(n+q)\right]}{(n+q)^{2}\left(e_{1}^{*} f_{2}^{*}+f_{1}^{*} e_{2}^{*}\right)}\left(f_{1}^{*}-\alpha e_{1}^{*}\right) \\
& -\frac{2\left(t L^{2}\right) \alpha^{3}\left(\alpha^{q} l-\alpha^{2} r\right)\left(\alpha^{q} l^{2}-\alpha^{2} r^{2}\right)\left[t L^{2}-N(n+q)\right]^{2}}{(n+q)^{2}\left(e_{1}^{*} f_{2}^{*}+f_{1}^{*} e_{2}^{*}\right)}\left[\left(1+\alpha^{2 q+1} f_{1}^{*}-\alpha^{q}\left(1+\alpha^{3}\right) e_{1}^{*}\right]\right. \\
& \left.+\frac{\left(t L^{2}\right)^{2}\left(d_{1}^{*} f_{1}^{*}-n^{2} d_{2}^{*} e_{1}^{*}\right)}{(n+q)^{2}\left[2 t L^{2}-N(n+q)\right]\left(e_{1}^{*} f_{2}^{*}+f_{1}^{*} e_{2}^{*}\right)}-\frac{2\left(t L^{2}\right)^{2} \alpha^{3}\left(\alpha^{q} l^{2}-\alpha^{2} r^{2}\right)^{2}}{(n+q)^{2}\left(e_{1}^{*} f_{2}^{*}+f_{1}^{*} e_{2}^{*}\right)}\left[4 f_{1}^{*}-\alpha(n-1)^{2} e_{1}^{*}\right)\right]
\end{aligned}
$$

The above equations contain the terms $\left[e_{1}^{*}\right]=d_{1}^{*}-2 \alpha^{q+5}\left(\alpha^{4} l^{2}-\alpha^{2} r^{2}\right)^{2}\left[2 t L^{2}-N(n+q)\right]$ and $\left[e_{2}{ }^{*}\right]=d_{1}^{*}-4 \alpha^{++5}\left(\alpha^{q} l^{2}-\alpha^{2} r^{2}\right)\left[2 t L^{2}-N(n+q)\right]$. The above equations also contain the terms $\left[f_{1}^{*}\right]=d_{2}{ }^{*}-2 \alpha^{q+6}\left(\alpha^{2} l^{2}-\alpha^{2} r^{2}\right)^{2}\left[2 t L^{2}-N(n+q)\right]$ and $\left[f_{2}^{*}\right]=n d_{2}{ }^{*}-2(n-1) \alpha^{q+\sigma}\left(\alpha^{2} l^{2}-\right.$ $\left.\alpha^{2} r^{2}\right)^{2}\left[2 t L^{2}-N(n+q)\right]$

The general solution of the system (B.7), for the $n$ quality levels are given by the equation:

$$
a_{i}^{M}=\frac{N(n+q)}{t L^{2}}\left[a^{*}+b^{*} i-\frac{i^{2}\left(t L^{2}\right)^{2}}{(n+q)^{2}\left[2 t L^{2}-N(n+q)\right]}\right] ; \text { for } i=1, \ldots, n
$$

The general solution of the (2q) price-quality equations for the $q$ outside competitorfollower firms is given by the following equations: 
$p_{n+k}^{F}=c_{1}^{*}\left(\alpha^{h}\right)+c_{2}^{*}\left(\beta^{h}\right)+\frac{t L^{2}}{(n+q)^{2}}$ for $k=1, \ldots, q$

$a_{n+k}^{F}=\frac{N(n+q)}{t L^{2}}\left(p_{n+k}^{F}\right) \quad$ for $k=1, \ldots, q$

The solution of the "undetermined coefficients" $c_{1}{ }^{*}$ and $c_{2}{ }^{*}$, respectively, are given by the following equations:

$$
\begin{aligned}
& c_{1}^{*}=\frac{\left(\alpha^{q} l-\alpha^{2} r\right)\left[t L^{2}-N(n+q)\right]}{\alpha\left(\alpha^{q} l^{2}-\alpha^{2} r^{2}\right)}\left[(n+q)^{2}\left(a^{*}+b^{*}\right)-\frac{t L^{2}\left[t L^{2}-N(n+q)\right]}{\left[2 t L^{2}-N(n+q)\right]}\right] \\
& c_{2}^{*}=\left(\alpha^{-1}\right) c_{1}^{*}
\end{aligned}
$$




\section{REFERENCES}

Anderson, Simon P., de Palma, Andre and Thisse, Jacques-Francois (1992): Discrete Choice Theory of Product Differentiation, The MIT Press, Cambridge, Massachusetts.

Braid, Ralph M. (1986): "Stackelberg Price Leadership in Spatial Competition”, International Journal of Industrial Organization, 4, pp. 439 - 449.

D' Aspremont, C, and A. Jacquemin, J.J. Gabszewicz, J.A. Weymark (1983): “On the stability of collusive price leadership", Canadian Journal of Economics, XVI, No. 1, pp. $17-25$.

Deneckere, R. and C. Davidson (1985): "Incentives to form Coalitions with Bertrand Competition", Rand Journal of Economics, 16, pp. 473 - 486.

Economides, Nicholas (1989, A): "Quality Variations and Maximal Variety Differentiation", Regional Science and Urban Economics, 19, pp. 21 - 29.

Economides, Nicholas (1989, B): "Symmetric Equilibrium Existence and Optimality in Differentiated Product Markets", Journal of Economic Theory, 47, pp. 178 - 194.

Farrell, J. and Carl Shapiro (1990): "Horizontal Mergers: An Equilibrium Analysis", American Economic Review, 80, pp. 107 - 126.

Gaudet, G. and Salant, S.W. (1992): "Towards a theory of horizontal mergers", in Norman G. and La Manna, M., (eds.), The New Industrial Economics, Edward Elgar, Aldershot.

Goldberg, Samuel (1958): Introduction to Difference Equations, John Wiley \& Sons, New York. 
Industry Canada (1998): "Bank Merger Enforcement Guidelines", Director of Investigation and Research, Competition Bureau.

Jacquemin, Alexis and Margaret E. Slade (1989): "Cartels, Collusion, and Horizontal Merger", in R. Schmalensee and R. D. Willig, eds., Handbook of Industrial Organization, North Holland, Amsterdam.

Levy, David T. and James D. Reitzes (1992): "Anti-Competitive Effects of Mergers in Markets with Localized Competition", Journal of Law, Economics and Organization, Vol. 8, No. 2, pp. 427 - 440.

Mussa, M. and S. Rosen (1978): "Monopoly and Product Quality", Journal of Economic Theory, 18, pp. $301-317$.

Perry, M. and R. Porter (1985): "Oligopoly and the Incentive for Horizontal Merger”, American Economic Review, Vol.75, No. 1, pp. 219 - 227.

Porter, M. E. (1990): The Competitive Advantage of Nations, Basingstoke, Macmillan.

Reitzes, James D. and D. T. Levy (1995): "Price Discrimination and Mergers", Canadian Journal of Economics, XXVIII, No. 2, pp. 427 - 436.

Salant, S., Switzer, S. and R. Reynolds (1983): "Losses due to Merger: The Effects of an Exogenous Change in Industry Structure on Cournot-Nash Equilibrium”, Quarterly Journal of Economics, Vol. 98, No. 2, pp. 185 - 199.

Salop, Steven C. (1979): "Product Selection, Fixed Costs, and Monopolistic Competition with Outside Goods, The Bell Journal of Economics, 10, pp. 141 - 156.

Scherer, F. M. (1980): Industrial Market Structure and Economic Performance, Houghton Mifflin Company, Boston. 
Shaked, A. and John Sutton (1983): "Natural Oligopolies", Econometrica, 41, pp. $1469-1484$.

Shaked, A. and John Sutton (1987): "Product Differentiation and Industrial Structure", Journal of Industrial Economics, 36, pp. 131 - 146.

Spence, Mịchael A.. (1976): "Product Selection, Fixed Costs, and Monopolistic Competition", Review of Economic Studies, 43, pp. 217 - 235.

Supply and Services Canada (1991): "Merger Enforcement Guidelines”, Director of Investigation and Research, Bureau of Competition Policy.

Von Stackelberg, Heinrich (1934): "Marktform und gleichgewicht" (Springer, Vienna), translated (1952), "The theory of the market economy", Oxford University Press (Oxford). 